Southern Branch of the

University of California

Los Angeles

Form L-1

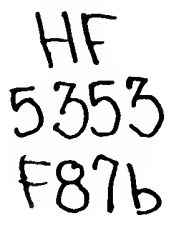


This book is DUE on last date stamped below

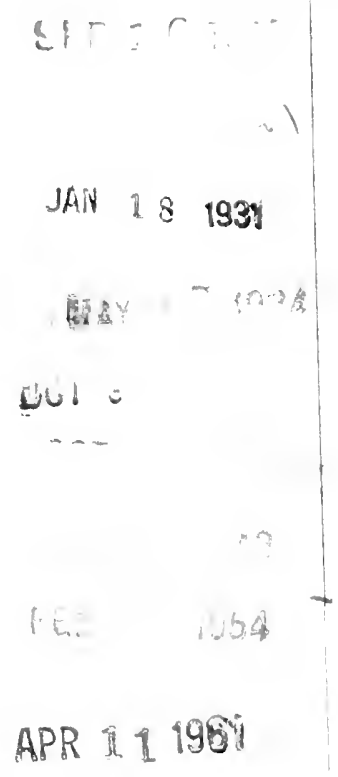

$-1$ 


\section{BUSINESS RESEARCH AND STATISTICS}




\section{BUSINESS RESEARCH A ND STATISTICS}

\section{BY \\ J. GEORGE FREDERICK}

IRESIDENT OF THE ECSINESS BOURSE, INT,, INC., NEW YORK AUTHOR OF "MODERX SILFSMANAGEMENT"

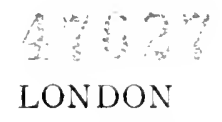

The Tibrary Presg Timited

26 PORTUGAL STREET, W.C. 2 
CopyrigitT, 1920, BY

D. APPLETON AND COMPANY

PRINTED IN THE U.S.A. 


\section{INTRODUCTION}

This book is intended for all those who shape policies, make markets, direct affairs or study investments in business, and also for those analytical executives, statisticians and researchers who assist such men to arrive at correct solutions to their problems. It is further intended to give a more practical and creative outlook to those who aim to make a profession of business research and statistics.

As the author see it, there are two defects in the pres(n) ent situation in business research which he hopes this book will help overcome. First, is the attitude of the average business executive, which has not yet fully grasped the profit and economy of making full and constant use of research and statistics, even in minor matters of business. Second, is the attitude of the average research worker or statistician, which is often too narrow and circumsclibed and uncreative. It is sometimes a mere hack statistical outlook, unacquainted with practical

business aim and necessity; sometimes too academic and inelastic in application, failing to realize that business research and statistics must aggressively serve live business ends and not be a mere musty alcove where records are kept. It must virtually be the chief executive's principal advisor; the eyes and ears of the business, - even a part of its brains.

It is folly to expect that any hack statistician, or dilettante "research" worker can serve business as it should be served, and apparently intends to be served in the matter of research. However well grounded such per- 
sons may be in the sheer mathematical technic of statistics, they cannot be adequate for the task of business research until the business aims, policies, strategy and basic conditions are understood and the research and statistical technic used as a means rather than as an end. The goal should be the successful development of the business, not the making of neat charts or intpressive reports and tabulations.

In writing this book, then, I have in mind this double ideal: I wish to demonstrate in business terms the concrete profit and economy possibilities of business research and statistics, not as a matter of theory, but of actual practice and daily application. I wish further to ontline the big targets of business and the main problems and conditious which research must aim at and solve.

The past ten years have seen a remarkable advance in the application of business research and statistics. Whereas business men once depended to a considerable extent upon a tradition of personal genius in business, the modern tendency is more impersonal, more statistical and more departmental. The specialist, the expert, the gathered facts, the outside point of view, the logic of the analyzed situation, these are now deciding factors, not the will and notion of one or two individuals.

Disillusionment about mystically successful business men came some years ago when in notable instances the makers of millions were found to be so powerful not because of their marvelous individual business genius, but because of secret rebates, political intrigue, child labor exploitation, monopolistic advantage and other methods now outlawed legally and morally. Efficiency and technical thoroughness thereafter gained ascendency, and these demanded the application of more of engineering 
exactness to business method; depended less upon privilege, graft and intrigue and more upon analytical ability, preparation, delicate adjustment and detailed knowledge. Thus was the way cleared and the secure place made in business for commercial research and statistics. Quite true, the rapid advancement of research in other lines, in chemistry, metallurgy and electricity, for instance, influenced business men, for it was not a difficult gap to bridge in their minds between appreciation of success in factory research and research in saies and administrative problems.

Information, consensus of opinion, comparison, fact and figure about business matters are now in a very fair way to be recognized as commodities quite as tangible in value and importance as wood and iron or steel. Policies and plans must be built upon a foundation of fact before they can be regarded as sound or businesslike; therefore the business of fact-getting, fact-weighing and fact-comparison is of quite primary importance in business, and must become increasingly more so as the men who operate business increase their respect for facts and seek them as underpinning for more and more of their business judgments.

As a profession, business research is but at its beginning. But the rapidity with which those who have acquired training in it are absorbed into business is a definite indication of its vitality and future. Business men of the forward-looking kind know this and are keen in appreciation of the benefits to be developed by business research which is directly connected to daily problems. It has little interest in the more remote aims of business research in the academic sense, but is eager to get results at once; to "annihilate time" and make short cuts by 
investigation and analysis. The "age of invention," so. called, has passed its heyday, apparently; the greatest developments of the future in commerce and industry seem likely to be developments in cutting down waste, more intensive cultivation of profit, finer-combing of territories and markets, mole fractional adjustments of detail.

If my analysis as above stated is correct, this book should find a definite place for itself with all who think in terms of moder'n business, which is my hope for it. At the same time I wish to record here my lull appreciation of the fact that a book of such breadth of scope on a subject still in its infancy, must of necessity leave much to be desired in the way of detailed treatment. At a later date I hope to give more concentrated attention in a separate book to some of the angles of research here only inadeqately treated.

New York

J. Georgm Frederick 


\section{CONTENTS}

CIIAPTHR

PAGE

INTRODLCTION .....................

1. Preliminary Business Constelrations.......... 1

II. WIIAT is FACT?................... 21

III. TrPes AND KINDS OF DATA.............. 31

17. Researcil Departanents and Data Sources..... 5 H

V. The Iaw of Averages as a Guide to Business.... 68

VI. Per Capita Consumption Study............ 88

VII. The Tossmle Mariet Analrsis and Saturation PoInt $\ldots \ldots \ldots \ldots \ldots \ldots \ldots \ldots \ldots \ldots . \ldots \ldots$

VIII. Investigations of Distribution I'loblems....... 113

IX. Prognostications and Tendency Curves........ 143

X. Measuring Intangible Factors of Business..... 152

XI. Survers and Reports by Specialists.......... 164

XII. The Technique of Field Investigations....... 172

XIII. PURely Statistical Investigations and Estimates 189

XIV. The Executive Application of Facts to Business 196

XV. Tile Dollar and tile Budget Idea in Business Finance Research $\ldots \ldots \ldots \ldots \ldots \ldots \ldots \ldots \ldots \ldots 212$

XVI. Inquirles into Management Probledrs......... 221

XVII. Researcines into time Human Factor as Relating 
XVIII. Grapind Cilarts and Maps and Tileir Part in ReseakCH . . ................... 251

XIX. The Convincing Presentation of Facts......... 259

XX. Hias, Error, Approximation and Estimate...... 268

XXI. Cooperative Development of Trade Data and Statistics .................... 255

XXII. International Trade Statistics and Researches. 301 XXIII. Tile Researcil Spirit and Professional Standards 316 SXIV. Imagination and Vision in Relation to Research 326

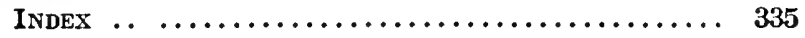




\section{BUSINESS RESEARCH AND STATISTICS}





\section{BUSINESS RESEARCH A N D S TAT IS T I C S}

\section{CHAPTER I}

PRELIMINARY BUSINESS CONSIDERATIONS

1. The passing of the simple and small in business.-Such a thing as a manufacturer distributing his output nationally was practically unknown a century ago, for we had not yet entered the industrial era in America. Most business done was of a local character, small in production, simple, slow and of narrow range and contacts. The owner of the business, like as not, knew all his customers personally, and personally supervised all or nearly all the operations in his business. His market was small but easy to visualize; his rate of grow th snail-like, but satisfactory. It was a personal venture rather than a business as we understand it in these days of corporations. The manufacturing processes were simple, even primitive; the administrative detail almost negligible. The problem was mainly one of individual energy, influence and common sense. Partnerships were the rule, and each partner was a craftsman rather than an organizer.

The modern business problem is a thousand-fold more complex. The corporation, the machine plan of quantity production and modern tools of selling have made growth almost compulsory, and with growth has come a multiplication of problems. The small business finds itself con- 
fronted with as great a variety of problems as a large business-often with even more problems. The world of business is no longer the same, mainly because business people and the business field are no longer the same, and business knowledge is greater. Manufacturing and distributing facilities are wider and greater; the facilities of communication are more numerous, the purchasing power and habits of people different; the margins of profit closer, the competition more keen. The marketing of goods is more wideflung, the inter-relationships more complex, the dependence upon organization policies and plans far greater, because the work of business is more subdivided and more individuals take part in its processes.

Whereas the owner of a concern might be required, in the days of more simple business, to weigh and consider let us say 10 factors, the modern business man needs to consider 100 or 150 factors or more. Whereas, he formerly dealt with five individuals in operating his business, now he deals with 500. To this extent has business multiplied in complexity and detail. Business was once the measure of a man, it is now the measure of an organization; there is no limit to organized size and growth except power to organize.

2. Range of the typical problems of a business.-It was a characteristic of the business man of yesterday that he recognized few problems. He had little patience with anything but hard work-the more manual it was the more he respected it. To act was his religion, rather than to think and to analyze.

The modern ideal of an executive head of a business is a man much more freed from detail, concentrating on the really important problems, and determined and suc. 
cessful in placing minor problems on the shoulders of others. He does little but these three things: (1) formulate policies, after getting the information necessary, (2) pick men and (3) study results.

The modern business executive gets rid of all routine detail in the execution of policies; but no detail is too small for his attention that bears upon an unsolved problem, or a matter of policy or plan. His is the job of think. ing out policies and plans, studying the operation of policies and plans, analyzing men, observing customer psychology, examining distribution factors, possible mar. kets, tendencies, risks, goodwill, administrative efficiency, financial budgets, sales resistance, cost of reduction, production, competition and general strategy.

All of these broad problems are prisms with a thousand facets, differing constantly according to the time, the firm and the situation. The modern executive would have no job at all if he refused to recognize these matters as problems demanding solutions and constant re-testing and reanalysis. The old time business man made instant decisions and had hard and fast convictions on all these matters, settling them "out of hand" without adnitting the need of seeking information, making comparisons and probing for hidden causes and factors.

As business of the modern kind has developed it has reached into astonislingly wide phases of life. On the side of materials, it has had to get into physical science and research; on the side of production it has had to study machinery and invention; on the side of labor management it has had to stully sociology, psychology, sanitation, architecture, health, housing and even domestic science. On the side of selling and distribution it has enormously difficult problems of economics, psychology, 
statistics, organization, politics and diplomacy, strategy and salesmanship.

The roots of all of these problems go down very deep, as any intelligent mind in business immediately senses; and such intelligent minds cannot conscientiously draw substantial salaries from employers by making superficial judgments-they crave more substantial foundations for their decisions involving these questions. For this reason they turn to business research as the one intelligent guide to follor:

3. The analytical idea vs. the one man "genius" in business. -For a long time there prevailed an idea in business of the owner or presiding genius who developed somewhat mysterious, inborn powers. He was supposed to have the ability to decide the most intricate questions about the business simply by his great mental powers and "sixth sense" and "marvelous commercial insight" or "instinct." All the others in his organization were usually but shadows of himself-they merely carried out his specific, detailed orders. Many businesses following this tradition, were one man organizations, absolutely dominated by one idiosyncratic will and intelligence.

This, as a matter of fact, was a Tapoleonic tradition of operation, for Napoleon brooked no strong men about him-he is reputed to have tweaked the ears of his aides merely to demonstrate who was their master.

The new conception, opposed to the dominating will idea, has long superseded the Napoleonic idea, even in military organization, for the modern army is a line and staff organization with specialist and sharply marked authority. In business too, the coming of the corporation has eclipsed one-man genius-lias found it a myth and a delusion, to be exact. It is after all a farcical idea that 


\section{PRELIMINARY BUSINESS CONSIDERATIONS}

any one man could possibly possess or coördinate all the required technical information, make all the decisions, even all the important ones, in a large organization. Human powers have no such versatility or extent. He must rely upon the specialized ability of others; he must divide the work and he must refuse to touch any of the details. He must reserve his powers for picking men, studying facts and results; deciding only broad questions of policy, and thinking ahead. In short, he must organize and supplement his own brain power in order that his authority and responsibility may bring results on the large scale which modern conditions demand. He must of necessity relinquish the idea of the omnipotence of his own faculties and must develop a humility of judgment and self-examination to such a degree that by augmenting his abilities with staff and counsel his organized and augmented brain power may be a perfectly balanced instrument, functioning up to the heavy-duty requirements of a great modern business organization. He will as shrewdly "size up" his own inevitable bias of temperament and natural deficiencies and tendencies toward specialization, as he "sizes up" the men whom he hires. He will elongate his ears and extend his eyesight by making use of modern investigative and research science. He will provide himself with that time which he now lacks, for deliberation over facts and for creative broodings over conditions, by means of counsel in research and analysis. He will, in short, equip himself to function efficiently as a super-executive suck as the super-organization of to-duy demands.

Only in this way can the wise modern leader of business make himself,-a mere human being,--into that superman with enlarged superhuman faculties which place him on 
an equal competitive footing witl other business men who make use of all the tools of growth available. The average human faculties of an executive are insufficient for the problems of business; even the exceptional and above the average faculties are insufficient. A new super-individual executive is required, raised to this level by the facilities of more exact information, coördinated experience of others, and specialized counsel. Such tools make the way open for many more men to become business leaders and developers; it places the possibilities of much greater business success within the reach, not of a few especially gifted and inhumanly hard-working men, but within the reach of every business man of fair ability and energy. It provides a way to get wisdom by the reasoning and investigative process instead of depending wholly on the intuitive process-always a gamble and an unsteady method.

This change is illustrated, as are so many other things, in the great war experience. Instead of depending upon lawhing individual generals, or heroic Horatios at the bridge, victory was won first by a superb information service, and next by making each individual soldier a super-soldier, with the right esprit de corps, with every modern equipment and accessory, with every science of planning, synchronization and organization, human skill and information could devise. It was actually made hard for an individual soldier to fail!

Sound research makes it hard for business men to fail.

4. The new union of practice and theory in business.To properly understand the new place of statistics and research in business it is necessary to comprehend the new mental development that is taking place in the busimess man himself. The tendency toward over-practi- 
cality, by which is meant a short rather than a long range of vision, is now correcting itself so that a more balanced point of view prevails in studying business problems. It is realized that the very best way to improve a thing is to step away from it and view it as a whole and apply a certain degree of theoretical principle. It is just like the case of the merely "practical" fireman whose idea of extinguishing a fire is to exhibit great energy and swiftness in throwing on buckets of water. The trained fireman on the other hand does not hesitate, even in the face of a ser:ous conflagration, to spend a small amount of time standing quite still and analyzing the details of the situation before he starts to act, applying certain basic principles and theories about fires in general to the situation in particular. As a result, the so-called practical fireman in a furore of anxiety and energy would break windows and open doors which make a furnace blast out of the fire, whereas the trained fireman, applying theory successfully, confines the blaze to a limited area.

Technical schools, college trained men, the influence of invention and mechanical engineering developments through the nse of theory have greatly encouraged the wider application of theory to all phases of business. It is now a common matter to see engineers enter sales management, office and executive management and higher positions. Their engineering training provides them not alone with a full respect for facts, but also complete appreciation of the place of theory and even of imagination in business.

Such men are the last to countenance sheer theorizing and vagaries, but they comprehend the part which a mind fully trained to all the phases of mental effort can bring in solving any particular problem. They realize that 
sheer practical application is meaningless and stupid without perspective and intelligent direction or full use of the accumulated mental skill of the world; but they also realize that there is even a greater danger of serious loss and complication when untested, impractical theories are relied upon. A new conception is a perfect union between practice and theory, in which practice is under the guidance of theory, and theory is disciplined by practice. In this way many things that are new and undreamed of develop solutions to previously "unsolvable" problems.

5. The place of imagination in business.-Many whose knowledge of business is very superficial have believed that business is far from an imaginative pursuit and even that commercial activity deadens the imagination. This is of course far from the truth, as the fact is that business affords a most unusual and responsive scope for sound imagination. It has frequently and with considerable truth been remarked that the men of brains and imagination in America go into business instead of into literature and art. The object upon which such men's imaginations focus is merely diverted in a different channel, when men of high powers of imagination are developed in business. James J. Hill had a masterful imagination when he built in his mind's eye the great Northwestern Empire; and Morgan had great imagination also in accurately foreseeing the marvelous development of the steel industry. Other minds were possessed of the same facts as these two men. but they alone projected their knowledge of the facts into a logical future and built practically toward that future. It is this combination of imagination and practical organization towards realization that marks the highly exceptional business 


\section{PRELIMINARY BUSINESS CONSIDERATIONS 9}

brain. There are many men who have the practical ability, and many other men who have imagination, but the men who have a balanced proportion of both and the staying power to sustain their vision through until its realization are not so plentiful.

The relation between statistics and facts to creative business imagination is very direct, and important. A trained imagination does not deal with vague visions, ideas or emotions-it deals with facts and builds towards facts, using imagination purely to make the span between the facts of to-day and the facts of to-morrow. All men of great constructive imagination are marked as a rule with the significant trait of passionate appetite for facts. The pure dreamer type who is all imagination and nothing else, is marked by the very opposite trait, an almost fanatical disregard of facts. This significant distinction is by no means as generally understood as it should be.

But it must not be thought that imagination in business is important only in great industrial leaders or great financial leaders or captains of industry. Dusiness rmagination is as fertile a source of constructice development and profits in a small retail business as in a hundred million dollar enterprise. Irost successful business men even in small capacities are men of a greater or less degree of imagination. The little retailer who takes advantage of a big snow-storm to turn the snow-heap outside his store into an advertisement has a fair modicum of imagination; the salesmanager endeavoring to sell an article not desired at the present, but who by a constructive educational campaign brings the public to realize that his article is important to them, is a much greater business man of imagination, chiefly because his 
imagination demands a more Iong-sustained flight, and a more carefully worked out program, more planning, more patience, courage, and insight.

There exists in fact a certain kind of prescience in business which is like the reporter's nose of ncws, or the sense of poesy in a poet. Such business men have an imagination which permits them to realize what to-morrow will bring forth, in time to prepare to-day to profit by it. A great deal that is profitable in the business world to. day was quite widely believed to be unprofitable but a very short time ago. Telephones and typewriters were once quite generally considered pests and vulgar imper. tinences. Cool analysis and fact demonstrated the wrong-headedness of this view, but this analysis had to be done for the public by the business men who were behind these industries, and who had constructive imagination.

The imagination has a tremendously important place in business, and the stuff which such an imagination feeds upou and disciplines itself is fact.

6. The complexities of the labor problem.-Nothing could better illustrate the simplicity of the oId and the amazing complications of the new in business than the labor problem. It is at its most acute point during these afterwar years, with a shortage of labor and dimands not alone for war-standard wages, but also participation in management. The entry of women into industry and the extent of rerolutionary agitation are further serious factors of uncertainty.

It is impossible to deal with such problems from the standpoint of sheer judgment or individual experience. It is easy for a practical executive to see that the new conditions eall for a detached, analytical view. He sees 
that he must make new fundamental policies, and to do so be needs a perspective and a collection of facts and experience from many sources as raw material from which to go to work to produce such policies. This is illustrated in the matter of labor turnover. It did not alarm employes to have turnovers of 1,000 or $1,500 \%$ until they made comparisons, secured statistics and a consensus of experience. The true facts about labor turnover then became visible, and developed further inquiry and action in matters of housing, hygiene, fatigue, psychology, etc. Labor and employment management are now professions, with much technique and many delicate factors, reaching into a great many allied subjects of study, especially sociological subjects.

Scientific management brought in its wake a whole host of specialized factors which changed production management until production management in itself is also a highly technical profession, with much still requiring research and analysis.

Simply the matter of record-keeping, cost accounting and systematic handling of production has piled up many special problems and factors upon which there are yet no standard answers and which must therefore be studied by means of the research and statistical method.

7. Distribution and market analysis and their never-ending problems.-As might easily be imagined, this division of business affords by far the greater proportion of problems for research and analysis. Selling and distribution are the least fixed and exact of all phases of business because they represent the human contact point. Sales depend upon demand and desire and the coöperation of a wide-flung organization of human units not directly controlled. The complexion of a market is never the same, 


\section{BUSINESS RESEARCH AND STATISTICS}

and the selling problems of no two manufacturers are exactly alike.

Furthermore, the range of selling territory is nowa. days so enormous and the local variations so many and fluctuating that merely the task of determining and visualizing conditions is a research task of difficulty. Quick action in getting facts, clear thinking in understanding them and in correlating various groups of facts, are the important requilements.

The sales and distributing problems start even before a company is formed to market an article, for a business itself must rest on sound sales basis, which can be determined even before capital is made arailable for an enterprise. Many failures are due to lack of adequate sales analysis at this embryonic stage of a business. Articles of merchandise may have merit, but no commercial mar. ket worth while. Bankers and investors are now appreciating more than ever the vital nature of a market analysis before risking capital.

The market analysis can determine not only that there is a market, but how much of a market, how rapidly it will absorb the merchandise, or how rapidly modern tools of publicity and sales organization will be able to force the market. These facts, when secured and studied, make possible a definite program of development for a period of years. Thus practical research work at the very start of a business, prevents very serious waste and error.

The established business may even have greater need of research than a new business, since it is axiomatic that businesses fall into groores and ruts, and fail to pay close attention to the constant changes taking place in marketing conditions. People's buying habits change, 
new articles appear, new events alter the situation and new opportunities arise, antagonisms and evils grow up, new outlets develop, markets wear thin, saturation points loom up, new tools and methods of selling become possible, costs change the status of the article on the market, and new trade conditions call for alterations of policy.

In all these matters correct information is the element of greatest value. Given certain conditions of fact the sound business judgment of a number of business men will not vary greatly; but until the facts are assembled it is sheer gresswork at the risk of money and prestige to make decisions. Instead of a contest of wills over individual guesses as to conditions, the facts themselves often shape their own answer when brought together. A Board of Directors might argue for many sessions over the problem of whether cigar stores should be made an additional outlet for the sale of high-grade candies, but an investigation and tests under trained observation will determine the answer much more simply and surely.

Until recent years the fixation, by means of a more or less exact engineering basis, of the exact extent of sales possibilities of small units of territory was not attempted. The situation was like that of other American situations, such as with lumber and coal-there was considered to be an inexhaustive supply. But in modern intensive selling, it became necessary to know what were the potential sales of a territory, if only to measure the relativity of results, and to judge resistance to sales effort.

This meant research of an unusually thorough kind, many cases, county by county, at a cost of many thousands of dollars. In cases of business of a local char- 
acter such as a hotel or a retail store, the same principle applied, equally with a manufacturer. A certain Pacific Coast hotel made a remarkable demonstration of the success of such intensive research under the guidance of a technically trained man; analyzing the logical territory it could tap, surveying that territory to locate every man in it who was a logical customer; and having located its "targets" reached erery one of them with effective persuasion.

A business no matter how small or large does very well indeed to ascertain by the investigative statistical methods its exact logical field and its exact possibilities. The jobbers, dealers and distributors and their points of view, and even the consumers are all the time presenting angles of study to which correct methods of investigation may be profitably applied.

8. Administrative problems and their call for solution.One of the most important business discoveries of the past ten years has been the possibilities of economy and efficiency in executive management. During the previous decade a great deal of attention had been given to the cutting down of cost in the shop and factory-in the application of scientific management to labor and production. The discovery that an astonishing amount of waste, inefficiency and crudity of operation prevailed in offices and administration brought about the need for many new researches, and such work is now proceeding with a great deal of energy. A new type of researchers and counselors has developed as the result, and a high degree of knowledge is obtainable on all matters relating to management of the detail work of administration. The field was not entirely new, as a most limited effort had been made in developing office economies prior to 


\section{PRELIMINARY BUSINESS CONSIDERATIONS 15}

this. The word "system" expresses the range and limit of vision of those who operated offices. Blank forms and other paraphernalia were depended upon for results. During all this time the chief offender was in faulty administration. The executive had been left out of consideration. It has now become apparent that a study of individual qualities in relation to the requirements of an executive position; and the development and shaping of a well-balanced organization of such individuals i.j the chief element in administrative success. Men of the right executive ability and outlook, will necessarily, because of their breadth of mind and analytical faculty, appreciate the value of the research idea and apply engineering principles to all the details of executive administration. Such research has developed facts and recommendations which have not only broken many standards of old type business administrations, but have achieved new records of management. The situation at one time was said to be somewhat alarming in view of the fact that because of the continuance of old fashioned office and administration metiods, the number of office employees per unit of business transacted was gradually increasing with the years, and serionsly affecting profits in many industries. Whereas manufacturing science had reduced cost of manufacture, administration ability had not reduced the cost of administration or production of sales. Many large concerns are still unaware of the change, of the scrapping of inefficient methods of administration and are obstructing their greater success.

The profits made by alert concerns with their highly modern administrations, and the research spirit which prevails within them should alone be incentive towards wider use of investigative method. Administrative prob- 
lems offer a fascinating variety for research, because of the great wealth of detail and scope of application, for the modern executive does not hestitate to reanalyze and investigate anything no matter how apparently well established and unquestioned any customs or plans may be. The method of approach to his daily problem is different from the modern executive because his attitude is that of testing and reconsideration, rather than of acting upon tradition or hearsay or even upon his own impulse or opinion.

In addition to researches of methods, plans, etc. in executive management, is the field for the use of statistics. Accounting figures are really statistics of management, for the natural purpose of assisting in determining administrative decision, and the variety of them which are of value in efficient administration is quite extensive, and in most organizations constitutes in itself a broad field of research. Many details of executive administrative problems are outlined in Chapter XVI.

9. General problems of economic relationships.-The economic development of the country is largely in the hands of business interests. Consequently, business interests cannot jossibly aroid responsibility for economic progress in all its phases. If business does not make the inrestigations and researches which need to be made in order to settle authentically the pressing economic questions, then politicians or unfriendly interests will make them, and develop great antagonism and prejudice because of lack of economic sanity and business vision in making such researches.

In fact this has already occurred to the great detriment of business. It may be said without any fear of contradicton that the highly destructive antagonism 
and prejudice to business, current for the past twentyyears is the direct result of the failure of business to broaden ont its researches and investigations to take in the general situation from the broad public point of view. The close and narrow application of business to its own individual profit, instead of a wider perspective in making researches which would be recognized as constructive for an entire industry, or even for the public weal at large has thoroughly widened the breach between business and the public, and brought prejudice on top of ignorance. This prejudice, like all prejudice, is most painful and difficult to remove.

The very fact that a small group of business executives developed industry to such a tremendous extent that it dealt in million dollar figures instead of the oid hundreds of thousands, which were the numerical limit of popular imagination in olden days, spread alarm and distrust. The average mind of ordinary range finds it impossible to visualize large figures, and because of this impossibility develops antagonism. Mere talk of millions of dollars becomes bitter to limited minds which interpret these figures, not in terms of economic respon. sibilities, which they are, but in terms of luxury, treasure and power. It is a simple psychological truth, long certified, that what we cannot understand we suspect and fear. The cracker barrel philosopher to whom hundreds of dollax's represent affluence, is appalled, angered and made bitter when asked to digest facts in relation to large corporations. His numerical imagination, so to speak, is outraged, and bristles up angrily at statistics of big business.

The situation of the packers is perhaps the outstanding illustration par excellence of this condition. 
From a purely efficiency point of view the packers represent marvels of administration and organization, but are hated mainly because of their size. This is definitely proved by the fact that only five of the ninety or more packers of the United States are visited with this prejudice-namely, the five who are espocially large. The other packers, differing solely in size, not in method, are rarely criticized.

It appears plain, then, that general economic researches and investigations of a kind which will place facts before the public, before distributors and even before the employees of an organization itself, are of the highest possible value. Moreover, the unique largeness of many corporations make it essential that in order to reach the ends desired, old fashioned and ready-made solutions which served well enough in other days must be overthrown and new ones developed through analysis and research which will fit the new day. Business is constantly breaking new ground, which calls for adequate survey.

In specific chapters further on are outlined specific examples of this situation; it is the aim here to point out the very broad bearing which research has on problems which before have been regarded by narrow business men as a field for philanthropists, theorists, reform. ers and dreamers. The war has drawn the economic world into a much closer union than it was erer supposed to be; has shown the relationships existing and proved the profits of coöperation. Business cannot afford to permit only academic economists and reformers to make researches-their amateurish effort in a realm all too difficult even for men trained, who know the intricacies of business, has already done far too much harm 
and let loose too much naive nonsense about economics.

It is d:stinctly a practical business enterprise to research general problems which have no immediate or direct bearing upon the profits of an organization; even if they profit competitors and the public at large equally as much as the company. The number of snch researches must necessarily grow as time gones on, and it is a cause for grave regret that such were not made years ago.

10. The fallacy of the idea that a business is "different."It cannot be male too clear that modern thinking about business has thoroughly established the fundamental sameness of a great many problems of business, thus making it of especially wide present importance that researches of business problems should be undertaken. The man in the plumbing supply business is always certain that his business is radically and hopelessly different from the man who sells safety razors or toothpaste. Until recent years he has not even been interested in sitting down at a meeting where business problems were discussed for the benefit of all types of business men; nor was he in the habit of reading business periodicals, even those dealing with problems directly related to his own particular type of business. In fact, so in-looking was his point of view in times past that he consulted absolutely nobody about his own particular business, believing his problems to be such as no other concern, not even in his own line of business, had to deal with.

The small elements of truth in such a position cannot possibly be made a basis of so narrow a view. Practically speaking, all businesses are operated upon the same fundamentals, and analysis of the problems of one is for the benefit of all. No one but the researchers or business counselors who have come in contact with the 
problems of many different types of business firms, can appreciate almost the dreary sameness of the most important matters which take up the time of the executives in all lines of business. The same problem of how to pay salesmen and stimulate them; the same problem of securing greater interest from workers, or finding executives, or of elucating consumers, or of relations to distributors, or of purchasing, or managing of correspondence, arise in any and all manufacturing industries; and when closely examined, the problems and factors which are absolutely individual to one firm, or even to one line of industry, are merely tangents of the same general problems. It is for this reason, and for this reason alone, that it is the merest commonplace of business experience that a successful business man in one line of business is as a rule successful in any line of business he might undertake, given the same general opportunity. As a matter of fact those who have accomplished marvels in industry or business enterprise have quite frequently been men who knew nothing ahout that line of industry and came to it from some other line of activity, thus proving the essential unimportance of the special technical problems of that particular industry. In fact, business experience goes further and probes that over. emphasis upon special technical conditions and peculiarities of one business tend very strongly to make for in. adequacy eren in that particular industry. The newcomer into an industry is usually the man to make in. restigations and conduct researches, because he frankly confesses lack of information and carries no pre-conceived notion and opinions in his mind.

This new attitude in itself makes for wider research, more respect for fact and investigation. 


\section{CHAPTER II}

\section{WHAT IS FACT?}

11. Human nature and fact.-Most people's conception of a fact is that of a hard and rigid thing, something stony and sharp and clear. Relatively this is true-a fact is usually something more tangible than the surrounding mass of uncertainty. Nerertheless, a fact is after all an elusive, unsubstantial thing. It is not my purpose to enter into any abstract discussion of the nature of reality, but even from a practical business point of view it is necessary to take into consideration the true, inward nature of facts in order that they may be handled with care and understanding. Neither too much trust, nor too little trust should be reposed in a "fact," so-called. A fact, defined for our purposes, is a statement of conditions or existing circumstances, and may be in the form of words or figures, or a picture in the form of charts, maps or design.

One should be conservative in what one calls a fact or treats as a fact. There is no such thing as $100 \%$ perfection in the statement of facts. It requires all the skilled training, the watchfulness and energy of anyone who deals with facts in order that some approximation to $100 \%$ be obtained. Even after it is once obtained, every minute that passes adds to the degree of possibility of error. Much that passes for fact is merely near-fact or guesswork. This by no means de- 
tracts from its value. It is an absurd notion that only $100 \%$, or neally $100 \%$ correct data is useful or safe. In all efforts, even in scientific work, approximation, estimates, arerages are of great value. As a rule, the only facts which are thoroughly attested as $100 \%$ correct are facts only seldom used or of no immedi. ate value, or mere records of the past. It is usually the case that the facts most needed and most useful are the kind hardest to get and in which there is no possiability of $100 \%$ accuracy. The serious place of business resealch, and the possible profit and advantage of it is illustrated in this situation.

The important thing is to distinguish clear-mindedly between that which is of a high degree of accuracy, near. facts and sheer estimates and guesswork; in other words, to discriminate between kinds and character of fact and degrees of accuracy. Untrained minds often have prejudices against facts and figures for the sole reason that they have used them unintelligently and with indiscriminate faith. Natural laziness of mind tends to make people accept facts and figures, especially when they look imposing and accurate, regarding them as infallible and exact. Human nature is constantly seeking a rule-ofthumb in place of original thinking, and often looks for statistics to back up preconceived ideas. This is fairly easy.

The utter carelessness of the average person with facts is well illustrated in a trial in court when witnesses persistently endeavor to get before a jury so-called "facts" barred out by the rules of evidence, which are deliberately shaped to eliminate near-facts and guesswork. It is one of the amazing traits of human nature that desire and emotion make otherwise honest people 
swear that something is a fact which is not a fact at all.

Nothing is fact (1) which gives only a partial picture of the situation, (2) which is based only upon opinion, (3) which is embellished by imagined details, or (4) which has not been rerified and doubled-checked. It is known that two people will report the same events or facts in a different manner-the difference being that one is a competent observer and the other is not. Every city editor on a newspaper is familiar with the inability of new reporters to get facts straight. In journalism, as in business research, it requires special training to report facts.

12. The limitation of figures.-To the uninitiated, figures usually look imposing and carry with them a certain air of unimpeachable finality. Yet it must be remem. bered that figures are mere counts of noses, mere numerical expression of facts, and that they represent only the quantitative measure, not a qualitative measure. Any numerical presentation of facts which is not based upon unifornity in the things counted is misleading. If you are merely interested in the number of people irrespective of their kind, a count of noses is valuable; but in any study of people a count of noses is a negligible or minor item. The U. S. Census is a very ambitious connt of people, but it has nothing to say about the multiplex richness and variety of character and temperament of the people counted.

The limitation of figures and the statistics available on a problem is quite another thing. Nearly all types of facts lead themselves to study through the figure method, once the right definitions and classifications have been made; and if only the proper data for study from the numerical side is secured, quite remarkable 
scope for analysis is open. But the limitation of such figures in reaching the result desired must not be over. looked before basing important decisions upon them. It is a practice too much indulged in to base a very great deal of conclusion upon a very slim foundation of figures. This is not the fault of the figures, for in nearly all cases much more vital information might be secured and expressed through figures if the proper effort and investi. gation were made. The strong tendency is to ignore the kind of facts most needed and be content with easy-toget-figures. Statistics are too frequently regarded as obliging servants and slaves, and it is widely believed that they can be made to "prove things". Statistics themselves cannot "prove" anything; they are mere inanimate pictures of supposed facts; the logic and reasoning of the writer or reader is needed to complete the syllogism. As James W. McIlraith says in his book on "The Cost of Prices in New Zealand," "a given economic fact is the result of numerous complex forces, many of which are in a state of constant variations, and react upon one another; and of these forces only a few can be adequately describer by the method of statistics. Consequently these few are often quoted as if they were the only active causes, whereas the effect attributed to them is probably only on the assumption that all other causes remain unchanged or suspended. Statistics even when compiled accurately, though often absolutely for a com. plete solution of a problem, do not in themselves provide that solution, but are to be used in conjunction with evidences of other kinds."

13. The psychology of statistics.-Although states of mind aud other delicate phases of life and economic facts which business must necessarily deal in are extremely 
hard to study through the medium of statisties, yet modern methods have brought even much more abstract and evanescent matters into the realm of statistics, by the application of laboratory methods. What we are here interested in is that the scope and range of facts for business purposes is greatly enlarged through this means, and that it is no longer necessary to regard the states of mind of consumers and distributors for instance, as matters to be guessed at in business, since they can be reduced to the forms of reliable statistics.

Similarly, it is possible to determine the "blind side" of statisties; to supplement with statisties the facts which explain the psychology behind certain figures. Facts and figures give out wrong impressions and in. vite wrong conclusions, often, until the psychology behind such statistics is analyzed and a further showing of facts based on this psychology is made. The statistics of high sugar consumption in America can thus be explained, or the statisties of divorce.

Psychology in connection with the mere use of statis. tics is in itself worthy of consideration. Few things are so well hated as statistics; largely for the reason that real facts are extremely stubborn and often disagreeable things which upset many illusions and comfortable notions. Real facts are so frequently inhuman because they are unanswerable. Most human beings live in worlds of illusion, and illusion is the natural and sworn enemy of statistics. The disappointment and irritation of individuals disillusioned by statistics are thus vented upon the statisties themselves and upon statistical method in general.

There are two attitudes of mind towards statisticsthat of too ready acceptance and dependence, and that 
of inattention, disparagement and antagonism. Truth often, therefore, goes begring, and is persistently rejected -it must be "sold" to those it alfects. A good statistician will make every effort therefore to have his data make no undue pretensions, clearly marking off their real province and forbear from making them indicate too great finality or inclusiveness, and clearly stating the basis from which they have originated. A certain modesty in the presentation of figures and statistics is extremely sound psychology, if it is desired to get respect for the facts to which they are entitled.

14. Checking up facts.-Although it is a fatal defect and a mark of narrow scope in the handling of statistics to permit oneself to be in a merely suspicious attitude, permitting no proper use of the intuitive imagination; nevertheless, a real and important part of all statistical work is the proper checking up of facts and figures. A great welter of facts and figures is constantly appearing in print, and the average person fails to realize with what haphazard method and slovenliness of research such statistics are frequently compiled; nor the great danger of error in reprinting and hasty proof-reading in the case of hastily issued periodicals.

As a matter of fact all statistics are open to criticism. The United States census figures, both of population and manufacture, and practically every other supposedly authoritative source of figures can be shown upon expert analysis to be crude and inadequate, if not positively incorrect and misleading in certain particulars and sections. No source of figures however high should be regarded as beyond suspicion. Nor should it be regarded as fatal to the use of such statistics if they do not check up. Infallibility and perfection are some of the virtues 
to which statistics can never attain, even though they may aspire.

The best that can be done in checking up facts is to have a clear understanding as to their source, and their limitations expressed frankly without reservation. If possible to check back to their sources this should also be done.

In the checking of conclusions from statistics some standard rules and guides are available. Newsholme has laid down these four rules:

1. Never have preconceived ideas as to what the figures are to prove.

2. Never reject a number that seems contrary to what you might expect, merely because it departs a good deal from the apparent average.

3. Be careful to weigh and record all the possible causes of an event, and do not attribute to one what is really the result of a combination of several.

4. Never compare data which has nothing in common.

Foley also gives these rules:

1. Every statistical estimate should be considered in the light given by corresponding estimates for previous years.

2. Every total should be homogeneous in that quality which concerns the argument.

3 . Where values are used the effects of replacing them by quantities should be tested.

4. The errors latent in the constituent which form an estimate should be examined, and their effects on the estimates should be tested with reference to the purpose for which the estimate is used. The maximum average crrors should be calculated to see if their concurrent would affect the result. 
5. The ideal measurements necessary to support each deduction should be conceived, and if the estimates accessible do not necessarily give the same view as the ideal measurement they should be rejected.

6. When the proficiency of statistics as estimated is establisher, the arguments based on them should rebound to the statistical results by the ordinary rules of logic.

In addition to this from a practical point of view it is important that statistics be pertinent to the definite problem in hand. One of the real difficulties with statistics is that figures are piled up where figures are not needed, and figures are lacking where they are especially important.

15. Changing the "facts."-The creative, virile, aggressive type of businessman does not take a servile attitude toward facts. He regards himself as a shaper of economic history, as the agent of business evolution.

In other words, when he is shown the gathered facts regarding a business situation, he first assures himself that the facts are really as stated, and then, if the fortunes of business make it worth while, he begins to in. quire, can the facts be changed?

This does not mean the facts about the past, but the facts of the future. If it appears that the market for an article is severely limited; or if the method of marketing has for years been a certain wày, or even if the habits of the public, in dress, or food, or outlook on life are shown to be thus and so, the aggressive businessman will not rest content until he is satisfied that these facts can. not be changed.

The most remarkable examples of such change of economic facts through long-continued business effort, inrolving the expenditure of millions of dollars are writ- 
ten into the business history of the United States. The makers of typewriters and telephones had literally to fight their way through the stubborn indifference and antagonism of businessmen to use either the telephone or typewriter, now the most intimate mechanisms of the business machine of to-day.

The elothing manufacturers, the Hart Schaffner \& Marx's, the Cluett-Peabody's of the country, brought about gradually an era of better dressing, and specific, permanent formulas of fashion. The American man without his ready-made suit, his linen collar, wouldn't be the American man; and most of us hardy realize this until we travel abroad.

Facts can be changed, even if they are quite deep-rooted in custom and human nature. Business men must think of business in terms of development, larger volume, lower price and profit, broadening of markets; and this almost necessarily means changing the facts, as they now stand.

Research is the balancing determinant as to whether the desire or resolution to change any given facts is an impossible dream or whether it is a realizable hope, near or remote. Many men have had "faith" that they could "change facts," but it was merely beating their heads upon impenetrable granite walls. Nevertheless, others constantly turn away, convinced that they cannot change the facts, when merely slight aggressiveness might quickly break down the fragile obstacle to realization. The important questions are, what is the thickness and the composition of the wall to be broken down? Is it granite a mile thick, or an eggshell? How long will it take to bore through and what will it cost?

In other words, the matter of facts as to present conditions must be riewed from the engireering point of 
30 BUSINESS RESEARCH AND STATISTICS

view. If a country is wild and untracked or untunnelled, engincers can survey the ficld and transform it into blossoming civilization-at a given cost of time and money and brains. 


\section{CHAPTER III}

\section{TYPES AND KINDS OF DATA}

16. Fundamental facts concerning an industry.-It is frequently the fact that those engaged in an industry know remarkably little concerning this industry at large. They bave but a vague idea of the general tendencies of the industry. Many of these ideas are colored too much by their personal experience-and they are therefore short-visioned in their own development, since no individual concern in an industry can remain unaffected by general trends and undercurrents. Knowledge of them can be turned into profit.

The corrective to such a situation is of course that of securing analytical researches of the industry at large if they can be obtained. Concerns engaged in manufacture can as a rule obtain such researches and reports, or have them made to order. To illustrate what is meant by such a research the following outline of the typical contents is valuable to study:

Origin and development:

a. History of product.

b. Past development of sales and distribution.

c. History of consumption and public attitude.

d. General status to date.

Present production:

a. Companies in the field.

b. Capital employed.

c. Financial history and status. 
d. Labor and factory conditions.

e. Location of plants.

f. Volume of business.

g. Raw material supply, past, present, and future.

h. Profit, turnover and costs.

i. Types and models and varieties manufactured.

j. Personnel of concerns in the field.

k. Mortality of concerns in the field.

Good-will and protection:

a. Patent or other exclusive basis.

b. Trade mark and priority status.

c. Relative good-will standing of principal firms.

d. Consumer reputation.

e. Peculiarity of article and field in relation to protection and possible future status.

f. Competition.

Distribution conditions and methods:

a. Present channels of distribution.

b. Possible further channels.

c. Distribution difficulties.

Sales organization and method:

a. Types of sales organization used by various concerns.

b. Sales policies and methods used.

c. Sales arguments and general basis of selling.

d. Price policy.

e. Guarantees and service offered.

Present consumption conditions:

a. Study of per capita consumption.

b. Analysis of character of present volume of business.

c. State of mind of consumers.

d. Conditions affecting consumption.

e. Consumption by states and sections. 
Future consumption conditions:

a. Statistical study of maximum selling possibilities by states.

b. Graphic comparison of production and consumption curves.

c. General analysis of future consumption conditions.

d. Study of purchasing power by grades and classes. Advertising:

a. Past methods.

b. Present character and trend of advertising.

c. Statistical review of mediums and expenditures.

d. Outline of needs for future.

e. Special methods applicable to the industry.

Competition:

a. Study of relation of various concerns in the indus. try.

b. Comparisons and relative strength and weakness.

17. Preliminary requirements in analyzing a new project.Whether it be an entirely new line of business, or a new article to be added to a line, the procedure of investigation to go through, if there is to be made possible a clear and accurate judgment of plans of procedure, should be substantially along the lines of the following data:

1. Technical test and analysis of product.

2. Practical test on typical consumers:

a. Actual trout by consumers.

b. Tabulation of consumer opinions and attitude, by actual canvass.

3. Analysis of consumption:

a. Present consumption.

b. Present manufacturing and selling conditions and success.

c. Present competitive status, territorially. 
d. Possible consumption.

e. Study of distributive channels and trade sentiment (actual canvass of dealers throughout the country).

4. Trademark analysis:

a. Construction of trademarks to secure maximum advertising value and maximum protection.

b. Search of mark among unregistered as well as registered marks.

c. Layout of protective records and plans for trademark conservation.

d. Coördiuation of trademark plan with general plans of label, package and all possible forms of publicity.

5. Analysis of price and profits:

a. Analysis of costs on basis of specific first vol, ume of manufacture.

i. Analysis of selling costs.

c. Analysis of distributers' profits.

d. Analysis of competitive costs and profits.

e. Layout of price policy and protection.

f. Study of "wlat traffic will bear" and fixing reasonable retailing price.

18. Operative data required before starting a new project. - Such data may naturally classify itself somewhat as follows;

1. Analysis of sales and advertising situation:

a. Layout of staff organization necessary.

b. Study of alteruative methods of campaigning.

c. Study of alteruative methods of advertising.

d. Investigation of parallel and competitive sales and advertising methods and experience.

e. Study of probable factors of resistance. 
f. Layout of maximum sales points and arguments.

g. Standardization of sales policy and of position.

b. Study of trade paper advertising efficiency for the proposition.

i. Study of consumer advertising mediums' effciency for proposition.

j. Study of auxiliary and special advertising efficiency.

2. Financial budget of estimated expenses and returns:

a. Tabulation of complete expense balanced against returns from $90 \%$ of proposed first yearly output: (1) per unit of material, and (2) per complete yearly volume.

b. Detail of manufacturing expense.

c. Detail of sales organization expense.

d. Detail of special advertising expense.

e. Detail of expected volume of sales and basis of estimation.

f. Detail of possible lesser and greater volumes of sales, with accompanying scales of graduated costs and expense.

g. Detail of administrative financing of proposition.

3. Blue printing and scheduling of plan of action:

a. Chronological layout for factory production and delivery.

b. Chronological layout of sales organization work.

c. Chronological layout of mail campaign to dealers.

d. Chronological layout of trade paper advertising. 
e. Chronological layout of tryout or local territorial advertising work.

f. Chronological layout of special stunts.

g. Chronological layout of general development.

19. Adequate records and reports of business operation.There are always plenty of reports or statistics about an office, covering the details of management; but the important difference between these and the records and reports above referred to are that something more than surface facts are required. Adequate and searching data about a business are not as a rule furnished by routine employees-they can only be secured through research and with the help of trained minds which have the ability to look below the surface.

The surprising fact is that men of high technical ability in routine positions will sit calmly day after day over a veritable nost of vital facts, needing only the right point of view and research ability and experience to bring them to light, yet innocently unaware of their existence; or if aware of them incapable of reading their true mean. ing or correlating them properly to other facts.

High executives often fail to read plain facts and to see their true indications, or do not know what factors to study. Theix perspective is too much foreshortened-they need to step away a few paces, or better still, hire someone do it for them and so stimulate them to do likewise.

Researches of manacement are of very wide scope, and are more fully detailed in a later chapter, but for the present purpose may be broadly indicated by a list of the vital types of data on business operation which has proved highly valuable to sturly.

1. A study of unit costs of general factors, suc' as the unit cost of handling each order. 
2. An analysis of cost of hiring and firing.

3. A study of cost of writing letters.

4. An analysis of average size of orders and the meaning.

5. An investigation of why customers cease buying, and a study of variations from average in accounts.

6. A study of tendency curves in various elements of the operation of the business.

7. An analysis of the proportion and kind of prospects turned into customers.

8. An inquiry into the nature of credit losses, or of finance of customer purchases.

9. Analysis of the consumer attitude.

10. A rigid technical study of competitive goods.

11. An economic inquiry into the status of the dealer or jobber.

All of these are actually reports on business operation -and the range of the subjects listed cover all the departments of business operation. Also the inquiries range from fairly small matters to exceedingly fundamental matters. They are listed here to build a clear picture in the reader's mind as to types and kinds of data which are important in business operation.

20. Analysis of consumer and consumption.-This is a special basic type of data which is not easily obtainable and must be accumulated and studied gradually, although there need to be definite researches before any expenditure or risks are undertaken.

The consumer is the decisive factor in all business, and his condition, location, number, vagaries, habits and changes must naturally be of first importance. It is foolish to run counter to the needs and wants of con- 
sumers, but equally foolish to lack courage or conviction in swaying consumers to your point of view. A nice adjustment of effort to requirement is needed, and in this work exact information plays the leading part in success.

The type of data on the consumer and consumption which is important to study is illustrated in the attached list of items:

1. Exact number and location of logical prospects (this work alone, for some lines of business, requires an enormous amount of research, but is always and invariably worth its cost).

2. Dissection of logical prospects into all possible classes and kinds.

3. Analysis of their present and possible volume of purchase.

4. Investigation of their present state of mind:

a. Toward line in general.

b. Toward various brands or types in particular.

5. Study of their habits of purchase, their present channels of receiving impressions and informa. tion about such merchandise.

6. Analysis of whom and what kind of persons enter into counsel in purchase of goods (of higher price levels).

7. Study of per capita consumption, together with domestic, territorial and foreign comparisons; also comparisons with per capita consumptions of other allied articles.

8. Inquiry into logical possibilities from a technical point of view, of increasng or broadening out per capita consumption. 
9. Analysis of auxiliary factors affecting per capita consumption.

10. Statistical research into average characteristics of purchase orders, of consumers and of consumption conditions.

21. Graphic summaries and reviews.-This type of data is simply a focusing operation into small range for the benefit of higher executives, in order that they may be able to readily and quickly grasp the manifold factors affecting the business, and see their relationship one to the other.

The best method is, of course, the graphic chart method. Details of methods of presenting subjects to boards of directors in graphic manner are given in a later chapter. The present purpose is to outline the kind of data which may be summarized and prepared, as a rule in a standard size loose-leaf binder, for executive study. A partial list of such summaries and reviews might be:

1. General business conditions.

2. Graphic record of orders, plotted in logarithmic relation to profits, expenses, bulgeted quotas, etc.

3. General and specific departmental unit of cost factors.

4. Raw material, stocks on hand, factory production, financial factors; cash balances, bills collectable and payable, notes and financial obligations, unfilled orders.

5. Sales factors, fluctuations in types of orders, origin and class of orders, size of orders, individual salesmen's records, etc.

6. I'roduction factors; labor, departmented output, etc.

7. Special reports in summary. 
Such summaries and reviews should not be entrusted wholly to accountants and record keepers-they should be the work of a research and statistical department, prepared with a broad perspective. For this reason the research department requires to be an active practical element in a business in order to be of its best possible use.

22. Inquiry into distribution problems.-In no department of business operation are there such complicated problems as in the distribution of goods. Sellers are at the mercy of the disposition and ability of distributors, and of fundamental facts and strategies governing dis. tribution. A firm has complete control over its labor, machinery and executives up to the point of finished production, but thereafter uncontrolled factors limit its success. These uncontrolled factors of distribution naturally offer the most inviting field for investigation and research. The problem is large, varied and deep-rooted. It touches many problems, social, economic and political, together with psychology, practical organization, foresight, and educational skill.

Concerns which have carefuly investigated such matters in a deep-going manner have been able to very wisely plan their future. They have also been able to undertake serious work which, if not in the immediate pres. ent, then within a few years, has produced very unusual results. Such wisdom in the use of research has ranked them as highly creative and constructive in their prac. tical vision-with a corresponding reward in superior po. sition in the market.

The following is an outline of the various problems and facts of distribution which will bear analyzing, investigating and charting; 
1. Inquiry into percentage of distribution.

Working out your selective position in the market; figuring present percentage of distribution; comparison of percentage of distribution with other's in field.

2. Study of jobbing zones of the United States in your field.

Data about the natural jobbing areas and their relative importance.

3. Analysis of changing conditions in distribution.

Readjustments in the kinds of merchandise carried by various classes of distributors; new possibilities for wider selling.

4. Comparative growth by territorial or zone growth or through nation-wide simultaneous effort.

The correct policy to follow. Conditions under which the territorial method would be soundest and conditions under which national selling and advertising would be best.

5. Analysis of trade channels and volumes.

Showing how the country's trade is divided up; volume of trading by retail outlets; expansion of retail stock lines; concentration of trade volumes; distribution and massing of population and retail outlets.

6. Analysis of jobbing policies and practice.

Showing historical comparison and evolution of jobbing; present day jobbing centers and reaches; comparative volume of trade passing through jobbers.

7. General analysis of retail outlets.

The typical 3-store shopping lines of goods; the subdivisions and proportions of trade 
volume going to department store, hardware, etc.; analysis of relative value of rural trade in cities of various population grades.

8. Inquiry into policy of selling direct to dealers.

Proportion of selling done direct in various lines of trade; reasons for and experiences with such policy; with chart showing typical sales, line of action and routes of communication; and suggested form of sales route to consumer.

9. Analysis of policy of selling direct to consumer.

Consideration of economics of direct selling; inquiry into comparative volume of business sold direct to consumer; illustrated with chart showing typical sales line of action in direct selling.

10. Study of louse distribution organization.

Organization chart of branch organization; and district offices; operated by other con. cerns; study of applicability of method to your proposition conditions.

11. Rural and small town distribution.

Statistical distribution of general stores; trolley systems and suburban railroad networks around cities, etc.; study of massing of rural population; radius of influence of the city newspapers, both daily and Sunday; inquiry into typical division of small town purchasers.

12. Study of national sales districting methods.

Inquiry into efficient layout of sales districts, examination of boundaries, transportation factors, etc., sales block system and direct routing. 
13. Inquiry into price and distribution standardization.

Study of price maintenance, possibilities, methods and experiences; working out of zone map of geographical price variations; study of quintity prices and discount scales; study of conditions effecting price raises and lowerings, margins or profit to jubber and retailer; consumer attitude to price.

23. General economic surveys.-When properly consid. ered, almost all business enterprises rest upon certain economic conditions or circumstances, which often are too much taken for granted, and viewed too uncritically or superficially. Deeper study often brings to view certain facts and conclusions which open up new opportunities for long-visioned constructive effort. Only a limited number of business concerns have considered that they had the breadth of interest, time and money to enter into broad economic studies, usually the leader in any single field of industry is the one to make the investigation.

Inquiries of this kind should naturally be made by public institutions, especially by the government, but are undertaken often in a public-spirited way with a shrewdeye to resulting business advantages in addition.

Surveys of this type may be along such lines as these:

1. Inquiry into causes of increased cost of living.

2. Study of distribution economy.

$\therefore$ Inquiry into technique of certain articles.

4. Mechanical, chemical or special scientific researches.

5. Special studies, compilation of books, etc.

These researches require a heavy expenditure, but are undoubtedly excellent investments from the point of view of good will, enlightenment, propaganda, etc. They can 
often be made so that they are good material for book publication, which adds to their dignity. Investigations of such exhaustive and broad nature are undertaken by concerns which make them for the benefit of their customers. Large pullishing firms, or advertising media owners make them for the benefit of advertisers. An im. portant future lies before such work. The Hart Schaffner \& Marx economic prizes, in their suggested range of subjects, list many of the broader economic problems which might be undertaken as researches:

What forms of education should be advised for the elevation of wage-earners from a lower to a higher in. dustrial status in the United States?

The influence of credit on the level of prices.

Should the government seek to control or regulate the use of mines of coal, iron, or other raw materials, whose supply may become the subject of monopoly?

What provision can be made for workingmen to avoid the economic insecurity said to accompany the modern wage-system?

Causes of the rise of prices since 1898 .

The best scheme for uniform corporation accounts.

The relative efficiency of American and European labor in manufacturing industries.

The value of protectionism to American workingmen. The value of organized speculation.

Would public interests be subserved by the amendment or repeal of the so-called Sherman anti-trust law?

A scientific basis for tariff revision.

How far is competition actually crippled to-day in American industries?

A study of various forms of combination.

Price regulation by governmental authority. 
A study on the changes of modern standards of living. Price maintenance.

Social insurance.

The theory and practice of a minimum wage law.

24. Retail problems of sales and management.-Not only are the 500,000 retail stores of the country interested in anything that will cut down the enormous mortality among them, but the jobbers and manufacturers who sell through retailer's are even more deeply interested in retail problems, as they cannot expand or develop except as the sales development and management ability of the general level of retailers improves.

So serious is this problem to manufacturers in some lines where the retailers are especially backward, that very extensive and costly researches have been conducted and far reaching policies adopted aiming at dealer education and development. In fact, one of the first commercial research departments established some years ago was formed by the U. S. Rubber Company under the guidance of Prof. Paul H. Nystrom, of the University of Wisconsin, an authority on retail problems. The purpose of this department was to inquire into the retailing problems of the company's customers.

The retail problem has been growing especially acute from the angle of the manufacturer, because of the pressure on the standard type of small retailer from three sides-the chain store in the cities, the mail order house in the small towns and the department store. All three of these modern Goliaths of retailing have had this great advantage over the small retailer-that they could secure the best possible executive braius, and operating from a centralized basis, standardize methods of operation. The small retailer has thus competed with his own smaller 


\section{BUSINESS RESEARCH AND STATISTICS}

degree of skill and knowledge against superior informa. tion and methods, to say nothing of purchase in quantity and other centralized economies.

Quite logically, therefore, since the three larger types of retail outlets have not been whole hearted coöperators with the arerage manufacturer, it has become recognized that the manufacturer distinctly owes it to his dealers to provide centralized researches of a kind that will not only help him sell his own goods, but all the dealer's goods. Mere uninformed efforts to advise retailers puts manufacturers in a poor light, as retailing is a complicated special business. In order to be of real assistance, unusual knowledge and information is required, and these can only be had by research, as modern knowledge of retailing success is not broadeastly available. The Harvard School of Business Administration has undertaken some exhaustive studies of value in several fields, but so many sides to the problem are presented that there remains a great deal to be done.

Among these many possible researches, a few may be listed:

1. Researches into turnover.

2. Analytical study of retail costs of doing business, and standardization of cost items.

3. Studies of retail salesmanship.

4. Methods of educating sales-people.

5. Bonus and compensation system for sales-people.

6. Price maintenance problems.

7. Trademarked articles, con trademarked articles, the private brands, and their place in successful retail policy.

8. Credit and cash methods.

9. Self-serving stores. 
10. Analysis of successful chain store methods.

11. Neighborhood buying and shopping habit and practice.

12. Study of the use of comparative prices and bargains.

13. Retail store arrangement methods.

14. Window display science.

15. Store location science.

16. Educational sales development methods.

25. Special department store problems.-Chain stores and department stores have their own problems, too. In fact a group of department stores now maintain a coöpera. tive research department which has been of considerable value, though confined to routine matters.

Some problems which department stores are interested in investigating are:

1. Analysis of methods of paying commissions on sales in department stores.

Complete analysis of subject, from all angles, in typewritten loose-leaf form.

2. Study of schools for training sales-people in department stores.

Analytical report giving details of methods used in schools; ontlines of studies; also reasons for discontinuing schools, etc.

3. Investigation of welfare methods among department store employees.

Details of plans in operation; methods discontimued, and consensus of opinion and experience in scope and application.

4. Comparison and study of wages paid to department store employees.

Tables of comparisons of wage standards in 
different cities; different grades and types of stores; different methods of computation, promotion standards, etc.

5. Analysis of methods of selecting employees for department stores.

Copies of application blanks and ads; standards of different stores; methods of handling new employees; turnover in stores; etc.

6. Study of profit-sharing systems in department stores.

Analysis of various plans in use or discontin. ued, details from financial point of view; consensus of experience; forms and literature of stores.

7. Study of employees' associations, social and benefit, in department stores.

Forms and literature, facts about each type and kind in operation; opinions of employer and employee, etc.

8. Analysis of mail order business in department stores.

Study of methods and success of various firms in different parts of country; methods of selling and advertising used; examples of catalogs, etc.

9. Study of use of statistical analysis in department stores.

How to organize records so as to be able to have vital statistics of the business quickly; what statistics of department store business are important to study daily and weekly; how various firms operate statistical plan, etc. 
10. Analysis of sales book methods and problems.

Methods and experience of various forms; problems encountered; how met and handled; critical comparison of various makes available.

11. Study of cash carrier systems.

Analytical comparison; experiences and confidential opinions; analysis of conditions.

12. Study of department store organization.

With ideal organization chart in blue print form; study of executive personnel, proper division of authority and responsibility; functions and individuals analyzed.

13. Analysis of ideal department layout.

Study of relative stores location values for department store; giving practice and experience of other firms; reasons for variations, etc.

14. Study of merchandise turnover in department stores.

Average turnovers in various departments; analysis of principles, of turnover; methods used to increase it; policies of successful stores in regard to turmover.

15. Investigation of costs of doing business in department stores.

Average costs of doing business in difierent grades of stores, different types and different cities; standard methods of computiug costs; comparison with other retail costs; study of cost factors and tendencies.

16. Study of department store general policies.

How stores increase effectiveness of their ef- 
forts with individual policies, basis of operation and merchandising idea. Description of instances; comparisons and analytical review.

17. Department store advertising methods and experiences.

Analysis of average appropriation and plan of basing it; advertising policies; relative merits of morning and evening papers; use of other mediums; conservatism and radicalism of tone; atmosphere and quality trade; bargain sales and price comparisons; advertising trademarked merchandise; freshness of copy; methods of various firms and experience cousensus.

18. Voucher and pay roll systems.

Analysis of best methods illustrated with forms; experiences of many firms.

In addition to the above types of researches are also researches into the buying capacity of the retail store's logical territory; a research of the types, prices and grades and quantities of merchandise which they can absorb. Inquiries into the earning power, occupations, shopping habits and trpical budgets, etc., are also valuable. Local surveys of an exhaustive nature are now more and more undertaken by department stores, chain store systems, etc. Research departments are being established and the application of the research idea made to all forms of retailing problems.

26. Scientific and technical investigations.-Although not altogether properly pertinent to our subject, the making of scientific and technical researches have an associated value and significance which will require outlining. 
This association and relationship is due to the inescapable merchandising or ssles point of view necessary to consider in the making of scientific or technical researches. It is the sheerest business impracticalitythough it may be splendid applied science-to conduct scientific and technical investigations which have only a theoretical or abstract value. One of the most pointed truths in business technique is that while many inventions and products may be devised which have some interest or even usefulness, there is only a relatively small percentage which has a commercial value.

Some of the most modern technical research departments combine both functions--that of technical as well as sales analysis. Other technical research departments have a free reign to devise and invent and investigate what they will, but their findings are tested in a commercial research department. Other research departments or laboratories take their orders from a commercial research department, which sinply asks that a solution to specific problems be found. For it is quite true that a great many brilliant commercial developments are the result of vision as to what the market desired and the concentration of technical brains upon the problem of meeting these desires. Richard Sears, head of the great mail order house, very frequently planned new grades and types of merchandise sitting in cousultation with his staff, simply in order to meet a price or a need which the market situation showed. Merchandising necessity or advisability is the logical mother of invention.

The great rubber companies are constantly making experiments as to new applications of rubber, and if it is discovered (as it has been) that rubber is an excellent material for picture frames, then the question is passed 
on to the commercial researchers who analyze the subject from the selling and consumption points of view. The market analysis may or may not show it wise to manufacture.

The scientific and technical branches of research have actually at present an entirely disproportionate degree of endowment and attention as compared with commercial research. The Rockefeller Foundation, for instance, has placed half a million dollars at the disposal of the National Research Council for scientific research, mainly in chemistry. The Bureau of Standards of the U. S. Government as well as many endowed laboratories have very great resources behind their efforts, whereas commercial research is at present entirely a private matter operated on a purely commercial basis.

Yet there is an increasing amount of what is really scientific subject matter arising even in commercial research, while on the other hand purely scientific research needs greatly to be coördinated with the practical ends of business.

Such a synchronization between scientific and commercial research was ably practiced in Germany before the war, and with remarkably swift and profitable results.

As illustrative of the types of investigation of partly or wholly scientific or technical nature, but which require amendations, additions, reviewing and reconsideration from the commercial research point of view, is shown in the following list of subjects:

1. The adaptability in cost, nature, operation, and use and general commercial availability of some article to be considered as a substitute for another now used. 
2. The usefulness, volume of possible sale, technical excellence or defects under average conditions of use and abuse, of an article or device.

3. The devising of new models or materials to fit certain market conditions or opportunities.

4. The reshaping and planning of an article or device to fit the commercial necessities and advisabilities, from the point of view of price, profit, class of users, volume desired, etc.

5. The selection and study of a new article of manufacture desired, which will meet with equal success the suggestions of technical economy and feasability as well as maximum sales and profit possibilities.

6. A technical examination of all competitive goods and an analysis of competitive claims, and the charting of the exact comparative standing of various brands or types of goods.

7. Purely scien ific researches of broad business problems; researches which are not merely physical or chemical, but which apply laboratory test principles to more intangible factors (see chapters xix and $x x$ on Psychological researches).

For greatest success in this much needed synchronization between commercial and the scientific research work there will be necessary an attitude of greater mutual tolerance and appreciation between scientists and busi. ness men. 


\section{CHAPTER IV}

\section{RESEARCH DEPARTMENTS AND DATA SOURCES}

27. The new tendency towards establishing departments of research.-Several years before the war there appeared a tendency which will undoubtedly go far before it will reach its complete development,- -the tendency to install research departments as a regular and permanent part of the executive plan of business organizations. Great business organizations like Swift and Armour, the United States Rubber Co., etc., were pioneers in this work. As the work was new, the heads of such research departments had to "find themselves," and are still at work finding themselves; but at no time since its inception has there been any uncertainty as to their value and result-producing powers.

The chief practical consideration advanced before business men for this new development was simply the fact that a business organization has a great many kinds of problems and conditions to consider, especially in its sales department. It finds that its need for information is so constant and so varied that quite logically a single department for the handling of business information and research is required. Under any other plan, executives were losing valuable time wrestling with problems of investigation for which they were not fitted. Ordinarily, unless a wider vision had been applied, this would simply have meant a slight enlargement of the asual 
"statistical department," which for a number of years has been common, but which suffered greatly from the fact that they were merely record-making departments, hardly distinguishable from the accounting department.

The new vision of a business research department went a great deal further than this and realized the need of highly trained intelligence not only in securing such routine information desired by the various departments of business, but also in conducting on its own initiative investigations and researches which might help in a larger way to solve some of the problems presented by the business as a whole. In one case where a considerable research department was opened, the initial purpose was that of studying the problem of the retailer in order that the company which sold its goods to the retailer might develop information and pass it along to the company's retailers, which would make them larger buyers and more active sellers of the company's goods. In another case the initial purpose was to better labor conditions; in another case to increase office efficiency. In all three cases the departments rapidly enlarged, with profit to all concerned.

The sound standard platform on which a modern research department may be built is that of bringing all the departments of a business into active coördination with the research department, and endeavoring in a creative way to see whether the problems of earh of these departments may not be solved to some degrcs by special work in research and information getting. This department shonld be aggressive ond wide-reaching, and have a suggestive authority to all departments.

28. The right type of man to head a research department.A very commendable tendency was started in the develop- 
ment of research departments by securing college professors who had some knowledge of the theory of economic matters and who therefore had an unbiased ana. lytic approach to business investigations. This tendency was an epoch making and radical departure for several reasons; that it established a working connection between industry and the university, between theory and practice, between the laboratory and the office. It has been on the whole a profitable plan for business, in that it secures the benefit of the scientific training of such men and of their ability to generalize upon the problems in hand and thus to arrive at conclusions and solutions more deep-reaching than had before been possible. Yet, the gap between university and practical life has been so great in America that much remained to be desired. It is extremely likely that a regular profession will be developed in the matter of business research and that special courses will be available in universities; and it is fairly certain that many more concerns will follow the footsteps of great industrial leaders and develop research departments, headed not by college professors but by those who will combine the specialized university training and business experience.

This will not occur, however, until the more perfect liaison can be established between theory and practice, between the university and the business office. Business men have been unable to shake off a conviction that even many of those who step from the professorial chair to the business research office have not ret mastered economics in a sufficiently concrete way to reach their ut. termost usefulness. After all, they want business men, not theorists; they wish to use theory for business ends and not merely for the pleasure of theorizing. As the 
situation stands now, there are not enough men of the proper degree of training and point of view to meet the demand; and business men will be slow in developing the research idea in business until more men who are properly trained can be found and developed.

One of the grave dangers and temptations of a research department as a part of a business is in becoming $b u$ reaucratized, and becoming infected with the very destroying narrowness which it is its function to eliminate. A professional pride and a desire to make a showing have a tendency to creep into the way of the larger developments and accurate functioning of such a department, which cannot be gauged or judged by the standards of any other department in the business. It must be a perfectly free agent, but also at the same time intensely practical, and it must not be hinged in the slightest degree with a pride of department, or personal slant of the slightest degree, or any prejudice or limitations whatever, for its very existence depends upon its sensibility to suggestion and external conditions. It is in fact the embassador of the outside of the business to the inside of the business, and must represent the exterior condi. tions accurately. It must remain unaffected by the business concern's traditions or limitations which exist therein. Research results of importance may hang upon the ability and courage to reach and apply completely new conclusions.

It will thus be seen that it is an extremely vital matter that the head of a research department in an organization be carefully picked and be a man of large enough calibre to understand his scope and function. The frequent and obrious mistake made is to put some "bright young man" in charge of a research department who has 
a superior self-consciousness of the wisdom he possesses, but little practical business instinct; $\mathrm{or}^{\circ}$ some man who has developed a set and established point of view and method of working, and who is chiefly concerned with maintaining the supremacy of his department in the face of all suggestions and criticisms. It is better to have no research department at all than to have one in name only with a clerical-minded head or a mere statis. tical hack or a man interested primarily in making a showing for his department, or susceptible to vanities, jealousies or other personal limitations. It is also important that such a research head be a man of sufficient strength and ability to be the confidant and frequent consultant with the highest executive in the business. Oth. erwise, the department becomes a mere information department and a supply or routine statistics, rather than a research department up to the level of modern needs and opportunity.

29. Organization and scope of a research department.Ideally the research department in a business shovid be just one head, with several capable assistants. Danger lies in the expansion of a research department into an executive department of considerable detail. Research work is frequently hampered by the pressure of executive detail, for the head of the research department cannot be looked upon exactly as a business executive operating a department. He functions at his best when he is almost free from executive management. For this reason among many others many of the ablest research depart. ments of the country do not undertake all the details of the work which is involved in their researches. They utilize special organizations better organized for the work and take the same attitude toward it that a business 
house does towards its printing or its engraving; it saves money and secures better results by engaging special concerns from the outside. It confines its own efforts to the checking up of the work, the planning of it, and the judgment of results and the making of reports to executives.

Herewith is an ideal organization chart plan for a business research department, and its simplicity in the face of the considerable scope of its activities will be noted.

30. Research and statistical organizations and sources.There are gradually being developed special organizations which render it possible to secure a wide variety of data, a wide scope of service, and ability in research which is at the command of any business concern or business research department. The principle of this type of service is well illustrated in the Dun or Bradstreet credit information service. It is hard to realize that most business houses years ago insisted on operating credit reporting bureaus for themselves. It soon became evident that a great central organization was vital, and it is now possible to secure information on the financial standing of any firm throughout the United States at short notice. The same is true of an organization now in existence for securing information on individuals. It is now possible to secure information concerning any individual anywhere in the United States, through an organization with ramifications into every county of the United States. Infornation on technical standards may be secured from the Govermment's Bureau of Standards; and export and a great deal of other business information can be secured from the department of Commerce at Washington. Specialized organizations 
now index the contents of the trade magazines; collate the advertising rates of periodicals throughout the United States, coördinate the catalogs of building material manufacturers; collect clippings throughout the United States on any subject whatsoever; provide full details of the profits and financial investment conditions of all concerns whose securities are on public sale, etc. These special organizations and many others in addition are intensified sources of information which it would be foolish to duplicate.

Another type of organization is developing which provides aц even greater scope and directly applicable service. One organization makes a specialty in examining the fundamental financial and trade conditions of the country, charting the rise and fall of prices and basic economic positions. Another organization, specializes in the making of local trade researches throughout the United States, for the securing of information of any trade nature whatever; also the development of special statistics, the compilation of information and data on specified industries, and the making of specialized inves. tigations with a trained staff of statisticians and investigators. Such a centralized service which could only be built up to a high degree of efficiency at a low cost by being a central organization, can perform services which no individual research department can well afford to undertake. The traveling expense to travel any investigators throughout the country is almost prohibitive, and wholly unnecessary, inasmuch as special organizations have trained investigators located residentially in a large number of cities and towns.

Naturally one of the first duties of a research depart. ment is to very fully familiarize itself with all the 
sources which exist for the making of investigations and researches and to be able to coördinate with such sources to a particular research end.

Public libraries are of only minor value, because of the fact that they are so largely repository for books which are years old, and because of the lack of up-to-date completeness; but more than all because of the utter lack of existence of much of the data which business most desires. It is to be hoped that public libraries will be made more valuable to business men in the future by a more aggressive policy coördinating with business needs. The Business Branch of the Newark, N. J., Public Library has set a very creditable example.

The Census department reports have very definite and severe limitations in their scope of information. Unfortunately census data on industries is very narrow in scope and far too broadly classified, also too many years behind date to be of any vital business value (except occasionally when it affords a good starting point for investigation). A movement is now on foot among business men to influence Congress to provide more commercially useful information throngh the Department of Commerce.

A source of information which is of growing value is that of business houses which have a natural interest in the development of information, so as to influence other firms to take such action which the information indicates to be logical. In fact, one of the most prominent research departments has been that created by a great publishing honse, which in order to serve its advertising patrons, made available to them extensive researches into certain industries and into general distribution conditions. Similarly, other adrertising media, such as 
street cars, billboards, newspapers, special groups of magazines, etc., have spent considerable effort and time in the development of statistics and information which is fully worthy of being studied, as it is rendered with high professional standards and at considerable expense. The natural deficiency of such information is the suspicion that it may be biased, and some of it no doubt is. But to the most business firms, without any research facilities these sources are at least of value in awakening an interest in business facts they greatly need to possess.

31. Requirements of research workers and assistants.Business research work has certain fairly well defined requirements of training and personal capacity. It is a serious mistake to utilize any other type in the liandling of business research. The combination of qualities required is somewhat unusual and not plentiful. Memory and observation, mental accuracy and some mathemat. ical ability are important; yet on the other hand it is equally desirable, at least for the higher type of research work, to have a certain degree of imagination and intuitive insight. Much of the facts and data to be recorded are not visible to the nakec. eye, and cannot be observed in an objective way. They must be approached from the subjective side. In the absence of the possibility of making laboratory and special tests, it is necessary to grope with the aid of intuition and practical insight. The extremes and faults to be avoided in a research worker are too great matter-of-factness or its reverse quality, a careless and loose way and too uncritical an attitude. The absence of an unusual degree of disinterestedness and capacity to let the true facts develop themselves without consciously or unconsciously moulding or influ- 
encing them is important. An investigator with a bias is like a prohibitionist with a bottle in his coat-tail. Bias however, is a very subtle thing (see chapter xxviii) which many of those who are affected by it would stren. uously deny possessing. It is for this reason that the training of the university and the college in devotion to science is of a great importance and opens up a future for thoroughly trained young men and women who can catch the true and scientific spirit of devoticin to truth.

Nerertheless, an obverse fault is that of such inimicable and impracticable devotion to complete accuracy that the ordinary working result of investigation cannot satisfy and cannot induce the investigator to arrive at a conclusion. It is impossible to transform the business world into the leisurely, timeless realm of pure science in which men spend a lifetime to determine, for instance, whether insects can reason or whether they have only instinct. Business positively demands conclusions and workable results, and a practicable aspect must be given to any search after true conditions. That point at which it becomes impracticable to seek after a closer approximation to $100 \%$ complete accuracy must be nicely judged by the investigator. Also that tendency to apply a thousand dollars' worth of brains and investigative energy upon a proposition which cannot afford one-tenth the expenditure. The business faculty, so called, is quite as important in research as in any other department of work, and no more fatal mistake can be made than to suppose that because a young man is "studious" and analytical and likes to bury his nose in books and statistics, he is therefore good material for business research. 
32. Research department operated by advertising mediums with space to sell.-Within the past five years a marked interest has been aroused among the owners of advertising media in the establishment of research or merchandising information departments. This has been in line with a strong effort to reduce the percentage of adver. tising failure and to develop the marketing facts vital to business success which seemed almost nowhere else obtainable, and which were particularly needed by the young, new advertiser and those who were still unedu. cated as to the place of advertising in business success.

Large sums of money have been spent for such research and in some cases rather striking successes scored. One research department for a famous newspaper is reputed to have developed $\$ 1,000,000$ worth of advertising by the expenditure of only $\$ 75,000$. Another newspaper spent $\$ 200,000$ on a survey of the city and greatly increased its advertising patronage thereby. A seller of street car ad. vertising space issued a notable book of merchandising statistics and operated a very businesslike merchandising research and service department with rapid results and wide reputation.

The case for the undertaking of merchandising re. search by advertising mediums is very ably put by a very large publisher of magazines who has gone further in the way of research than almost any other individual business firm. In a statement regarding its research plan and policy this firm says;

It has been stated that no manufacturer should adver. tise withont first inrestigating.

It is just as true that no publication should inaugurate the advertising of a manufacturer without first investigating. Before advising a firm to spend its money the 
publisher's representatives or the agents should them. selves know the conditions in the industry, the markets, and what results any given publication may be expected to bring.

The days of advertising gambling have gone forever. While the degree of success can never be accurately forecasted, still advertising has so far approached an exact science that one need never-should never-advocate it without a precise study of conditions. This is more keenly realized perhaps by the publications themselves than by the manufacturers. Reputable publishers of long standing, who have stood by and seen campaigns fail and manufacturers deterred from advertising by the example of these failures, know how strongly it is for their own interest to accept only advertising which is reasonably sure to succeed. Thus future increase in patronage is insured.

Ordinarily, publishers' representatives, when they have sought to establish the soundness of a proposed campaign, have necessarily started by accepting as a basis of procedure the manufacturer's own data relative to the industry and the selling field. They then, in a conscientious manner, have studied whether or not that particular manufacturer could use advertising profitably in that field.

This has been the accepted method, the only variation being the degree of actual consideration for the probable success of the campaign which the publication felt itself obligated to assume. And yet advertising campaigns have failed. And yet thousands of potential advertisers have remained passive, asserting the impossibility of advertising their particular wares. In both instances the reason has frequently been that the original 
hypothesis was wrong. The manufacturer himself did not know enough about actual conditions in his own business; usually not enough about selling couditions.

Advertising structures reared according to the best rules of molern advertising engineering have toppled through no fault of the publication which built them, because the fonndation, for which the manufacturer assumed responsibility, was set in sand. Imposing advertising structures for which correct plans have been drafted have frequently failed of erection because the manufacturer never had it proved to him that he had good rock for his foundations.

The publisher to-day must go down to the ledge.

The — Company to-day investigates the problems of its advertising clients long before it knows who its particular clients are to be.

The company maintains for this important task a Commercial Research Division. The duty of this division is to search out the exact facts about various industries and trades, manufacturing and selling conditions, trade tendencies and future possibilities. The purposes of the company in maintaining this division are:

(1) To enable its representatives to approach a manufacturer armed with the fullest information as to the extent of his national markets and the avenues by which he may enter them.

(2) To equip them so that they may give to manufacturers advice and ideas in merchandizing broader than those which any one manufacturer could obtain without a costly investigation of his own, or perhaps not at all.

(3) To learn for its own use what advertising possibilities each industry offers, so that the whole broad field of merchandising may be approached intelligently and 
with a viewpoint that is both national and inclusive. (4) To render on occasion specialized service to clients.

The work of this department is not merely statistical. It does not simply pore over the records of the United States Census and similar institutions, taking figures already existing and putting them together for the purpose of deriving conclusions. Neither is it partisan; it does not seek colored information. The men in it are not advertising men; they are experts in research. The department is quite as much interested in discovering what cannot be advertised as what can; in discovering what conditions exist unfavorable to advertising as well as those which favor it; in making it possible to provide against the future as well as to take advantage of the present.

A representative of this department, therefore, is expected to probe to original sources, digging out information which has never before been collected. A very large proportion of the work consists in interviewing disinterested persons in the field and in obtaining a consensus of opinion upon each question involved. 


\section{CHAPTER V}

THE LAW OF AVERAGES AS A GUIDE TO BUSINESS

33. What is the law of averages?-Business men are as a rule not yet fully accustomed to either the meaning or the use of the law of averages. As they become more analytical they are more and more appreciating to the full the very delicate and wonderfully useful tool that the average can be in unlocking doors of knowledge to business success. The average has heen described by experts with great clarity. For instance, Bowley says: "By the use of averages, complex groups and large num. bers are presented in a few significant words or figures; the object of a statistical estimate of a complex group is to present an outline, to enable the mind to comprehend with a single effort the significance of the whole." Von Mayer also graphically descrinos an average as "A short expression of the phenomenon which levels all differences of the individual members of the series." Zizek offers a further illuminating definition of an average: "The essential nature of an average consists in describ. ing theories of divergent individual values by means of a single comprehensive expression."

Rather crudely putting it, an average is a tool with which to get at a fact which is hidden; to see the many sided whole accurately in one picture. Most facts which concern large groups are hidden, because a mass represents unusual difficulties of study and analysis in direct 
proportion to the numbers of that mass. An individual man is easy enough to study as to his age, sex, color, height, weight, etc., as these facts about an individual are easily obtainable. But, when it is necessary to make inquiries into the nature of the masses of individuals, it is quickly discorered that masses are confusing and defy analysis, especially human masses. The exact reaction or nature of inert masses of metal or other materials is almost exactly ascertainable. Engineers in examining a carload of material will inspect a certain number of units picked at random and thus by means of the tool of the average judge the entire carload with a very high degree of accuracy. The same principle has to a most surprising extent been applied to human beings. The law of arerages is a law which applies to anything, dead or alive, from the composition of soil to the emotional reaction of a woman bargain hunter.

It must first of all be recognized that the law of averages is in effect a high-power lens manufactured by man's brain and ingenuity to extend the vision of his eyes which unaided can see but a certain distance. Once this comparison is grasped and appreciated, a business man will no more think of being without the aid which the law of averages can render him than a sea captain will permit himself to be without his glasses. The reason for the great efficacy of the law of averages is that units of all kinds, whether of steel or of human beings, are after all modelled to a large degree upon uniform patterns with uniform reactions and nature. These can be depended upon to be true to the average, no matter how great the individual rariation. Without the average, man would be remarkably handicapped. Even without the help of mathematics, human instinct endeavors to 
make use of the law of averages, by making some rough mental approximation.

34. The present business use of the average.-To illustrate the opportunity in business for profitably becoming better acquainted with the use of the average: There are two kinds of businesses using the law of averages to the tune of millions of dollars. The first is the insurance business, and the second the mail-order business. It would pay any business man to spend considerable time getting acquainted with the remarkable use of figures in either of these industries. The insurance companies have approached almost the uncanny in the use of statistics. It is often popularly believed that the insurance companies take a large element of risk in wagering many millions of dollars upon the chances of people t) live to certain years of age; or the chances of acci. dent, theft, fire, etc.

As a matter of fact the actuarial statistics, as they are called, upon which the insurance companies base their rates, their risks, and their capital, are almost an exact science. To the average person it is naturally a curious thing to say that risks in railroad accidents have been reduced to almost an exact science; or risks from theft or suicide or fire. As a matter of fact, it is known to insurance companies as a hard-and-fast fact, proved by the law of averages, that out of one hundred average healthy men, twenty-five years of age, sixty-four will reach the age of sixty-fire years. Eight out of every one hundred men will die by accident, and a similarly known number out of this one hundred will commit suicide, have their automobiles stolen, suffer a fire, etc. It might seem as if this were going far enough, but the experts in the use of the law of averages in the insurance business go con. 
siderably further. They know that out of every one hun. dred men, twenty-five years of age, one will be rich, four will be well to do, five will be earning their living and fifty-four will be dependent upon friends or charity, when they reach the age of sixty-five. They also know that a majority of those who have money at thirty-five years of age will have lost this money by the iime they are sixty-five. The relative average chances of men and women in accidents are calculated because it is knowu that three times as many women as men die by aceident; and five times as many men are killed on railroads as women. One might fill many pages with statistics based on averages which the insurance companies have been wise to spend a great deal of money to accumulateoften working coöperatively at very heavy expense of tabulation.

But the use of averages is by no means confined to insurance companies. In the men's apparel field it is known that $23 \%$ of customers will wear hats of $6 \% / 8$ size, and 1.10 of $1 \%$ will have $61 \%$ size; also that $33 \%$ will have 15 size collars.

In the hotel restaurant business it is known that $1 \%$ will order oysters, $5 \%$ will order fish, $7 \%$ will order soup and $20 \%$ will order salads.

The mail-order business has discovered the value of statistics chiefly because every move that it makes is controllable, and every response it gets is tabulatable. Numerical tests and statistical applications of the law of averages are not only possible to make, but quite im. perative if a great deal of money is not to be spent with fatal blindness. A mail-order house can control statistically all the letter's or catalogs it sends out, and as a check on results its order blanks or price numbers in. 
dicate various details, through symbols, and as it can by electrical machinery quickly tabulate the characteristics of its orders resulting from its controlled sales efforts, the possibilities of the use of the average are unlimited. Averages from many angles, from the character or amount of the money received, whether it is money order, cash, check, etc., up to any individual characteristic of the buyer may be tabulated and studied while they are "hot from the giiddle" and their lessons applied. Mailorder concerns large and small which operate with modern technique in the use of the law of averages, never make any mailing of circulars, nor in fact take any step involving any expense or new developments, without first making accurate tryout tests on small quantities, and considering the results from the point of view of averages.

In fact, the executires of a mail-order business learn after a while to discuss the entire matter of development effort in the special lingo of the law of arerages. They will talk of "operating on a $3 \%$ basis," or "approaching the $11 / 2 \%$ dead-line." Before sending out a great quantity of mail matter, an entire series of tests is made of a considerable variety and scope, upon certain groups, in certain territories, with certain enclosures and using certain appeals in order to determine the relative merits of each method, and thus establish the rate of expectation of returns if the larger volume of circulars be sent out. A test mailing is made of a thousand names, usually thoronghly representative of the entire broad list; or selecter to form groups, separate thousand name individual tests made in each group. If such preliminary tests show a percentage of results which is above the necessary percentage for making the larger mailing 
a practical proposition, the profit possibilities of the circularization of the larger list are definitely calculable, as the average will vary very little if the test work is well done. The law of averages properly applied will almost certainly match very closely the final result as made in the test, no matter how enormous the number of units. If the test does not result in a paying average, alteration in the methods may be adopted and a new test made. Or a readjustment of method based upon the story the various averages tell may be worked and a new test made. As the number of customers of Sears, Roebuck $\&$ Co., for instance, number over $7,500,000$, it will be seen that the great number of units available for the test afford remarkable scope and the results may be called pretty conclusive.

35. Gauging the variables with the law of averages.-The mail-order houses have also considerable bodies of facts developed by their more scientific methods, as to their field, the exact proportion of its clientele which will make its purchases at certain periods of the year; the exact proportion of its orders, which will be for certain lines of goods; the exact proportion which will return the goods for credit, the proportion which will have incorrect addresses or enclose incorrect amounts of money. In fact, no kind of purchase, or peculiarity of locality escapes the keen eye of the law of averages in so rich a field for application as the mail-order business. The growth of volume of business of the mail-order houses in a decade from a few millions up to $\$ 210,000,000$ for Sears, Roebuck \& Co. is impressive evidence of the profitmaking application of the law of averages.

It is common, however, to suppose that the mail-order business and the insurance business are special and pe- 
culiar and that they alone perhaps can make the most extensive use of the law of averages, having the most ex. act data to deal with. The fallaciousness of this is disclosed, for instance, by the fact that a number of the large hotels have made most profitable use of the law of averages, gauging in advance their restaurant or room requirements. For instance, one large hotel in New York, on consulting the weather man, determines about how many plates of soup will be ordered at its lunches or dinnels; how many orders for cold dishes, or salad dishes, etc. It has also determined differences between days of the week, specific days of the month, days in proximity to holidays, and seasons of the year. How valuable this is, may readily be seen by the fact that hotels which rather blindly prepare for one day almost in about the same quantity as another day, are shown by these average statistics to be from $10 \%$ to $30 \%$ wrong in their calculations, about one-half of the time. To eliminate the waste occasioned by the stocking in of perishable foods, is a matter financially worth while to the tune of many thousands of dollars.

Many other businesses under wise analytical guidance have also learned to make use of the law of averages with profit. There is practically no business, from the retail grocery store to the largest corporation in existence which cannot apply the law of arerages with profit. In fact, it is the mark of a superior man of business intelligence if he has applied the law of averages, and understands something of the technique of thinking in terms of the law of averages. It may almost be said that business judgment requires to be able to think in terms of arerages, in order that policies and plans may be laid wisely, since business is full of balances and 
counter-balances, inequalities and compensatious, which in order to be controlled and guided toward a general beneficial and profitable result must be viewed from the point of the application of averages, whether they be of profit or loss, risks and failures, strong and weak territories, over-or-under-price items, etc. The average result is the real result, and the best perspective with which to look at any business enterprise, either in whole or in part. Even a great sport like baseball must partly be looked at from the point of view of averages in order to be both fully understood and fully enjoyed.

36. Scope of application of law of averages in business.Next to appreciating the general importance of the average as applied to business, is a practical comprehension of the departments of activity and lines of effort upon which the law of averages can be applied in the usual operation of business. The application of the law of averages very well begins with the very fashioning or shaping of the article of merchandise itself. In the absence of the application of the law of averages, many articles or merchandise are planned and shaped for a minority rather than a majority of users. They are shaped not for the average man, but the exceptional or rare prospect. An article to be of highest conmercial value must be shaped and planned to appeal to the average. If it does not do this, it is doomed to a limited market and consequently a limited profit. Studies of average requirements and average reaction to the type of products planned are highly essential, especially since inventors are notoriously indifferent to the imperative lessons of the commercial arerage, and are particularly obsessed with adding refinements and complications for reasons of vanity or professional pride, which from a 
commercial point of view, based upon the great law of averages, should be utterly eliminated.

The very selection of an article or a line of merchandise or industry in which to engage may profitably also be analyzed from the point of view of averages. The average degree of risk in comparison with other fields of industry; the average mortality in that line of industry; the average of the concerns in that industry, the average size, speed of growth, or length of life of concerns in the specified line of industry, all have a most important bearing upon whether or not to embark in the enterpinise at all.

Even upon determination to enter a line of industry, it is of some importance to inquire as to the average type of organization, equipment, method of operation, etc., which prevails in the industry, as it is always a matter of indisputable logic that the line of least resistance lies along the line of the average. This does not invalidate the equally powerful value of change, novelty and originality in method and plan; it merely emphasizes the other side of the matter, which is at least important to inquire into.

Even in the formation of a sales organization, experience shows that the dependence upon exceptional types of salesmen is unreliable; that dependence upon the average type of salesmen is most certain of results. In administration of business affairs and executive management, the law of averages may be applied even to such minor details as the average length of time in filling an order, the average cost of handling an order, the average size of an order, the average calls made per day by salesmen, the average number of strokes written on the typewriter per day by individual typists, the average number of 
days required for collection, and to many other factors which will develop in seeking detailed management efficiency.

In considering the more difficult phases of the business in analyzing the market, and the basic tendencies and factors which underlie it, the average is of equal value and of times of quite surpassing importance. In analyzing markets and market factors almost all statistics of social, economical and financial nature are of value. Facts such as the average wage in any given community, the average expenditure on various items, even the average marital conditions of individuals may be of import. ant business value. It is the privilege and the opportunity of the thoughtful business researcher to delve very deeply into fundamental causes, which at a certain depth become almost exclusively a study of averages, in order that he may dig out precious bits of information and guides to business men who must depend upon his analytical ability to see for them into the future and into the unseen present as well.

37. Fundamental factors in relation to averages.-Of late years, thonghtful business men, perhaps moved by the exceedingly erratic fluctuations which have prevailed in the United States, have given considerable thought to the matter of fundamental conditions. This thought, however, has been mainly that of following certain fluctuations in a few standard fundamentals, such as bank clearings, business failures, building activity, money conditions, foreign trade, gold movements, commodity prices, railroad and industrial stocks and bonds, crops, railroad earnings, idle car's, labor shortage or surplus and other factors of a similar nature. Ready-made summaries or index numbers, combining these various fun. 
damental factors have been offered to business men, but the general result has been to use such figures more or less as an automatic rule-o'-thumb, without appreciation of individual contrary currents, which modified the general tendency in their own instance, and in fact sometimes reversed it. All standard rule-o'-thumb signs have failed frequently in general studies of fundamentals, and it may be said that while study of general index numbers and summaries have had a wholesome tendency to increase the respect for study of facts and statistics by business men, the time is ripe for a less primary consideration of the use of statistics and averages, and a more extensive use of individually applied facts and figures to the business man's own particular case.

Business is surprisingly like an individual, and the same comment may be made with regard to differences between the individual and business in general, as the study of medicine in general and diagnosis in particular of an individual. It is important to understand medicine in general, but, as is so often remarked, medicine has its crucial tests and its most frequent failure in individual diagnosis. To have complete knowledge about disease in general, hardly helps unless the disease in particular can be stamped out. It is therefore highly im. portant for any research man or business man to estab. lish himself in a correct relationship to fundamental conditions, as applying to his own business. By obeying a general admonition to contract or expand, buy or sell, according to the interpretation of general fundamentals, a business man may be, as a matter of fact, ignoring his most exceptional opportunity or his gravest danger.

In other words, the important thing in the applica. tion of knowledge of fundamentals is to determine what 
fundamental conditions in the first place have real and vital relationships to the individual business; just what the extent and character of such relationship is, and then a more minute study of those relationships and their character and extent in the light of averages. If, for instance, the industry hangs very definitely upon the matter of building activity, then far more than the usually available material on building activity should be obtained. At present the statistics on building activity, as usually reported under the title of "fundanental conditions," are confined to little more than 100 cities. To take, therefore, any report on these 100 cities as conclusive of the entire country, would be entirely to ignore the fact that the rural and semi-rural markets are also vital and are often direct contradiction of the tendencies in the cities.

Furthermore, there are always a far greater number of fundamentals which apply to any one specified business than are even outlined in any of the general summaries and reviews which are available and current. To really get ahead of competitors and really be fundamentally informed beyond the usual situation in a line of industry, a business man will definitely require individual research work. Men of astute business ability and financial vision have always realized this, and many a corner in a basic commodity in past history has been due to the astuteness of some man who hired research brains to secure for lim the information which bore vital relationships, and thus disclosed advance information about the coming conditions of the commodity. Wherever raw material purchases are of vital importance and subject to general economic influences, basic studies of the situation should be undertaken. It should be ap- 
preciated that the average attitude of business men is that of merely following others, and of taking readymade information. This puts most men in the position of sheep following a bell-wether, and provides the finest kind of opportunity for a man of ability and resource who will make the proper researches to determine an individualized line of action. Only statisticians know with what astonishing lack of originality or intelligence business men often follow the beaten path of information, and fail to take the obvious steps to arm themselves with the choicest lind of ammunition. Many business men camnot be persuaded that it pays to spend money in securing fundamental facts and analyzing fundamental averages, having somewhat unintelligent, rough-and-ready notion that such researches are frills and furbelows. But the big financiers, the bankers, and the market operators know very differently of course, and for this reason in most cases fundamental conditions are anlicipated and discounted by men of this type long in advance of the common possession of such knowledge by the bell-wether sheep type of business mon.

38. Various kinds of averages and their technique.-It is not the purpose of this book, nor does the author consider himself competent, to provide a text-book on the technique of statistics. He merely aims to outline broadly the scope and possible application of the technique of business research and statistics, and for this purpose considers it of value to review the various kinds of averages. It would be absurd in such a book to discuss the harmonic mean, the contra-harmonic mean, or the quadratic mean. Such terms would be an incumbrance to the successful use of this book. The commoner type of aver- 
ages, outlined for the average business intelligence, are sufficient for our purposes.

The simple arithmetic mean, which is, of course, the common form of average compilation, represents merely the dividing of the sum of the items in any group for study, by the number of these items. The meaning of such an average is a leveling-off process; a standardizing of each of these units into an average; a re-making of each individual variant into a uniform variant based upon an equal division of the elements of their size into one standard or level size. In other words, if there are twelve men of various heights, their average height means the division by twelve into the sum total of all their heights, the result being a hypotheticul, average in. dividual whose height is a composite of all their heights. This explanation may be superfluous, but it is well to visualize the process which the simple form of average represents. The arithmetic mean is different from the other means such as the median and the mode, in that its value will be affected by a change in any member of the series. This cannot happen with the median and the mode, as they may remain unchanged even if considerable parts of the series are changed, since the median and the mode are not computed for all the items, but are arrived at by selection of one item as representative of the group or series because of their characteristic position in the series. The arithmetic mean is valuable of course in the great majority of simple statistical uses, but the median and the mode are only to be extracted from a series arranged according to magnitude.

39. The difference between mean and median.-The difference between the arithmetic mean, the simple arerage, and the median is well illustrated by an example of in- 


\section{S2 BUSINESS RESEARCH AND STATISTICS}

come. If in a small village where the majority of people have an income below $\$ 1,000$ there also live two men who have very large incomes, then if the average wealth of that village is computed, on the simple basis of an arithmetic mean, we will have a quite fictitious picture of the conditions there, because the wealth of the two individuals upset the representative character of the average. It would be statistically correct, from the basis of the arithmetic nean, to say that the average income was, let us say, $\$ 2,100$ (due to the presence of the two men of wealth); but as a matter of actual fact the so-called average thus disclosed would be an untrue picture. It would take the median to uncover this situation and give a true picture. The median income of that village would permit the securing of an average much more accurately reflecting the character of the income of the people of the village. The median is more accurately the probable value of the average rather than the arithmetically computed average. In insurance statistics this median is called the probable length of life, which is different of course from the average length of life. The use of the median is as a rule confined to quantitative, individual measurements and observations, for instance, in the matter of wages, income, ages, etc. The median is usually computed by taking the average of the two central items in a list of items, if the number of items is even. The median can eren be applied to more or less intangible and difficult matters. Zizek would apply it even to the matter of the average intelligence of a group of people. He would arrange the people according to the degree of their intelligence in a row, and then take the student in the center, or the several students if the num. ber is even, as the median intelligence of that group. 
He indicates that this method is entirely applicable to locating the median for a broad class of data.

40. The "mode" and the weighted average.-The mode like the median depends merely on the sizes at a definite place in the series; but just as the median is found by studying the center of an arrangement in order of size, so the mode is found by locating that item which on account of its relatively greatest frequency is considered characteristic of the whole series. It, too, can only be used in studying a quatitative ind vilual series such as wages, individual characteristics such as sex, age, or income. The mode is the type of arerage most valuable to represent the normal or typical size of a variable line of units. This is of importance becanse of the fact that scarcely any unit in a class of objects for statistical study fails to have a variation of some kind, and therefore fo $i^{\circ}$ careful study for certain purposes must be analyzed from the point of view of typical or normal. The arithmetic mean and the median very frequently are far from typical even though they may be correct arerages. The morle is to be found at the place of concentration around which the series is distributed in both directions with regularity. It is always that value which general complex of causes has produced.

The "weiglted" arithmetic mean is an effort to give to the single members of any series an influence varying with their general importance; this arbitrarily added influence being the "weight." The items, before their addition for the regular arithmetic mean, are multiplier by coefficients or "weight" of different sizos, and the sum of their products resulting is finally divided by the sum of all the coefficients.

This method of "weighting" is valuable and economical 
in computation, in order to get a uniform basis of consideration. For instance, if in securing average prices of different commodities, sold in different kinds of units, such as yards, pounds, tons, etc., then a weighted arithmetical mean is computed by first multiplying the prices by the quantities sold, and dividing this sum by the num. ber of units sold. Similarly, if a computation is desired in which the items are to be "weighted," from an intangible basis, then the different weights must be estimated and computed from these estimates, thus securing the results desired; taking care that the relation to each item is proportionate to the surmised relation between the items. It is in such matters of using great ability at estimation that a modern business statistician becomes most valuable, for the reason that highly desired basic data is so rarely available either in any form what. ever, or in a complete enough form in order to secure desired results. It is then necessary to call upon the technique which is part of a competent statistician's training, in order that a dependable result may be achieved; a result which will approximate, at least, the end desired and greatly improve upon guesswork which is so often necessary in the conduct $\mathrm{c}_{i}$ business.

A great deal more might, of course, be said of the technique of the average, but this is more properly the subject of a special textbook and special study.

41. The visualization of the "average man" or "average consumer."-Few phrases are more frequently heald than the expression of the "average man," the "average woman," or the "average consumer." When carefully examined it will be found that the process of visualization of this average is extremely faulty and haphazard in any usual method of thinking. It has been told of a 
famous editor of a woman's magazine how he would invariably close his eyes when enleavoring to visualize his average reader, and think of a certain house, in a certain little town in Ohio, which he once had visited, as constituting the average reader throughout the country. He would then edit his magazine in a manner which his instinct told him would bring forth a response from this typical or average reader. This crude method is unquestionably the method most frequently employed in any one's imagination in conjuring up the so-called "average dealer," consumer or customer.

As a matter of fact, Quetelet many years ago undertook the task of determining "the man who is to society what the center of gravity is to bodies"-the "average man" in whom were bound up the average result obtained for human kind by society; the mean about which the elements of human nature oscillate.

Quetelet's average man possessed in an average measure the physical characteristics and mental attributes of Quetelet's time, and although his methods were stimulative, his results were untrustworthy. In the first place, in considering the average man statistically certain absurdities are immediately encountered. According to actual statistics twelve men in ten thousand commit a crime each year; but how are such averages to be applied to typical arerage individuals? His so-called average of crime would be an absurdity as this "average man" would either commit a crime or he would not. Nor can an average wage be ascribed to an average man since many men receive no wages at all. We could not even marry our average man, because some men do not marry at all, and we would not know at what age he married, for the same reason. We must therefore conclude that 
in regard to many things the average man cannot be vis. ualized statistically as a standard of judgment for in. dividual cases.

The question arises, and has often been debated, as to whether there actually exists a living man or woman who might really be called an average type. It is agreed by most of those who have given thought to the subject that the paradoxical statement may be made that those who represent even but a few averages in different factors, whether plysical, mental, moral, economic, or otherwise, are in fact exceptional! In other words, our average man would of necessity be exceptional and abnormal. This line of reasoning would minimize the possible value of any statistical average man in the concrete flesh.

As a matter of fact, the so-called average man is far from the typical normal man, and therefore the term as so frequently used of average man, average reader, etc., is a mechanical abnormality of imagination, which has no proper place-he is a pure abstraction, a hypothetical individual, without any specific value, statistically or in practice.

42. The typical as a basis of practical study.-It is different, however, with a typical character. The typical man is a man who has not only the typical weaknesses, but also has typical variations from the statistical average.

For purposes of stimulation and focusing of thought and effort, it is valuable to visualize, if not the average man, then the typical man or woman, selected more after the fashion of arriving at a mode.

It is an interesting process to set about to more scientifically visualize typical man by a statistical process which will keep away from the unnatural and impossible average man, but tend to make concrete the type as he 
will be ordinarily encountered. This can be done by the investigative method, through questionnaires, localized investigations and other means, whereby a composite picture is built up which has something of the same individuality which is found in the ordinary course of busincss, having typical faults as well as characteristics levelled up by the averaging process.

As a matter of fact, it usually is most effective to trust to no type or average in specific matters of analysis of the point of view of the consumer, but to make actual tests for reaction upon the specific matter in hand, a sufficient number of actual consumers to secure a combined reaction test which will form a good representation of what might be expected with a larger number. This can be done even by testing out the reaction which a series of advertisements will receive if published; the reaction which a certain product or device will secure if put out. Again, the standing in goodwill of a concern may be tested by means of certain methods of getting reaction from typical consumers.

The business use of the typical, located by the investigative method with care, offers the largest practical possibilities. 


\section{CHAPTER VI}

\section{PER CAPITA CONSUMPTION STUDY}

\section{The value of the per capita basis of commercial study.}

--Whether one is marketing lead-pencils or drill presses, population is to a greater or less extent a guide to mar. ket possibility. For an article used by everyone of whatever age, color or sex (like lead-pencils) the use of the per capita measure is quite obvious. But, even in selling machinery or anything, except perhaps mining or farming machinery, the volume of sale in any territory will linge upon the number of people in that territory to some degree, small or large.

Therefore, it is one of the first and most fundamental methods of inquiry to study a market by dividing the total production or sales into the population. And by popnlation is meant not adults but the general population as taken by the census.

This gives us the true per capita measure, which is simply a process striving to arrive at some measurable relation between the number of people, and the amount of consumption. It is of course a fictitious measure, becarse the average individual user uses considerably more than the so-called per capita measure. Like the "Average Man" the per capita is an artificial result, and unreal. The arerage consumer in this method of inquiry would mean the median or the mode, speaking in statis. tical phraseology. The per capita consumption is merely 
a straight arithmetical average or mean, and like the arithmetical mean, is an artificial measurement for pure statistical purposes of comparison.

No matter if in such a calculation the resulting per capita is a matter of small fractions, figures in decimals, still it is a most valuable figure with which to work. It makes many things clear which were not clear before because they could not be expressed in figures. For instance, a general vague impression is that America drinks more coffee and uses more sugar than any other nation in the world; but such a statement means but little, in contrast to the far more definite statement that the per capita consumption of sugar in America is 100 pounds, as contrasted to the per capita of 14 pounds in Europe. As soon as these figures are stated the exact comparison begins to make itself known and the situation clears itself up in the mind. It is true that one might say that the United States consumes a certain number of millions of pounds of sugar, as contrasted with a certain other number of millions of pounds, consumed in another country, but at once it is necessary to re-examine such figures in the light of the amount of population. A small nation might consume as much of an article in quantity as the United States with its very large population, and on the face of it the two countries might appear to be consuming about as much as the other. It takes the per capita measure, based upon population to understand correctly the difference. The exact per capita measure is also valuable in other ways, in measuring growth in per capita consumption; contrasting one per capitawith another,either in localities orbetweenarticles.

44. Per capita contrast between village, city, county and nation.-As the chief ralue of the per capita figure is for 
purposes of comparison, it is important to review the kind and types of comparison which are possible. The per capita measure is available for contrast between any group of population for which the consumption of any given article is known. Thus it is possible to contrast one city, one county, one country with another. It is very important in studying the consumption condition. to contrast not only cities between each other, or counties between each other, or smaller units; but it is also important to contrast one type of territory with another type. For instance, it is valuable to contrast the per capita consumption of Iuxuries among the people in the Corn Belt, so-called, and people, let us say, in New England or in the South or on the Pacific Coast. It is also valuable to contrast one state with another, or one general geographical division with another, or one arbitrarily marked sale district with another.

Fven m re important for general comparisons are per capita contrasts between rural, semi-urban, and urban population; also between groups of towns of certain average size, with groups of towns of a higher or lower average size of population. Thus it is important to know, what is the average per capita consumption of linen collars in towns of 25,000 or 50,000 in population as contrasted with towns of 1,000 or 500 in population. Such statistics will gleatly assist in lnowing what territories are sub-normal or above normal, or what individual cities or towns are sub-normal or above nor'mal.

Per capita data will quickly select the weaker or more undeveloped spots of sales territory.

By contrasting per capita consumption between nations, a perspective of the state of development of this 
country as compared to others may be obtained. An excellent instance is that of margarine butter, of which Denmark, although a dairy country, consumes 44 pounds per capita, as contrasted with the consumption in America of but $3 \frac{1}{2}$ pounds per capita. All other European countries have many times the per capita consumption of this article than America. It is therefore obvious that unless this country has an unlimited and cheap supply of dairy butter, there is bound to be a large increase in the use of nut margarine. A reverse instance in the study of foreign markets is that of automobiles or telephones. Measured upon the per capita basis, European countries are far behind America in consumption of these articles, and the relative state of development of these industries is thus clearly defined. Many definite sales policies and plans may be developed as the result of study of such per capita figures. A seller of canned goods who learned that the per eapita consumption of canned goods in New York City is about $\$ 28$ per capita, as contrasted perhaps with only $\$ 12$ to $\$ 13$ in most other large cities will certainly be moved to inquire into causes and make investigations which may lead to very profitable information. Disclosures of abnormally high per capita consumption in certain localities or cities or towns may prove vitally important in disclosing automatically the location of some special factors or successful sales methods at work which might help the business if applied elsewhere, and thus serve as an automatic alarm bell for the study of local conditions.

In this connection it should be pointed out that many communities and towns throughout the country have an unsuspectedly large consumption which would be elroreously computed if figured on a per capita basis from 
the town's own population. Such towns are of ten brying centers for large territories surrounding, and the ostensible consumption is really not that of the town itself, but of a wide shopping area around it.

One of the things most greatly needed statistically is a national survey which will disclose the towns with unusual surrounding buying radius and high per capita consumption, throughout the length and breadth of the country.

45. Per capita contrasts between different articles.-From a broader point of view the use of the per capita consumption figure is important in order that constructive planning and thinking may be stimulated by knowledge of contrasts and by reasouing from analogy (see later chapters for further details).

Scrutiny of per capita consumption of different articles and balancing one against the other is certain to provoke unusual contrasts and ideas. The habits of the average American consumer when measured upon the per capita basis show themselves with suggestive clearness. For instance it is certain to provoke thought that in New York City the per capita consumption of meat is nearly $\$ 40$, whereas the per capita consumption of milk is only about $\$ 1.50$. Milk is one of the cheapest and most nutritious and least wasteful of all foods, yet apparently the per capita consumption of it is but a small fraction of the consumption of meat. The contrast becomes even more striking when the meat expenditure is contrasted with the expenditure for vegetables and fruit in New York City. The per capita consumption of regetables and fruits is about $\$ 1$.

The contrast between other articles of consumption is even more striking. The per capita consumption of one 
article of pure luxury, contrasted with the per capita consumption of a necessity gives rise to creative thoughts of possibilities of sales developments. If the people of the United States can spend over $\$ 10$ per capita on soft drinks, as they do, a manufacturer of many other types of articles appealing to the taste or comfort or luxury of the people, whose consumption is reckoned merely in cents or even in mills, may take hope. It is an exceedingly important study even from a general social point of view to analyze the per capita expenditure of the statistical individual, as it is thus possible to get at what might be termed "the per capita budget of expenditure" for the people of the United States. This pure population measure is a little more fantastic than is quite necessary, being only an arithmetic mean, not a mode or a median. The matter can be made somewhat more real by applying a per family measure, simply by multiplying the per capita by 4.6 , which the census gives as the statistical measure of the number in a family.

46. Applying the per capita measure to individual sales volume.-There is even more immediately practical use in business for the per capita plan of measurement. The per capita consumption need not necessarily mean the consumption of all articles of a type, but can also be applied on the basis of consumption of an individual firm's goods. This is always the practical first step because the data is as a rule available, from the firm's own records, and thus an exact measure for small units of territory are much more readily ascertainable.

Such statistics of consumption of a concern's own goods, have a highly strategic value in actual field work in selling. For instance, a number of fims now use this plan by establishing average per capita consumption 


\section{BUSINESS RESEARCH AND STATISTICS}

figures for various territories, various sizes of towns, various districts and localities, so that the salesmen when visiting dealers or jobbers in any given community are enabled to make vital and stimulating contrasts by means of their figures. They can tell a dealer or jobber that the per capita sales in that territory are a certain figure and go on to say that the average established in all other territories, cities or towns of similar size, grade and type, show a sum above that of the town in question. This is constructive work for the dealer or jobber and compels him to make an actual fact comparison between his own efforts and those of other units in similar territories and pass in judgment upon his own accomplishment. A certain degree of local pride assists this plan, in that no dealer or jobber wishes to be stigmatized with being thought less aggressive or able than his compeers elsewhere; nor is he willing even to admit tinat his community must be regarded as below the standard of other communities comparable to his.

Aside from the use of this method for sales purposes, the figures of statistical comparisons, from a firm's own record of sales, are valuable also to measure exactly the state of development of different territories, from the point of view of salesmanagement, advertising effort, and general educational work. More important still in some instances is the measurement of territories as a basis for the establishment of salcs quotas for salesmen, branch managers, etc. A really just and fair sales quota cannot be properly developed without very carefully estimating the possible consumption of a district or territory, and one of the means of arriving at such a figure is by means of the per capita method-contrasting the possible per capita or the actual. These "actual" per capita figures 
may mean the firm's own sales alone or those of all firms now selling. It is important to make researches which will disclose the per capita sales of competitors. If the quota figures based for various territories require to be altered to fit special conditions, they may be "weighted" in the well-known statistical manner.

47. Increasing the per capita.-Naturally all sales efforts tend to increase the per capita consumption. However, the increase of per capita consumption is of two kinds -first, the increase of the number of people who use an article, and second the increase in the volume of consumption of the average individual user. An article of universal use may have a certain set per capita consumption, which perhaps cannot be increased by increasing the number of users, but which can quite appreciably be increased by developing the individual volume of purchase. The contrary situation may sometimes prevail where there are a number of people who are using a very considerable amount individually, but the very large number of people who do not use the goods at all may tend to keep the per capita consumption very far below what is the average consumption of those already using it. In such a case the correct policy is not to develop more use, but to increase the number of users. Either of these two steps will naturally increase the per capita consumption. It is not the purpose of either this book or of this chapter to ontline the general method of trade development which will increase per capita consumpton; it is simply the purpose to point out that there is no more accurate barometer or measuring instrument for trade development than the per capita measure.

48. Securing data for estimation of per capita.-The calculation of per capita consumption is, of course, play 
compared with the labor of securiug the data from which to figure it. For many articles which are entirely importer, per capita statistics are ry casy to figure, as an accurate recold of total imports is always available from the Bureau of Foreign Commerce. The per capita comsumption of tea and coffee are thus the work of a few moments of calculation. However, information of per capita consumption in many other lines is enormously difficult, because not even the census has any total figure available of annual production, to say nothing of consumption by states or localities. In fact there are no definite consumption figures by localities for any industry generally available, and a number of calculations must be entered into to establish the consumption of almost any item of merchandise. For nearly all commodities, however, it is possible after employing competent research service and counsel to establish a $95 \%$ or even $100 \%$ accuracy in total production for that line of goods. Such data in $75 \%$ of cases, may cost anywhere from $\$ 35$ to $\$ 500$ to compile; and for the remaining difficult cases considerable larger expenditure may be necessary to arrive at even $95 \%$ accuracy. This is due to the complication of manufacture and classification such as in the paint business. Furthermore, it ofttimes is imporant for business purposes to segregate consumption into specific subdivisions for special types of goods, such as liquid, paste and powder in considering dentrifices. This requires patient unraveling of what seem like hopelessly merged figures and diffic-rlties of many kinds. But it is modern business principle not to be daunted by dificulties or apparent failure, and business research must be operated on the same principle or fail of a vital place in business. ${ }^{3}$

\footnotetext{
"The author has very fully covered this subject in his book on "Modern Salesmanagement;" D. Appleton \& Co. 1919.
} 
Even though the cost may be high, the value of such data is so undisputed that it should be undertaken. If the results approach somewhere within practical working distance of $100 \%$ accuracy the purpose is well served. It may be necessary to make actual field canvasses among a considerable number of dealers or consumers throughout the country; it may be necessary to send investigators into every county in the country, and to spend even hundreds of thousands of dollars upon it-nevertheless the profit possibilities are commensurate. It may be that analogous statistics from other sources and other fields may give clues and data which by careful comparison and computation may be valuable in filling in the gaps of unknown data. It may be tha' oöperative efiort by an allied group of manufacturers is the most economical. Business men of shrewdness and capacity rarely nowadays omit careful consideration of the per capita figures pertaining to their line of trade, and even to their own volume of consumpton. 


\section{CHAPTER VII}

POSSIBLE MARKET ANALYSIS AND SATURATION POINT

49. Vital nature of future sales analysis in buisiness.All business is operated upon expectation from the future, and all business plans are based upon trading possibilities that are known or believed to exist. The enormously high mortality in business has chiefly been due to overconfident optimism and lack of facts and of the habit of analysis. Trade possibiities that were believed to exist, but actually did not exist; the existence of facts unsuspected and unknown-these have been the grave diggers for a great majority of business ventures.

Nowadays careful business men do not undertake business ventures without researches and facts from which to assure themselves with all the accuracy that modern business practice makes possible as to the expectation in sales which must be faced. The enthusiasm of an inventor over his contrivance, the optimism of an egotist whose thought is mainly of his own invincibility, the pure ignorance of the tyro in business who has no conception of the complications or conditions he will have to meet, are business wasters and positively spell failure. The foundation platform on which to build any basis is sound possibility of future sales. The business has no excuse for existence otherwise. Therefore to build a business structure without delving deep into the ground to secure a permanent hold upon rock bottom facts is so vital as to 
make it absurd to emphasize. Nevertheless, thousands of quite capable business men are constantly making serious mistakes along these lines, simply for the reason that they trust to their own experience, gambling instinct, and general judgment in order to make the basis for future sales possibilities. They use the intuitive method, instead of the laboratory method of analysis, and while it is quite true that men of exceptionally astute ability can sense the failure or success of a business, the facts are that business conditions of to-day are so ex. tremely varied, wide-flung, and full of complexites that nothing short of actual specific investigation and research will give a high degree of probability of accuracy. To use judgment alone is a dangerous sign of incompetence. Even at best, with all possible research, there is consider. able possibility of error, for infallibility is a thing which should not be claimed by any research worker, since it cannot possibly exist.

Bankers and investors who are asked to under-write industrial securities have for many years been in the habit of making engineering investigations into the various propositions placed before them, and they are only now beginning to realize that facts as to the extent of the machinery owned, the factory, the raw materials and other physical factors regarding a concern can tell nothing about the future profit possibilities of a business. The present and the past are importai to examine, but the future alone can make future profits. Commercial researches into the possible market, competition, consumption and distribution factors involved in the merchandising of a concern's goods; the outlook, the trade and consumer trend, are necessary. The profit possibilities depend wholly upon these future sales possibilities, and can 
be analyzed with the same engineering principles and accuracy that prevails in engineering investigations and reports as to projects is yet only on paper.

Such researches into future sales possibilities are not only of value to investor's and high executives, but they are intensely valuable in the actual executive planning of the business. Upon the sales possibilities in detail rest many important executive policies-speed of growth, sales development, plans, advertising, factory and raw material plans, and finances. It is the first business of the commercial firm to have highly concrete facts, at no matter. what expense, as to his real possible market.

50. Surveys of basic consumption conditions.-Always at the base of trade development possibilities of a business, lie the individual conditions surrounding the typical or average consumer. Therefore, the first step in any analysis of sales possibilities, must be as close as possible and as thorough as possible an analysis of the typical consumer and the factors which make for sales resistance, and the factors which might develop greater consumption. Surveys of basic consumption conditions can of course be made in any degree of exhaustiveness from a brief study of a hundred or two of individual consumers, all the way up to detailed consumption studies, analyzing the exact possibilities of each unit or territory, and each type and class of consumer, and even in limited lines of business, an actual investigation of every single purchaser personally.

Just what type of survey to make for any individual concern is a matter which first depends upon the relative degree of importance of information to the development of a company, and its ratio to the amount of money avail. able for research expenditure. A certain large concern 
which has had practically no need to search far for orders since it began business sees now approaching five or six years hence, a period of severe competition and the peak load of its career. It is now ready to spend every dollar necessary to secure in such a consumption survey a greater amount of information than any competitor can secure. It is at present making a survey, county by county, throughout the entire United States of the exact number, character and location, and type, and even the name of the possible consumers, and is sparing no effort to get every fact which even in an indirect manner may give light on its possible market, both quantitatively and qualitatively. It appreciates that soon the market will change from a seller's market to a buyer's market, a condition calling for great preparation in advance if its enviable position is to be beld.

There are unknown factors in the possible market of almost any product, and it is thoroughly profitable to analyze them before they crop up and demand to be analyzed. In other words, it is far preferable to determine the location of rocks in steering one's course, than to wait to bump upon them.

Even when a general investigation of basic consumption is not possible at the time, specific inquiries into phases of consumption statistics are always important and never out of place or order. Consumption conditions are constantly changing, and a research department in any business can profitably keep itself occupied simply in developing new angles in the consumption situation, and also in the distribution situation, by working out in the field among consumers and distributors constantiy.

Such consumption investigations among other things, can inquire into: 


\section{BUSINESS RESEARCH AND STATISTICS}

1. What kind and types of people purchase goods?

2. What individual influences them or has joint au. thority or activity in making the purchase?

3. What are the habits of mind and general conditions surrounding the purchaser?

4. What is the exact need which the consumer feels, how does it arise, and what instinct, needs, desires and feelings does the article satisfy?

5. What preconceived ideas, prejudices and notions does the consumer bring to the purchase of the articles?

6. What are typical past experiences of consumers in the purchase of such articles?

7. What are the shopping or purchasing habits or inodes of procedure of the average consumer?

8. What impression, reputation and general standing of brands prevail in the buyer's mind?

9. What standards in the matter of price and quality and service prevail in the mind of the consumer?

10. Analysis of consumer preferences for sizes, marking, types and models, etc.

11. Statistical study of consumer, from a quantitative basis, giving facts as to number, distribution, 10cation and concentration of consumers.

12. Inquiry into possible manner and means of developing application of article.

51. Sales possibilities by territorial units.-There is the utmost practical need for data and statistics on this subject, since the performances of salesmen, branch agents, jobbers, etc., cannot be justly judged unless such means are available. Nor can it be operated justly and accurately without an unbiased technical survey into the sales possibilities of definite territory units, in cities, counties, 
sales districts, states or by general geographical sectors. Sales resistance is different in different territories. The consumers in one territory may be fairly well educated to the general uses of the products, whereas in other territories they may be not only indifferent, but sometimes antagonistic to it; or local conditions may be such as to raise strong general resistance. Unless such individual territorial factors of difference in sales possibilities are understood and tabulated, grave injustices and harm may be done in big sales organizations. It is a common phe. nomena that a salesman or branch manager taken from one territory and placed in another may fail, in spite of bis excellent record in other territory. This may often be wrongly attributed to the man, whereas the differences in the territory in contrast to the territory from which he came are such that a man's special ability is unable to overcome them. His type of ability may show best results in a well developed or semi-developed territory, while another man may develop best in a pioneering territory, and go to seed in a well developed territory. Full knowledge concerning the conditions in each territorial unit, a knowledge not merely made up of intuitive ideas or general judgment, but of facts which can be put down on paper in definite manner, so that when the salesmanager dies or leaves it may become of great value to the succeeding executives-makes for far more efficient and economical management of a sales force than is possible within it. It is due to every salesman that the conditions of his territory be thoroughly understood in relation to his results, and there is no more powerful developer of esprit de corps among salesmen than the knowledge that a just and accurate investigation of such facts has been made and that a crmparison of his efforts and those of 


\section{BUSINESS RESEARCH AND STATISTICS}

other salesmen has the basis of mathematical adjustment so that he will neither be favored nor handicapped.

The technique of the derelopment of data regarding territorial units is naturally difficult and of ten fairly ex. pensive. The most exhaustive method is to make investigative calls upon each dealer, jobber or consumer and ascertain definitely the volume of consumption of that line of goods, including the ratio of preference or volume of leading brands. The next best thing, if this is impossible in any given state, is to investigate a certain num. ber (as large as can be afforded) in each territorial unit, so that a statistical basis of estimate may be established and the full sales possibilities worked out from the present consumption, the competing situation, and the basic merchandising conditions which affect sales. Experienced research service can accomplish this even from a minimum number of 100 units from which to figure in each territor. ial unit. It is even possible, if absolutely necessary, to get information, without investigation, which will approach to 6.5 or $70 r_{0}$ of accuracy, in some cases even higher, by means of an examination of central sources of statistics and data about local units which will provide a sound basis for estimation by experienced analysts and business statisticians.

In other words, the situation is that no concern, how. ever limited its financial resources, need be without statistical research or territorial sales possibilities. There are methods economical enough for any business. A business may thus increase the accuracy of its knowledge and judgment, and stimulate its sales force by a greater and more intimate knowledge of its territory.

52. Setting of quotas upon a point basis.-In order to secure a high degree of statistical accuracy and managerial 
judgment in developing facts about the local sales unit, the point system has been devised and used with great success in many lines of business. The point system is simply the reluction of a number of factors into a single "index figure," "weighting" it in the well known statistical method, with the varying factors in the territory which require consideration. The final result is a single figure representing the possibilities of sales quotas of a unit of territory in an accurate proportional relation to the figure for other territorial units.

53. The point system for adjusting differences in territorial sales possibilities.-The point system has many forms and uses from a simple arbitrary one based on sales alone (calculating each unit of sale or dollar as so many points) up to an elaborate calculation in which a dozen or more factors of statistics and research are included.

These point systems are used mainly in sales contests, but are also used for general sales quotas and for general sales study and comparison.

Some of the factors which upset calculation (before the Point System was developed) were:

1. The differences in merchandise and the profit considerations concerning them. Nearly all firms which make more than one article find that for one reason or another, or at one season above another, the relative desirability of sales is different. In other words, the National Lead Company, for instance, does not desire to induce its salesmen to spend a great deal of time selling lead to tinsmiths when that time can be more profitably employed in pushing a line which is not as staple as learl, but which is a specialty which the market is not edu. cated to buy automatically. It desires to bave 


\section{BUSINESS RESEARCH AND STATISTICS}

salesmen sell its specialties before all other things.

2. The differences in territories are so great that few firms are in a position to pit any one territory against any other except on the accurate basis afforded by a Point System. Some territories are in a raw state of undevelopment; while others are in a high state of development.

The amount and character of salesmanship required to secure a thousand dollars' worth of business in undeveloped territory is greater than in a developed territory. Other factors which make territories differ are the density of population, the accessiability, etc. (Full list described further.)

3 . The amount of the order is also a factor which in lighly developed Point System is considered important.

A salesman who sells to concerns which buy in large orders, takes a greater volume of business with less effort than the salesman who sells a smaller type of concern which takes smaller average orders. 4. The feeling often justified on the part of salesmen that the quotas were inexact, the comparisons un. fair and the calculations haphazard.

The Point System does for a sales organization what the decimal system does to arithmetic-it makes elaborate reckonings simple. It applies mathematical exactness to matters which would otherwise be arbitrarily and crudely handled.

The Point System is by no means only for large com. plicated businesses. It is usable in very simple formsmerely to represent a unit of sales (as National Cash Register plan described above) or for a group of special bonus offers for various tasks and goals, each with a vary. 
ing importance and point-value. The smallest business as well as the largest may use it with equal economy and facility, because it is a principle of efficiency of reckouing, and not a mere device.

54. Data required for more elaborate "point" calculations. -A careful research or survey should be made and the results merged with all data on the elements which affect the local situation. Among the factors which will likely be useful in establishing a ratio figure for territorial differences, are the following:

1. Volume of goods sold by all manufacturers in the line;

2. Density of population;

3. Density of dealers (per square mile and per 1,000 ) of population);

4. Railroad mileage, population per mile of railway, miles of railway and trolley per square mile;

5. Inaccessible population;

6. Volume of prior sales;

7. Character of population;

8. Distribution of per capita valuation of realty, bank deposits, business offices, etc.;

9. Distribution of building activity or other vital factors affecting the business;

10. Special considerations.

It is no simple task to coördinate all these factors, but the variety of factors used shonld make the final resuiting quota nearly free from arbitrary elements. The aim is to secure something like a rcasonable comparative figure, by means of composite figure rating all the individual factors used, for each unit of territory.

55. Merchandise factors measurable by point system.There are any number of considerations which may affect 
the relative desirability of the sales of various products. They should be rated according to relative desirability of sales at a very careful conference of all of the heads of the business, including the directors, in order that the wisest strategy of the business may determine this important thing. Among the considerations which are valuable in this connection, are:

1. A new product which is going exceptionally well because of its novelty should not be ranked first, even though it is very profitable. Experience shows that salesmen give such preference anyhow.

2. Articles which are staple and routine must not always be placed at the lowest ratio because they are naturally given a lesser amount of attention, and careful policy may develop reasons why they should be pushed.

3. Trade conditions must also, as well as strategy enter into consideration, since there is ofttimes extra resistance on some products on the part of distribution.

4. It is desirable to establish groups of products so that some weaker ones of the group may secure attention because of such grouping.

56. Point calculated from sales performance.-A specific stimulant to the liveliest development of all around sales possibilities, the point system plan provides for special rewards for particular work done. This plan makes pos. sible the direct application of selling energy to certain sales objectives which investigation and study show to be of importance in the sales plan.

The following are some of the factors for which points may be given:

1. Largest number of orders; 
2. Largest per cent of increase over estimate;

3. Largest increase in dollars and cents;

4. Largest number of towns visited;

5. Lowest per cent of expense to sales;

6. Ratio of town reports to number of workable towns in territory;

7. Highest percentage ratio between gross and net sales;

S. Highest percentage of estimate new agents or dealers stocked;

9. Lowest number of past due accounts in territory (based on quarterly showing after deducting suspense accounts collected);

10. Largest number of orders taken;

11. Highest percentage of gain over previous year in Group I;

12. Largest number of individual prospects (or towns) visited; also lowest number of towns or prospects visited.

57. The meaning and significance of "the saturation point." -What is a market "good for"? What volume can it absorb? At what point will a line of goods begin to be "a drug" upon the market? These are questions of very definite importance in any sales research.

It is a peculiar fact that many industries after a period of difficulty develop a demand for their article, and then, this demand becoming visible to others, new concerns flock blindly into the field, expecting also to enjoy a big market. But, unfortunately, this demand may have very definite limitations which competent statistical investigation might have uncovered. There may be no sufficient market left for the new companies, and the usual order of failure or absorption occurs. 


\section{BUSINESS RESEARCH AND STATISTICS}

Then, too, a firm which is not aware that its article is rapidly approaching a saturation point, may suddenly be caught in a serious situation of lack of preparation; whereas statistical research might have demonstrated the fact in plenty of time to lay lines of new development, either for manufacture of new or related lines, or for expanding the uses, scope and application of the product, and thus put of the coming of the saturation point. This saturation point has been skillfully avoided in the automobile field by the reduction of average price of automobiles; each new decline of $\$ 50$, opening up new hundreds of thousands of prospects. Price is the most frequent arbiter of the saturation point on articles of high cost; but in others it depends largely upon the number of people who can logically use the article to good advantage.

Most figures on markets are too optimistic (remember Col. Starbottle's eye wash!) and there is too naive and inexperienced use of statistics by the rosy-eyed inventors or promoters. The possible market is never easy to determine, and sometimes it can be demonstrated that a proposed industry could manufacture enough of the article in 3 montlis in a sizable plant to supply the demand for 10 or more years to come. It is of importance to plan for a term of years ahead, and not on a basis which will ignore the possible early exhaustion of the business by saturation. The country's population is not growing so rapidly as before and markets are not so "bottomless" as once they were.

Shrewd bankers, investors and other's study industries not by what has been done, but by what is possible to do in the future, realizing that it is an old and favorite argument of promoters to "lamb" investors that the Jones 
Co. has made millions in the past ten years, therefore the new company can do likewise! The parallel in such cases is truly deadly, because usually statistically unsound. What a company has done in the past camnot, so far as sales are concerned, be even a moderately sure prediction of the future. There are companies which the writer knows paying now and for a long time past a great deal of money in dividends, but which "insiders" on matters of sales development know are doomed to bankruptcy or complete reorganization within a couple of years-because of market changes and selling factors.

The "saturation point," it is quite true, has not in America up to this time cut much of a figure in calculations, because most markets for good articles have grown almost automatically to the extent of at least $10 \%$ per year. Creative salesmanagement cannot logically take credit, in many industries, for growth up to $10 \%$. The saturation point has on this account been sneered at as a "bogey" but from now on it will increase as a factor of consequence. It is already a very definite factor in foreign countries, and the huge enlargements of factories for war production have brought many firms in the United States to the realization that the ordinary market will not be big enough to take care of new capacity for consumption. The saturation point is too near; new plans must be made.

Saturation point statistics are constantly in need of revision. Conditions, wealth, population, and other factors change the situation at least yearly, and figures should be revised at least that often.

Also, it is possible to postpone the saturation point by widening the usefulness and appeal of an article. It is 


\section{BUSINESS RESEARCH AND STATISTICS}

this factor (as well as price) which belped save the automobile from reaching the saturation point years ago. The economic usefulness of the automobile was developed, thus taking it out of the purely "pleasure" class of commodities. 


\section{CHAPTER VIII}

\section{INVESTIGATIONS OF DISTRIBUTION PROBLEMS}

58. Great fundamental economic problems involved in distribution.-To avoid confusion in the consideration of this wide-ranging problem it is important to separate it into elements, as it is unquestionably the most vital problem in business to-day, and will remain so for years to come. President Wilson made the solemn announcement in August, 1919, that nothing else would s":fice but the tak. ing over of the means of distribution. Other serious public utterances have been made on the subject. Much research has already been focused upon this problem, and already many investigations and surveys have been made by legislative communities, city, state and national, as well as other researches by private and quasi-public agencies. The after-war pressure of high prices upon wages and standards of living, and the resultant outcry of laboring and middle classes at their plight, quickly resulted in focusing the undivided attention of the President and Congress on the problems involved, which are always principally problems of distribution. The world over similar conditions have prevailed.

Examined basically for a brief review of the situation from the business research angle, the present situation is a logical result of the concentration of American genius for many years past upon production and consumption, with but negligent regard for improvement in the equally 


\section{BUSINESS RESEARCH AND STATISTICS}

vital factor of distribution. The great inventive era made quantity production possible in staples, and also placed upon the market an unbelievable variety of new and in. teresting specialty merchandise. To find a market for this Pandora's box of riches, advertising was employed with its lightning swiftness and power of word and picture to portray, simultaneously in every city and village, the wonders and desirabilities of this new merchandise and new standards. In comparatively few years, by the use of the high degree of literacy prevailing through free edu. cation in the U. S., the advertising profession metropolitanized the country from Atlantic to Pacific, in city, town and country; the rural free delivery connecting every home, however far from a post office, with the newest facts of the grea, national bazaar of merchandise catering to every human instinct and necessity. The habit of reading either newspaper or magazine is enormously developed, there being about $12,000,000$ readers of magazines alone, while newspapers are quite universally read. More advertising created better periodicals and better periodicals created more advertising, in ever mounting circles.

From a distribution standpoint this situation could not but result in a certain degree of chaos, confusion and consequent abnormality of cost, for an unbearable load was placed upon the distribution machinery, which was not only archaic but actually at war with itself internally. Those who operated the distributive machinery of the country lagged far behind the brilliant inventors and producers of merchandise in their ability, vision and resourcefulness to meet the kaleidoscopic changes and growth in American business. The inventors and producers and advertisers of an endless variety of merchandise (most of it 
adding spiendidly to the advancement of health, sanitation, nutrition and happiness of the world) found ready and instant response from the consumers appealed tobut the effecting of the distributing bridge from producers to consumers was and is the weak and defective link in the entire business scheme of things. Its persistent and baffling problems would long ago have been solved were they problems of the same concentrated simplicity as inventing, producing or advertising. The difficulties of the di iribution problems arise chiefly out of the fact that they embrace so many independent units and require such nice coördination of so many varied individual factors, many in dire conflict with each other.

59. Phases of the distribution problems.-The "distribution problem," so called, then, has numerous research phases, each one of which is full of subsidiary angles. These phases may broadly be classified as follows:

1. The public policy phase-a consideration of the subject from the point of view of law, regulation and consumer benefits. Congress, the Federal Trade Commission and other bodies have already inter. ested themselves deeply in the subject.

2. The transportation phase-a consideration of the relation of public carriers to distribution, costs and facilities; questions of terminal facilities, congestion, car shortage and rates.

3. The farm producer phase-a consideration of the problem from only the point of view of those basic staples which originate on the farm, and which have their own typical distribution machinery and problems. This includes the study of public markets, parcels post, distribution, speculation, storage, destruction of goods to prevent glut, etc. 


\section{BUSINESS RESEARCH AND STATISTICS}

4. The economic theory phase-a consideration of the fundamental matter of the operation of the law of supply and demand, price control, price maintenance, speculation, public ownership, coöperative effort, price agreement, etc.

5. The retail distributive phase-having to do with costs of doing business, margins of profit, turnover, neighborhood versus centralized buying, chain stores, maii order competition, cut prices, bargains, price maintenance, cash and credit basis, delivery costs, self-service, coöperative buying, rental values, salesmanship and service.

6. The wholesaling and jobbing phase-relating to the question of utilizing jobbers or "selling direct," size of jobbers' "spread," jobbers' private brands and retailing, resulting in mixing and perversion of jobbing function; national and local jobbing; jobbing centers and zones, jobbing credits, etc.

7. The national seller's phase-the position and problems of the maker of merchandise, questions of his control over his merchandise after leaving his hands; of establishment of branch warehouses, of selling direct, of establishing his own retail outlets, of price maintenance, of selling territorially or nationally, of quality discounts, of stimulation and education of distribution units, of substitution, private brands, margins of profit, exclusive agency, broadcast selling, service to consumer, etc.

8. The consumer phase-a consideration of the typical defects of distribution from average purchaser's viewpoint; failure to secure articles desired; neighborhood and centralized buying, shopping habit, cut prices, service, bulk and packaged merchandise, 
coöperative buying, public markets, standards of living, package labeling, pure food standards, one price system, deliveries, bargains, comparative prices, legislation, family budgets, etc.

9. The cost and statistical phase- the relative cost of distribution; investigation of elements of distribut. ing cost; margins to maker, jobber, railway dealer, etc., detailed comparison of items of cost. Graphic representations of statistics of distribution.

All of these phases will be searched in fine detail in the years just ahead and the brains of the country will undoubtedly be focused upon them as never before. They call loudly for solution, and business research will naturally bear the brunt of the responsibility for increasing distribution efficiency. An almost grotesque ineffectuality is now apparent in grappling with the problem.

60. The number of distributors contrasted with producers and population.-The startling and immediate nature of the distribution problem is best illustrated in an examination of the total number of all distributors and their increase since 1850 . In that year $2 \%$ of the population was engaged in distribution. This percentage has steadily grown, until it was in 1918 approximately 7\%. The number of producers, on the other hand has decreased. The number of producers to each distributor in 1870 was 7 ; it has steadily declined until to-day there are only approximately 3 producers to each distributor. On this basis, maintaining the same tendencies, there will be in 1990 an equal number of producers and distributors, or one non-productive distributor to every producer! The ghost of the old Malthusian theory that population always tends to outrace the food supply thus appears again!

Obviously the changes in character of population are 


\section{BUSINESE RESEARCH AND STATISTICS}

important factors. Urban population (towns over 2,500) is growing at the rate of $34.9 \%$ annually, while rural population is growing at a rate of only $11.1 \%$. The population per square mile was but 6.41 in 1880 ; in 1910 it was 30.99 . On this basis it may be 60.0 by 1950 . New York City is growing twice as fast as the rest of the country, and there is every likelihood, if tendencies do not change, that by 1950 two-thirds of the country's population will be in cities and towns, and thus add certainty to the tendency to increase the ratio of distributors to producers. The total number of all engaged directly or sadirectly in distribution is to-day approximately 7,420 ,000 . To distribute $\$ 1,000$ worth of goods the number of people required has increased over $50 \%$ in the past 20 years; whereas to produce $\$ 1,000$ worth of goods the number of people required has decreased.

From these facts may be gleaned the outline of many suggestions for researches on the general phase of the distribution problem. The more practical and immediate phases must now be considered.

61. The practical goal of greater distribution efficiency.In all likelihood business men themselves will ultimately solve the distribution problems, if they will more generally make use of the research tools which alone can equip them with the facts anent the puzzling situation. Already the principle upon which the solution will likely hinge is emerging.

Automatic selling is the keynote of distributive effeiency, and will work wonders when the way is cleared so that it has an opportunity to function. Automatic selling is an arbitrary term representing the ideal of all salesmanagement, whether for a staple or a specialty, and it is the goal to strive for in building and distributive 
organization. By "Automatic Selling" is meant continuous repeat orders coming on because of ideas of quality or service engendered in consumers and aggressive selling help from retailers and jobbers. There are hundreds of firms making good articles which could be sold in large quantities at a fair profit if their executives had ability to build a larger distributing organizaton and knew how to keep up an even sales development which brought a steady stream of repeat orders.

Quantity selling is the greatest modern profit policyand quantity selling is only possible when backed by a system, a machine, an organization of distribution. One box of cartridges sold each week in one store seems an infinitesimal amount of business, but when there are 80,000 stores each selling for you at least that amount each, as have several of the large ammunition manufacturers, large aggregate sares become possible. The same is true of Ingersoll watches. The little profit on a dollar watch is not much; but multiplied by the 70,000 or more stores that are selling, the profit on the volume of business is large.

As a matter of fact the "key log in the jam" of most manufacturing concerns' failure to reach greater size is the inability to get beyond a certain localized or limited distribution. All other problems may be well solved by such concerns but in the development and maintenance of a broad net of distributors pushing their goods they frankly confess a large or small measure of defeat. They admit the problem is to some extent beyond their powers. Their distribution organization is exasperatingly spotty - sales are good in one territory this year and poor the next; at no one time is their anything like a uniform or even flow of orders. The distribution machine creaks and 
spurts spasmodically. It needs the attention of expert counsel and research on distribution. There is no reason why any good article should not approach the ideal of an automatic demand-not of course as automatic as a staple product, if it is a specialty, but still a really automatic demand which has something like an eveu flow because it is stimulated wisely and correctly.

62. The seven elements of successful distribution.-The specific factors in successful distribution may be said to be about as follows:

1. A maximum number of live seling units (retailers or canvassers).

2. A rigidly uniform and fair method of dealing.

3. A smooth-running channel of midulemen, if necessary (jobbers, selling agents, commission houses or local branches).

4. A steady "pull" or "demand" from the consumer, arising from advertising direct to consumers.

5. A steady "push" toward the live selling units-to keep them supplied with enthusiasm, new ideas, assistance and conviction, accomplished througl salesmen, trade paper advertising, house organs, letters, etc.

6. A system or campaign plan to extend the reach of the distributive organization, in the shape of specially designed advertising, special crews, "missionary salesmen," etc.

7. An efficient routine organization to handle all matter's without friction or complaint or loss.

The nature of these elements readily explain why there is so frequent failure to attain them. They are very complicated and very difficult factors to master, each and every one of them. It is foolhardy for any but a mind trained to handle such factors to expect success. They 
show on their face the degree of generalship and organizing ability required, to say nothing of the men, money and careful examination of facts necessary to success.

63. Building a distribution machine to order.-A distributive organization has many of the same peculiarities as a machine. It needs much oil and a good deal of expert attention, and it is composed of a great many parts, all of which must be perfectly meshed into each other without friction.

Now, a machine of such proportions as will sell an article in an adequate manner, is necessarily a delicate poised and individually adapted machine. It must be practically built to order.

The distribution machine which is most perfect, most profitable and smoothest running, is naturally the machine that sells your goods most automatically (with the least cost, time, effort or parley). An ideal distribution machine is composed of many selling units. In the case of Ivory Soap about 250,000 or 300,000 stores sell the goods. That is a very huge machine, but essentially simple. It puts 300,000 people to work, and if each one works only the tiniest bit, it rolls up a big volume of sales automatically. The law of averages is the speedometer to such a machine.

The reason for a distribution machine is to have goods ready for the consumer in his own locality, to render local service, to display goods in the recognized centers of buy. ing, to unload small credit risk, to save time and cost, and to more thoroughly canvass local possibilities. Whether selling belting or machine tools or breakfast food, the aim is a machine which will represent the firm to prospects with the same degree of aggressiveness and skill as the firm would display if it were operating that 
store or agency itself. That ideal of a distribution machine is very rarely achieved, but is the goal to aim for and a goal to attainment of which is twice as certain with the aid of analytical research as without it.

64. Minute analysis of local distributive units.-Since there is no way for one investigator or analyst to call personally upon each distributive unit and thus secure at first hand the facts which throw light on the distribution situation it is important to get full and adequate information about the distributor and make up a composite or detailed picture of the situation from the data obtained.

The information required may or may not be as ex. haustive as the data here outlined, but the questions will serve to suggest those pertinent to any individual case.

65. The changing character of distributive outlets.-There was once a set or fixed notions as to distributive outlets. Hardware stores sold hardware only; drug stores compounded prescriptions and sold patent medicines mainly. We are now in the midst of many very extensive changes of distributive outlet. Both dealers and manufacturers are breaking precedents with great rapidity. Drug stores have become veritable department stores for innumerable types of merchandise from safety razors to cigars and even eggs. There is apparently no principle at work except that of public convenience and shrewd suatching of profitable specialty lines from the hands of inalert lines of trade. The hardware stores have added other lineshousehold goods, silverware, electrical goods, and now they are in the act of becoming important distributing outlets for automobile accessories.

Manufacturers who are seeking increased volume and more alert retail coöperation naturally study these tendencies, and much success has been accomplished by re- 
searches followed by action along this line. A notable instance is that of Ingersoll Watches, now sold in many lines of stores-sporting goods, haberdasheries, news stands, cigar stores, etc., whereas once all watches were rigidly confined to jewelry stores.

The Winchester Arms Company is a notable example of the application of research to a distribution problem. With the beginning of 1920 it announced that as result of careful research it planned to distribute si me new products through its own wholesaling and even retail outlets. This was a radical break of tradition, and a well known research man was engaged upon the task for a considerable period.

Every day other firms are announcing new or changed distribution policies, which indicate how vital are in. vestigations into this situation from the standpoint of trade may severely limit the possibilities of sales often mainly by reason of the special private deals known to be in existence, shutting out a fair opportunity to develop. Distribution inquiries would usually cover something like this ground:

1. Statistical tabulation of present outlets by types, location, size, etc.

2. Analysis of their estimated total and average sales, by classes and territories and present limitations. 3. Statistical study of other possible outlets, baser upon free investigation of fitness, receptivity and chance of success of widening of outlets into new fields.

The difficulties of such widening processes are many, arising mainly from friction in the trade as a result of widening out, and laggard interest in the new line by newly developed distributors. In the hardware trade 


\section{BUSINESS RESEARCH AND STATISTICS}

there was a strong tendency to sell electrical supplies-a tendency fought very definitely on policy by some makers of electrical goods. Competent research will develop the facts and probabilities of degree of seriousness of incipient changes-or advise as to the starting of new logical tendencies.

In Chicago another distribution experiment is being tried. The large building formerly occupied by the Siegel Cooper department store is to contain a number of independent retail businesses. The management of the building will provide for each merchant much of the "overhead" service such as advertising and delivery and will charge each retailer according to his use of the general service. The object is to combine the advantages of both the large store and the small store.

During the "after war strike season" there was talk in the labor union of their "own stores" and their "own factories." However impractical those ideas may be it is important to inquire if they point toward a ripening of American conditions for the introduction of the coopperative merchandising and production plans that have succeeded in Britain.

66. Perverted and mixed distributive functions.-This factor is the cancer spot in the distributive situation today. Instead of making their own strictly distributive functions more efficient and profitable, distributors have been lured by the desire for greater expansion into undertaking simultaneously other functions than distribution. Large dealers have become wholesalers, then manufactur. ers also. Large jobbers have become retailers, then also manufacturers. In such capacities they antagonized their own logical customers by entering into competition with them. In addition to selling Jones saws, hardware job- 
bers offer their own brand of saws (and give them distinct advantages in presentation). This leaves manufacturers whu distribute only througli jobbers in a highly anomalous situation. Cases are known where manufacturers made up goods for jobber"s market witin jobber"s name, which would compete with their own goods from the same factory. Even dealers began to acquire the "private brand" notion, to the utter and wasteful contusion of all concerned. The range and ramifications of the distributive snarl as it exists to-day is wortly of a book all to itself. Suffice here to indicate the principal facts concerning the situation-that jobing or retailing pure and simple is in a muddled state, with both functions perverted widely by units large enough to make the chaos stultifying and widespread.

Into such a situation a manufacturer of ten comes like a lamb into a wolf pen, and has almost no chance from the start, except at uneconomic, ruinous terms. There is the utmost need for examining the strategic situation and possibilities for each individual case and thus securing material for sound jurgment and economical policy. His policy of distribution largely depends upon this analysis, and how important such a matter is may be judged by the following radically different choices of distributive method:

1. Contract selling, or selling to a small group of large consumers.

2. Selling direct to a comparatively large number of consumers.

3. Selling direct, through branch offices, to a large number of consumers.

4. Selling in two or three or more ways simultaneously.

5. Selling to jobbers only. 


\section{BUSINESS RESEARCH AND STATISTICS}

6. Selling to jobbers mainly, but also direct to dealers.

7. Selling direct to retailers mainly, but also to some jobbers.

S. Selling direct to dealers only.

9. Selling by mail.

A manufacturer needs totally different brains and organization and possibly forms of merchandise if he sells in either one of these ways. It is no longer possible to look with suspicion as an unnecessary and unsound innovation, upon the proposal to change or shift the plan of distribution. Conditions are more radical and onerous than any policy that may be developed to meet these con. ditions.

The many syndicated selling movements such as the United Drug Company, or the chain store, or department store, or mail order outlets are forcing new policies and terms or challenging new methods in a manner to make important the utmost research to arrive at correct solutions.

67. Analyzing percentage of distribution.-The position of a national seller of merchandise upon the chess board of distribution is to a certain extent measured by his "percentage of distribution"-a term applied to the ratio of the number of stores selling his goods to the total possible number of stores who could or should sell his goods.

Crurle and costly mistakes have been made by immature merchandising counsellors who have initiated large na. tional adrertising efforts when the percentage of distribution was exceedingly low, with no sound plan behind the effort.

There are about three or four ways of distributive de. velopment, roughly classified as follows: 
1. Growth by definitely marked local territorial development one after another.

2. Growth by national "high spots"-usually the cities and the "cream" of the national market; adding the hinterland at leisure.

3. Growth by full and adequate national eliort.

4. Growth by attempted national effort, on a catch-ascatch-can policy based on developments and opportunities as they can be stimulated with the means at hand.

In any of the above modes of distributive procedure the percentage of distribution nevertheless remains a measurement factor of importance, as correctly gauging the current situation. Practically no concerns enjoy $100 \%$ distribution-that is, sell all possible dealers. The almost universally distributed articles enjoy often as high as 86 or $\$ S \%$ distribution, but rarely more. From this highest actual performance the percentage of distribution ranges downward to 5 or $10 \%$ and must be judged in accordance.

To correctly determine percentage of distribution, it is first important to correctly determine the number of possible distributors, and this is not an easy task. In the grocery field, for instance, there is no standard, certified count of grocery stores, since many are unrated and unclassified by anyone-"holes in the wall," in business slang. Yet they are exceedingly important. It may be necessary to make a very careful information canvass of distributors. This is merely by way of illustration of the problem before the statistician.

68. An international distribution expert's analysis.-Because it is suggestive of the problems which face business and the country, the author prints herewith the state- 
ments of Dr. Alonzo E. Taylor who was associated with Herbert Hoover in his world labors in distribution during the war.

After saying that the experience of every country at war has taught the necessity of a definite control upon distribution, he outlines the three phases of the subject:

"(a) The present current system of distribution of foodstuffs through the wholesale grocer, the jobber and the retailer is inefficient. There are entirely too many tradesmen, too much orerhead, too much waste, too mang bad debts, and the consumer pays the final bill. Bank. ruptcy in the distributive trades has for years been no. toriously existent. When one tours the Continent in an automobile the thing that impresses one in all the small towns is the excess of small shops and churches. The experience of the chain stores confirms the statement of inefficiency in the older system.

"(b) It is a rule that whenever any operation is ineffi. cient in normal times this inefficiency will be exaggerated in abnormal times, as in panic and war. The operations of the American grocery shop and the distribution of milk are pertinent illustrations.

"(c) The practice has become general to sell an article not on the basis of a fair profit over cost but on the basis of a probable or feared cost of replacement in accordance with a trend in the market. In other words, the distributors are playing safe with a double margin. The cost of transportation and distribution is above normal. The speculative element is in excess of the normal, and, of course, wage and the other fixed costs of operation are above normal.

"The sum total of these considerations leads to the conviction that the distributive trades are exacting a heavier 
toll from the customer than in the pre-war period. To what extent it is arbitrary and to be defined as 'profit. eering' is a subject of specific investigation in each commodity in each section. The experience in every European country since the armistice has been to the effect that the retailer has run wild. I ann not in a position to state whether the American retailer is trying to catch up with him or not.

69. "Is the standard of living too high?-This is a question of taste. Physiologically it is unnecessarily expensive. The words 'high' and 'low' mean 'expensive' or 'cheap', not 'good' or 'poor.' Our standard of diet is excessively expensive. It is luxurious. It contains a luxurious amount of high priced foods. It conld be materially cheapened without being in the least deteriorated. We have the lowest consumption of cereals and potatoes in the civilized world. The standard of living is to-day fully as high, if not higher, than before the war.

"While we complain of the cost of living, we do not wish to change the type of living. It is the old adage of the 'cost of living high.' We have what most Europeans regard as an absurd degree of luxury upon our tables. This is all well enough in times of prosperity, but it is directly opposed to that thrift in the period of reconstruction after a war tha' alone will bring us back in the direction of normal prices.

"In other words, we are living beyond our means in the matter of foodstufs. When the American public wants to reduce the food cost in the diet, it can do so by decreasing the consumption of meats, sugars, fruits and regetables."

Speaking upon the subject of American standards of living, before the American Bankers' Association, Senator Owen of Oklahoma said: 
"There should be a campaign in the United States, through moving pictures and on the forum, in the press and in the pulpit to teach men the dignity and need for homest labor and production, the shame of waste, the dishonor of willful extravagance and to discredit the vain ostentation of wealth.

"The enormous disproportion of wealth distribution in America has led to false standards of extravagance and ostentation, going far beyond the reasonable bounds of mere luxury."

The high cost of living "threatens the stability of Gov. ernment throughout the world.

"Increased production, better and more economical distribution and avoidance of waste are the chief remedies for the high cost of living," Senator Owen said, "and to accomplish this the banks of the United States should encourage production by extending credits preferentially for productive processes, for improved warehousing, lending against warehouse receipts and using their good offices and friendly counsel to stimulate production and improve distribution."

70. Analysis of dealer density.-There is a new way of approaching distribution conditions-to say nothing of the other suggestive uses of such data-in the analysis of the density of dealers in any given state or unit of territory. This is the same statistical operation as for the ascertainment of population density; the division of the number of dealers of any line of trade into the number of square miles of territory. The resulting figures when compared to the population per square mile, afford a most interesting general light upon the distribution situation.

In Massachusetts the population density is 450.6 people 
per square mile. The number of dealers per square mile in this state, in contrast, is as follows:

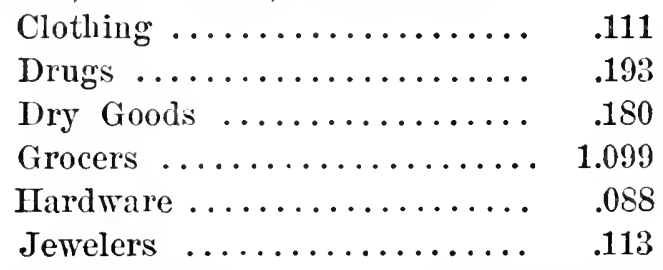

This, when examined in contrast with the figures for any individual state or for the United States at large affords specific comparison. The density of grocers for the entire United States, for instance, is .058, which in contrast with 1.099 for Massachusetts or with .001 for Wyoming, gives a most uniquely interesting sidelight.

Another way of calculating-the number of people to each grocer or other distributive unit-is also interesting, since it enables calculations, comparisons, and estimates to be made which greatly assist in arriving at sound basic conclusions.

The direct relationship of "dealer density" to the distribution problem is outlined succinctly by Emerson P. Harris, an economic student who has operated definite experiments with coöperative stores:

"The two outstanding facts are that competition brings about conditions which make food purveying wickedly wasteful by causing two stores to exist where one is needed, the expenses of the duplicate shops being charged to the consumer. The second fact is that competition utterly fails to protect the consumer's interests.

"The cure is to be found in the adoption of a policy which recognizes that needless duplicate plants cause an unmitigated burden to the consumer and should be for- 


\section{BUSINESS RESEARCI AND STATISTICS}

bidden for the same reason that duplicate gas, electric and water mains are not allowed in the same streets.

"Let the food purveying franchises be limited to the number needed and leased to bidders who will perform the service at the lowest gross average profit, cost to be figured on the basis of quotations at sources or primary markets. This kind of an arrangement under proper safeguards, would mean two things; distribution under such conditions and in such volume as to make the utmost economy possible, and second, real competition.

"It would also avoir the turning over of the highly technical business of food distribution to the inexperi. enced-a thing which is often proposed by theorists."

71. Factory location upon a scientific distributive basis.There is going on at present a widespread re-grouping of factory locations, in an attempt to remedy a situation begun in the earlier industrial history of the country when plants were located withont relation to distribution. Persistent disregard of this factor resulted, as in the shoe industry, in loss of trade by the older companies in New England to new and more scientifically located maunfactmrers in St. Louis.

Distribution cost in a great market like the United States to a firm selling nationally to large numbers of distributors (either jobbers or retailers) in the larger lines of trade, like drugs, hardware, groceries, dry goods, is a rery large item of cost, especially since freight cost is borme by manufacturers to an increasing degree.

Therefore, it is thoroughly well worth while to make a detailed research into the location situation, balancing raw material and labor conditions, and distribution costs to the jobbing centers, on a ratio of estimated quantities shipped annually to each center. 
It is not too much to say that for any industry there is a choice of four or five locations which are the ideal or scientifically accurate locations, all considerations weighed and balanced. It costs money, sometimes a great deal of money each day, not to be located in these logical centers. This cost may equal the company's net profit, or constitute the decisive factor between net profit and loss, or success in competition on price. Many firms are relocating themselves after making such researches. New concerns have little or no excuse not to make adequate researches, in any case where distribution cost is a factor. Where it is not a factor of importance, labor and raw material factors may be deciding considerations, also requiring analysis and scientific location.

Some profound changes in distribution costs have occurred through the opening of the Panama Canal, and the readjustments of freight rates on only a partially level basis. Thus it is now cheaper to transport Pacific coast lumber to a port like Baltimore, in the east, and then to points in the middle west, than to ship by rail overland eastward. In consequence the new fleets of ships carrying lumber, etc, eastward are looking for western cargo, and eastern ports have freight advan. tage even over Chicago to the Pacific coast, and points just eastward of it. This revolutionizes distribution to some degree and makes new economies of location possible. Much research work in this direction becomes necessary.

72. Distributive equality and quantity price.-These elements have been matters of contention in distributive relations for years, and are only now becoming understood in principle. The basic equity of providing an equal wholesale price to small or large retail buyers has 


\section{BUSINESS RESEARCH AND STATISTICS}

been debated in detail and conceded. The small neighborhood store cannot, in strict distributive justice, be placed at a purchasing disadvantage as compared with chain or department store by providing quantity prices to these larger units. Quantity "in principle" is not a fair basis for price reduction. Service in selling may be, but not quantity.

Therefore, the policy is now becoming more general of making no quantity discounts whatever; the price per case or unit being the same to jobbers irrespective of their quantity of purchase. The larger retailer must depend on multiplication of standard profit, and to turnover for his larger profits, and not upon a price bearing a weighted adrantage to the ratio of the quantity purchased. The small retailer is a business and economic necessity, with sufficient unfriendly pressure to veer him toward failure without a handicap being placed upon him because of his relative size.

'The well known tendency of the larger units to cut prices, because they can afford it through securing quan. tity prices (or "free deals," longer credits, larger cash discounts, etc., which amount to the same thing) is a highly unfair and uneconomic proceeding, demoralizing and discriminative. It "throws a monkey wrench" into the distributive machinery.

In any individual case, a careful research of trade practice and tradition sentiment and conditions is im. portant, in order that a wise policy may be determined. It is extremely difficult to introduce innovations without serious disturbance, and before making changes the exact situation needs to be understood. At the same time courage in taking a seemingly radical position is important, once sure of the facts. 


\section{The "Ryzon" plan of special discount for distributive} device.-A unique policy has been adopted by Ryzon Baking Powder in relation with chain and other large centralized retail buying units. Refusing any quantity discount it recognizes and pays $5 \%$ for distributive service. This is not the full wholesaler's discount of $10 \%$ and $2 \%$. Frederick W. Nash of that concern outlines this new policy in principle, as follows: "In outlining a distribution policy, right information is vital. The advantage which the large chain store, non-service grocery institutions are apparently enjoying in purchasing as wholesalers and selling as retailers, is the chief cause of their growth.

"To an American, it seems positively immoral, as well as poor business, for a manufacturer to discriminate unfairly as between his retail distributors by putting one class of retailers in a position, through buying arrangements, to undersell and discredit the services which the majority of the retailers handling his line provide in the marketing of his goods. At least this is the view which our Campany has taken in formulating the Ryzon Sales Policy, which contemplates a square deal to all concerned, and coöperation with the service and quality grocer to provide improved quality and greater service, as the principal basis of our competition for the public patronage. On this basis we are selecting our trade and confining our dealers to the character of grocers, both wholesale and retail, who recognize these principlss of fairness in business and the underlying economy of a coördinated organized service in the marketing and distribution of a food specialty.

"We are entirely satisfied to allow our competitors to enjoy all the benefits which may accrue from selling and 


\section{BUSINESS IESEARCH AND STATISTICS}

coöperating with any class of grocery trade that does not consider the rights of others. We are entirely willing to forego the distribution of our product in what. ever number of stores of this character there may be which will not recognize our inhereut and fundamental right to be ourselves the competitors for the public patronage for Ryzon, which we are offering to the consumer at a fair and standard price in free competition with all other Baking Powders. We neither do nor wish to dictate the policy or methods of any distributor, wholesale or retail, in his general business relations with his customers, but on the other hand we are not willing to surrender our right and principles."

74. Demand and jobbing margins.-The entire distributive organization has for some years been in a turmoil over "spreads" and margins. Wholesalers have bitterly complained against the standard margins, holding that their costs have increased and that the margin provided by manufacturers were too low. They used this as their reason for manufacturing private brands on which they could make wider margins. They have also bitterly opposed reduction of large margins by manuiacturers when their product was new and demand had to be created. The fact that demand was now made automatic by the manufacturer's advertising, and that only the standard jobbing margin was earned has been met with recriminations of desertion and moral disloyalty to a distributor who had built un his business.

It requires statistical representations and investigations to make a convincing showing in such cases; the development of facts as to exact state of demand, the experience and practice of other firms in other lines, the analysis of the jobber's own condition and economics in 
the matter, demonstrating that he has been paid currently for his services, in proportion to the character of service needed.

Jobber's are not sales agents, they are distributors pure and simple, and require demand before they can afford to handle goods on a regular jobbing basis. The status of demand is thus a most important factor in making representations to jobbers, and facts about such demand put up in the right manner, are important. The exact jobbing margin, above the minimum margin, to offer or accept is a matter calling for research. Jobbers ask for a maximum, whereas, their desires should be analyzed in the light of a number of factors, such as:

1. Status of demand.

2. Average practice with parallel articles.

3. General range of profit margin and price and cost limitations.

4. Strategic policy, speed of growth desired, character of sales organizations and plan operated.

75. Retail margins and turnover-One of the most highly controversial friction points in distribution is the size of the dealer's "spread" or margin of profit. Being somewhat incapable, as a class, of clear statistical vision, dealers confuse percentage of profit margin with turnover profit. In other words the majority of retailers seem slow of comprehension of the fact that even though the percentage of profit on an article be but $15 \%$, if it is earned often enough, in a jear the annual turnover on money, or rate of profit on investment may be many times 15\%. The fact that his cost of doing business, if $25 \%$ annually, camnot correctly be used to demand a $25 \%$ margin of profit on each item because it is the percentage of profit on one sale, not on a year's investment. The 


\section{BUSINESS RESEARCH AND STATISTICS}

vital point of comparison is how much profit can you make a dollar earn selling the article. An article like Uneeda Biscuit turns over as many as 52 times a year. A dollar invested in this goods may earn the percentage of margin 52 times. A dealer could get rich earning a $5 \%$ percentage of margin on an article if he sold it often enough times, and on the other hand bankrupt himself on an article offering $100 \%$ percentage of margin if he rarely made a sale.

Researches into turnover margins, true costs of doing business and general educational assistance and propaganda on these subjects are greatly needed, as the antagonism of many dealers to trademarked advertised goods, which have a more rapid turnover but lower percentage of margin, is still widespread and retards business.

76. The service feature in distribution cost and theory.Considerable agitation over the service element in rais. ing the cost of living has occurred. During the war de. liveries and service were reduced. How far service is a necessary economic factor is a subject calling for more research. It is often said in business that what is usually being sold is $60 \%$ merchandise and $40 \%$ servee. How far service policies in distribution should go or what their future is, constitute important business as well as social questions.

In the grocery trade considerable headway has been made by so-called "non-service" or self-help stores, the idea being to eliminate the cost of service and thus permit lower prices. Frederick W. Nash of Ryzon Baking Powder, has clearly defined the situation in this regard:

"No single feature of our established food distributing methorls has been the object of such unfair assaults and 
has had such little fair understanding on the part of the general public as the service organization of the wholesale and retail grocery trade. The housewife who has seen the cost of food advancing without understanding the real reasons therefor-reasons that were entirely beyond the control of the food distributor-has joined with the price-cutting non-service character of food distributor in attacking the institution of the service, quality, and credit grocer, who has had to meet unjust accusations and misrepresentations. We have recently had socalled economy shopping by ladies in limousines, expending several times the value of any possible savings thereby, in expenditures for gasoline, wear and tear on their machines, and sometimes a chauffeur's time, to say nothing of their own, apparently blind to the fact that the so-called saving they were effecting was costing them or their lusbands more than it saved.

"We have seen communities of five hundred homes located at an average distance of a half mile from the trading center, arrange to have representatives of these homes travel an average distance of a mile, or 500 miles, per day to the store and back, taking up the time of 500 individuals in order to perform a delivery service in the grocery line, which could be more efficiently and econuomically performed by two or three grocery wagons and delivery boys as a part of the regular service grocer's establishment, and we have heard attempts to justify this comparativeiy tremendous loss of human effort because of freeing two or three grocery boys for war service.

"We have seen the family grocer who had acted as the family friend and banker to many men whose character and earning capacity he knew, but who were not known 


\section{BUSINESS RESEARCH AND STATISTICS}

to bankers, apparently forced by cut-price, cash-andcarry competition to put his business on a cash-andcarry basis, thereby not only inconveniencing his customers but forcing some of them to go to loan sharks or pawn shops to raise the necessary cash to pay their current grocery bills in advance of their income receipts, at an interest ranging from 12 to $60 \% \mathrm{pel}^{2}$ annum, instead of the interest previously charged by their grocer friend financing these food purchases on a basis of less than $1 \%$ per month to cover the cost of the use of the money as well as lost accounts as a part of his regular service. We have it on the authority of an investigation conducted by System magazine, that the average loss on account of bad debts in the average service and credit grocery business amounts to just 3.10 of $1 \%$ of the volume of business done.

"We have seen the newly married housewife out for a self-serve price-cutting saving in food purchases, gambling on unknown brands and inferior goods. These inexperienced young housewives have by the thousands 'fallen for' the idea of the apparently lower price of the non-service store, and they have often wasted more money in thus speculating without the expert and kindly advice of a good family grocer than they would have paid for the better quality and more accommodation, as provided by the service dealer.

"The lure of the cut-price has never been more effective than during the past year, due principally to the mistaken idea that the individuals of a neighborhood could perform their own service in food supply and distribution more economically than the coopperative service plan of the organized grocery situation, and that thereby they might not only save money themselves but release 
labor; whereas the real saving of human service in this connection can and will come only by improved organization in the grocery trade through better delivery systems, better accounting systems, and more careful se. lection and study of food values by expert grocery buyers whose business success in any community depends upon the service in all these functions combined which they furnish.

"It is variously estimated that from 80 to $90 \%$ of the entire food and grocery business of the United States continues to be done by the service merchant who includes the various accommodations, such as delivery, credit, and special attention to the special needs of his customers, as a part of his business policy and organization, while on the other hand it is also conceded that the cash store and non-service idea in merchandising is no new thing. It is argued, however, by those who are promoting the cash-and-carry idea in the grocery trade, that the percentage of the non-service grocery business, and the demands therefor, is constantly increasing and that it will increase until it becomes, perhaps, the most important factor and character of business in the grocery trade. This seems improbable.

"The so-called economy, chain store, or non-service institution attempts through cnt-price camouflaging on some trade-marked articles (it is able to buy as a wholesaler from the manufacturer, and retail at prices sometimes lower than their cost to the regular retailer purchasing through his wholesaler) to create the impression with the public that it is more economical to selfserve than to be served in their food supply, that the public cannot afford to pay for desirable service at the great difference in cost of foods apparently existing in 


\section{BUSINESS RESEARCH AND STATISTICS}

the prices of the so-called economy stores as compared with the regular service grocery trade.

"It is a common experience that has happened in a thousand homes during the past year, for the thrifty housewife to discontinue her purchases with the service grocery store and undertake to supply her family by purchasing from these so-called economy institutions, only to have her discover a little later that all the saving she has been able to make in price has been more than offset by the inferior quality of some articles which were wasted or discarded because not up to her usual standards.

"This condition illustrates fairly the policy of the typical cash-and-carry store merchant, who will not handle a standard price article because he cannot obtain an unfair trading privilege thereon." 


\section{CHAPTER IX}

\section{PROGNOSTICATIONS AND TENDENCY CURVES}

77. Foresight and profit.-A great deal of business success hinges upon fore-knowledge of future events. Most business departments, with the exception of accounting departments, are engaged with to-morrow's expectations and orders. Even the factory, except in oversold times, manufactures goods on expectation of orders. The most typical element of business success is tendency-knowledge and prognostication. J. Pierpont Morgan and James J. Hill typify American business superbly, and the marked thing about each was their correct prognostication-Morgan of the future steel needs of the country, Hill of the future railroad needs of the Northwest when a wilderness.

It must not be supposed that either of these men listened to a mystic oracle or gambled in any sense on pure chance. They were remarkable business researchers, keen in their appetite for facts and amazing in their command of them. Both maintained what would to-day certainly be known as research departments.

To-day such work of pronostication is less personal and private and more organized.

The New York Telephone Company employs a special staff of engineer's whose duty it is to study the telephone conditions of New York fifty years ahead, so that in all its planning-financial, managerial, and constructive 


\section{BLSINESS RESEARCH AND STATISTICS}

work-the company can anticipate for its future needs and its future grow th without lost motion.

Recently a million dollar firm in Chicago, manufac. turing petticoats, was forced into the hands of receivers because they had "failed" to foresee that style changes that made petticoats umpopular and neglected to devise in time protective measures for their business.

These are two opposite illustrations of the importance of "foresight" in business.

The financial and general business situation of the country has fluctuated constantly for twenty-five years, and has always been successfully forecasted by wise business men who studied carefully the symptoms of changes in business conditions.

Well managed firms watch for changing conditions, and by keeping their finger on the business pulse guard against overproduction when a glutted market is probable and against money stringency which might prevent them from taking advantage of opportunities, also against changes in public sentiment and political activity.

The principles of business forecasting have two phases: (1) general business conditions and (2) the individual situation of each line of business.

78. General business forecasts.-In making a general forecast, factors are studied indiridually and in groups, based upon the nature of the venture, through the means of the latest available figures which, while raried and intricate, may be grouped as follows:

1. Bank clearings in the United States and in chief cities.

2. Number of business failures, also total liabilities of failures. 
3. Bank statements (also loans and deposits, reserves and surplus reserves).

4. Building activity (as reported from about 100 (ities).

5. Foreign trade (import and export "balance of trate," being difference in volume between the two).

6. Gold movements and money rates (meaning shipments of gold to or from the United States; monthly average price of prime commercial paper and "call loans" and average bank rate for Germany, England and France).

7. Money in circulation (per capita).

8. "Index figures" of commodity prices-based on averaging of prices for a standard group of products, compared weekly by Bradstreets and Iondon Economist.

9. Gold production. When much gold is produced it becomes "cheap" and prices for standird articles increase; when less gold is produced prices decrease.

10. The volume of investments sold. This indicates activity.

11. The arerage prices of stocks and bonds are also vital factors.

12. Volume of new securities. These indicate amount of activity in planning.

13. Production and price of pig iron. This has for years served to indicate general conditions because of the universal use of iron.

14. Railroad earnings and idle car figures. As transportation is a universal business necessity, it is a natural business indicator. Gross earn. 


\section{BUSINESS RESEARCH AND STATISTICS}

ings do not tell everything, but net earnings do. Idle cars expressly indicate volume of freight. These figures are issued every alternate week by American Railway Association.

15. New corporations. Naturally these reflect the business tendency toward expansion. This is one of the indexes for men starting in smaller businesses to watch.

79. Individual basiness financial forecasts.-It has been found that the most successful firms are those who watch the general conditions carefully and adapt the individual conditions of their own business to them, and who also anticipate as far and as much as practical the flow and fluctuations of their capital, their assets and obligations.

In this sort of business forecasting it has been found advisable to consider the following factors:

1. The purchase market, in which the materials or goods are to be bought in order to be resold.

2. The estimated sale of each grade of goods during the coming year, so this may be used as a basis to estimate funds needed to carry on operations.

3. The estimated manufacturing and running expenses of the business.

4. The estimated aggregate of sales and maturing of Accounts Rc eivable, which will indicate the extent to which the business can anticipate receiving payment for goods sold.

In the light of these factors it has been found possible to properly balance the funds needed with the funds received; always providing, of course, a sufficient margin of safety to allow for discrepancies in the estimates and for unforeseen conditions.

One of the great chain store organizations goes to con- 
siderable expense to forecast the volume of business in each locality for weeks and months ahead, as approximate guards for foreclosing and financing. It can predict within 10 or $20 \%$ by its researches.

80. Researches into future markets.-It would be foolish to ignore the fact that markets change very markedly, almost year by year. In many cases the changes are fundamental and completely decisive for the industry. Good business demands that these tendencies be anticipated if possible-whether they are farorable or unfavorable. It often happens that a concern develops at high cast in money and energy a market which reaches at last a fair volume. Then, resting upon its accomplishment, such a concern very often fails to prognosticate the coming harvest of results. It fails to foresee that its business will now double and treble within a few years. It is consequently brushed aside and prevented from enjoying the leadership and preëminence it deserves by the action of more prepared forward looking concerns whose "dope on the future" was better than theirs, and who are ready when the peak point of the business arrives. Diametrically opposite cases are often noted, too, of concerns whose heads are turned by a certain amount of success, and who then begin to dream hashish dreams of business affluence, and expand and inflate themselves like a frog. They, too, misread the future, and thus commit an error which is fatal, though lack of sound research. In either of such cases the cold facts of an investigation conducted as a study of future probabilities would have saved a great deal of money-thousands of times what it would have cost.

A methodical survey of the consumption field, the tendencies that affect it, up or down, their relative strength 


\section{BUSINESS RESEARCH AND STATISTICS}

or weakness on a measured scale, are all parts of the technique of research available in such cases. Is the consumption of wood office furniture moving downward in an inevitable, inescapable tendency as a result of the competition of steel office furniture? Is there a minimum below which it will not likely go? How rapid is the decline, and how rapid, in comparison, is the rise of steel furniture? These are intensely important questions to a maker of wood office furniture who may need soon to decide to change his article from wood to steel. It is folly to guess, and economy to investigate.

What is the future of the iron or steel stove? To what extent must it become still more of a rural and semiurban article? Is the industry slowly going to decay? What counterbalances may be developed in the future to clieck the depleting market?

What effect will prohibition have on candy sales? Soda fountain sales? Soft drinks? What will be the public's drink habits once prohibition settles down to its pace? Will it despise the near-beers or is there a big future for them? Or will it turn to fruit juices?

What permanent effect will the war have upor food habits? Upon jewelry purchase? Upom book-buying? What will immensely high prices for men's clothing to men's clothing standards? Whose hands will it strengthen? The high grade ready made or the lower grade? Or the tailors-to-the-trade or the custom tailors?

$\mathrm{Or}^{2}$, to the still more subtle problems, are women going to be more larish in dress, or less so, as a war result? Are American people going to be more or less extravagant and saving as a permanent result of the sobering war and its millions of new bond owners?

Here are seen some of the trade problems as to the 
future which are constantly subjects for business debate and settlement. Iecisions nust be marle; events press for answer, and none but the researcher can offer worthwhile answers. Field investigators, careful consumer tests, statistical studies, etc. are needed to throw profitable light upon the subjects.

Even researches of narrow scope are bound to get much nearer the truth than sheer guesswork or unsupported judgment.

81. Basic raw material prognostications.-Whenever a raw material constitutes $33 \frac{1}{3}$ to $666_{3}^{2} \%$ of the wholesale price of an article and whenever this raw material habitually fluctuates in price, it is of very real importance that basic studies be made of this raw material for market prognostication reasons. When, in addition, the price of the finished product fluctuates in the open market in sympathy with the raw material and simultaneously with it, the need for such prognostication is doubly great. An article like lard substitutes, manufactured from vegetable oils, is a case in point. It can be made with equal facility from any one of half a dozen types of oil-coconut, soya, cottonseed, peanut, etc. The price in the market of these oils is the determining factor. The lard substitute prices, in finished tins, must fluctuate, at least to some extent in keeping with the current raw material price. The mar wins are close, the cost proportion of raw material to the wholesale price of the finisher article being about $66 \frac{2}{3} \%$.

The result is that such a business is only half a manufacturing business-the other half is speculative by necessity; a speculation which must rely extensively upon highly capable prognostication. It must keep in close touch with the cocoanut plantations of the world; 


\section{BUSINESS RESEARCH AND STATISTICS}

the cotton crops, the soya and peanut plantation areas; the newly arising factors of supply and demand; the weather conditions affecting such crops from time to time, and the distributive machinery, transportation facilities, purchasing competition, rates, etc. It must analyze and ferret out certain danger signals and watch them assiduously.

Accurate forecasts in this, as in other industries with somewhat similar problems, may mean a saving of much money otherwise lost. The technique of hedging, etc. may need to be backed by very careful study in rendering intelligent buying and selling recommendations.

Prognostication of crops is likely to become a better organized science as a result of the coördinating efforts of the war. At present considerable difficulty continues in the way of authentic data.

82. Tendency curve charts for uncovering hidden factors of change.-Few changes are abrupt or instant. Most of them are gradual, but are rarely visible to casual observers at the moment of change. This is true of much that occurs of business importance. Tendencies are at work, but are invisible because their slow gradations of change are not permitted to register.

A market or a territory or a man can be showing signs of "fall-down" six months or a year ahead, if only the opportunity were given for the facts to demonstrate themselves.

Capable statisticians have devised means of permitting facts to register themselves. One of the very valuable tools for such purposes are the electrical tabulating devices; and for all such concerns having a sufficient volume of units to make count by the punch card plan possible, this method opens up many avenues of approach 
to facts hidden before, because countable rapidly and cheaply enough. The tabulating machine makes possible counts of minor factors which could not be economically undertaken before, and provides them in time to profit by the readings of the facts for their future significance.

The moving annual total chart, for expressing hidden tendencies, is also an interesting and valuable aid. For instance, let us suppose it is applied to the study of a salesman's business record. It plots a chart line showing the total volume of the salesman's business for the twelve months ending with each consecutive month for a three year period. The moving annual total operates like a barometer, since it always at any point represents a complete cycle of twelve months; a view which measures the man from a yearly, rather than a monthly performance. The fluctuation is not so incidental, therefore, as the plain monthly or cumulative curve, and a gradual decline in performance of a salesman will register perfectly in this manner, whereas it might fail :o evidence the tendency otherwise.

This moving annual total may, of course, be applied to any type of data or statistics, and is invaluable for any form of data, in studying its future course.

A further use of the chart in prognostication is to project a theoretical curve from the curves already recorded to some future time period. Correct measurement of the angle or tilt, downward or upward, will result in a curve of great significance for future guidance. Even when records for only a few years are available, a projection of value, even if lesser probability, can be made. This method is simply a methodical manner of guessing or prognosticating a means of supplanting intuitive guesswork with logic. 


\section{CHAPTER $\mathrm{X}$}

\section{MEASURING INTANGIBLE FACTORS OF BUSINESS}

83. Invisible but real elements of business.-Only a tyro in business will claim that business is constituted of concrete, all-knowable and tangible values only. All business men who can think know that if this were the truth, business would long ago have become mechanical and automatic, which it now certainly is not.

The conduct of any business is filled with not only the unexpected, but also with unknown and invisible but very active factors which make for success or failure. It is the business of research to attempt to measure, estimate and study all of these intangible factors as best it can and thus to reduce inaccuracy and misjudg. ment to a minimum.

It should be understood, first of all, that as a principle there is nothing which is absolutely unmeasurable. There is infinity, immeasurable only because man's means of measurement are not on a grand enough scale, but whatever is, is measurable in some manner. The measurement of the parallax of an unthinkably distant sun, or even a measurement of the density of the Milky Way are not outside of the power of automatic science. Nor are such supremely delicate matters as the degree of sanity of a human being or the amount of goodwill enjoyed by a business house with its trade.

Although always the human element is the most 
intangible of all values, this chapter will not deal with it, as it merits another separate chapter or two (chapters xix and $\mathrm{xx}$ ). The matters which will be dealt with here are those of intangible elements peculiar to business, which are regarded habitually as vague, uncertain and defying measurement. Modern developments in business research have marle long steps toward scientific accuracy in analyzing the intangible, and thus in reducing business wastage.

84. Studying the degree of risk.-Properly understood, all business is primarily an assumption of risk with the expectation of profiting through the use of enterprise and sound judgment in measuring such risk. The inventors, owners, or stockholders who take $\$ 500,000$ of money, build a plant with special machinery, hire labor, executives and salesmen to manufacture and sell a new breakfast food in which they believe, are undertaking a risk, which in practice, they are actually endeavoring to measure. They believe that by risking $\$ 500,000$ of capital they will gain $10 \%$ or greater return upon that capital. They may even measure more optimistically, for the breakfast food field has witnessed some remarkable successes.

If instead of using, for their process of measurements, merely faith, belief, shrewd (or naive) weighing of values in the light of their experience (or lack of experience), they were very ably alvised and employed the tools of business research to measure this risk, these men might not make of their venture such a decided "gamble." In no field of business has the gambling element been so prominent as in just this field of break. fast food selling. In consequence there are in the business graveyard at least twenty-five times as many 


\section{BUSINESS RESEARCH AND STATISTICS}

breakfast foods as are now in existence! It is well known that a number of breakfast food enterprises were actually gambling ventures by grain speculators.

The elements of risk in any business enterprise are quickly determined by a competent business research man, and then the process of measurement can begin. In the breakfast food field, for instance, the elements of risk, roughly outlined are:

1. The psychological reaction of the public taste to the article;

2. The hold of the breakfast foods already in the market upon the public taste;

3. The distributive situation, jobber and dealer states of mind, price and margin considerations;

4. The advertising appeal possible to make;

5. The availability of capital, and executives, and the shaping of sound strategic policies.

There is no reason why everyone of these factors may not be subjected to a very specific measurement-even to a statistical ratio. Risk element No. 1 (as enumerated above) is a matter of try-out with a representative group of consumers, say 1,000 , selected with standard statistical care to procure a reliable average for the entire country. By being watchful of the technique of such an inquiry (as outlined in chapter xvi) it will be possible to secure a high correlation to the actual result when the article is put upon the market.

Risk element No. 2 is a matter presenting even less difficulty, as a means of measurement may readily be developed to secure a very close approximation to $100 \%$ accuracy, also through the use of consumer investigation.

No. 3 is a more dificult and intricate matter requiring 
a series of tests, with the results coördinated into a fiual composite result.

No. 4 is also a matter of delicacy, but is much sup. ported by the findings in No. 1, and the result when examined by tests similar to what one able advertising man has already designated as the "twelve tests" of advertising efficiency, may make an important element in the final determination of the risk ratio.

No. 5 is perhaps the most difficult when viewed as a whole, but as in all problems af analysis, becomes much less formidable when separated into subdivisions in an orderly manner, each given its arithmetical degree of importance. The ratio of available capital to ideal estimated capital requirements is quickly ascertained; the ability of executives is measurable on a percentage basis, as outlined in chapter $\mathrm{xx}$, while some substantial degree of accuracy in percentage rating of policies and plans as compared with ideal is not an illogical or an inaccurate expectation. It is merely a plan to judge with figure rather than generality or feeling; to be systematic about risk assumption, and to use a disciplined instead of an undisciplined business imagination.

The final result when merged into an index figure,"weighted" if necessary, with other factors,-representing ratio of risk, may to some appear a novel or futile compilation, whereas in reality it is a result necessarily more accurate in expressing a general judgment as to chance of success or failure than the usual language employed.

85. Risk ratios in investment.-Risk is always a matter of degree, therefore it not only can but should be measured. Risks from an investment point of view are particularly valuable to study, as the ratio or risk differs not only as between individual projects, but also 


\section{BUSINESS RESEARCH AND STATISTICS}

as between different lines of business. One of the com. monest methods of floating well-nigh worthless, highrisk securities is the endeavor to have them classed as to risk with some other concern or line of business which has made money and is therefore a good risk. This con. fusion and juggling with the degree of risk involved is an enormous drain upon capital, especially in America where the public is careless in calculating the risk factor. The study of the general degree of risk in an industry at large would be immensely helpful, and someday there will undoubtedly be fairly accurate comparative data on the degree of risk involved in any line of business. Already some such figures are in existence. At present also some such use is roughly made of the statisties furnished by credit agencies showing numbers of failures of lines of trade. The fatal defect in this data is first of all that the reported failures cannot include the numbers who are near-failures (insolvent, but not dissolved) or the number of failures saved from open acknowledgment as such and sold or reorganized. Second, the classifications used are too general and broad.

86. Measuring goodwill.-Here is a research task not only definitely possible but of a high degree of practical and immeliate importance. Goodwill is an evanescent quality, ever changing, and each change is highly signifcant of the general management of the business. In fact nothing in business could be more significant, not even the record of sales, which is usually regarded as the most practical measure of the situation. Figures as to sales increase or decrease represent the actual arrival and presence of the good or ill portent. It is the immediate sunshine or the rain on the window. But a measurement of the status of goodwill represents the 
barometer which senses and records the invisible atmospheric conditions which precede rain or sunshine. No ship's pilot consider's himself practically equipped with. out a barometer; nor should any business house fail to make an audit or an inventory, so to speak, of its goodwill. A typical situation was uneovered by research by the writer. A famous company, almost a century old and known throughout the world, had begun to feel in various more or less intuitional ways, a ehange in its status. Its long-time president, habitually in-looking, plumed himself upon the company's great past, and drugged himself with the idea of success because the sales were each year showing some growth. He was finally induced to have an investigation made of the company's goodwill status in all its territories, and separately with architects, mill jobbers, three types of dealers, and with the public. Being made by other than the company's representatives, the real facts were ascertained-facts which because of general respect for the company's age and position, had not been made clear to any of the company's representatives, who were all salesmen, and true to their type, were peculiarly poor investigators.

The facts, finally assembled, shocked the old organization to its depths, resulted in almost a complete change of executives and policy. In cities close by the factory, where sales were supposed to be normal, there was disclosed widespread indifference to and neglect of the company's standing and logieal claim of goodwill and service. The so-called normal sales were proved to be entirely abnormally low. The old and respected name of the company was being dragged into dust, and while commanding, ont of habit a certain degree of respect 


\section{BUSINESS RESEARCH AND STATISTICS}

among the older factors in the trade, was in practice and in sales effort by the younger element, becoming more and more ignored in favor of competitors, who, though having no aged goodwill reservoir to draw upon, were making new goodwill every day.

The goodwill ranking and percentage ratio of this firm, when finally measured and charted, was a document of exceeding importance. A policy is now in force to make annual surveys of goodwill standing. The byproducts of such measurement investigations are worth the cost in themselves, as they always develop new angles of value for all departments, from manufacturing to sales. In fact, the details of this measurement survey call for a percentage measurement of the company's standing as compared with other companies of such variety of factors as:

1. General all around ranking;

2. Rank as to best article;

3. Rank as livest advertising;

4. Rank as to service and adjustment policy;

5. Rank as to best sales organization;

6. Rank as to collection policy;

7. Rank as to best selling help provided;

8. Rank as to promptness in correspondence and attention.

These separately measured items stimulate the departments in question, and are also valuable for comparative year-to-year study and charting.

87. Goodwill valuation for legal purposes.-Perhaps the most striking value of such goodwill measurement is evidenced in matters of trade mark litigation or in general valuation. To base claims for the value of trade mark solely upon the amount of money spent in adver- 
tising is extremely crude and inaccurate. The advertising may have been very poor or exceptionally good-in either case the mere advertising expenditure would be an entirely erroneous measure; while it is also the nature of goodwill to flit away no matter how much money is spent on advertising, if the article, the service and the poiicies are wrong. Goodwill, as the English jurist, Lord Eldon, once authoritatively defined it, is "a probability that the old customers will resort to the old place." It must always remain a probability-a volatile quality and essence, which must be remeasured constantly to speak of it accurately. A company's goodwill may be worth much this year, and little or nothing next year, according to a compound of qualities measured by the effect they have left on customers. Age and adver. tising develop a greater resilience and staying power, and must of course be reckoned in a measurement. They do reckon themselves into any field test measurement of goodwill. It is significant to note that expert testimony in the appraisal and measurement of goodwill has been given before courts. The writer has several times served in that capacity.

In view of the fact that much controversy exists over the proper valuation or capitalization of goodwill, the research made of measurement is bound to be given increasing attention. ${ }^{1}$

88. Tests of consumer response.-It should be obvious to anyone that there is a decided lack of caution and logic in the usual advertising procedure of expending hundreds of thousands of dollars upon word and picture appeals which it is only shrewdly guessed will bring

1 The Archires of Psychology contain an interesting monograph on "A Psychological Study of Trade Mark Infringements." By Richard H. Paynter. 
the response desired. It is an unnecessary risk to assume, since modern research method makes it entirely practical to determine in advance the arerage reaction to any advertisement or series of advertisements. Not only may loss be avoided by eliminating advertisements with weak pulling power, but the relative efficiency of alternate proposed series of advertisements may be determined within 70 to $80 \%$ of accuracy as compared with the test of actual results. Especially is this method of testing consumer response important to those of advertisers who sell through distributors and who can therefore never know, except in a general way, the relative value of individual ads or series, since there is no true way of checking the results.

Skepticism of its value has kept many from applying this method; such skepticism being due mainly to lack of information as to the reliable technique and research principles which may be employed to secure a dependable result. It is supposed that, as the public responses to advertisements are mainly unconscious-many people often denying that they have been influenced at all when the facts prove they have-therefore, it is believed that to ask questions of the public will result in self-conscious, inaccurate answers. But trained researchers do not apply so naive a methor in making so all-important a test. They aim to elicit the unconscious answer, and give the greatest possible care to the presentation of their questions, and never attempt so naive a direct question as to whether it is a good advertisement.

What the careful researchers seek is a true response to the purchasing appeal in the advertisements, and to carefully note the character, strength and comparative effects of the responses. When this result is obtained 
from a suflicient number of representative units, the resuits will have high co-efficiency of correlation with later actual results.

The next and most frequent objection raised is that not a sufficient number of units can be called upon to make the results representative. In this again there is failure to understand modern research mathematics. Even as small a number of units as 25 , properly controlled and selected, would correlate very closely with results from many thousands of people. Tests upon 1,000 readers, selected as to character, location, age, sex and general conditions to accord with an analysis of the audience for which the ad is intended, conld hardly fail of a correlation of less than $60 \%$ to actual results and would easily approach $80 \%$ if well handled. Roughly speaking the judgment possible to use in any other way as to the effectiveness' of advertising does not reach $60 \%$-it would arerage $50 \%$ or less.

Whether for magazine, newspaper trade, or technical paper, biılboard, street car, painted or electric sign, a nice adaptation of the test to the couditions found can produce, and has produced for those who have tried it, a most profitable method of elimination of guesswork. In mail order selling and advertising the preliminary test is a standard procedure; an executive who disn't use it before sending out circular matter costing but a fraction of the sums now spent on pure judgment by the general advertisers, would not retain his position. The consumer response test is one that is in every way feasible for the general adrertiser, and Dr. H. L. Hollingsworth of Columbia University has thoroughly attested the possibilities of the method from the scientific standpoint. 
89. Sales resistance measurement.-The exact degree of resistance which any selling proposition must meet in the sales field is of great importance. Without this knowledge salesmanagel's are often misjudged-too much or too little credit being given them-and the selection of the right men and methods is hampered.

In any selling proposition there is a definite volume of degree of resistance, arising from various factors peculiar to the goods and the field. This resistance is of different kinds and varies in different territories, but has an average for the entire country or sales territory.

A research to measure this sales resistance will determine this general ratio, but most important is the careful analysis of the various kinds of sales resistance and their relative importance and strength, in each unit of telritory. It clarifies as nothing else could do the conception of the work, and puts the various sales difficulties in their right perspective.

A sales resistance analysis means field investigation, statistical research, conferences with and examinations of salesmen, collaboration with salesmanagers and higher executives, and a final tabulation of all factors into a statistical result.

Such measurement has its highly practical value in its utilization in territorial quota making.

90. Other factors measurable.-Business does not lack in intangible factors. Only the most prominent general factors can here be treated. The measurement of esprit de corps in an organization is fully practicable, as also is the degree of distributive coördination among the various factors employed in distribution.

Among the other factors which even though they are intangible permit of measurement, are: 
1. Executive efficiency;

2. Competition;

3. Demand;

4. Sales efficiency;

5. Quality and service factors. 


\section{CHAPTER XI}

SURVEYS AND REPORTS BY SPECIALISTS

91. The modern staff conception of business organization. -It is necessary, in order to properly understand the subject of surveys and aports by specialists to grasp the notion of organization and function under which highly developed business of to-day operates. The business plan or mode of operation is to separate the executive function from the planning function-principally for the reason that the business of developing and formulating the correct knowledge is a specialized kind of ability and which rarely combines itself with the similarly specialized ability to formulate policies from information and execute them. Army organization has similarly learned the lesson and utilizes the line and staff idea. The Carnegie conception of business organization was a pioneer for the molern business organization idea and quickly demonstrated its great superiority over the older idea.

In this modern line and staff conception of business, the specialist comes into his own. So does the executive. No longer need the president of a large corporation before entering it, necessarily be a man who even knows well his own line of business. In fact, many striking successes have been turned from failures by the placing in supreme executive control men who knew nothing of the individual industry, but who were able exceutives. 
And what makes an "able executive?" The ability to secure, coördinate and translate into action the specialized ability which the task requires. If he has a well balanced judgment, is an able analyst, a good selector of men and a judge of their ability, and knows how to organize for action, he has most of the qualities which will bring a business to success.

Such executives are not in the slightest degree ashamed to acknowledge their inter-dependency upon staff men and specialists, whether permanently or temporarily in the employ of the company. They have not the slightest desire themselves to qualify as specialists; and on the contrary they are immensely grateful that they can find men who have specialized upon their problems, and regard it as a blessing rather than otherwise that it is possible to hire professionally the specialized brains of many men. They regard competent counsel as the cheapest commodity they can buy.

The medical field is an excellent example of the splendid fruits of specialization. Instead of the old general practitioner who tinkered with your body until serious damage was done, because, in spite of seven or eight years of study he naturally could not master the details of all branches of medical knowledge, we now have the specialists. There is a doctor who does nothing but remove tonsils and has his fore-finger insured and keeps it protected in a case; the surgeon who specializes on maternity cases; and there is the dentist who does nothing but extract teeth. The gain is in the fact that one man, with swift and sure strokes, without bungling or uncertainty, does what otherwise might be imperfectly, lengthily and unsatisfactorily accomplished, if at all. Constantly in medicine, as well as in the other sciences, 


\section{BUSINESS RESEARCH AND STATISTICS}

a subdividing process, resulting in more and more specialists, is going on. By this process progress is en. hanced and time annihilated.

In business the specialist is about to come into his own. It took many years to make business men see the value of technical and chemical research and specialized counsel; but so much profit has resulted from it that the same principles are being applied to general administration. Operating a business is now to a certain degree a matter of digesting the reports of specialists and staff men, for from the time that the modern industry is born, to its sale or uestruction, reports of specialists are relied upon. Capital refuses to stir unless engineers and specialists reports have approved the proposed enterprise and reported in detail upon it. Factory, office and sales developments are made upon specialists' recommendations, and finally many enterprises are closed down, sold out or readjusted by reason of recommendations of specialists.

The morlern executive cannot function without facts and expert opinions; and, while research departments are looked to for facts, specialists are looked to for opinions.

92. Types and kinds of specialists available.-To be able to "send for the man who knows" at the time he needs him is only a part of the executive's function. The executive may know little or nothing about technique, but he must know what kind and character of technical counsel to get, and he must also know when he gets the right advice.

The following are some of the types of specialized services available to-day by business men, starting from the type of counsel required at the start of an enterprize, 
through all developments and broad departments of activity :

1. Market analysts;

2. Corporation and legal counsel;

3. Business finance counsel;

4. Business organization counsel;

5. Office equipment counsel ;

6. Factory planning counsel;

7. Factory production counsel;

8. Time study experts and standardizers;

9. Power counsel;

10. Mechanical engineering counsel;

11. Chemical counsel;

12. Labor management counsel;

13. Welfare and betterment counsel;

14. Sales counsel;

15. Advertising counsel;

16. Export counsel;

17. Research counsel;

18. System counsel;

19. Personnel counsellor;

20. Cost accounting counsel;

21. Auditing and general accounting counsel;

22. Trademark counsel;

23. General management counsel.

There are subdivisions eren of these classifications. There are counsellors on salesmen's compensation alone, or on speed alone, or on profitsharing alone.

93. Diffuculties and dangers in using special counselSlow progress in the use of counsellors in general business has been made principally because many more claimants of specialized knowledge have trumpeted their services than have actually possessed ability and experi- 
ence of value. Competent counsellors are really few in number and not very easy to obtain.

On the other hand some of the most competent specialists have not had anything like the ability to "sell" their services which less valuable counsellors have possessed and used. The result has been that a certain number of mountebanks and pretenders have spread an impression among the more skeptical and inexperienced users of counsel that most specialists are "fakers." This is a foolish and costly obsession, and of course untrue.

The real difficulties are plain human ones, the kind upon which the good executive specializes. He must pick his specialists with the same care that he picks all important employees, and make allowances for human nature as in dealing with every class of people.

A specialist often possesses both the vices and the virtues of his specialization. He may or may not be a diplomat, and thus may not mix well with the regular organization; he may or may not have personal idiosyncrasies, temper, vanity, obstinacy, etc., which must be discounted. He may tend to over-stress certain phases of his work, having abnormally fixed ideas regarding them as a result of long concentration upon his work.

In other words it is an executive mistake to regard any specialist as an Angel Gabriel carrying the flaming sword of absolute final truth. His work, too, must be weighed, checked and perhaps revised.

Many specialists have the vice of meticulousness and rigidity of ideas. They automatically take an absolute stand and refuse to be moved by plain facts; placing their reliance upon fixed theories which are to them sacred and massailable.

Worst of all is the vice of not sticking to their legiti- 
mate lasts, their correct sphere of knowledge. A cost accountant will glibly venture to counsel on almost any administration problem; a factory efficiency engineer will venture counsel on sales; finance counsel on advertising, etc. Few specialists have the courage rigidly to mark off a sphere and stick to it. Possibilities of fees, vanity of opinion, and undervaluation of the technique of other branches of knowledge are the explanations.

The reports of specialists are also sources of difficulty. They are ofttimes vague and negative and diffuse. Sometimes they are almost hopelessly theoretical. The difficulties of dealing with specialists are real, and maximum value from them may only be had by working with them to a considerable degree.

94. Specialists in relation to regular organization.Most failures of efficiency engineering work and the work of other specialists arise from a failure to coördinate with the regular organization. Human nature being what it is, fow regular executives relish the introduction into an organization of a man of greater ability who is to tell them what to do or what not to do. Average minor executives have not yet achieved the line and staff point of view. They resent the specialist, very especi. ally when imposed upon their departments from above. This mistake is disruptive and should be assiduously aroided. A specialist should be educated into the organization-i. e., he should be planned for and the responsibility and desire for him should be developed within the department. The idea that a specialist is a little tin god who will go about finding things wrong is a very antiquated one. It arouses ire at what seems like snooping and fault-finding, whereas a real specialist's mission is far more constructive. 
A department head requires to be taught that lee is hiring brains merely to supplement his own in the same manner as the head of the company. Also, he should be shown that under proper coöperative auspices, the specialist's work is in reality the work of the department head, for the specialist is merely his employee. The credit and the value belong to the department head, and instead therefore of being antagonistic he should be keenest of all to secure special counsel.

It is very typical of some firm's use of specialists that they put into operation some of the recommendations made, and after a short while "throw them out." This is often done with some grim satisfaction and disdain by minor executives, with a feeling of having proved the specialist to be wrong-headed and theoretical. This is merely costly self-spite, and as a rule is without any justification except a subconscious antagonism to the specialist. Specialists cost money, and it is suspiciously like paying a medical specialist one hundred dollars for a consultation and for advice as to what diet to follow, and then disdainfully refusing to follow it.

The organization which is not sold on the specialist's work will always sooner or later manage to overthrow his work, especially if it can be found to have ever so slight a flaw. No plans work automatically, and all require the goodwill and discipine of executives to carry them out successfully.

95. General surveys and reports.-One type of survey and report especially deserves increased use-the broad survey of departments or general management by competent counsellors. This amounts to appraisal and audit of the entire organization, and serves executives in 
giving them a point of view and perspective about their business not possible otherwise.

The types of general surveys and reports possible and desirable to secure are:

1. A survey of general outlook and future;

2. A survey of general management policies;

3. A survey of sales organization and marketing method;

4. A survey and analysis of executive personnel;

5. A survey of administrative and office efficiency.

Invariably these pay for themselves. The writer has seen a good counsellor render splendid value to a client in a six day survey, even after other engineers and specialists had done likewise before him, and the organization was reputed for efficiency. Such surveys should be made yearly, not by one specialist, but by several.

The truth is that a competent specialist becomes trained and highly sensitive to conditions, and can with a facility and speed that seem remarkable to men inside the organization, place his finger upon weak spots never uncovered before. 


\section{CHAPTER XII \\ THE TECHNIQUE OF FIELD INVESTIGATIONS}

96. Types and kinds of field investigations.-A field investigation refers to any survey or report of conditions as they exist in a broadcast way. A field investigation may refer to a study of conditions in a company's own sales organization; it may refer to distribution condi. tions generally; it may refer to consumer conditions, or it may be a study of the methods of competitors in any or all branches of the business, or it may refer to the outlook for an entirely new article or business, or a survey of business conditions in general.

Whatever the object of a field investigation, there are certain standard methods of approach available. These may be broadly grouped as follows:

1. Securing answers to questionnaires sent by mail ;

2. Telegraphic inquiries;

3. Answers to questionnaires secured by local resident investigators by personal call;

4. Traveling by one man, or a group of men who make the investigations personally;

5. Use of salesmen or employees or representatives.

Such investigative methods all have their value under certain specific conditions and experience and judgment will indicate which method to apply to any individual case. 
97. Questionnaires sent by mail.-Only in a few cases are mail questionnaires advisable, as they do not provide ade. quate or reliable data. Questionnaires to be worth anything must ask questions of importance, and many recipients of questionnaries by mail are known from experience to give but slight consideration to the questions, even when they undertake to answer the questions at all. The typi. cal answers to important questions in a mail question. naire, are "sometimes," "once in a while," "don't know," "don't understand," etc. Often the answers are illegible, and in many other cases the questions have been entirely misunderstood. This latter consideration is particularly serious, as many times the failure to have understood the question properly is not apparent in the answer, with the result that the investigation is seriously in error. If a question blank is only partially answered, its value as a statistical unit in tabulating results is almost destroyed.

Approximately $8 \%$ of retailers will adequately answer mail questions (although this differs with various lines of trade, the hardware trade being the most responsive). On this basis the mailing of 100 blanks means an expenditure of approximately $\$ 15$ inclusive of return postage and clerical work and supervision; whereas only about eight replies are secured at a cost of nearly $\$ 2$ each. This is higher than the cost of a report guaranteed to be accurate which can be secured through a resident investigator's personal call, while of course it is not nearly so reliable, since an investigator can make certain of the proper understanding of the questionnaire (or "schedule" as professional statisticians call it).

Many investigations are made upon units which can. not read English, or at least imperfectly. Other investi- 
gations require a check up of the class and character of the unit being investigated; and obriously an investigative unit cannot appraise himself with reliability. Often the questionnaire falls into the hands of clerks or subordinates who do not know the information asked for and render their own inadequate guesses. Furthermore, the patience of someone receiving a questionnaire becomes exhausted before the end of the question is reached. In other cases, an unconscious rather than a conscious judgment is required and this is best secured by a personal interrogator who will take careful note of the "reaction."

In a great many respects then, the mail questionnaire is not a success. There is something to be said for it under special circumstances, but generally speaking it is unsafe, and high grade statistical organizations do not use it except in rare instances.

Telegraphic inquiries of course fall in the same category except that there is greater speediness, and also great fore-shortening of the words in the inquiry, resulting naturally in an even greater possibility of error.

98. Questionnaires handled by resident investigators.This method is the most satisfactory, as it controls the unit of investigation carefully and provides a closer average of results. Field investigation arerages are accurate only when they are representative, and when the units are under control. The relative accuracy of a personal call questionnaire and a mail questionnaire are shown by experience to vary about 15 or $20 \%$ in favor of the personal call method of field investigation.

There is also a far wider flexibility of service possible when personal call investigations are made, as mail 


\section{THE TECHNIQUE OF FIELD INVESTIGATIONS 175}

questionnaires are strictly limited to very simple and few questions. A personal call investigation may go into details, subtleties and lengths almost without end. It can include a size up of the unit from an independent point of view; a check-up of the answers given by means of a standard prearranged formula, to avoid cases of false answers. The investigator can explain the subtle or difficult questions; he can answer suspicious queries regarding the purpose of the investigation; urge reluctant ones to make answers; assist in arriving at the basis for an answer, and conduct delicate inquiries with tact and persistence.

From a business point of view the advantages of using a staff of local resident investigators is also considerable, since they are controllable and teachable units who can perform an investigative piece of work with skill and completeness when properly drilled, and thus produce results which will have the highest significance and accuracy. In addition, there is real financial economy from two distinct points of view: first from the point of view of total cost, because of the fixed cost per unit; and second in view of the cost in relation to accuracy. To obtain a specific degree of accuracy, it is necessary only to make an investigation of 500 personally called upon units, let us say, whereas by any other less controlled means it would be necessary to get answers from 750 to 1,000 units. The reliability or results is in ratio to the strictness of selection and control; therefore, 100 personally investigated units will produce as trustworthy results as 200 secured by any other means.

A national organization of such resident investigators in about 200 cities and towns is now commercially available. 


\section{BUSINESS RESEARCH AND STATISTICS}

99. Securing figures and percentages in field investigations.-Knowing the loose habits of mind of most people and their inaccuracy of observation or memory, the problem of securing reliable figure facts in a field investigation becomes a real one. An active array of obstacles present themselves:

1. The possibility of a desire to deceive;

2. The danger of inaccurate statement;

3. The incapacity even to estimate;

4. The unwillingness to be specific.

The desire to deceive is often present when figures are desired which may involve prestige or success. In securing figures as to the total volume of business, for instance, it is advisable to apply a method of checking. In an investigation of the volume of business among shoe dealers in New York City, the number of clerks in the store was also secured, as experience had demonstrated that a volume of about $\$ 10,000$ per year per clerk could be roughly assumed, and any gross misstatement was thus made to stand out if the number of clerks did not tally. The checking question can be made of a character as not to disclose its purpose, and then it serves as a check also upon the accuracy and fidelity of the investigator.

The inaccuracy which is unintentional is the hardest to guard against, and is most constantly arising in seeking information from units in the field. Whether retailer, consumer or jobber or business house, the habits of mind of the average individual approached are not analytical or concretely observative; yet the investigator must secure some measurement of the matters being studied. General statements cannot be tabulated, averaged or compared; the need is for statistics rather than 
general statements. It appears to be a defect in a great many people not to think in accurate, measurable terms, or to be able to talk in figures. Ask the average dealer even such a simple question as to the approximate percentage of his customers who are men and women, and he balks, more than likely. It is necessary then for the trained investigator to work with the man and lead him to his final answer in percentage by a series of preliminary questions, such as, "are there more women than men?" Securing a definite answer to this question he can proceed to fractions, asking whether the women number two-thirds. If he answers too readily further inquiry should be made, as he may merely be ridding himself of the questions by too rough guesswork.

Once a question has been answered successfully by the percentage figure, other questions can be answered readily by the same method; and it is extremely important that all matters measureable should be put in question form calling for percentage answers.

Stubborn cases must be handled even more in detail and with patience (if the unit is important to count in the investigation).

A method which has been demonstrated as efficient in awakening the investigative unit out of his sluggishness as to figures is to "try on" a hypothetical figure. If a man persists that he does not know how much business he does in one department or division; or if a consumer simply "can't tell" approximately how much he spends on phonograph records each year, then by saying "do you spend $\$ 100$ a year?" a challenge is thrown out which usually brings an almost automatic response. "Oh, no," may be the reply; and then suggestive amounts can be stated until some close approximation is reached. This 


\section{7s BUSINESS RESEARCH AND STATISTICS}

method works equally well in all classes of field investigative work, even in cases of close-mouthed unwillingness to give figures.

100. Securing an unconscious reaction.-There are many who discount the results of field investigation, especially the questionnaire type of investigation, because they claim that the answers secured are too often self-conscious answers. For instance, if an investigator was calling upon women in their homes to tabulate the magazines subscribed for by that family it is claimed that a direct question tempts the woman to mention magazines whose reading implies prestige, let us say Atlantic Monthly, Harpers, etc., and that she would be tempted to deny that she read the Parisienne or the Red Book or Cosmopo'itan. Even if she gave correctly the names of the magazines subscribed for, she would, it is feared, give false answers as indicated above, when asked which she was most fond of reading. She prefers her neighborsperhaps even herself-to think that she dotes on the Atlantic rather than the Red Book.

The same is true in any effort to get a consumer to inlicate, first, whether he is influenced by advertising in any purchase, or second, which form of advertising media jnfluences him most. Most people plume themselves on forming judgments independent of advertising.

Undoubtedly, thus stating their case, these critics are right. But it is entirely naive investigative work to ask questions so directly on matters which reguire an answer from the unconscious.

The conscious self is a censor, and it "edits" real thoughts, both for its own and other people's d lusion. Therefore, the planner of a good investigation would no more go to the conscious self on such matters than he 
would go to a political candidate for a true forecast of a vote. Investigations requiring a study of unconscious reaction must have most carefully framed questions, and a strategie plam behind the entire presentation. This form of question and strategic plan must never make the investigated unit aware that in answer to the question or plan there will appear an answer to the real question. For instance, in securing a judgment by consumers as to the effeetiveness of a certain series of advertisements, prior to inserting these ads, consumers were given a sheet showing the ads and asked to tell whether they believed the article was worth while buying. When the answer was given, they were asked why, and the adver. tisement containing the argument mentioned was rated the highest effectiveness in the group. The law of averages took care of the other factors involved in the test, and the results tallied most closely with the tests made. The normal reactiou was obtained in such a questioningi. e., a subconscious reaction.

In many investigations this factor of the subconscious reaction comes to the front in planning the phraseology of the questions and the methor of investigation, and the intricacy of the subject and its vital bearing on dependable results make the work of field investigation more and more a matter of technique and psychology. The laboratory methods of a psychological test must more and more be applied to investigation, and can fully demonstrate its economy in the reduced number of units necessary to investigate in order to achieve a co-efficiency of coördination. A considerable area of business is yet strongly affected by the subconscious, especially in sales, advertising and labor relationships, and needs, therefore, to be more closely analyzed. 
101. Field surveys for data and statistics.-So great and widespread an expanse of territory is the United States that for intelligent knowledge of the field, a consider. able amount of data is important to have. A paint manufacturer who put out his spring sales campaign at the same time throughout the country and could not get uniform attention and results, was faced with the facts, overlooked before, that spring is a month late in the Dakotas and a month early in the southwest; that in fact the temperature variations and seasonal situation were remarkably varied at different points in the country.

The character of people, the local factors of economic consequence, are all vital to possess. The following might be listed as the principal items of information for average use which should be possessed:

1. Population of city.

2. Nationalities of the population.

3. Names of newspapers.

4. Net paid circulations.

5. Morning, evening or Sunday issues.

6. General character of city's business-whether commercial or industrial.

7. Number of factories, with number and total wages of employees.

S. Different types of factories, with number and wages of employees, for each type. Also pay day dates.

9. Number of wholesale houses, and annual volume of their business.

10. Number of office buildings in the city.

11. Number of schools, with number of teachers and pupils.

12. Type and mileage of street railways. 
13. Number of railroads entering the city and num. ber of employees resident in the city.

14. Number of individually owned houses.

15. Number of traffic teams in use.

16. Number of traffic automobiles and of pleasure automobiles.

17. Proposed public improvements.

1S. Projected office or factory buildings.

19. Number of banks and their annual earnings.

20. Number and character of investment companies.

21. Amount of bank deposits both checking and savings accounts.

22. Character of motive power used, in general, in the industrial plants.

23. Natural facilities for producing construction material.

24. Total population within a business radius of fifty miles from the city, of which the city is the natural center market.

25. Conditions of transportation and of highways which favor the use of the city as a central market by this outside population.

26. Number of various dealers in different lines.

27. Number of residential suburbs within commuting distance, with population.

28. Number of people by grades of incomes, $\$ 1,000$, $\$ 2,000, \$ 3,000$ and over.

29. Bank clearings, building records and per capita property assessments.

30. Charitable institutions, public buildings, public debt, tax rate.

102. Territorial layout for local dealer and consumer investigation.-In arranging trade investigations, it is not 


\section{BUSINESS RESEARCH AND S'lATISTICS}

always necessary to canvass an entire state or section to get the maximum amount of information. By canvassing a carefully selected group of cities, data concerning the whole district can be obtained. The cities given in the following analysis were selected after careful study because they are so located as to reflect conditions in surrounding sections.

The following are the kinds of information which are useful and possible to obtain through such investiga. tions:

1. Competition: (Finding what competing brands dealers carry; what competing brands they push; what competing methods are, etc.)

2. Jobbing or branch conditions: (Checking the service which jobbers or branches give to retailers; finding out the names of dealers who handle your goods; finding out the names of jobbers with whom dealers habitually deal.)

3. Consuming possibilities: (Analysis of the possible consumption in that territory; calling on consumer to get the correct consumer idea; learning per family consumption, preferences, etc.; feeling of manner of presentation, etc.)

4. Trade sentiment: (Feeling of the dealer on special propositions, analyzing proposed price and other changes from dealer viewpoints, etc.)

5. Statistics of distribution: (Checking dealers who handle goods; picking out dealers of a certain certified type; compiling local information as to grade of people, volume of purchase, etc.)

6. Checking sales work: (Checking the work of salesmen, jobbers and branch houses; studying overloading; getting a line on competitive sales work, etc.) 
The dealer figures can be applied to the grocery and drug trade, and with some modifications, to hardware and dry goods. The total number of dealers in each class, and also the number of dealers per thousand of population, were the considerations in fixing the number of dealers necessary to be called on in each city to get adequate information. An estimate of the cost to make the nation-wide investigation here outlined is $\$ 1,250$.

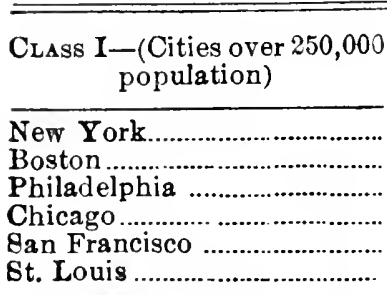

TOTAL

CLASS II-(Cities of 100,000 to 250,000 population)

New Haven, Conn..

Rochester, N. Y.

Atlanta, Ga.

Grand Rapids, Mich.

Denver, Colo.

Portland, Oregon

TOTAL

Class III-(Cities of 25,000 to 100,000 population)

Reading, Pa.

Kalamazoo, Mich.

Elgin, Ill.

Oshkosh, Wis

Davenport, Ia

Mobile, Ala.

Lincoln, Neb.

Dallas, Tex.

\begin{tabular}{|c|c|}
\hline $\begin{array}{l}\text { Population } \\
\quad(1910)\end{array}$ & $\begin{array}{c}\text { Approximate } \\
\text { number of dealers } \\
\text { to be canvasued }\end{array}$ \\
\hline $\begin{array}{r}4,766,833 \\
670,585 \\
1,549,008 \\
2,185,283 \\
416,912 \\
687,029\end{array}$ & $\begin{array}{r}225 \\
70 \\
100 \\
150 \\
60 \\
75\end{array}$ \\
\hline $10,275,700$ & 680 \\
\hline $\begin{array}{l}133,605 \\
218,149 \\
154,839 \\
112,571 \\
213,381 \\
207,214\end{array}$ & $\begin{array}{l}30 \\
41 \\
32 \\
25 \\
33 \\
30\end{array}$ \\
\hline $1,039,759$ & 191 \\
\hline $\begin{array}{l}96,071 \\
39,437 \\
26,000 \\
33,062 \\
43,028 \\
51,521 \\
43,972 \\
92,104\end{array}$ & $\begin{array}{r}20 \\
9 \\
7 \\
8 \\
11 \\
15 \\
12 \\
18\end{array}$ \\
\hline 425,195 & 100 \\
\hline
\end{tabular}




\begin{tabular}{|c|c|c|}
\hline $\begin{array}{l}\text { Class IV_-(Cities of } 10,000 \\
\text { to } 25,000 \text { population })\end{array}$ & $\begin{array}{c}\text { Population } \\
(1910 ;\end{array}$ & $\begin{array}{c}\text { Approximate } \\
\text { number of dealers } \\
\text { to be canvassed }\end{array}$ \\
\hline 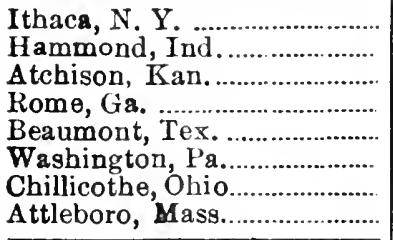 & $\begin{array}{l}14,802 \\
20,925 \\
16,429 \\
12,099 \\
20,640 \\
18,779 \\
14,508 \\
16,215\end{array}$ & $\begin{array}{l}5 \\
8 \\
6 \\
5 \\
8 \\
7 \\
5 \\
6\end{array}$ \\
\hline TOTAL.................. & 134,396 & 50 \\
\hline GRAND Total.................. & $11,874,350$ & 1,021 \\
\hline
\end{tabular}

103. The broad types of field investigation.-Quite apart from the more incidental kind of investigations of the field are those investigations analyzing methods, tendencies and general basic conditions.

The first type, that of methods, is best illustrated by an investigation made by the Business Bourse covering the problem of selling direct to the retailers versus selling through jobbers. This problem upon which hung the possible change of the entire 80-year established practice of a famous concern, took a number of months to study. Most of it was done in the field. It consisted of the following divisions of phases:

1. A national field inquiry into the state of mind of consumers as to service impressions, from the present mode of distribution.

2. A national field inquiry into the state of mind of retailers.

3. A national field inquiry into the state of mind of the jobbers.

4. A technical inquiry into the freight costs involved in shipping under a policy of selling direct.

5. An inquiry into a more scientific factory location. 
in relation to distribution under a plan of selling direct.

6. An inquiry into the field as to a system of warehouses and branch offices.

7. An inquiry into financial matters involved, credits, overhead, etc.

8. A field statistical survey of retail distributors as to character, kind, standing, etc.

9. A detailed survey of the methods of other firms who were or had sold direct.

10. A general coördinated study of the entire situa. tion as evolved by the various separate field studies.

Broad investigations of tendencies are of still another sort, and have taken a year or two of time. Such investigations have been made, for instance, by the Curtis Publishing Company on distributive conditions in dry goods and women's wear. Among the significant factors studied and developed in such an investigation were that there are to-day in the United States the following retail outlets for textiles and women's apparel:

Department Stores ....... 1,770

Dry Goods ............ 30,031

Fancy Goods ........... 4,721

Clothing $\ldots \ldots \ldots \ldots \ldots \ldots$ 20,843

57,365

These stores do a total business of nearly four billion dollars. Forty-five per cent. of this sum is concentrated in the 100 largest cities of the country. Twentyeight per cent. of the business done in each of these cities goes to the leading stores-one in each city.

In adapting the facts herewith given to any specific 


\section{BUSINESS RESEARCH AND STATISTICS}

proposition, it is necessary to bear in mind the classification into which the commodity falls-whether it is

1. "Convenience" goods bought at the handiest place; like children's stockings, handkerchiefs, etc.

2. "Emergency" goods, immediately necessary, like rubbers, umbrellas, etc.

3. "Shopping" goods, which are of sufficient importance to justify a trip to several stores in order to compare values.

It has been found that $43 \%$ of the total business is obtained by stores doing an annual business of over $\$ 200,000$ per year do $75 \%$ of their buying direct from the manufacturer.

There are, of course, a larger number of stores whose volume of annual sales is less than $\$ 200,000$, and these stores do $57 \%$ of the total. This second class of stores buy through jobbers, generally.

104. Factors that determine possible demand for a textile.-

1. The sales of that article in a section where it has already been tried out.

2. Whether it is a "convenience," "emergency" or "shopping" commodity.

3. The total local dry goods business, and per capita consumption.

4. Whether the article appeals to any specific class of women, or is desired especially in certain sections. 5. Success, failure and general history of similar products.

6. Dealer attitude towards the class of goods.

7. Consumer attitude.

A study of retail sales developed a territorial division made according to the retail characteristics of the vari. ous sections of the country: 


\begin{tabular}{|c|c|c|c|}
\hline Section & $\begin{array}{l}\text { Population } \\
(1910)\end{array}$ & $\begin{array}{c}\text { Volume of } \\
\text { retail business } \\
\text { Dry Goods and } \\
\text { women's ready- } \\
\text { to-wear }\end{array}$ & $\begin{array}{l}\text { Per- } \\
\text { centage } \\
\text { of U. S. } \\
\text { Total }\end{array}$ \\
\hline 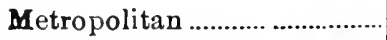 & $16,097,000$ & $\$ 439,862,955$ & 21 \\
\hline $\begin{array}{l}\text { Northern New England and } \\
\text { Northern New York............. }\end{array}$ & $1,854,528$ & $41,892,130$ & 2 \\
\hline Central New York..................... & $3,000,808$ & $73,310,493$ & $31 / 2$ \\
\hline $\begin{array}{c}\text { Western Pennsylvania and } \\
\text { West Virginia......................... }\end{array}$ & $5,602,119$ & $146,622,00$ ? & 7 \\
\hline Virginia and North Carolina & $4,885,448$ & $115,202,202$ & $51 / 2$ \\
\hline 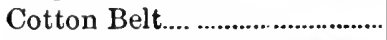 & $5,526,335$ & $146,620,000$ & 7 \\
\hline Kentuck $y$ and Tennessee...... & $3,724,694$ & $83,783,420$ & 4 \\
\hline 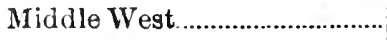 & $20,241,359$ & $523,646,375$ & 25 \\
\hline 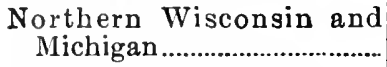 & $1,106,741$ & $20,945,855$ & 1 \\
\hline Missouri and Arkansas.......... & $4,217,784$ & $104,729,275$ & 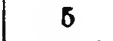 \\
\hline Texas and Oklahoma .............. & $3,853,107$ & $94,256,347$ & $41 / 2$ \\
\hline Prairie States............................... & $5,483,697$ & $146,620,955$ & 7 \\
\hline Mountain States........................ & $1,998,522$ & $41,891,000$ & 8 \\
\hline Arizona and New Mexico .... & 526,655 & $10,472,928$ & $1 / 2$ \\
\hline Washington and Oregon........ & $1,794,095$ & $41,892,000$ & 2 \\
\hline 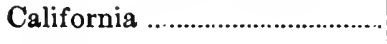 & $2,365,549$ & $62,837,565$ & 3 \\
\hline $\begin{array}{l}\text { TotaL, United States...... } \\
\text { *Exclusive of Negroes. }\end{array}$ & $82,278,441 *$ & $\$ 2,094,585,500 t$ & 100 \\
\hline
\end{tabular}

† These 1914 figures may now safely be doubled.

105. Field factors of statistical interest.-Broad studies of basic conditions might include, for instance, the density of population and the density of dealer distribution in the United States.

The density of population (i. e. the number of people per square mile) and the density of dealep distribution is an important index of the fertility of a state or section for merchandising and advertising. The figures used in calculating the following data are the July, 1914, 
census estimates and the list of dealers in six prominent lines:

Dealers Par Square Mile-East of the Mississippi

\begin{tabular}{c|c|c|c|c|c|c}
\hline $\begin{array}{c}\text { Population } \\
\text { Per Square Mile } \\
\text { New England }\end{array}$ & Druggists & Clothing & Drs Goods & Grocers & Hardware & Jewelers \\
\hline Maine, - 25.4 & .012 & .017 & .016 & .060 & .005 & .005 \\
New H'shire, 48.7 & .024 & .024 & .028 & .091 & .012 & .016 \\
Vermont, - 40.1 & .017 & .018 & .017 & .064 & .017 & .014 \\
Massach'tts, 450.6 & .111 & .193 & .180 & 1.099 & .088 & .113 \\
Rhode Isl'd, 591.1 & .092 & .238 & .192 & .142 & .080 & .180 \\
Connecticut, 240.6 & .072 & .106 & .096 & $.5 \% 2$ & .038 & .530 \\
\hline Total, - 112.4 & .034 & .053 & .046 & .271 & .023 & .296 \\
\hline
\end{tabular}

The table here given has been compiled to show (1) the density of population as compared with transporta. tion facilities; (2) the average wage earning capacity, individual prosperity and thrift of the people in different sections of the country.

Such data is valuable in analyzing the market for an article that appeals to definite classes or characteristics, and indicates where are the most responsive markets.

\begin{tabular}{|c|c|c|c|c|c|}
\hline New England & $\begin{array}{l}\text { Population } \\
\text { per mile of } \\
\text { steam } \\
\text { railway }\end{array}$ & $\begin{array}{l}\text { Population } \\
\text { permile of } \\
\text { street and } \\
\text { elevated } \\
\text { railway }\end{array}$ & $\begin{array}{c}\text { Insurance } \\
\text { in force }\end{array}$ & $\begin{array}{c}\text { Average } \\
\text { Manufactur- } \\
\text { Ing per } \\
\text { capita wage }\end{array}$ & $\begin{array}{l}\text { Per caplta } \\
\text { valuation of } \\
\text { realty and } \\
\text { personal } \\
\text { property }\end{array}$ \\
\hline 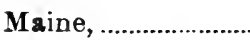 & 330 & 1408 & $\$ 153$ & $\$ 436$ & $\$ 608$ \\
\hline New Hampshire,... & 345 & 1526 & 157 & 422 & 610 \\
\hline 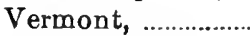 & 323 & 3669 & 182 & 459 & 567 \\
\hline Massachusetts, ..... & 1592 & 1094 & 265 & $4 \% 5$ & 1417 \\
\hline Rhode Island, ......... & 2557 & 1227 & 254 & 432 & 988 \\
\hline Connecticut, ........... & 1115 & 1100 & 227 & 484 & 827 \\
\hline AvERAGE........... & 827 & 1206 & $\$ 233$ & $\$ 466$ & $\$ 1090$ \\
\hline
\end{tabular}




\section{CHAPTER XIII}

PURELY STATISTICAL INVESTIGATIONS AND ESTIMATES

106. Possibilities of the application of statistical method. -Besides the various specific phases of research outlined in other chapters there are a great many other uses for statistical inquiries which while calling for no new or conplicated statistical knowledge are nevertheless of ten neglected.

Such simpler forms of statistical research have application to many phases of business, marketing, administrative, financial and otherwise, and represent the effort of keen-visioned, constructive business minds to make use of all possible methods of increasing definiteness of knowledge before action.

To secure fullest value out of the possibilities of statistical method, it is necessary to learn to think very readily in terms of statistics, and this is not usual with average business men. The habit of considering most business matters statistically is only another name for the habit of "thinking in terms of dollars and cents." Yet the former is often derided while the latter is praised. Such a provincial attitude calls for revision, and this is rapidly coming about. The most successful men in business-Morgan, Rockefeller, Harriman, etc-were accountants and therefore early acquired the habit of applying to most business matters the acid test of statis. tics. However, the statistical researches here meant are 
not routine accounting statistics, but are inquiries into more difficult and special matters, small and large, for the purpose of clearing up doubts, throwing light on rough places, unraveling snarls and illuminating details. The necessary subdivision of this book has compelled the author to consider some matters apropos under this head in other chapters.

107. Searching for hidden causes.-Factors of business success and iailure have a way, because of their natural tendency toward invisibility, of being buried beneath in. nocent and deceptive layers of other factors. Only in. tuition can suspect their existence, and only research can bring them fully to light. In fact, business research is at its best and in its prime when engaged in such work, for it is then engaged at a task peculiarly its own, with a possibility of rich findings also peculiarly its own. Among examples which may be cited of inquiries along such lines are:

1. Statistical comparison in detail of highly profitable with markedly unprofitable territories or articles or methods.

2. A statistical study of the relationship between sea. sonal slumps and net profit.

3. An inquiry into relative frequency of various char. acteristics of returned goods orders, to discover leading causes.

4. Analytical comparisons of records for the location of loss, wastes and inefficiencies.

5. Statistical review of details of credit losses to 10 cate clues for future guidance.

6. Statistical study of rise and fall in prices of basic materials; world and national supply rolumes, as guidance for the future course of prices. 
108. Statistical researches from records.-There are three broad avenues of statistical research, as broadly agreed upon by professional statisticians. ${ }^{1}$ First is that of assembling data from official records, public or private, or generally available statistics. The second is by making counts, taking a census, so to speak, or developing statistics from original sources; and third is that of projecting estimates.

As the second of these methods is well described separately in the chapter on field investigation, and the third one in the chapter on tendency curves and prognostications, the first one only calls for treatment at this time.

Those broad visioned accountants who wish to desig. nate their work with greater dignity and constructiveness, prefer the term "statistics of management" as applied to analytical studies of records. This throws the proper light upon such work, too often viewed merely as records of things that are past. A very great deal of value lies hidden in the ordinary records of a firm's business, if such records are complete and well kept, for the significant details have all inscribed themselves there. The right statistical research can develop these details. True, it is a "post mortem" operation when regarded from the point of view of the year that is gone never to return; but viewerl for the benefit of the year to come it is immensely important.

In fact, modern accounting now makes it possible to hold such post mortems every day or week or month, and the lessons to be had from statistical analysis are surprisingly varied and fruitful. They can answer such questions as:

\footnotetext{
${ }^{1}$ An Introduction to Statistical Methods, Secrist pg. 41.
} 
1. Why have our sales seemingly borne so little rela. tion to our rate of advertising expenditure?

2. What has been the general result of our policy of guaranteeing our goods, as compared with the years before such a policy was operated?

3. What relation do our profits bear to the fluctuations in price of raw materials?

4. Why has our surplus each year been so out of pro. portion to our rate of profit and volume of sales?

5. What relation does our volume of profit bear to general business fluctuation?

The latter question illustrates the type of statistical research from records other than the private records of the company, or a merging of private and general records. To get a significant perspective it is important to go outside of the books and records of a company-it is often necessary for good results to consult as far as possible the records of other companies, the statistics of the industry at large, and also the broad economic and business statistics of the country and the world.

It is in most cases inadvisable to expect an account. ing department to prepare or secure such data. Although accountants are prone to dispute it, they are not trained statisticians and hare no statistical training or perspective. Even if they were, the point of view of an out. sider, disinterested and unhabituated to the firm's methods and outlook, is in itself an important asset.

Statistical research from records may constitute any. thing from a mere use of routine census figures to the adaptation of statistics of bank clearings, building permits volume, export statistics, etc. All the routine sources of statistics offer some possible assistance, and afford some basis for comparisons. 
It is a serious mistake, however, to rest content with routine records. Year in year out certain standard records are available and they have their value. The danger lies in failing to go behind them. Their very general availability is a limitation, as they are available to everyone and constitute no special advantage. They breed set methods of regarding them, whereas some new research may turn up far more accurate and reliable methods of comparison or information. Added to this is the regrettable form and inconclusiveness of much standard data, making it of small value and doubtful usefulness. Standard, easily obtainable records, therefore, merely afford a temptation, breed laziness and encourage conventional statistical reasoning, when more original data and thinking are needed.

109. Analytic and synthetic statistical processes.-Despite the fact that statistical method is predominantly a numerical method, the gravest problems of a statistician are not those of counting, totaling, dividing and subdividing, but in sifting and sorting the material for counting, reclassifying it, discovering new aspects and subdivisions and outlining new definitions and standards. It is, in brief, an exploration and mapping of country known only in rough outline or not at all.

Secrist points out ${ }^{2}$ how even such a unit of measure as a ton-mile may on examination hare various aspects:

"While a ton is invariably a ton, and a mile a mile, all tons, except as to the only quality, weight, are not the same, nor are all miles, except as respects distance, equivalent. One ton may be bulky, low-grade freight; another ton may be compact, high-grade freight. One may be the measure of a quantity of storepipe elbows, the

'Statistical Method pg. 59. 
other of a quantity of silks. Likewise, one mile may be easy grade in a prairie, the other of heavy grade in mountainous tunnels. The conditions necessary to the movement of one ton one mile-the ton-mile-may be wholly dissimilar in spite of the common name which is assigned to the service. Units must be referred to the conditions which they describe, and since these are widely diferent, combinations of them should be made only with care and circumspection."

The same situation is very often true of not only other units of measurement but even more often of other definitions, terms, classifications and elements and factors to be measured.

Business statisticians constantly come upon terms and phrases used by statisticians of other kinds-social statisticians, labor statisticians, etc.-which from a business point of view and for business purposes are inaccurate. The census is almost completely the product of social and labor statisticians, and its terms and classifications are not business terms and classifications. The material in it if desired for business purposes of a seri. ous kind, needs to be re-analyzed and re-stated, even if all the information desired is there. The census lumps in one classification all "chemicals" which have many great and important subdivisiors, and yet it also names as a separate classification, horse clothing, of which there are but 26 manufacturers: Similarly it lumps all "confectionery" together when there are various large and widely different subdivisions, such as the chocolate and hard candies. Also it has a general classification for cooperage and wooden goods, having a total volume of several hundred million dollars; also a broad classification of "printing and publishing," (a large billion dollar 
industry of many varieties) while it has a separate classification for hammocks, of which, nevertheless, there are but a bare dozen of manufacturers!

Naturally such statistics require re-analysis to ascer. tain more sharply defined classifications.

The same is true of questions of the statistics of "business failure." What is a business failure? The credit agencies apparently regard a business failure a foreclosure or a receivership due to voluntarily acknowledged insolvency or forced action by creditors, resulting in bankruptcy. Yet true analysis of business failure would certainly require to take into consideration the failures which are no less failures becanse they are not spread upon legal records as such. A majority of businesses which become insolvent are either sold, closed np, taken into stronger hands, carried by creditors upon private agreement, or otherwise prevented from being openly branded as failures. In fact, speaking strictly technically, very many businesses are fairly constantly insolvent.

It will thus be seen how statisties and definitions of business failure require considerable re-analysis. Many other business terms are in the same condition, and it is the work of serious research to accept nothing for granted and search down to root causes and facts, so that, no matter how accepted and unquestioned are certain figures and assumptions, they will be re-tested and re-analyzed to check up their validity and their connotations. 


\section{CHAPTER XIV}

\section{THE EXECUTIVE APPLICATION OF FACTS TO BUSINESS}

110. The head of a business and his sources of information. -No business man is greater than the amount and facility of his information. His rate of growth in business is about the rate of his ability to secure, absorb and adapt information. Therefore, as an executive it is his prime duty, not merely to study routine information, but to be aggressive and ever alert for facts. He is in serious need constantly of fact and figure and accurate factpictures of conditions. His judgments are exactly as good as his information, no more and sometimes less. It is a severe enough task for the best of business brains to plan wisely and with originality even after the essential facts are in hand; to attempt to do so with poor or incomplete information is a grave and an unnecessary business risk.

No business man should rely entirely upon the information provided for lim by his organization. There is no more pathetic condition in business than that of a high executive surrounded by men who conspire, consciously or unconsciously, to keep information from him. It is like a king surrounded by courtiers who never let a hint of revolutionary rumblings get to his ears, until one day the deluded ruler is overwhelmed and lost. Yet such conditions in business are far from rare; in a limited degree they are actually universal. 
The average executive depends wholly upon his own eyes and ears (aided perhaps by an occasional bit of tattling) and upon the information of his executives. It appears never to penetrate to such executives that they virtually live with the wires cut between them and real fact about their business. They wait until something happens before they realize true conditions. Sometimes this is too late; always it is a costly mistake.

It must first of all be realized that two or three strong factors prevent subordiuate executives from providing their superiors with the exact truth, and all of it. First, such executives are too close to their jobs-they suffer from a natural and inevitable myopia. A laborer on a scaffolding cannot describe the building upon which he is working; he can see but a small fraction of it and his eyes are even with that small portion so much that his powers of observation about it are untrustworthy and stereotyped.

Then, too, feeling, prejudiced and biased almost in svitably creep into the attitude of a worker toward his own special bailiwick. This is because the mind ever tends to adopt a certain fixed attitude toward the objects surrounding it and in constant intimate association with it. The critical, attentive faculties are relaxed, and habit crystalizes around the daily routine. Certain opinions and ideas become fixed and "freeze" around the situation with the hard grip of ice.

True, there are many executives who by constant struggle and alertness keep themselves free from a considerable degree of this-but there needs to be an adequate "check-back" for even the most alert of executives, if facts are to be had without bias.

Finally, few executives are either good observers or ac- 


\section{BUSINESS RESEALCH AND STATISTICS}

curate reporters. They may be very high grade executives for their particular functions, operating upon policies decided for them or with them in conference, but they are often incapable of deciding, first, what are the essential facts to secure, next, to secure them reliably and, third, to pass upon them without conference and debate. Indeed, the highest grade executive especially plans to apply the acid test of investigation and recon. sideration to his own work.

The head of an alert business needs to go outside of his own organization for information; must depend upon men trained to do the work and responsible only to him, no fixed or preconceived ideas of the matter in hand. He must arrange for his own sources of informatiou as check-up of his departments and of his position broadly in the field and in relation to maximum possible efficiency.

111. Appreciating the outside point of view.-The most profitable business information is frequently that which is a cross-fire upon the information developed from the "inside." In other words, the point of view of the outside-of the analytical man who knows nothing of the technique of the business-is often of the most remarkable value. This is illustrated by the fact that the idea of a dollar watch did not originate among manufacturers of watches, but was conceived by a man in another line of business. The idea of the Uneeda Biscuit, a national. organization, to sell bakery products, originated not in the cracker industry, but with a lawyer. These men did not sufiel from an habitual point of view-they could reason from new information, and eagerly sought new information.

$\mathrm{By}$ the outside point of view is not meant the crude 
method of asking cousins, aunts, policemen and chauf. feurs for opinions (which are of course practically worth. less because of the self conscious bias involved in such questioning). The trained outside point of view is the important thing; also the consensus of opinion plan of research by means of carefully worked out questions, carefully asked under controlled conditions and from well chosen representative units, and the results statistically averaged. (Technical details of the making of such investigations are described in chapter xvi).

The problem of the head of a business is to know what types of information are desirable, upon what questions to consult the outside point of view, and then after hav. ing secured it to apply the knowledge thus gained. The scope of trained counsel in outside point of view is constantly widening. The banker was originally the only outsider whose counsel was respected, but he did not represent a competent general advisory point of view, and was only too frequently a narrowing influence. This has also been the case with consulting accountants. The advertising agent followed and has been of very important assistance. Efficiency engineers so called have been very great broadeners; both of these because their influence was an eclectic, creative and productive influence rather than a mere narrowed and repressive one.

Research counselors have a special future in this regard, as by the very nature and breadth of their task, (if they will conscientiously keep it broad and creative) they are beholden to none, are technicians of the outside point of view, and are adaptive to individual needs. With an able research organization at their elbow, high executives have the machinery to combat most of the special diseases and barnacles that limit business effi. 
ciency and profit, and are afforded a great personal service in that they can get real information from direct, or. ganized sources without wasting energy in an endeavor to get it from their own organizations, built to do other things.

112. The faculty of coördinating information into action. -Colonel Vache relates of Napoleon his significant trait of eager and determined search after information; his personal interest in details of information down to inquiry into the very quality of the soldiers' mess before going into action, by personally tasting the food in some random field kitchen; and then, once having coördinated all his information into a plan of action, making a special point of carrying it out with great swiftness.

It is a typical weakness among executives to appreciate any information gathered, but to lack facility in formulating a plan of action from it. This is a twin weakness to that of much reading and absorption from books, but procrastination and inaptitude in applying such learning.

The first mental effort comes in separating the non. essential information from the mass, and in learning how to face facts. A strange peculiarity resides in many men that although in the back of their minds is knowledge and acceptance of the facts, there is a lack of realization of the proper deductions from these facts. Or perhaps still worse, a knowledge of the proper deduc. tions, but a laziness of mind and readiness to put things off, which vitiates the deductions.

To be fair to facts and the business which should profit by them, facts should never be laid away before being very squarely faced and a bona fide decision for action made concerning them. It is very easy to make a con- 
venient or dissembling disposition of facts, to stick into a pigeon-hole a report with recommendations, but it is a very costly thing to do. Facts, by their very nature, have a way of being upsetting and inconvenient, calling for severe mental labor to analyze and digest; and decision is a quality which the average mind rather naturally shrinks from and avoids as long as possible. Psychanalysts say this is because, on the least excuse, human nature reverts to the easiest path, the lazy attitude. Yet the greatest value and profit in business research and statistics lie in securing information in adrance and putting it to work at once while others fumble in the dark or remain indecisive.

Conferences on fact findings between executives and research counselors are extremely valuable, for stimulation and training in translating facts into action, for part of the knowledge and equipment of an able man in business research is to be able to assist in making practical deductions and concrete applications of his research and investigative work. It has been one of the chief troubles with research workers, efficiency engineers, statisticians, counselors, etc., that they so frequently confined their efforts to making reports and did not obtain the corrective discipline of seeing their ideas through.

The head of a business who improves his faculty of reasoning closely from fact to policy, from data to correction of method, and relation to principles, and from statistics to future plans, is certain to greatly add to his stature as a business man. A very considerable part of an able modern business man is the ability to make sound decisions from reports, data and statistics.

113. Human difficulties in applying information -One of the main difficulties, both in having facts respected by 


\section{BUSINESS RESEARCH AND STATISTICS}

business men, and also applied, is the basic liuman difficulty of translating any knowledge into action. It has well been said that a millenium would arrive to-morrow if all people applied no more than the knowledge they already possess. Great numbers of business men possess the facts essential for wise action, either in the form of leports rendered to them by records, counsel and invesiigations, or else in the form of experience or judgment or the recommendations of their own executives. Action is not forthcoming because high grade executive ability is even rarer than investigative ability. More men can be found who can plan a splendid military of fensive than there can be found generals who will successfully bring such plans to a conclusion. The imagination and the paper plans easily outrun the courage, will-power and organizing ability to use information in actual practice.

Another vital difficulty in the way of applying informa. tion in a modern large scale or average sized business is the immense amount of coördinative work which is necessary to carry out plans; also the large risk and large expenditures called for, and the consequent natural conservatism of directing heads in reaching a conclusion to start. This principle was illustrated with great clearness in the efforts of the United States Government to prosecute the war expeditiously on an unheard-of scale. The enormous and complex factors involved were prop. erly analyzed, the information was secured, and the researches made, but the unexampled complication of actual administration of the work of carrying out the obrious conclusions and organizing the work brought about the necessity for an executive revolution. Authority had to be highly centralized, so that a few men of decision could 
put the obvious and carefully gathered facts into practice. Indicision and interminable fumbling over the facts were thus greatly reduced.

How important is this matter of the relation of information to action in the psychology of practical affairs was well illustrated by what Dr. Hugo Münsterberg, the famous psychologist, told the author shortly before his death. He related that the Hamburg-American Steamship Line had called him into consultation in the very important effort of correctly classifying all their steamship captains into one of two definite classes: (1) The class which in a serious emergency delayed so long in observ. ing all the points and information about the situation that judgment and decisive action came too late; or (2) the class which rendered a judgment and took action before all proper observations were made and all the im. portant elements of information were in hand. Both of these types of captains were undesirable and lacked the finely balanced and more perfect attitude, which of course, is that of knowing precisely what information is vital, and then immediately upon securing this information taking decisive action, properly based upon the information.

The same principles are definitely applicable to executive action in business.

114. Shaping information for practical business application. - A grave error is constantly made in the assembling and presentation of facts and business research data. It is male to assume the shape of a treatise, a legal brief or an abstract discussion; or it is made with an idea of exhaustive completeness as a piece of work for its own sake. This is a very serious mistake. The making of business researches and the gathering of business infor. 
mation is not strictly a profession by itseif nor is it governed by standards solely its own. Business stand. ards must govern research work to an almost complete degree. It cannot possibly advance the cause of commercial research as a vocation or a thing of value, if academic or other standards are made the ruling consideration. The only ruling considerations must be those of pertinence and effectiveness in achieving the practical business ends desired. Information as information means nothing to business men; compilations and researches merely as such do not and should not mean any. thing to business men. The splendid academic principles of accuracy, thoroughness and devotion to the cause of truth are highly important parts of cominercial research, but they must be engines operated for the definite goals of business. The professor who was hired to improve the English in a business firm's correspondence, and who beld up the mail for a week in order to eliminate split infinitives is the comical example of the academically inappropriate and the lack of practical adaption which is here referred to.

The business man's habit of thought, his habit of reading and manner of absorbing information must be correctly understood by anyone who undertakes to make researches and present his findings. Business men desire to reach conclusions fairly rapidly, and to initiate action and get results at once-they are not at all in. terested in the bypaths or the technique of researches, or in the delicate nuances or the vaguely relevant factors. Time is so all-important in modern business that the very purpose of research is to annihilate time in experimentation, to aroid waste, delay and futility; therefore, a report rendering facts and information must move in 


\section{THE EXECUTIVE APPLICATION OF FACTS 205}

a straight line to specific conclusions from the point of view of the executives. This throws an unusually heavy load upon research workers, investigators and counselors, because the business man is fairly new in consciously coördinating information and data. He has been in the habit of absorbing information and reaching a somewhat unconscious intuitive judgment; whereas the concrete and orderly presentation of facts in detail often paralyzes his will and judgment or floods his mind with so many considerations, facts and figures that he strug. gles in vain to reach a logical conclusion and line of action to follow, with the result that he becomes disgusted with research and information in general, and goes back to his intuitive methods.

Very often the fatal situation is that the business man does not know what facts are desired or what he needs to have, and his investigator or counselor or statistician has not the practical analytical vision or viewpoint to make the selection of information really pertinent and important, or to analyze it and translate it into terms or action when he does get it. For this reason hack sta. tisticians and mediocre unbusiness-like investigators and researchers are definitely proved a failure. It cannot be too strongly stressed that the situation calls loudly for the best brains, not the poorest; the finest business ability, not ill-balanced theoretical minds. Research work calls for men of the highest degree of training, in. telligence and practical insight rather than the type of statistical book-worms, one-track minds and misfits who in the past have taken up commercial research. This fact is now thoroughly realized by all the large concerns who are paying very large sums indeed for investigation and researches, because of the manifest absurdity of basing 


\section{BUSINESS RESEARCH AND STATISTICS}

vital policies upon the findings of men inadequate to the responsibility of weighing facts so important.

115. Co-ordinating a plan of action from facts.-It is deadly folly and extravagance to make investigations, hire counsel and secure surveys and reports only to read them and stick them into pigeon-holes. Yet this is a fairly common practice. Sometimes it is due solely to the general blurred impression which such a report pro. duces, and a lack of a summary of specific lines of ac. tion recommended. In other words it does not put something up for decision immediately.

The first point in the technique of making practical value of information is to get clearly and concisely before the individual executive or group of executives the exact steps of action which the logic of the facts makes desirable or expedient. Then, point by point, the specific recommendations can be debated, their soundness tested in the light of the supporting facts, and a definite conclusion reached. The exact manner of carrying out the recommendations, the time, and also the presentation of detail orders and plans for the coördination and organization necessary to make such a plan an assured suc. cess, are sometimes necessary in properly presenting a set of recommendations.

To reverse the consideration of this subject, it is frequently important that a proposed plan of action be analyzed from a point of view of vision, imagination and foresight. In other words, the report may counsel delay of action in order to make examinations and researches of the facts and general conditions in order that the ad. visability of any action whatever be properly determined, or the best manner of procedure be worked ont. In fact, this is by far the most usual and also the most healthy 


\section{THE EXECUTIVE APPLICATION OF FACTS 207}

application of the business research and statistical and analytical methods. In such a case the outlining of pos. sible plans of action or recommendation are prepared in adrance and investigations made and information secured in order to determine if and how such action is to be undertaken with the largest chances for success. It is not infrequently the case that a considerable number of investigations are pyramided one on top of the other, increasing in scope and accuracy of aim as the knowledge developed by the investigations make advisable. Many first investigations are necessarily gropings and searchings for some substantiation of intuition or im. agination or a projection of logic. In this manner investigations and actions become practically right and left-armed, proceeding simultaneously, the one correcting and guiding the other. Such a method annihilates time very rapidly, and althougl 1 it is by no means free from a margin of error, it gets closer to $100 \%$ accuracy than any other method. Other more cautious and leisurely concerns take a year or two for exhaustive preliminary investigations before any action is decided upon, and then only after experimental "try-outs."

116. The test or try-out mode of application.-In the mailorder business, which is so situated as to render almost perfectiy exact records and tests possible, it has for years been the logical thing to make preliminary tests based upon statistical arerages, and thus decile almost with the exactness of actuarial statistics such as insurance companies use, the probable percentage of results within a narrow fraction of error, and thus to a large degree avoid waste and futility.

In a general way, this method has become available in all departments of business to a large logree, and is 


\section{BUSINESS RESEARCH AND STATISTICS}

rapidly spreading in application. The tryout idea may be applied, under careful research guidance, to such business matters as:

1. Tryout of product on various selected groups of consumers.

2. Tryout of dealer and distribution opinion as to sala. bility and strength of market.

3. Tryout of various methods of distribution.

4. Tryout of various methods of introduction.

5 . Tryout of various methods of selling.

6. Tryout of various forms of advertising or modes of appeal.

7. Tryout of various territories, classes of consumers or grades of cities.

8. Tryout of campaign ideas and plans.

The tryout idea is only as valuable as the brains di. recting and analyzing the results. Tryouts, like statistics generally, may be manipulated, consciously or unconsciously, to prove anything. When very painstakingly analyzed they are of enormons value, as they can be made absolutely reliable indicators of results when operated on a wider scale.

117. Coördinating the experience of other business firms. - It is one thing to get the experience of others for sturly and consideration, and another thing to make use of it. For generations business men have flouted the idea that the experience of other's could be of benefit to them, by the simple assertion that their business was "different." Of course, all business is different and no two concerns are identically alike in all respects. Neither are two human beings alike, but this has not dismayed merlical research. Business has adranced so far from this narrow point of view, that shrewd men have delib. 
erately studied businesses representing their absolute opposite, remotely unlike their own, to find possible light on their problems. In fact many brilliant ideas in business are the result of such reasoning by analogy from the methods and experience of others in totally different business fields. To make the fullest use of experience, then, reqires originality of thought, adaptation and openmindedness.

It is an immediate temptation to decide that a suc. cessful method used in another line of business is unus. able; but the cautious mind will resist the temptation to reject, knowing that simply because it is new in that field there is a tendency toward rating it valueless. Careful adaptation may make it an even more brilliant success in the adapted field than in the original field. It is part of alert business methods to maintain a constant degree of novelty. Such novelty is impossible to maintain without a constant scanning and searching anong all types and kinds of business experience.

There should of course be sounded a warning that there is a strong tendency for concerns to rate their methods and experiences as successful or at least extraordinary in some manner, whereas the actual facts when carefully investigated may be that their experience or methods were not nearly so successful, and perhaps even a failure. It is also a tendency to be guarded against, to rate a method or a plan which another is using, as a success before it has run its logical course, and before it is possible to judge its real success or failure. There is a human weakness to think the other fellow's methods more right and more successful. Sometimes, with malice or forethought, in order that competition be misled, firms let it be known that certain methods are successful or 
that certain facts are the case about themselves, whereas quite different situations exist. This possibility alone demonstrates the importance of making a serious work of analyzing the experience of other's, without depending upon the haphazard commonplace methods of inquiry, or upon careless periodicals or business elub speeches, which are quite generally characterized as "hot air" and known to be intended to create impressions contrary to or beyoud the truth.

118. When judgment advises disregard of experience of others.-There is in certain situations still another reason for ignoring the experience of others quite separate and distinct from the possibility of that experience being false or inflated. There are many examples on record of concerns who, although they have carefully studied the experience of others, have nevertheless then decided deliberately to ignore the lesson that such experience seemed to disclose. The decision may be to proceed where the experience of others would indicate likely failure; or to withdraw where experience encouraged to proceed.

If a business man should thus fly in the face of all the experience available, simply from sheer stubborness or perversity, the action would merely be stupid. However, business is a field in which the alert and the aggressive are constantly doing the things that nobody ever did before. What was impossible to do yesterday may perhaps be possible to-day, or vice versa. That was a failure yesterday may be a success to-day because of the new tools and methods that are available, because of additional margin of safety, capital, markets available, etc. Sometimes it comes down to nothing else but sheer nerve and courage, based on the logic of the plan and its well 


\section{THE EXECUTIVE APPLICATION OF FACTS 211}

calculated probability of response. In matters of business things "turn upon hairs." One set of men may operate a plan and fail, and another set of men may operate the same plan and succeed. The personal qualities of courage, energy, ability to win confidence, personality and hard work may bring success to a good plan-or even to a mediocre or poor plan. To ignore the lesson of experience, and depend upon sheer logic calls for the highest kind of comrage in that it usually means the expenditure of a great deal of money; and of course it calls quite especially for full investigation and all possible facts in order to make the step more sure.

It was once popular to call business a gamble. There are still some business men who are hypnotized with their own infallable record of business success, yet whose series of successes are only the preliminary to a gigantic failure. To know when to disregard experience and to know when the logic of the situation or the psychology of the market are ripe for new and untried articles or nethods is a merehandising ability which though once dependent largely upon a so-called merchandising instinct, is now to a far greater degree a matter of fact study. 


\section{CHAPTER XV}

THE DOLLAR AND THE BUDGET IDEA IN BUSINESS FINANCE RESEARCH

119. The value of focusing analysis upon the sales dollar unit.-There are at work in business tendencies of diffusion of attention and interest in the analytical study of business results. When the general totals and separate totals and statistics of operation are examined, their relation to one another from the point of view of critical study is lost because of relative magnitude.

To bring the entire business into a small enough focus, yet exactly correct, is a matter of great value. The dollar is the logic unit upon which to focus, for many reasons, but chiefly because it is the general unit of measurement of finance, and because it represents 100 cents and thus permits a parallel reasoning in per cent as well.

As business research must occupy itself practically with profit and loss and assist in the analytical process aiming toward reduction of operating costs and increase of profit, a close look at this subject is of definite value.

Every single dollar of gross income in any business represents, when divided up, so many pennies for material, so many for labor, so many for administrative cost, so many for sales cost, so many for advertising, etc. The remaining pennies (if there are any) represent profit.

A delicate balance of pennies and percentages in each dollar must be maintained to come out right. You can- 


\section{THE DOLLAR AND THE BUDGET IDEA 213}

not come out right at the end of the year unless you plan every step of that year. The old way was to examine the status of the business at the end of the year, when all is over-a post mortem, so to speak! The new way is to plan for the year in advance.

120. Safeguarding the dollar with the business budget.Although mainly railroads, governments, etc., have in the past used the complete budget idea, nevertheless everyone in business uses the budget plan though frequently does not realize it. The full-fledged budget plan of operation is now rapidly being applied to business.

The object of the present day Business Budget is to so carefully gather together and coördinate the plans, estimates or forecasts of a business that whether they have been carried "in the head" or in the books, the most ex. act, complete and successful plans for the business may be made for as long in advance as possible. It is in effect establishing a fixed railway time table for the arrival of a fixed ratio of profit at the end of the year. It is, in a sense, "dollar dispatching" to safeguard the dollar on its journey toward profit.

By handling as a systematic whole, the budget details which every busine s has in some form, future plans can be departmentized and may be easily checked up periodically, monthly or even weekly, to ascertain whether each and every department is reaching or exceeling the goal set. The bulget makes it possible to take steps to adjust any differences immediately, rather than when conditions become so unsatisfactory as to force special attention to them.

No change of general methods or even figures or details are necessary to operate on the budget system, but merely a systematic coürdination of all known factors 
and figures, and properly marshaling them. The task is hardest at the start of budget operation, but thereafter is largely automatic and highly labor-saving, greatly facilitating research of management factors among other things.

The getting together of such facts and figures as are needed in a budget often points the way to adjustments and improvements of great value to the business, entirely aside from the benefits of the budget proper. Researches are very timely just prior to fixing upon budget figures, as they can help shape the policies behind the budget changes.

All old methods should be placed under scrutiny and discarded if unsatisfactory. The entire operative costs and methods should be reviewed and analyzed.

The budget should be based on a proper relation between the past and the future of a business and to plan with possibilities of the future in mind, even to a certain extent, the years to come.

121. Psychological side of the budgeted dollar.-Aside from hard business facts, there is a psychological side to the forecast of proposed or budgeted quotas of business for the year. It sets definite goals, rings alarm bells automatically when any subdivision goes off the bud. geted track, and makes researches peremptory to locate causes.

The stimulative effect of a properly planned and operated budget is undoubted and complete, reaching to every capillary of the business organization. Depart. ments vie with each other, and general divisions of the business work for the best showings, and even individu. als are made to work with a more accurate sense of di. rection. 
The posting of the standing of the various divisions and departments gives a contest character to the business which is relished by all human beings and which threatened to become lost through the size and complexity of the business.

Even to the executires and hearls themselves there is a psychological stimulation in a simplified visualization of the business through analysis of the dollar and the use of the budget.

122. Typical divisions of an expense budget.-The accompanying table graphically illustrates the finally accepted divisions of each sales dollar among the divisions and sub-divisions of a typical mercantile business. It also shows the pennies of profit for which all divisions and individuals strive.

Also, there is used in analysis of the budget, a form showing:

1. The proposed or budgeted figures accepted in full for the entire term of the budget (usually 12 months).

2. Actual results achieved to date by each division and, preferably, also their per cent of the corresponding budget figures.

Corresponding figures, for the past year or an average of several years, may also be shown, but are not in any way essential to the complete comparison and analysis of current results.

Whether a hudget is a sub-budget or master budget (gathering together arid showing the results of the subbudgets), the same general plans and divisions are followed and the same three main divisions-mounction, marketing and administrative-remain the same, and only the sub-headings or the sub-divisions of the busi- 


\section{BUSINESS RESEARCH AND STATISTICS}

ness are altered according to the needs of the particular business being budgeted.

It will be seen how inducive to investigations such a budget plan is, as the first wavering variation in "budgeted" and "actual" immediately sets up query "why?"

123. Some business finance inquiries.-A tendency prevails toward too much concentration of the investigative method upon sales problems, and a slighting of the value of research into what were once the private sanctums of the old-fashioned banker.

Business finance is somewhat different to-day, and is more clearly understood in principle. The financial relationship of business honse to banks, customers and to the requirement of the business under differing conditions are now considered in more detail. A new profession, that of "finance manager" is developing, which expands the old narrow conception of the treasurer or auditor, and provides for greater initiative, investigation and study on the part of the man responsible for the finances of a business.

There are many researches which the financial heads of businesses are making at the present day. They are refusing to consider financial matters a mere following of precedent in an uncreative way.

The following are some researches which have been made and are being made:

1. Study of the adaptability of trade acceptances to various types of business.

2. Analysis of efficient voncher systems.

3. Study of the application of the budget system to business.

4. Analysis of good will capitalization and treatment in accounts. 
5. Investigation of most efỉcient methods of financing contracts and special classes of business.

6. Analysis of best methods of handling bank ac. counts to secure most favorable credit accom. modations.

7. Study of best methods of securing additional capital.

8. Study of cash discounts and terms under various conditions.

9. Amortization methods in business finance.

10. Methods of handling surplus funds to best business advantage.

There are now available business finance counselors on an entirely professional basis who analyze questions of business finance with the aid of business research, just as any other commercial problem is handled.

124. Analyzing the consumer's dollar.-While studying the dollar as a business unit, from the angle of business research, it is pertinent also to study the consumer's dollar as well as the manufacturer's sales dollar (representing only wholesale price). Such an inquiry has equal pertinence here as a distribution analysis, as it is part of wise business finance planning to consider the consumer dollar.

William H. Ingersoll, marketing manager of R. H. Ingersoll \& Bro., has written clearly of the consumer dollar, illustrated with a circle chart which makes the matter graphic and instructive.

This chart, explains Mr. Ingersoll, represents diagrammatically the results of an inquiry made in the early part of 1916. The products of 40 typical factories producing foods, drugs, hardware, supplies, fuel, honsefurnishings, clothing, jewelry, shoes, dry goods, notions, au- 
tomobile supplies and sereral other lines, were traced from maker to nser through large and small stores widely scattered. The observations were reduced to composite averages and are exhibited in the chart before us. The

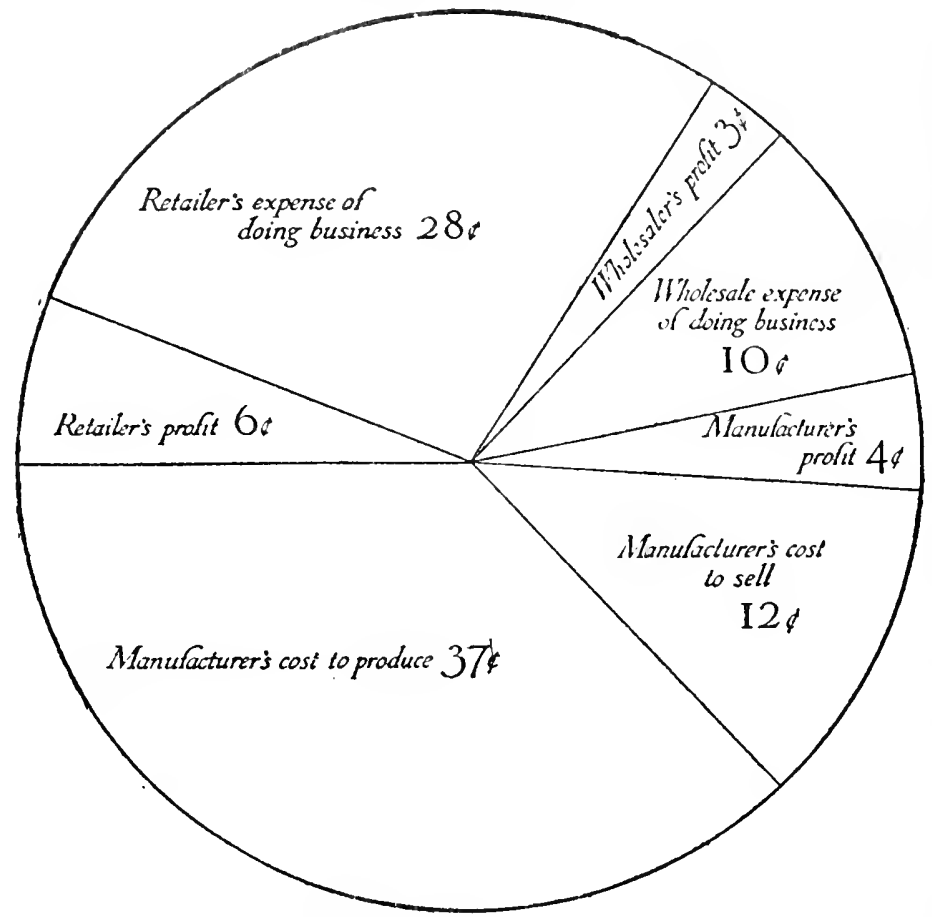

effects of the European war in the form of increased operating costs are shown in the figures, yet there is not a wide discrepancy between the retailers' expense of doing business at this time and at the time of the investigation. The consumer's dollar thus dissected reveals unreasonably heary expenses, in distribution, but the profits of the middlemen are not an unreasonably heary burden upon the consumer. 
The retailing profit of six cents remaining after the operating expense of 28 cents is deducted from the gross profit of 34 cents out of each dollar taken in, would pay a return of $\$ 1,800$ a year on the ordinary store's volume

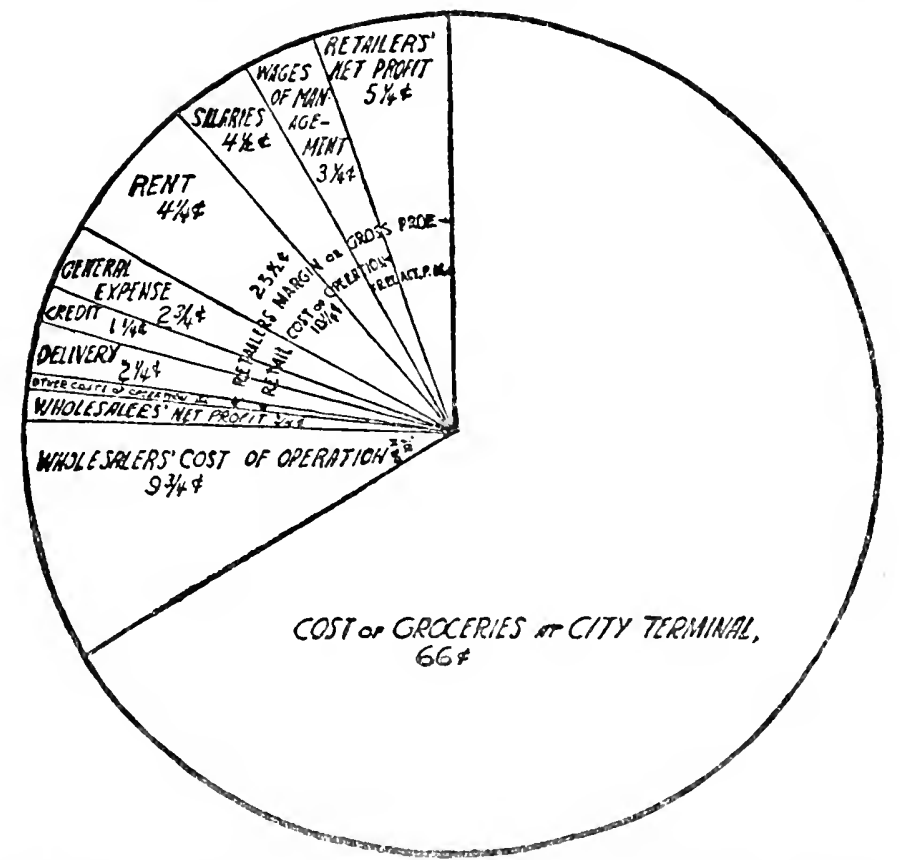

of $\$ 30,000$ sales. This is sightly less than $\$ 9.5$ per week, and considering a usual investment of from $\$ 5,000$ to $\$ 10,000$ in the business and the risks taken, it is a modest reward for the services to the community and with interest on investment subtracter amounts really to less than 830 per week, which is less than the skilled lahorer frequently receives for shorter hours, less anxiety and without risking his money in the enterprise.

For purposes of simplification in the diagram, frac- 


\section{BUSINESS RESEARCH AND STATISTICS}

tions of cents were discarded and the nearest whole number taken. Thus the wholesaler's profit shown as three cents really figured to be only a trifie over two and a half cents. But taking it at three cents, and adding

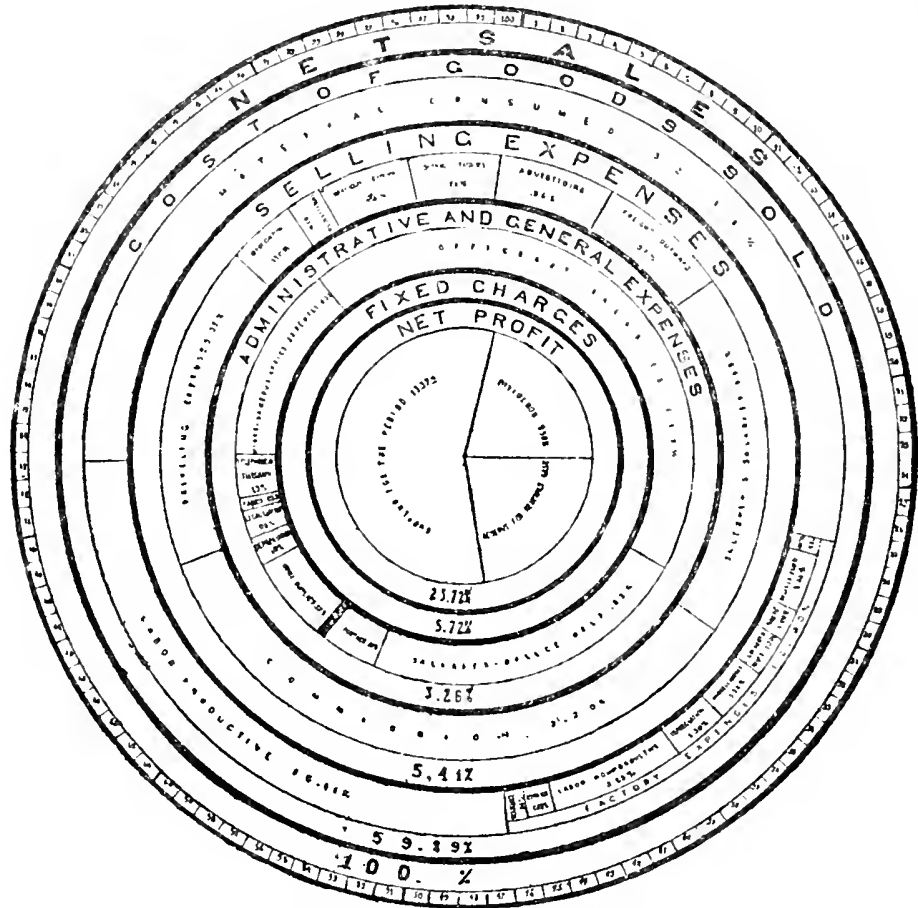

the retailers' six cents, we have the total of those two middlemen as nine cents out of the consumer's dollar.

The most then that any scheme of saving middlemen's profits could hope to attain would be to save a part of this nine cents. Interest on investment and salaries of managers in place of the proprietor's profits would necessarily reduce the amount that could be saved. Only a narrow saving could possibly be looked for. 


\section{CHAPTER XVI}

\section{INQUIRIES INTO MANAGEMENT PROBLEMS}

125. Management researches as distinct from others.Less is known, comparatively, of management than any other division of business activity. Judged purely by results, management, in the average understanding of the term, is a failure the world over. Mechanical wonders, scientific wonders, chemical marvels there are galore, but the science of management has yet to rise to the technique of an approach to scientific method. It is in its infancy.

Business organization has not only had to deal with far greater aggregations of workers than ever before, but it also has had to deal with personalities far more intricate and self-willed than ever before. There being no longer possible a refined species of enslavement and exploitation of workers, management becomes more and more a study of personality, humanities, spirit, organization, function, authority, responsibility, courtesy, stimulation, leadership, development, reward, etc.

Such matters are evanescent and intangible, and like other such subjects they are clustered about with dispute and dissention by fanatics, theorists and misguided enthusiasts with special recipes. For ten years there has been witnessed the spectacle of every form of "black art" being practiced in the field of business management -phrenology, therapy, pauedo-psychology in a dozen or more pompously phrased guises; semi-technical and 


\section{BUSINESS RESEARCH AND STATISTICS}

semi-fanatical doctrines, and fallacies of many forms, colors and types. Such an evolution is always to be expected in the development of a new field of knowledge. Medicine, astronomy and other sciences went through their black art period.

Good management, properly defined, is the work of coördinating the work and workers of an organization into a correctly functioning whole, producing results at a low unit cost of effort, time, materials, money and friction. The human body is a well nigh perfect example of good organization, and an effective human be. ing is an example of management, since he represents a high degree of coördination of many parts toward a specific result, with a minimum of effort.

This point of riew of management is of value in attaining a perspective for research of business management problems, which like any other problems, respond to careful, minute analysis of specific problems. Specialized studies and inquiries are the logical methods of attack upon management difficulties.

126. General administration researches.-So many hundreds and thonsands of live business firms face similar administrative problems, and such a considerable number are spending money to learn how to deal with the more lifficult ones that it is obvious how researches into such experience must be very profitable. Trade maga. zines have served to some extent in this direction but are under many and severe handicaps of space, diplomacy of publicity, expense, etc, which preclude adequate or thorough researches into many important subjects. Inter-visitations of executives, interchange of courtesies, club and organization meetings have helped somewhat, but of comrse the correct and somnd method is that of 
serious compilation and research into such problems, working ont careful records of experience, failures, successes, etc., with general analytical conclusions. Already a great deal has been accomplished. Some of the subjects which have already been given attention by researchers of general administrative problems are:

1. Types of Departmental Organization Best Fitted to Certain Requirements.

2. Methods of Laying Out and Planning Offices Efficiently.

3. Branch Office Organization and Control.

4. Standardization of Salaries and Promotions.

5. Setting of Work Standards.

6. Report Systems for Executives.

7. Choosing and Rating Executives.

8. Study of Letter Writing Cost.

9. Elimination of Useless Records.

10. Analysis of Unit Costs of Administration.

11. Methods of Stimulating an Organization.

12. Profit Sharing Methods and Plans.

13. Democratic Plans of Control.

14. Suggestion Box Methods for Employees.

15. Inter-Departmental Communication.

16. Pension Systems.

17. Inquiry Into Best Methods of Managing Women Employees.

18. Elucation of Employees.

19. Welfare Work, Its Value, Dangers and Defects.

127. The serious need for labor study.-Here is an almost endless field for research. Never before in business history has there been such a focusing of attention upon labor as to-day.

World war has tilted the scales of advantage from 


\section{BUSLNESS RESEARCH AND STATISTICS}

capital to labor. Whereas money was once the decisive element of power, now primitive military struggle has placed decisive power upon numbers, upon human bone and muscle. "ifter the war," said Dean Inge, "labor will determine whether England will sink or swim," and his prediction seems in process of fulfillment. Sir Edward Carson says incisively and correctly that labor will never return to pre-war conditions.

Why, indeed, should it? Why, indeed, should anyone with psychologic vision and human understanding wish for such a calamity?

The world is awake to a new meaning in organization. A whole world has not fought shoulder to shoulder, black, yellow and white races in the same trenches, without learning much new lore concerning how to harmonize and humanize for the doing of great common tasks.

What is it that war has been teaching us about a new labor generalship? Exactly the same thing that industry was already teaching to the few who cared to learn, long before the war started-that labor problems must be settled by close study of the psychology and point of view of the laborer, not by the point of view, however philanthropic and kindly, of the employer.

To one who has given specialized attention to the psychology of the worker, it is ludicrous but more often sad how many and fatal errors are made in dealing with labor, even under the best of intentions and with numerous paid welfare workers assisting.

The first great error has been in regard to labor as a commodity. This is an unpardonable sin against human psychology-an error which modern research might have long ago established, if research had been a part of business. As it stands, the researches were made by 
non-business interests. For centuries without number, men with money have brutally used it to buy labor as they bought stone and mortar and wood. Most books and ideas of economics until very recent years have accepted labor as a commodity and agreed that its price was properly a matter of barter in the market-place. Even our well-meaning welfare workers have discuisseil zealously but coldly sucli subjects as "labor turnover," "labor inventory," etc.-terms lifted right out of the merchandise dictionary and pathetically foreign to a sensitive quivering substance like a human being. Business research, unbound by traditional economic theory, and trained to think about facts as they are to-day, would unquestionably have uncovered this grave error long ago.

Scores of nicely colored, pleasant-smelling panaceas such as profit-sharing, pension systems, elaborate boutus systems, etc., are in operation by proud employers cager to receive plaudits and advertising for their adventures in labor placation. Most of these deserve real credit and praise as they are certainly improvements over the old order. It is even somewhat unkind to suggest that such efforts are merely patchwork and makeshift in place of the true principles so greatly needing to be applied. But it must be said - the times are intensely serious, and in the middle of her greatest national need America has had the worst series of epidemics of strikes the country has ever known. She is reaping a bitter harvest of tares in the wheat because she failed to analyze the soil correctly and treat it in time. We have so miserably fumbled these problems of labor psychology that a British Conmissioner could say to us during the war that if England had had but one-half of our labor trouble she would 


\section{BUSINESS RESEARCH AND STATISTICS}

have been forced to accept a dishonorable peace Iong ago.

What is the true labor psychology, and what must constitute the new labor generalship of the future?

123. Learning from researcl.-Capital must first go to school to see things from the level of the average wage-earner. The best way for capital to go to school is to set up its own school-an enlightened, trained research department and trained special counsel. Capital must cease treating with labor as though it had the same habits of mind as capital. It must operate every plan from the point of view of the average wage-earner, and it must take the responsibility of going behind the worker into his general temperament, hopes and aspirations, home life and weaknesses. It must learn how to stimulate the man and make his life rich and worth while, studying his psychologic incentive quite as carefully as bis time card records, but much more humanly.

It must come to regard it as a black mark against itself to discharge any man for inefficiency, and learn the superior profit in high-grade, trained labor.

It must then begin to build the great future of laborcapital coöperation. It must plan for conferences between the capital and the labor in any specific industry looking earnestly toward the development of that industry. It must encomrage labor to see beyond the rim of class ontlook, and it must sell these ideas to labor on sheer logic and mutual interest. Labor must be led to have the same creative, constructive dream and aspiration as enlightened capital has with regard to its line of work. Labor must be given back its rightful heritage of share and share alike in the great game of industrial progress-it must feel again the flush of power in making fine, big things-which is something that the hugeness 
of modern industrial organization has destroyed. Honor and rewards for success in such broad, constructive progress must be available to the humblest worker as well as to the most exalted oflicial; both their bosoms must be permitted to swell with pride at a piece of work that made industry brighter and bigger.

The industrial generalship of the future will mean things of this sort-it can never again mean mere hugeness of factory, billions of capital, nor tons of product. It must be human progress as well as industrial prog. ress, for without it it is meaningless and distorted, as the collapse of the German industrial Frankenstein has so gruesomely proved.

Industrial generalship must now consist of psycho. logical genius as well as mechanical or financial genius. It must, as Schwab predicts, consent to the greater participation of labor in affairs heretofore subjects chiefly for stiff-necked boards of directors who rotated austerely between bank, stock exchange and directors' rooms and breathed no cubic inch of air of common laboring folk.

We are in new times and the political changes coming over the world afford close parallels to the changes about to cover over the industrial world. Democratic principles rule; individuals must be developed to share in responsibility even if now they seem incapable and indifferent; standards of efliciency and personality must be raised; new dignity must be vested in the human unit and new power granted individual judgment-all in the knowledge and faith that it is now proved beyond all doubt that all other principles of living and working together are finally shattered and outlived.

In these great basic movements and changes in human 


\section{BUSINESS RESEARCH AND STATISTICS}

relationship, in industry, there is no guide but analytical study. Rules o'thumb, panacea's, precedence, experience, tyrannical method, theoretical notions are all makeshifts and costly experiments.

The most economical and wise expenditure possible under the circumstances is to make inquiries, study the experiments of others, compare, investigate and make sound deductions applicable to the case in hand. This is the research method and the only nethod which can give any results until an organized body of accepted knowledge is finally developed.

129. Some specific lines of labor inquiry.-The breadth of scope of the labor subject is well illustrated by the group of special investigations and researches listed below. All these subjects have already been investigated, and data on them is available:

1. Analysis of Extent and Causes of Labor Turnover.

2. Study of Housing Conditions in Relation to the Efficiency of the Worker.

3. Analysis of Suggestion Box Methods.

4. Service Bonus Plans (for attendance, punctuality, and application).

5. Pay Roll Methods.

6. Analysis of Scientific Management Systems; Comparisons and Deductions.

7. Time Study Methods and Applications.

8. Study of Routing Work in Factories fo: Labor Efficiency.

9. "Industrial Democracy" Methods (methods of sharing in management).

10. Employment Test Methods.

11. Employment Department Operation.

12. Factory Cost Accounting Methods and Principles. 
13. Relation Between Production and Sales Departments.

14. Standardization of Shop-Instructions.

15. Health and Hygiene Factors.

16. Fatigue and Rest Periods.

17. Best Forms of Shop Organization.

130. Salesmanagement investigation.-As so many of salesmanagement problems are marketing problems which have already been treated, this division will need to confine itself to problems of sheer management of sales organization. The problems involved in this phase of salesmanagement are numerous enough, and present a more difficult phase than almost any other side of management because of the management of salesmen and distributors. Tremendously costly experiments are constantly being made by business firms.

Very decided profit results immediately from the application of research and investigation to salesmanagement, because there is so little exactness as yet in this department of administration. An increase of one per cent in the efficiency of the sales organization may mean hundreds of thousands of dollars in sales results. A sales organization operates largely on spirit and ideas, and is thus readily amenable to research developments of value.

Among the subjects which are particularly live and generally interesting for research are the following: Automobiles for Salesmen:

Actual figures and facts concerning automobiles for salesmen as against travel by train; statistical comparisons by concerns which have used both methods; methods of routing, express system, service, ownership, etc. 
Brunch Office Methods:

Experiences and methods used in handling salesmen, districting of territory, etc.

Bonus and Compensation Methods for Salesmen:

A 150 page analysis of prize, bonus and compensation methods; and salesmen's contract and commission arrangements.

Correspondence Courses for Salesmen:

Methods in use by firms as to form and delivery, reasons for their use, outlining special plans for study.

Dealer Stimulation Methods:

Study of various methods in use for getting dealers active in selling and coopperating with them; many plans outlined.

Efficiency of Sales Call:

Report on methods of figuring the individual efficiency of salesmen and of rating them accorling to their various factors.

Exclusive Agency and Branch Store Methods:

Study of how Singer Sewing Machine Co., Globe Wernicke and other firms handle agency and exclusive dealers successfully.

Exclusive Wholesale Agency Analysis:

Study of method of operation of exclusive wholesale agencies.

Jobbing Map Analysis:

Study of the grocery field, creating jobbing centers according to size of jobbing business, map $28 \times 24$, marked with colored pins.

Keeping Goods Fresh on Dealers' Shelves:

An analysis of methods of keeping perishable goods up-to-date and fresh. 
Merchandising Plans-Compilation of Successful:

A complete analysis of a great many plans of merchandising and the results of these plans in actual experience. Detailed information on selling plans and campaigns of the country's most aggressive concerns.

Merchandise Quotas-Establishing:

Definite figures and data for figuring apportionment of sales quotas, including a great many statistics and plans.

Missionary Sales Methods:

Analysis of various methods of handling missionary salesmen; breaking open new territory; coöperating with jobbers, developing backward territory, etc.

\section{Price Maintenance:}

200 page analysis of complete subjects of maintaining price; legal decisions, reproductions of agreements in use, etc.

Prize Contest Analysis:

Detailed study for methods used in consumer prize contests through advertising; exact figures of various firms' experiences; legal restrictions, etc. Prize Systems for Retail Clerks:

"P. M.'s" for" retail clerks and jobbers' salesmen; experiences and details.

Sales Bulletins:

Analysis of Sales Bulletins of various firms with illustrations of bulletins in actual use.

Sales Conventions:

Reasons for holding sales conventions, details of methods used and results of such conventions and their effect on the men. 


\section{BUSINESS RESEARCH AND STATISTICS}

Sales Districting:

Study of the different sales districts now used; methods of providing districts; compilation of facts concerning districts.

Sales Manuals

Complete report on sales manuals, giving concrete examples; compilation methods, sample chapters, ideal plan of contents, etc.

Sales Manuals for Dealers' Clerks:

Standard outline of contents, errors and pitfalls to avoid, methods in use for securing the study of such manual.

Sales Organization Chart:

Blue print of ideal sales organization with instructions; notes on best forms of sales organization. Salesmen Handling Advertising of House:

Methods of instructing salesmen in advertising, training them $m_{0}$ making them representatives of advertising department and getting best advertising results.

Sampling and Local Crew Work Methods:

Exact methods of handling crews to best advantage; experiences, successful ideas.

Schools for Salcsmen:

Analysis of the various experiences of firms, small and large, and methods used in conducting sales schools; many details.

131. Office management problems.-At one time in business history the office manager was a mere glorified clerk or time-keeper, and dealt in a few simple routine details. The office manager of to-day is an executive of a high type. He is often more thoroughly alive to the need for researches than executives in most other departments of 
business, because he deals with a great many varied factors, and his practical mind seeks more exact solutions than he finds available.

In practical effect, a good office manager, who grades to his position thoroughly, is an efficiency engineer, a production manager who has a technical task of turning out office work. As there is far less exact technical data available in office management than in factory production and management, there is considerable unknown ground to study. Also, there is capital opportunity for profit through more exact methods of management and the application of brains and research, because of the large amount of details involved.

Among the problems of value to study, and which already have had research effort expended upon them are:

1. Methods of Laying Out Offices for Highest Efficiency.

2. Filing Methods Best Adapted to the Business.

3. Training of Employees.

4. Setting Standards for Routine Work.

5. Increasing Efficiency of Correspondence.

6. Methods of Operating Stenographic or Dictation machine Departments to Satisfy Executive Needs and Peculiarites.

7. System Methods and Forms.

8. Symbolic Systems.

9. Testing and Inquiry Into Office Equipment.

10. The Value of Standardization of Equipment.

11. Efficiency Conference and Committee Methods.

12. Efficient Handling of Incoming Mail.

13. Best Method of Handling Callers and Solicitors.

14. Comparative Tests of Fountain Pens vs. Slip Pens in Office Use. 


\section{BUSINESS RESEARCH AND STATISTICS}

15. Lighting and Ventilation Methods.

16. Bonus and Contest Plans for Office Workers.

17. Tests for Employment of Various Types of Office Workers.

18. Oftice Work Speed, Methods of Measuring and Increasing.

19. Methods of Banking In and Following the Record of New Employees.

20. Time Studies and Scientific Management in Office Work.

132. Research and purchasing management.-Purchasing once went by favor, and is now approaching a science. Where once orders were placed according to the most energetic salesmanship or graft or "pull," now the initiative often comes from purchasing departments after exhaustive tests and researches.

High class organizations purchasing immense quantities of material now employ experts and researchers. One large organization employs permanently an expert steel, an expert wood and an expert paint man who do not take the word of sellers, but test materials not only before purchase from samples, but after purchase.

With the technical researches used in purchasing we will not concern ourselves here, as they are obvious, merely illustrating the strong and fixed tendency toward analysis which exists.

Purchasing management in its non-technical aspects represents still further applications of the research idea. Even in the matter of qualities essential in a purchasing manager there is required some study and analysis.

An excellent conception of the various types of problems, difficulties and special divisions of study in purchasing may be had from the attached list of subjects 
which are now or have been for some time under research:

1. Correct Attitude Toward Sales Solicitation.

2. Purehasing Method and the Organization of a Purchasing Department (Illustrated).

3. Purchasing System and Forms (Illustrated).

4. Relation of Purchasing to Budget Plans (Illustrated).

5. Terms, Discounts and Financing of Purchases.

6. Retail Purchasing Special Problems.

7. Wholesale Purchasing Special Problems.

8. Railway and Public Utility Purchasing Special Problems.

9. Manufacturing Purchasing Special Problems.

10. Purchasing Science in Relation to Basie Tendencies and General Business Conditions.

11. Buying on the Speculative Basis.

12. Purchasing Polieies and Principles.

13. Costs, Turnover and Profits in Relation to Purchasing Science.

14. Purchasing Standards, Inspection Methods and Systems.

15. Inventory and Requisition Methods.

16. The Promotion of Economy and Education of Department Heads.

17. Centralization of Purchase and Its Possibilities and Limitations.

18. Municipal and Govermmental Purchase Reform and Economy.

133. Broad advertising management problems.-Endless varieties of problems present themselves with regard to advertising, which is evolving out of more or less mistery, and has a thousand angles and ramifications. There are more points of contact, more units to deal with, more 


\section{BUSINESS RESEARCH AND STATISTIOS}

unknown factors, more uncertainties and more arts and sciences, methods, mediums and tools involved in advertising than in perhaps any other division of business. In consequence there is a great deal of research which has never been done which is too expensive for most indi. vidual firms to undertake. University researches, fellowships and privately endowed efforts have made attempts with fair success. The American Association of Advertising Agents and the Association of National Advertis. ers, the Advertising Bureau of the A. N. P. A., as well as individual advertisers, or small groups of them coöperatively, have undertaken specialized researches of limited scope. Little of a fundamental type of research is at present being conducted.

Owing to the controlling nature of sales strategy over all advertising plans, merchandising researches have been considered more immediately important. However, fundamental factors of investigation such as the following (to select a few among many) are bound to be studied more in detail in the near future:

1. Analytical Study of Responsiveness to Advertising by Different Classes and Types of People.

2. Study of the Reading Habits of Various Types and Classes of People.

3. Investigation of the Relative Efficiency of Argument in Advertising and the Indirect Appeal.

4. An Inquiry Into the Nature and Extent of the Loss of Advertising Effectiveness Because of Increased Volume of Advertising.

5. Study of the Psychologic Suggestiveness of Various

Types, Colors, Sizes, Shapes, etc., of Advertising. 6. Analytical Study Into the Nature and Operation of Goodwill, Reputation and Prestige. 


\section{INQUIRIES INTO MANAGEMENT PROBLEMS 237}

7. Tests as to Cumulative Effect 'n Advertising; ratio and length of time of development and of Disappearance after cessation of advertising.

8. Relation of Reader Interest and Editorial Standing of Periodicals to Advertising Effectiveness.

134. Technical advertising problems.-The more immed1ately useful types of advertising research which are of Jirectly profitable value are, of course, more numerous and varied. They include technical researches and marketing studies which are indispensable to the success of advertising, and may be partially listed as follows:

1. Analysis of methods of fixing advertising appropriations.

2. Study of comparative strength of various types of media for specified uses; also comparative strength of individual medinms in a group.

3. Investigation of the effects of a campaign of advertising.

4. Tests and analysis of proposed alternate series of advertising.

5. Consumer investigations to check up the strength of various appeals and arguments.

6. Study of dealer attitudes toward advertising.

7. Comparative study of various forms of "dealer helps."

8. Tests and researches on trademark names, name confusion, ete.

9. Studies of reactions and preferences in regard to packages, shapes, labels, etc.

135. Business finance management analysis.-Because of mere routine banking advice, or, as is so frequently the case, no banking or financial advice at all, the business world has long recorded $95 \%$ of failure among all those 


\section{BUSINESS RESEARCH AND STATISTICS}

who enter business. Reasons assigned tell their own story-the principal one is usually "inadequate capital," which is a polite way of saying financial mismanagement.

With bankers narrowly uninformed on the creative operation of business, and business men without sound knowledge of business finance, there is little wonder that modern studies of the subject are opening up much that is new and profitable. Researches and analytical digest of experience and method are now being made by business research workers and definite steps forward are already occurring in business finance knowledge, especially along the line of budgeting business operations and more scientific financing of credits.

Among the items of business finance which have already been receiving study by specialized business finance counselors and researchers are:

1. Analysis of commercial credit relations with banks; methods of buying the use of money most cheaply.

2. Best methods of financing new developments.

3. Most modern methods of operating a treasurer's department.

4. Financial handling of trade acceptances.

5. Most resultful methods of interesting new capital.

6. Operation of a commercial business on a budget plan.

7. Best methods of adjustment of stock control; new security issues, etc.

8. Most modern methods of handling surplus funds.

9. Executive salary standards and methods of adjustment.

10. Operation of speculative side of a business dealing with fluctuating basic raw materials. 
11. Methods of adjusting of price policies, discounts and terms.

12. Best procedure under various financial difficulties. 13. Business amortization applications and methods.

136. Management by investigation rather than hy opinion. -Like the proverbial fallacy of people generally, in thinking they can run a hotel, a railroad or edit a newspaper, so in a measure is the idea prevalent that management is a matter of second nature or inherent ability.

Management, on the contrary, is more of a science than an art, and in consequence no man is ever fully master of the subject, just as no man can be master of any science. It is always in a state of growth, calling constantly for humility before the unknown factors.

A very stimulative point of view along these lines was voiced by Herbert Casson, an American with efficiency training, who has done much to awaken England to her need of more knowledge on management. He outlines what he calls "The Seven Costly Mistakes in Management." They are:

1. The mistake of thinking that authority is management.-Authority is not knowledge. Power is not technique. No matter if you are the sole owner of your business, you are none the wiser because of that.

Ownership is not education. On the contrary, the more you own, the more you must study and learn.

Merely to give an order is not management. You must take the responsibility for that order being properly executed. You cannot merely sit in your chair and say to your employees-"Go ahead. It's up to you."

Management has its duties-this tremendous fact is slowly coming to the front. The coal operators-those duty-dodgers-are finding this out to their cost. 


\section{BUSINESS RESEARCH AND STATISTICS}

2. The mistake of not learning from your own employees.-The employer who always tells and never asks -who has a busy tongue and an idle ear-is cutting himself off from his main source of information.

Usually he is living in a fool's paradise. He does not know the details-the methods-the wastes, of his own business.

$\mathrm{He}$ is not really a manager. He is only Sir Oracle. And presently his employees discover that he prefers flattery to efficiency.

An efficient employer, on the other hand, is always learning from his own people. He has a spirit of teachability, which inspires all his workers to learn more and to do better.

3. The mistake of supposing that the size of a business is more important than its policy.-It is better to have a small business going up than a large business going down.

The most important word in the language of business is not gross, but NET.

Recently an American firm sold $£ 10,000,000$ worth of motor-cars in one year, yet it failed. Its expenses were $£ 12,000,000$ a year. It would have been a much better business if it had sold $£ 12,000$ worth of motors and made $£ 2,000$ profit.

Size is not efficiency. It is not even safety. To rightly judge a firm, you must measure it by its policy and its results.

4. The mistake of substituting a discussion for an investigation.-Is it not true that almost every board of directors is nothing but a mere debating society? Is it not also true that they are concerned more with opinions than facts? 
We are now having hundreds of committees and conferences, very largely because managers in these perilous days are afraid to make up their minds.

We must not think that five or six opinions are necessarily better than one. They may all be quite worthless.

A firm should be run by FACTS, not by talk. No conference can ever take the place of an investigation. If a conference is called, and it discovers that it is not in possession of the facts, it should not proceed to decide matters. It should adjourn.

5. The mistake of thinking that managers, supervisors, experts, staff trainers, etc., are non-producers.-Firms prosper when they have skilled management; and they fall behind when they hare bad management.

It is not labor that makes success; it is LEADERSHIP.

The managing director can double the output by wise management. He can therefore become the chief producer in the firm.

A planning department can double the ontput with the same labor and the same machinery; yet some directors regard a planning department as an expense.

It is not the army that makes the general. That is silly Marxian nonsense. It is the general who makes the army. That is a shining truth that is being forgotten.

6. The mistake of thinking that low uages mean low costs. - This is a natural mistake. It is made by nearly all beginners. But it is a mistake that has caused hundreds of strikes and thousands of bankruptcies.

The cheapness of an article does not depend on its price as much as on its value.

A diamond may be cheap at $£ 1,000$ and brick may be dear at $2 d$. 


\section{BUSINESS RESEARCH AND STATISTICS}

A $\mathfrak{E} 3$ suit of clothes may cost you twopence a day, while a pound suit may cost you only a penny a day.

So a worker at $£ 4$ a week may be worth, as a producer, $\mathfrak{f 5} 10$ s., while another worker at $£ 2$ a week is only worth $£ 2 \% \mathrm{~s}$. You make $£ 110 \mathrm{~s}$. gross profit on the first worker and 2 s on the second.

There would probably be a NET profit of $10 \mathrm{~s}$. a week on the one and a net loss of $4 \mathrm{~s}$. a week on the other.

7. The mistake of getting new buildings and new machinery ahen your present buildings and machinery are being operated at only 50 or 60 per cent of their capacity. - "It is vastly better to double the output of your present works than to double the size of it.

"I have seen many a factory spend a fortune on new buildings and new equipment, when it had plenty of un. used floorage and when the actual working time of its machinery was six hours a day.

"It is a curious fact concerning a board of directors that it will spend $£ 50,000$ on new buildings and new machinery, and yet it will refuse to spend $£ 500$ on efficiency work and staff training, so as to increase the output of its present works.

"I venture to lay it down as an axiom of business that no firm should spend new capital on equipment until it is sure that its present equipment is being used to the best possible advantage." 


\section{CHAPTER XVII}

\section{RESEARCHES INTO THE HUMAN FACTOR AS RELATING TO BUSINESS}

137. The pivotal human element in business.-In all directions in business the human element is encountered. Shese human relationships, possibilities, limitations and developments are the crux and center of business. At the moment of writing the entire industrial world is halted with labor troubles small and large. A "hang over" of war psychology affects the peoples of the entire world and business is in consequence abnormal.

This "human factor" is of course the key mystery for all research, beside which all other research is simple and easy. The increasingly troublesome nature of this human element in business is of course due to the increasing self-consciousness of the human units involved, their increasing education, sense of power and political cohesion, and the increase of desires, standards and individuality. To weld a mass of over 100 million human beings of many tongues and temperaments into a contented, efficient productive machine for mutual profit is a task of human organization straining all the knowledge we may possess.

Added to this as a business problem is the need of the study of consumer psychology and of the psychology of distributors. The entire business program is therefore in a primary way, a program of successful mastery of the human factor. 


\section{BUSINESS RESEARCH AND STATISTICS}

Unfortunately, the human factor is in many ways an unknown factor. We know more about electricity or astronomy or fossils than we know about human nature. Slowly a body of knowledge of a valuable sort is being accumulated, and business men have recognized the im. portance of the problem. The writer is president of the Economic Psychology Association, which is an endeavor of prominent psychologists on the one hand and business men on the other hand to work out together some of the problems involved. Already considerable individual progress has been made by such men as Dr. H. T. Hollingworth of Columbia University, Dr. Walter Dill Scott, Prof. Hugo Münsterberg, and others. General intelligence and special vocational tests were made in great number during the war, thus enhancing modern knowledge on the subject. Some special endowments have been made, and others should be, to facilitate further research.

138. Some uses of psychological inquiry already proved.The use of psychological research is already an approved thing. Extended experiments in many directions have proved of definite value. In fact, psychological laboratory researches and experiments are now on a par with chemical, electrical or physical laboratory testing, for useful and concrete results.

Among the uses to which psychological researches have been put successfully in business are:

1. Salesmen for several concerns have been examined by means of psychological tests, and their test results compared with their actual work in the field for a period of time thereafter. The two sets of data showed a correlation of as high as $90 \%$, indicating that the good salemen could have been chosen beforehand by means of the tests. 


\section{RESEARCHES INTO THE HUMAN FACTOR 245}

2. Measurements of advertisements, in the psycological laboratory, have several times been compared with the actual number of inquiries and sales protluced by these advertisements when issued. The two sets of data show correlations ranging from $75 \%$ to $100 \%$, indicating that the effective advertisements could have been chosen beforehand, and waste thus eliminated.

3. Laboratory researches in advertising have been shown to be so fruitful in practical results that the Advertising Men's League of New York and the Association of National Advertising Managers maintained for three years a Fellowship in Ardver. tising in the Department of Psychology at Colum. bia University, the Fellow giving his full time to research in problems in the psychology of adver. tising.

4. Psychological tests have been found so useful in selecting clerical workers, telephone operators, and other office help that several concerns now use mental tests regularly in their placement depart. ments.

5. A large industrial concern in New England had thirty efficiency experts in their employ measured by psychological tests. Their records were compared with the judgment (independent) of three supervisors who hal charge of the men. The tests and the judgments correlated by $57 \%$, indicating that this particular set of tests could correctly detect the competent efficiency expert.

6. A household commodity, the name and package for which are reported to have been determined in the 


\section{BUSINESS RESEARCH AND STATISTICS}

psychological laboratory, has proved to be a phenomenal commercial success.

7. Psychological measurements of the degree of resemblance and confusion between trade names and trade-marks are now being used in court, and when such measurements are compared with previous decisions they show these haphazard opinion-decisions to be untrustworthy, and to require actual checking up by psychological measurement.

8. Many of the foremost organizations, such as the National Electric Co. at Cleveland, and the Eastman Kodak Co., maintain research psychologists on their staff, investigating such important topics as vision, illumination, color, etc.

139. Psychological problems calling for research and solution.-Wuch problems are almost innumerable, as almost all business problems have some angles of psychological mystery and incompleteness. Herewith are listed a group of problems which give a very wide range of application of the research method.

1. Comparative study of the various methods now used by different prominent concerns in selecting salesmen. How do these different methods work out in practice, how do their results compare with the actual efficiency of the men chosen, what combination of the various methods would perlaps give most reliable results?

2. Thorough psychological examination of each of a group of first-class salesmen and of each of a group of poor or mediocre salesmen, for the purpose of learning what the characteristics and traits of the first-class salesmen are,-what type of personality, intelligence, temperament, etc. 


\section{RESEARCHES INTO 'THE HUMAN FACTOR 247.}

3. Formulation and trying out of a reliable set of mental tests for the selection of competent salesmen, clerical workers, ete.-tests which shall be more direct and more reliable than the randum methods now used.

4. Similar attempts to discover reliable tests for the selection of and detection of competent stenographers, typewriters, secretaries, etc.

5. Similar tests for selection of executives and also operatives such as telephone operators, inventors, machinists, etc.

6. A study of moving advertising signs and moving window and shelf devices, as compared with sta. tionary devices,-determination of their relative merits and advantages, the most desirable types, their defects, etc.

7. Study of standard pages and flat pages with advertising next to reading matter. At present no one knows the rative value of these forms, and it should be accurately determined, for the sake of the advertiser, the publisher, and the public.

8. What is the most economical distribution of work and rest for different types of work? How much does this vary with the individual and the type of work? To what degree can general rules of practice be formulated?

9. Discovery of tests which shall measure such important traits of personality as persistence, competitiveness, ingenuity, inventiveness, and similar traits, in some such way as "general inteliigence," can now be measured.

10. A sturly of the influence of mild doses of drugs (such as caffein, nicotine, etc.) on the efficiency of workers in different types of work. 


\section{BUSINESS RESEARCH AND STATISTICS}

11. Reliable and accurate measurements of the degree of confusion between two trade-marks or trade names, so that the question of infringement need no longer be a mere matter of opinion of some judge or commissioner.

12. A study of the relative legibility of different kinds of type, and selection of the most easily read and least fatiguing type face.

13. Studies of the influence of time of day on such factors as efficiency, fatigue, accidents, death, etc. 14. Studies of the influence of temperature, ventilation, etc., on the ability and efficiency of various kinds of workers, in factory, shop, store, office, school, etc.

15. A study of men, women and children as purchasers. What do the various groups buy, as a matter of fact? How can each group be best appealed to? What differences do they display as purchasers?

16. A study of retail selling (selling over the counter) from the psychological point of view.

17. To what degree can one judge character from photography? How much value is there in the common practice of requiring applicants for jobs to send photographs? Can one judge some traits, but not others, from a photograph?

18. How reliable are letters of applicants as signs of ability of different sorts? No one has ever made a study of such materials, yet they are relied on daily in selecting applicants.

19. What traits should be inquired about in requests for information as to the qualifications of applicants for different kinds of work? Are people's iudgments of some traits more reliable than 


\section{RESEARCHES INTO THE HUMAN FACTOR 249}

their jndgments of other traits? How much do different people differ in their judgments of the traits of others? Are some people better judges than others?

20. A study of functional periodicity in women and a determination of the degree to which it interferes with their efficiency as a matter of fact. Most opinions of this matter are mere supposition, and the problem should be investigated experi. mentally and accurately.

21. Educational Qualities Used in Business-study of the qualities of use or of hindrance in busi. ness activity.

22. The Psychology of the Public's reading habits; amount, character and tendencies of the reading propensities of people.

23. Study of Public Prejudices-how formed and how it operates.

24. The Psychology of Esprit de Corps in business or. ganizations.

25. The Psychological Effects of Specialization.

26. The Employee Attitude of Mind; to what extent there is a recognizable state of mind developed as a result of employment under supervisors.

27. Buying Characteristics of the Public-study of traits shown in the purchase of goods by consumers.

28. A Study of Prestige-its elements and its development.

29. An Analysis of Inefficiency-what are the mental traits and characteristics of the chronically inefficient? 


\section{BUSINESS RESEARCH AND STATISTICS}

30. Various special problems could be undertaken as proposed by individual members of the association,-questions bearing immediately on their particular interests and businesses. 


\section{CHAPTER XVIII}

GRAPHIC CHARTS AND MAPS AND THEIR PART IN RESEARCH

140. The average executive's need for graphic methods.Statisticians, bookkeepers, auditors and all who habitually work with figures, develop a special faculty of reading figures quickly. It is their language-they have a life long training at it. Even they, however, are incapable often of seeing figures in their proper perspectivesimply because they are so close to them.

But the average executive, or member of a board of directors is entirely helpless to grasp the correct relationship which figures are supposed to give, without a great deal of time and special care. Figures are brain energy wasters because they do not provide an eye-meas. ure of differences and relationships-they compel the use of a mathematical imagination--which few people have to any well developed degree. Yet, even to one who has a well developed faculty for figures there is a limit to which a human brain can go in grasping ideas represented by figures, because figures were never meant to convey ideas, and to require them to do so is to greatly strain their capacity and limit the understanding of the reader of the vital ideas and facts which those figures would have to show if they were assisted by the graphic method.

Here is a typical illustration of how the head of a company came to use graphic methods extensively: 


\section{BUSINESS RESEARCH AND STATISTICS}

The president of the company expressed decided annoyance one day when the auditor brought some statistics on large sheets, which baffled him to grasp properly. "For goodness sake, man," he exclaimed, "find some way of showing me something without making me choke trying to swallow a barrel of figures!"

The auditor grumbled something about how some folks were like children when it came to figures; but he knew an ultimatum when he came up against one, and he consulted special counsel at once to help give his boss some easy way to understand the currents and cross-currents of finance, sales, costs, etc.

To-day that president slips in his breast pocket each week-end a special loose leaf binder holding as many as a dozen or twenty graphic charts of uniform size, from which he can get his bearings about many aspects of the business, almost instantaneously. $\mathrm{He}$ is able to detect tendencies in the trend of the business, while going uptown in his car, which he missed after pouring laboriously and fretfully over masses of figures. He is now given some glimpses of side aspects of his business which he thought he never could take time to look into, and which, he is constantly surprised to discover, have a far more important meaning than he ever imagined they could have.

Just for instance, he overheard something one of his salesmen said one day about deciding to "make a cooler place and a more comfortable hotel over Sunday." The more he thought over this apparently commonplace remark, the more he became convinced that there were things back of it which he ought to investigate. How much extra traveling expense was it costing him to keep his salesmen personally comfortable? How many first 
class prospects were sidetracked to accommodate the personal notions of salesmen?

So he had a chart made showing the percentage of long jumps made by his fifteen principal salesmen. The result was revelation-also revolution.

As a result, this president is almost a crank on the subject of the use of graphic charts in business. He won't look at sheets of figures. "I must see a group of figures in their proper relation and perspective," he says, "I am not a high dimension mathematical wizard to whom figures are pictures-I can judge them only when they are delineated in relation and contrasts such as my eye and ordinary brain are accustomed to. Why torture my brain with the cumbersome way, when the graphic way is so much bntter? Scientists and engineers who must deal in complicated subjects long ago gave up trying to grasp a situation from a mass of loose figures-they developed and perfected the graphic chart. Business is getting more and more complicated, and yet a man in my position very much needs to keep his finger on the pulses. The smallest detail, in a large business, often yields the easiest profits. I have saved $\$ 60,000$ a year in the past three months throngh detecting things I could never have time to study but for the graphic chart."

141. Research and analysis made easier with charts.Fundamental facts are made clearer and easier to see as soon as charted. The general manager of a great pack. ing house in the west, noted for its intensely close study of detail, one day asked for a graphic chert depicting the "valley" in the load-carrying career of the company's privately owned refrigerator cars: and of course notel that more than half of the time many of these cars were empty-either on the side-track or en-route home. Next 


\section{BUSINESS RESEARCH AND STATISTICS}

he had prepared a geographical chart showing the loca. tion of the cars while empty. Then, after studying the most abundant products of the regions affected, he acted. "Prepare a fruit canning and preserving factory," he or. dered. "We can fill our empties with fruit coming back and therefore shave off costs enough to underbid the average canner and preserver." This is the explanation of the strange anomaly of pork packers beginning to sell preserved fruits.

Of course, charts are frequently used for simple things which everybody thinks of, such as the relation of costs to profits, but this is simply dipping into the possibilities of the method. They are too frequently looked at as toys or novelties and not as working tools, as they might be. An interesting thing about the systematic use of charts is that matters formerly dull and meaningless become invested with deep interest.

Take the matter of "Cessations" in a sales offce. A certain world famous concern discovered not so long ago that during the year past it had lost 1,100 accounts with retailers. This was not an alarming percentage when contrasted with past years, and nobody around the oflice had thought it particularly worth while noticing until a graphic chart was made showing the relation of new accounts to cessations. What had snugly been regarded as progress then came embarrassingly close to mere "hold. ing on." The general manager ordered an investigation -another graphic chart, to show causes of cessations. But the auditor reported inability to get at causes, because in most cases none had been reported. When the general manager went a good many feet up in the air over this, the whole sales staff was grieved at what it considered a tempest in a teapot. But to-day that con- 
cern requires the most thorough reports from its salesmen on the road. This makes considerable detail work necessary; but the company is proceeding with full light on every step made, as a result. Graphic charts are now possible once a month, showing the details of cessations. The reasons why dealers quit are now so geographically available that when the credit department incurs enmity by being over-drastic in collection, or when the shipping department is "falling down," or when the factory is making goods "off standard," or when com. petition is dereloping strength, the exact facts in ratio come home to roost conspicuously on the graphic chart, in very short time.

Before the time of the charts or salesmen's reports, any one of these things might have been sapping the firm's success for months and years before discorery. Scores of concerns hear nothing from their salesmen when a dealer turns him down, whereas the reasons for his turn downs may be quite as important as his orders, in shaping manufacture, sales and advertising policy.

But graphic charts are valuable not only when analyzing details of honse business, but also in studying related things outside.

142. Charting sales and advertising factors.-A certain salesmanager grew tired not long ago of hearing his district men report "depression" and "slackness" as excuses for lack of orders. They would sas, most convincingly, "Why, it's really lucky that I've done even as well as this. You have no idea how dull things are in onr town." The alert salesmanager, knowing that depression was in truth a general factor, nevertheless felt dissatisfierl. He had prepared a series of graphic charts, one for each district, showing a composite line averaging the bank clear- 


\section{BUSINESS RESEARCH AND STATISTICS}

ings, building activity, etc., then he bad laid on these charts the record in sales of the district managers, to make a contrast and comparison with the line showing average business conditions. Whenever a district man's sales-line ducked under the line of business conditions he got a letter asking for an explanation, and when they soared above appreciably he got congratulations. The recipients of the latter kind of letter were tickled, and talked about it, and the entire selling line was gingered up by this simple fact-method of keeping tab. The honest men were relieved to know that the boss wouldn't accuse them of excuses if they were hit by special dullness; and the professional excuse makers were spotted beautifully.

In the advertising office especially wide use of the graphic chart is profitable. For instance, there is no more graphic method possible to show the proportioning of an appropriation, either exhibit to house executives, directors, stockholders, or to dealers as part of a campaign-than to divide a circle into segments of calculated ratios for each subdivision of expenditure (see illustration). It instantly masses for the eye the ratios of expenditure, and proves an effect far more positive on the mind than any table of figures would.

Again, the graphic chart affords a graphic method of studying the relation of results to expenditure. By plotting a line to represent cost of all kinds of advertising, and plotting on top of it another line, coördinated in value to the other, some valuable deductions are possible.

Season charts, indicating when the "valley of lowest results" occurs are very suggestive. So are charts showing the upward or downward movement of the rating of the dealers being stocked (to show whether the goods is 
going into the bigger or the smaller stores). Sometimes sales-staffis unconsciously get into the habit either of ignoring the small dealer or inversely "get scared of the big fellow and going for the easy one." Charts showing dealer's arerage monthly or annual consumption; volume of trade per 1,000 population in any section (or group of sections contrasterl); volume of purchases contrasted by class of customers or class of dealers-these are pretty sure to give rich food for thought when studied. Charts contrasting the fluctuation of profit with fluctuation in selling expense and cost are really vital. Such matters really cannot be studied more effectively in any other way excent by charts.

143. Securing proper information for charting,-Next to the importance of the use of the charts themselves is the seriousness with which the matter of securing data for charts is undertaken.

Ordinary routine statistics about a business are, as a rule, not the kind of facts which are most valuable. The facts which are the most vital and important are usually the most difficult to obtain. The cost of them is often high, but this must all carefully be judged in relation to the results which will follow the careful study and use of such facts.

Ordinary hack-statisticians or accountants will chart the same old standard time-honored line of information which as a rule is a backward rather than a forward look into the business, without meaning and without possibility of adequate comparisons and analysis. As a matter of fact, it is as a rule, inadvisable to use statistics for charting purposes which are secured solely from accounting records alone, as a great many other factors require to be charted, in order to properly study the 
business. In other words, the charts which executives are to study are by no means only the charts which are made up from the bookkeeping and system form records, which are in the main mere records of routine past performance, without even complete detailed information of this kind. Field investigations, researches, new data, comparisons and surveys are often more needed than any information already in the office.

If an electric tabulating machine system is used whereby full and complete details can be quickly calculated so that the results may be charted in time for the application of the knowledge thus gained, the range of charting possibilities is widely increased in a most highly valuable manner. 


\section{CПAPTER XIX}

\section{THE CONVINCING PRESENTATION OF FACTS}

144. Making reports effective.-Many a very able official executive, consultant or research man has never secured full acceptance and credit for his effort for the simple reason that his rejorts have not done him justice.

The business of to-day is largely done by representation on paper. Not only has the increasingly large size of business corporations made it impossible to maintain the old standards of personal contact, but the principles of efficiency have demanded that things be in vriting, rather than in conversation.

Whereas a man was in close personal touch constantly with his employer, and was able to make his personality count in rendering verbally his reports and opinions, today the facts are presented to most executires in any business of size on paper.

As a result, the making of reports has become a very important and vital part of any executive or research job. He must be able to know what facts are important, to present those facts comvincingly, clearly and in logical sequence, and also to he sure that he las all the facts, and all sides of the facts which executives higher up might want. In older tines when executives drew out of their suborinates verhal reports and explanations, it was possible to depend upon cross-examination to get all that the executives wanted; but to-day the whole case, in all particulars, must be worked out by the sub- 
ordinate executives and placed before the chief executive.

The making of such reports, therefore, becomes a new department of technique in executive work and responsibility, and every executive should be keen to know how to meet it.

Many fateful decisions are made about a man's capacity and ability after any inadequacy, incompleteness or carelessness in the preparation of reports.

145. The elements of a good report.-Let us take first the simpler form of reports. These elements and prin. ciples in the main are:

1. Pertinence.

2. Direct presentation of facts.

3. Logical sequence of facts; adequate data in backing up subdivisions, statements; conservative handling of facts; clear summaries and conclusions.

4. The spirit of the report-its fairness, its clear-mindedness, the arrangement of the most importaht, important and least important elements.

As a matter of fact, the first great essential in the making of reports is ability to think clearly. The report must first have its perfected existence in the mind of the writer. This ability to think clearly is not something which can be acquired like some other smaller kind of technique-it is something which must be cultivated over a long period, but it should be cultivated just like one cultivates the technique of a game of tennis or golf. As a matter of fact, thinking is nothing less than the application of the will to a specific problem, its orderly and intelligent dissection into parts, the arrangement of these parts into the more important, the less important and the least important, the securing of facts necessary to 
form judgments, and the use of the powers of reasoning and logic and imagination to construct a plan out of these elements which will reach the required solution.

Patience, concentration and application of ordinary principles of common sense are the most important elements of clear thinking, and it must not for a moment be thought that the making of any reports or the analysis of any subject requires necessarily any superhuman brilliance or genius. The most of the so-called brilliant work on analysis and reports is composed mainly of the most painstaking, hardworking care with detail and clear-sighted handling of facts and conditions. The chief thing the matter with reports, as a rule, is that they are scatter-brained, incomplete, with a point of view too close to detail, or too little of detail, too biased with some personal point of view, or too patchy, and without point. High grade executives desire to have subordinates come to them with conclusions, not with questions unsolved or half solved.

146. Graphic illustrations of reports.-There is no doubt but that graphic charts are of very great assistance in making any report understood and appreciated. Such graphic material may be used either as part of the report itself, or in the shape of special size charts or blue prints to be tacked temporarily on the wall while the report is being considered.

It is easy to overdo this chart matter, however. To appear to inake up in variegated colors and designings for what a report may lack in analysis, investigation and clear thinking is a strategic mistake.

In the first place it must be carefully attended to that the charts be made for really useful purposes, built to the individual need of the executives and the individual 


\section{BUSINESS RESEARCH AND STATISTICS}

business. The chief temptation in the handling of charts is to make eharts for their own sake rather than for the use to which they will be put. Very frequently the statis. tician or ehart-maker has not the flexibility of mind which will enable him to carefully study the particular needs of the executires and the line of business and thus produce charts which will serve the business rather than impede the handling of business information.

In order to get full value out of charts, conferences will be necessary between the exeentive heads and the chart specialists to work out from both the point of view of the exeeutive and the chart-maker just what details of business are important to chart. Often certain personal preferences and peculiarities of the executives give hints to the graphic statistieian to prepare charts of a certain kind. It should be particularly the work of the statistician to give the executive no more complieated clarts than he can fully understand and get value from. If the complicated chart is a necessity, due to the com. plicated business, then it slould be made in order to work with the executive until he fully understands such a complicated chart and is not annoyed or confused.

147. Standardizing chart shapes and sizes.-The shape and form of charts are also extremely important in the matter of getting value out of them. Quite frequently charts are carelessly prepared in sizes, shapes and designs without coherent plan or any thought of the execu. tive who must carry them about with him and handle them. It is impractical to handle charts in such a careless way, and there should be a standard form and shape and plan for them. For instance, perhaps the most universely practical method of handling them is to have three-ring leather binder, preferably with a stiff cover, 


\section{THE CONVINCING PRESENTATION OF FACTS 263}

in which the charts are permanently kept. The charts are all put on the same size sheet- $\$ \frac{1}{2} \times 11$. If a large chart is necessary it can be folded one or two times and made up from special chart paper and punched to fit the binder. Only a most exceptional situation would need charting which will not be easily handled in such a manner.

When the charts are in this form it is possible for a man to carry the binder with him in an ordinary carrying case in traveling to and fro from home, or in making other travel visits; or if desired it can readily fit into a standard vertical file in a desk drawer or filing cabinet in his office. In this way the charts may be kept in good order, filed in their proper rotation and, if necessary, under classified headings and thus serve all of the good purposes which charts can serve.

It is important that an executive train himself to consult these charts regularly and give attention to the details, carrying in his head a general mental picture of the situation, and having these charts brought up to date constantly so that the picture will be complete.

148. Attention and respect for charts.-An executive should be constantly studying the charts for variations in and comparisons with the vital factors in which he is interested. It is this purpose alone which the charts are best designed to serve-to give a graphic indication of variations, comparisons and relationship between different sets of facts and figures. It is important that such charts not only represent, factors of immediate activity, but also have their proper comparisons and relations with facts and figures, reaching backward into the business for several years or more. On the other hand, by means of estimated or budgeted projection, 
charts can indicate the probable or expected line of travel of the various curves plotted on the chart for years ahead.

In other words the great and principal value of charts will be to picture trend and give a correct perspective of the facts of the present day in the light of the facts of the past and of the expected future.

It is a mistake frequently made by executives to consult such charts at odd intervals. One of the most valuable habits in regard to charts is to consult them with regularity, and to have them brought up to date with regularity. This is for the purpose that charts and their attendant statistics may serve not only as a record of the past, but an actual immediate guide in managing the present and preparing for the future. If the charts are worth anything at all, they are at their best when indicating a trend in advance of what the ordinary study of figures might indicate, and thus ringing a warning bell at the longest possible distance ahead of the events which should be anticipated and provided for.

149. Chart systems and plans.-It is frequently desirable that a complete system of charts and a plan for handling them be devised, so that different executives in different departments, etc., can study the same charts at the same time and thus be prepared for discussions in conferences. It is therefore necessary that the original charts be prepared with a special view towards making either blueprints or photographs or duplicates, and that a series of binders be prepared so that each executive may secure the proper insertions at the proper time.

In order to set in motion the right kind of a system of this sort, a conference is necessary at which all the details which eacil executive wishes to have charted are to be worked out and the schedule be prepared so that a system 


\section{'THE CONVINCING PRESENTATION OF FACTS 265}

can be inaugurated. There may be necessary a special set of charts for the president; or a special one also for the Board of Directors; or a special chart for other absentee owners or principals. In addition, there are probably required-or at least should be required-special sets of charts for each of the principal executives, so that each of them may understand something of the facts of the rest of the business as well as those of his own department. Especially when a business is operated on a general budget plan is this important, as then the incentive and stimulation which lies in seeing clearly the relationship of the performance of one department measured graphically in contrast with the performance of another department may be given. It is therefore of the highest value for increased efficiency if one department sees its own relation to its budgeted quota fall, while the budgeted quota of another department rises above the line of expectation. Such a method of charting the budget quota has a distinct bearing upon a charting system as such a charting system should be a part of every molern budgeting system. Although it is not generally known, the factors of efficiency eren in the general offices of a company may be just as readily charted as the sales records of a sales department. The performance of a department by means of the budget plan and carefully analyzed details provide a chartable measure of performance for practically any department in a business, and therefore makes available all the stimulation which a charting plan may have to all the departments.

Special binders stamped with the name of the individual, or the department in a business, should be provided, with special indexes for that particular department, behind which the charts as they are provided can be filed. 
If it seems desirable, duplicate copies of hand-drawn charts can be used; but in cases of fairly complicated types of charts, it is usually better to draw the original on tracing paper and have blueprints made; or else have some photographs and secure positives (not negatives).

It will round out such a chart system if a number of investigations are constantly undertaken to secure the type of infornation which executives ought to have in order to study the fundamental trends and the field conditions from an outside point of view, which it is impossible to get actively or even disinterestedly from within the organization. It is hardly to be expected that only statistics produced from the inside alone will be suficient for the proper guidance of a busiuess; and therefore a chart system for executives is incomplete unless a place is made for such investigations and the proper facts developer.

It is also the fact that in a great many instances there is not available the adequate information or train. ing in securing information or analyzing records in order to get the basis for the cliarts which an executive should have. In this case it is highly advisable to secure the services of trained statisticians and chartographers who will carefully work over the business of the company in order to make a chart and secure the right kind of data and put the matter upon a standardized basis so that the ordinary executive can follow the plan after he leaves, without complication.

150. The reading of reports.-It is a common belief that in order to insure a report being convincingly presented -or rearl at all-it shonld be read aloud by the author. There is sound common seuse in this under certain circumstances, if the anthor has a good voice, will adjust his 
speed of reading to lis audience, and will give proper emphasis and shadings to the reading. Otherwise the report had better be read by someone else.

There are those who cannot follow another's realing; but then there are also those who cannot be brought to read a report, or at least carefully. On the other hand there are many very able executives who have become used to forming judgments in a deliberate way in their office or at home, after reading careful reports. They far prefer to operate their mind in this manner and are irritated and upset by any pressure to change this habit. A compromise is to read if possible a report to an executive who has failed after a time to read it himself. Or, if all efforts are unavailing, then at least the summaries and conclusions should be read, by the author, or by the executive while the author waits. Then if a mere reading of a summary leaves a question, the author is present to make a verbal synopsis of the report on that point. 


\section{CHAPTER XX}

BIAS, ERROR, APPROXIMATION AND ESTIMATE

151. The nature and inevitability of error.-Few people besides trained statisticians appreciate the large part which possible error must figure in all effort to ascertain fact. Nor do they appreciate how inescapable error and mere approximation is. The popular notion of a statis. tician (when this notion is not cynical) is that statisticians can or should provide rigidly exact fact. Uninformed business men who hire statistical work done for them often look for rigid exactness to a degree impossible to render.

Right at this point is necessary some education both for the business man and the statistical and research worker. The business man requires to understand that there is no such thing as complete accuracy. There is no perfect measurement for anything, precisely as there is no perfectly straight line. No way is known yet to weigh anything lighter than $1 / 10 \%$ of a milligram. Even the astronomers at Greenwich, with highly perfected apparatus, cannot measure anything less than 1/100 part of a second of time.

All statistical effort is therefore open to a small or large degree of possibility of error. To criticize statistical work because it is not infallibly correct, or because conscientious researchers or statisticians must refuse to claim "absolute correctness" of their work is to be 
ignorant of the very nature of fact. To be dissatisfied and distrustful of results for which $100 \%$ accuracy is not claimed, or for which only 60 or $70 \%$ accuracy is claimed is also an ignorant proceeding.

152. Business men and statistical margin of error.Since the confidence of the business man in the statistics provided is a most important part of statistical service, this situation is an exceedingly delicate one. If, on the one hand, the statistican takes pains to impress upon tile business man the dogree of possible error and the factor's of uncertainty in any given piece of data, he often takes all the heart out of the business man in using such data since his mind is not accustomed to appreciation in degrees. He often either must believe in it as absolutely true or entirely wrong. He cannot understand statistics which, from his point of view, are half true and half wrong. Or, if he is not so grossly simple-minded as this, he dislikes spending time over academic uncertainties and margins of error. He operates his business on the modern principle that he likes his subordinates to come to him with finalities and conclusions, not with questions and uncertainties. Therefore he dislikes statisticians, who present lim with facts which are half right, or threequarters correct, or are ledged abont with a clond of "ifs" and "buts."

Here then we come upon the education which statistieians need in dealing with business. They must become business men to a sufticient extent to lnow the practical necessities and aims of business, so that they will speak not purely as professional statisticians, but as business men with statistical training. They will then subordinate the professional details in making reports, and render results from a practical business point 
of view, estimating the chances of error and calculating it correctly, but not obtruding unnecessary doubts and qualifications merely to be professionally exact. Beyond. a certain point in any problem it is unnecessary for business purposes to be more exact, or too expensive to seek greater accuracy. To judge this matter is one of business intelligence, plus statistical knowledge of the factor of error.

The statistician who would figure costs of labor per second would be fantastic; the effort to get populations of cities correct to within 100 would be wasteful nonsense, even if possible; the effort to secure production figures for an entire industry filled with many small mannfacturers so that they would be eren $95 \%$ correct would be in many cases impossible. Statistics for business use must be conceived from the basis not only of practical need but from the basis of relative importance of error in different types of data, so that in such data where a high degree of importance of accuracy is present the highest degree of accuracy consistent with expendi. tures advisable will be made; and so that on the other hand where rough approximation will be entirely practical no useless time and expenditure will be made.

153. Errors of carelessness, misprint and omission.Figures are the most troublesome of all data to handle. They present unusually large chance of upset, error, miscalculation, omission and misprint. It is or should be part of the special training of statisticians and research workers that they handle figures with a conscious technique, just as a foundryman handles molten metal or a laboratory worker handles germs or poison or gases or explosive material. Figures have a high possibility of error in transcription, owing to the human equation 
involved, and for this reason as little as possible should be left to human hands. The use of adding and calculating machines, the use of photographic machines for reproduction of tables or data and careful proofreading are highly advisable. Statistics taken from magazines and newpapers have a grave possibility of error and mix-up, due to hasty handling. Even the official government reports are known to have a certain percentage of misprint and error. In business matters of great im. portance, data should invariably be traced to the original sources.

Oddly enough, even the most careful statisticians sometimes make rather grave errors, usually those of omission or narrow perspectives, rather than those of miscalculation or carelessness. Their very care breeds a closeness to detail which shuts out of view highly important data which from general angles of consideration should be included.

The close coördination of business knowledge and statistical research technique is shown here to be the ideal method of operation, as it saves time, energy and possibility of error and annoyance. Balanced faculties of these kinds function to the best advantage and obviate that type of error which is most serions of all, the error of general misconception of the problem and the factors entering into it.

All researches should be outlined in advance in considerable detail, and desirable standards of accuracy set in percentage figures, both for the whole research and for important parts of it, since not the same standard or degree of accuracy is possible for all parts of an investigation. This tends further to avoid errors of omission, and is a check upon carelessness. 
The finished result should also indicate all deviations from auy standards of accuracy set, or any abnormalities, (ircumstantial limitations or doubts which have, by their degree of possible error a possible practical effect upon results.

It must not be forgotten that a total cannot be any more accurate than any item making up such total; which illustrates the surreptitious manner in which a minor item may gravely affect a major one.

There are two types of errors of earelessness in calculation, one of which is the compensating type of error and the other the cumulative type. By compensating type of error is meant the kind which adjusts itself becaise of the large number of units involved, and by cumulative error is meant the kind of error which, quite the contrary, beeomes that much worse with each unit counted. If a clerk measures with yard stick too short, the volume of the error grows with each additional yard of measurement, forming cumulative error. On the other hand, when in the trenches in France our doughboys were asked by the men handling the guns to estimate by eye-measure the distance to a certain tree or landmark, the guesses of none of the soldiers was aceurate individually, but the more soldiers who guessed, the more accurate became the arerage of all the guesses. The error in this case was compensating, because just as many soldiers were sure to guess short as long.

There is considerable more technique in error from a professionally statistical point of view, which will better be studied in such volumes as "Elements of Statistics" (Bowley); "An Introduction to Statistical Method" (Necrist); "Elements of Statistical Method" (King); and "Statistical Averages" (Zizek). 
154. The two kinds of bias.-Since bias is deadly to reliable research results, it must be closely watched and elininated or calculated. Bias differs from error in that bias is intention, conscions or unconscions, to influence the result. Bials in the investigator needs no discussion, as it is so obviously fatal to true result. The employment of biased investigators is folly, if not dishonesty.

The bias with which researcher's have most usually to do is the data which is collected from inaroidably biased sources. All those very close to a situation develop bias, and it must constantly be guarded against. Nevertheless, it is usually necessary to collect data from those close to the matter under investigation.

There is a known direction, which the two kinds of bias takes. There is the bias of those who have an interest, conscious or subconscions, in seeing data taking a certain course. Their combined estimates are bound to be too high or too low by the ratio which corresponds to the estimated strength of their bias. This ratio must be deducted or added. For instance, it is chargerl by some that the group of employers who under the name of the National Industrial Council investigated the facts as to the rise in cost of living, estimated the rise of cost of living too low on the one hand, and the rise in the level of wages too high. Labor sympathizers on the other laand, it is charged, exhibited bias in the opposite directions, estimating the cost of living increases too high thy obtaining their figures from too narrow a range of family purchases) and by estimating wage increases too low (too utterly discounting the stability of war time wages). We have here a prominent example of bias working in opposite directions, according to the character of the bias, but all calculable from the nature of such bias. 


\section{$27 t$ BUSINESS RESEARCH AND STATISTICS}

On the other hand, another type of bias requires different calculation. If any average group of men or women are used upon investigative work, especially of a social or economic type, they will each exhibit bias according to their natures and abilities and circumstances. These results tend to compensate each other, as is similarly true in the type of compensating error; and in this respect bias operates like error. It moves in both direc. tions with equal facility and tends to obviate itself. But it should be understood and watched nevertheless.

Another familiar illustration of bias is the fact that women in census returns tend to indicate themeslves younger than birth certificates show. This is the first mentioned type of bias, since it is calculable in a definite direction. The other type of bias is illustrated also in census returns in the tendency of people to indicate their age in nearnest round numbers. But this again is compensatory.

155. Approximations and estimates.-Business requires basis for action irrespective of whether or not such a basis is obtainable in any degree of accuracy. Being based upon risk, business activity ranges anywhere from sheer gamble to a fair degree of certainty. Of course it is constantly emleavoring to arrive at more degrees of certainty.

In this situation approximation and estimate become of great value, eren if rough or tentatire. A calculated guess is better than a wild or fanciful guess. Statisticians trainerl to too rigid professional standards, and having little msiness understanding, often shrink from approximation and estimate, both because of the speed with which they are demanded, and because of the slim data available from which to make calculations. But business requirements must rule, and approximations and estimates 


\section{BIAS, ERROR, APPROXIMATION, ESTIMATE 275}

must be made-ofttimes in a very great hurry. It is no business satisfaction to have waited ten days to calculate a more accurate and well built estimate, which would bring praise from fellow professionals, when for lack of some rough estimate made within 24 hours, thousands of dollars were lost.

Rather, it is the business of the able business researcher to be aggressive rather than to wait for orders in research matters and to persuade executives to substitute roughly calculated estimates for the slieer judgment estimates and sheer gambling guesses. It is the basic business of research to tatie over as much as possible of the guessing in a business organization and put this guessing on some semblance, at least, of a scientific foumdation.

Approximation and estimate can be applied to three kinds of data (1) factors of the past, (2) present conditions of a diffeult or hidden nature, (3) future conditions or possibilities. In all three divisions approximation and estimate may be of very fruitful effect.

156. The deficiencies of judgment.-A judgment is always a leap of the mind from such facts as happen to be on hand, or even from a position withont facts, to a workable conclusion. It is chamateristic of human vanity to fass julgment with or athout facts. The callow routh voices his opinion on the grave and complicated questions of the day with even more assurance than does the older man whose experience has tanght him to be wary of realy julgment. It is, of comse, one of the great teachings of experience that juigment must be withlesh, if it is to be a sound jurgment, until there is some aldedlate information in hand.

Nevertheless, a vilally important distinction to bear 
in mind is that business demands action to-day and not next month or next year. Thus the one great difference between the scientist and the business man is that the business man must act, even upou meager information, and reach his conclusion; whereas the scientist may insist upon years and years of experiment, test and verification before he makes up his mind and ventures a conclusion. The scientist's conclusion is more final; the business man looks only for a tentative conclusion. An increasing amount of scientific verification to form the basis of a more sound and complete judgment is nowadays available, however. Whereas the business man of years ago was sailing an almost uncharted sea, feeling his way much more in the dark than business men need to do to-day, the road is open now, with our more perfected facilities of commercial analysis, to get closer to $100 \%$ sound judgment on business problems. The explanation is that experiments are going on all the time throughout the country on similar problems, and the factors of a problem may be studied at close range.

In other words, a higher grade of judgment is possible to-day on business problems, because no business man is forced to decide matters out-of-hand or in the dark. A wealth of fact and data is at his hand or can be developed.

157. The limitation of individual experience.-In those earlier business times when business was less of solidar. ity, and the facilities at the command of business men much more crude, the indiridual experience of a business man was practically his sole guide. He was exactly as good as his experience and no more. If he had no experience with a problem he usually bungled it. This explaius why many more business institutions than now 
were merely the length and shadow of an individual man, since the knowledge and understanding gurling the busi. ness was confined to that which resided in one brain. Now, it is very obvious indeed that the personal expericnee way of learning business, when depended upon entirely, is the slowest and most costly possible method. In the first place, it is both blind and slow-going. In the next place, business matters have become so complicated that the ground an individual executive of first grade is expected to cover with his authority and responsibility, is so great that he would have to have fifty year's' experience before he could possibly be ripe for his position. To make matters worse, experience actually does not teach most people. Even after the above mentioned fifty years of experience, the human chances are that the mind comes out of the experience not with ripe and wide wisdom, but just as often with prejudice, lack of balance, over-development in one direction and undevelopment in others, and much bias and limitation.

These facts account for the paradoxical but undeniable situation, that older, "experienced" men in business are really not as much desired as younger men, in a great number of cases. The saying is often heard that a man has had "too much experience," by which, of course, is meant that in an ordinary span of a man's life the experience which he achieved may be varied, but it does not measure up in results to the value of other qualities and requirements which it is realized are more important than mere experience.

158. The typical narrowness of individual experience.-A concrete case need only be studied in order to clear up this point very definitely. Mr. Iohn Jones starts his business eareer, let us say, at twenty-three. If he is like 


\section{BLSINESS RESEARCH AND STATISTICS}

most youths he has a floundering period of perhaps five or even ten years before his permanent line of work is settled upon. In that time he may be everything from an offlce boy to a mere itinerant adventurer, or floater. Somewhere around thirty years of age he no doubt hits upon his permanent business specialty. It must be remembered that while this appears to be an injustice to many who get settled in their right line of business much earlier than that, that there are, on the other hand many others who actually continue to change about until much later than thirty years of age.

Now, when finaliy John Jones settles down to his permanent line of endeavor, he usually spends at least five or six years, unless he is an incompetent, with one firm; and during the next fifteen years from thirty to fortyfive he may perhaps have two or three positions. It often happens that he is with one firm during all this time; if so he is usually regarded as fortunate, and if he is an unusually good man he may be taken into the company and become an officer. It is by no means uncommon for men of ability to have had only one or more connections in their entire business lives, and there are plenty of examples of men who have never worked for more thain one firm in their lives.

The point proved is that the average man's experience is limited to a rery small number of firms; and any one who knows business knows perfectly well how severe are the limitations of the experience of any one firm (with some exceptions, of course). The average business house operates within a very narrow space, and the conditions of the business develop certain ironclad necessities and limitations beyond which it is even not necessary or profitable to go. The typical experience or business scope 
of Mr. Jones, therefore, becomes but a pin-spot npon the very broad and varied surface of business. His judgment has been exercised within a very narrow range-a range that is shortening all the time, because of the necessary development of industry and administrative organization.

When one remembers, therefore, that the mechanism of the human brain has its greatest absorptive assimilat. mig power up to $3: 3$ or 35 , or even less; when one realizes that this absorptive time of life is usually spent in a quite infuitesimally small seope of business environment, it will be thoroughly appreciated that the experience of om $\mathrm{Mr}$. . Tones is something which alone, unaided and msupplemented, is vitally deficient in comparison with the modern demands of husiness. It should not be forgotten that there is a striking contrast between experiencegetting in business and days in school. From six until twenty-one, people are usually under trained tutelage, with every effort being made to instill into their brains the condensed experience of the world. They are constantly being pressed by expert teacliers to absorb carefully condensed experience as represented by text books and lectures. Then, as soon as school days are over, the teaching process ends and individual experience begins-which is slow aud awkwall as a smail in comparison with the rapid process of the educational system. Inless this slow and awkward process of inclividual experience is supplemented with a continuation of learning through the experience of others, a dangerous condition of mind sets in-a reliance upon the utterly inadequate mode of learning by individual experience. It is into this siturtion that business research fits so desirably and perfectly.

159. Sound process of business judgment making.-In the face of the very grave insuflleiency of indiridual experi. 


\section{BUSINESS RESEARCH AND STATISTICS}

ence, how then is sound business judgment to be attained? It is a coördinative process. The very fact that it is a coürdinative process of a quite unusual kind, calls for an increasing amount of brains and mental training, which fortunately the large number of college-trained men who have entered business make available. However, in this coördinate process, not only pure mental ability is required, but also general qualities and characteristics such as courage, vision, imagination, etc. We have here the explanation why men of unusual intellectual ability are frequently of no value in business. Also, on the other hand, this situation explains the severe limitations of those who have native qualities and characteristics, but not the intellectual, coördinative ability. Prominently successful business men of the old school who had native qualities which took them a long way in business success, without a high degree of intellectual coördinative ability have always been sources of mysterious interest to those who stumbled over the paradox that so many men with such high quality of brains have not been able to make prominent business success, whereas others who have had no mental ability have made such success.

The making of a judgment is a pure intellectual pro. cess, starting with the segregation of the problem in hand into logical parts and divisions, the orderly examination of facts bearing upon each of these separated prob. lems, and with great care reserving the judgment until all the necessary facts have been assembled and until these facts have been tested and weighed for their authenticity, their pertinence, their adequacy. Also, until it is made certain or reasonably certain that there are no vital factors, or conditions which nullify and invali. date the facts. 
In the typical case requiring the making of a business judgment, there are always gaps, uncertainties and com. plications, which confuse and intimidate the mind un. used to the rough-and-tumble necessities of commercial procedure. Business is based upou risk-taking, and consequently many judgments are to a certain extent a risk. It is good judgment to take such a risk, but very poor judgment to fail to eliminate as much of that risk as possible by a study of the facts.

It is at this point that the average mind in business undergoes its serious and usually disastrous test. It cannot balance and weigh the large number of complicating factors involved in the solution of a problem; or if it has the mental ability to make the sound judgment, it lacks the courage to translate the judgment from purely intellectual terms into concrete policies and plans of actions; lacks also perhaps the energy and organizing ability or the patience and persistence to "see the thing through."

A business judgment made to-day upon the facts may require to be reversed to-morrow on other facts, and is, therefore, closely bound up with action.

For the arerage mind the problem of reaching a sound business jurlgment is to ward off the tendency to make an intuitive julgment at various points before reaching patiently the real and logical answer by the investigation process.

The old instinctive habit of the ages before man depended very much on reason crops out and urges shortcuts, easy decisions and roughly cut judgment. On the other hand this is not the problem at all with some types of men-their problem is to avoid dawdling over details too long and to realize that they are merely unintelli- 


\section{BUSINESS RESEARCH AND STATISTICS}

gently puttering over minor matters rather than coördinating detail and lefinitely moving toward a sound decision via the most important considerations at stake. Still others, when logic points unmistakably to a certain conclusion, find themselves swayed toward repudiation of their own julgment, or a disinclination to accept it, or even an antagonism toward it.

A really soundly developed business judgment is as craftsmanlike and interesting piece of work as any mechanism could be. A mind well trained to make the right quality of judgment in business is the mind which is both the rarest and the most result-producing, and also the most highly rewarded mind. It is perhaps the most marvelous of all economic machines, because it is a good deal more than a mere machine, while operating on dependable principles of reasoning and energetic clearheadedness.

160. Profiting by the errors and successes of others.One of the cinief preparations for the making of sound judgment, and one of the chief ingredients in it, are the errors and successes of others, who are grappling with problems which are alike or have some basis of similarity. Thousands of business houses are engaged separately in solving almost identically the same problems. As each of them are usualiy situated somewhat differently and have different types of men operating them with various degrees of experience in training, it is easy to see that rery decided profits can be gleaned from gathering and coördinating the experience of all of these firms engaged upon the same problems. It is for this reason that the business and trade papers flomish so decidedly, and why business clubs and organizations have multiplied so rapidly. The interchange of experience, the compilation of the methods 
and ideas of others, at luneheons and dinners to verbally discuss mutual experiences, all give evidence of the decided appreciation of business men of the value of such interchanged knowledge. Determined efforts are made in many incustries, through the formation of a central organization for that industry, to mutually benefit each other. The grave defects of most efforts at interchange have been that the work of a periodical, for instance, can only be jonrnalistic, can only publish what is broadly general, and "harmless" from a competitive standpoint; while on the other hand the speeches and talks made before business clubs suffer from the off-hand manner in. which they are delivered and from the lack of concen. trated technical attention to the coördination of such experience.

Only in the past ten years has it become recognized that this work of collecting and coördinating experience is in itself a special profession of a supremely important nature. Germany, years ago paid attention to this factor in business and hugely profited by it.

Business firms have now become so well aware of the importance of such aceumulation of experience of others that a great many make a practice of inter-visitation among each other, or maintain research departments, or purchase special consensus of opinion reports, or hire investigator's to do certain work for them. They realize, of course, that thousands of dollars have been and are being spent by others to learn the facts and reach the conclusions on the same problem which they are desirous of solving. Obriously, it is an economic waste for concerns to experiment along paths that have already been proved useless and profitless. It is seldom realized what a remarkable body of information and experience is al, 


\section{BUSINESS RESEARCH AND STATISTICS}

ready available on a great many problems of business and to what a rapid extent this information and experience is being added to.

The rate of growth and progress in business is constantly accelerating, due chiefly to this very fact that the experience of one concern is being made use of profitably by another concern, at a great saving of time, money, energy and brains. The time is approaching when the answers to many business problems will be made, as in agriculture, a matter of consultation with specialists and central experiment stations and bureaus. 


\section{CHAPTER XXI}

\section{COOOPERATIVE DEVELOPMENT OF TRADE DATA}

161. The new "competitive coöperation" in business.Although beginnings had been made in isolated cases before the war in business coöperation of a kind little known, the war advanced this idea with great rapidity. Through the agency of the United States Chamber of Commerce, entire industries selected groups of men empowered to deal with the government for the industry, and to represent the industry in various considerations for united action. Under this centralized organization of over 100 industries, swift action and remarkable economy were obtained solely by the ease of general agreement upon problems and solutions which research and study showed to be valuable. Reductions in models, agreement on fewer standard sizes and changes in trade practices followed wastefully for years solely for lack of leadership and organization in making decisions for the entire industry-together also with removal of fear of legal complications through united action-were some of the rich fruits of such competitive coöperation.

Since the war, the knowlelge of the benefits of coopperation has served as an educator and an impulse toward organization. Those industries now have trade associations, and more members of trade associations take them seriously, and plan to make such associations of larger practical benefit through the centralized opportunity for research. 
In fact the whole spirit of business has undergone a subtle change. The period of "cut-throat competition" is now recognized as a callow if not suicidal period, and the public on the other hand is not so vindictively determined to assail business only because it is large, and to be suspicious of all coöperation.

The subject of competitive coöperation is so relatively new, however, that research alone may be relied upon to indicate the ways to greater usefulness in this principle. In order that this spirit may not evaporate into thin air and a narrow-visioned matter-of-factness take its place, some aggressive experiments and study of this principle are in order.

162. Trade association researches and statistics.-The first and obvious step in competitive coöperation is the use of the machinery of a trade association for compiling for members statistics and data of mutual value. There are now a number of very interesting examples of this type of work. The "open-price plan," is a specific type of coöperation practiced by certain trade associations.

Under this plan every competitor reports to a central office the details of every transaction involving a certain amount of money or a certain quantity of goods.

Under another milder plan, the different manufacturers who belong to an association send in reports of the volume of business they are doing, either daily or weekly, as may be determined, and either in dollars or dozens or some other quantity units. These figures are charted. They will report their shipments, their sales as billed out; volume of new business that comes in, and usually the amount of unfilled business on hand.

With such information from twenty or thirty manufacturers, or from a considerable percentage of the in- 
dustry, a very good picture, or idea of the trend of conditions is had.

The manufacturer, from such facts, gets an idca of what his opportunities or lack of opportnnities for doing business really are. Such data also helps to stabilize a manufacturer's market.

In an industry that is running along, for example, for a period of months with rery little business coming in, manufacturers who don't have this information, feel that they must get business, and indiscriminate price cutting is of ten the result.

A box-board manufacturer whose business had been slim for a few weeks, said: "I went out and put my prices down $\$ 5$ a ton and waited a couple of days and didn't get any orders so I put them down another $\$ 5$ and still no business is coming in. Now I am going to make another cut and see if I can't land some orders."

If that man had had statistics of his industry he would have known, for example, at a time like that, when he wasn't getting anytining, that the whole trade wasn't getting anything either. He would have seen the futility of putting prices down. If customers are not buying and they see the prices slipping, they stop buying just that much more and wait perhaps two or three months, waiting until things get down to the bottom, and then buy to the serious loss of the seller.

Very often another thing hapreus. If buying has been slow in an inciustry for forr or five montls and a mau puts up his prices because of allvancing costs, higher overhear, ete., it brings out a spurt of order's. Everybody runs to get unler cover.

163. Study of stocks on liand.-In some associations, statistics of procuction and stocks on hand are also 
collected. When new business was dropping off, when the armistice was signed, while production was still running along at a pretty good pace, statistics showed stocks on hand piling up and "running away." It wasn't long before manufacturers who were operating on a limited capital had a lot of money tied up in stocks, and in order to realize on them they did the usual thing-they offered them down at a sacrifice.

This is another instance where a trade organization's statistical record is of considerable help. In a case like that, if the manufacturer sees a stock-on-hand line jump way up on a chart, there is danger of his competitors going out and unsettling the market and making costly sacrifices because they are compelled to turn over their stocks.

On the other hand, if in a period, say, of six or eight months, there has been rery little buying among the whole trade, he knows that a strong underlying market structure is being built, and if he watches his statistics, he can manage to get the cream when business does pick up again, while the other fellow may have sacrificed a large part of his production.

164. Watching the capacity of the market.-Cases are common of concerns having good business for a year or two and who doubled their production capacity, without the slightest knowledge of what the capacity of their market is. They have no conception of how much business they can do; they have no idea that if they went out and tried to sell twice as much goods as they have been selling, they could perbaps only do so by taking it away from some of the other concerns in the business; and naturally the others wouldn't sit by quietly and let them "get away" with it. 
In an industry that is collecting this sort of information and where they chart a manufacturer's individual figures and volume of business for him, he will see his own volume sometimes for a couple of months going down and he will begin to get worried and think he has to do something to get business, whereas if he consults his chart, looks back two or three months, he will find that perhaps for two, three or four months he was running along 10 to $15 \%$ relatively stronger than the rest of the market or than his competitors were running on an average, and now there is a "leveling up."

Size statistics alone have saved some concerns thousands of dollars on just one item. One of these bad been carrying along a particular size that hadn't been selling for about six months, and the superintendent wanted him to sell the lot off as a job because he needed the room. Before be did so he looked up the figures that the association was giving him and he found out that a demand had suddenly sprung up in that particular item, although it apparently hadn't reached him.

They were also of importance in arranging his schedule of factory production.

165. The delicacy of price problems.-It is, of course, a delicate situation under the laws as they now stand for associations to talk prices or to exchange information on prices. It has to be handled very carefully and even the lanyers differ very much as to what can or cannot be done. But if it is confined to information as to what has happened, as to what a manufacturer has done, and if at all times the association excludes any information as to what a member wants to do or expects to do, it is within the law.

The cost work in a trade association is really of vital 


\section{BUSINESS RESEARCH AND STATISTICS}

importance. It was only by the organization of the Franklin Society that printers, for instance, were able to learn how to figure their costs correctly.

Researches of a broader and bigger scope are bound to be undertaken as a result of the formation of live trade associations. Too often now they have but a very little sum of money at their command, most of which a secretary and office expenses eat up, and there is nothing leit for research. This is a mistaken policy, as an organization must function or it fails, and one of its possibilities is that of making an adequate and exhaustive investigation of the industry.

166. Coöperative researches by independent groups.-Perhaps the most practical way to get coöperative results in research is for a selected group of the liver units in an industry to undertake a research together, through an independent research agency. This is more feasible and satisfactory than for a trade organization for the reason that the weaker members rarely can contribute a pro rata assessment for a coöperative investigation, or else impose restrictions and conditions not agreeable to others. There is great efficiency in a group of half a dozen or more joining to make a jointly needed investigation and dividing the cost. More and more of such investigations are now being made, as the scope of usefulness of this method unfolds itself. All such investigations which seem to an individual company too philanthropic or expensive to make alone are economical and feasible under the coopperative plan. The method is simply for each contributor to ontline the specific factors he wishes treated or emphasized, and an assembly of the combined wishes of the subscribers becomes the instructions for the investigation, insuring to each concern that which 
he especially desires, in addition to what others have noted as valuable.

In effect, this is the plan worked out by such organizations as the Business Bourse, since there is provided data to fit the individual needs on a business basis, which is, in one sense, coöperative.

167. Specialized business data coöperation.-Other types of coöperative development of data exist which are of vital importance in business. A fine example is the actuarial work of insurance companies, which operates coöperatively even on an international basis. Another excellent example has been the National Industrial Council which undertook investigations as to the real facts as to the cost of living. The Civic Federation is another high type of specialized coöperation; and of course there are others, such as the Russell Sage Foundation, Carnegie Foundation, Carnegie Institute, and agencies partially philanthropic and partly coöperative. The Har. vard School of Business Administration, the Economic Psychology Association, the American Export Manufacturers Association, the Economic Club, the Association of National Adrertisers, the Salesmanager's Club, the Associated Advertising Clubs of the World and other bodies have done a great deal to make serious inquiry into the basiness problems of the country.

Such efforts are of intense significance as illustrating the thorough acceptance of the principle of coopleration, and of centralized research as against the narrow principle of purely individualistic effort. They help to estab. lish solid foundation for the future of business research.

It is an established fact that the bonanza growth of the antomobile industry was made possible only by remark. able esprit de corps in coöperative research and stan. 


\section{BUSINESS RESEARCH AND STATISTICS}

dardization among the motor car manufacturers. Had there been a narrow and purely individualistic policy adopted; had not coönerative committees gone abroad to study steels, standardized screw types and general sizes, etc., it would have been mechanically and psychologically impossible to develop the automobile to its present position of the second or third industry.

Unfortunately, collection of marketing data has not beell as freely coöperatively undertaken as mechanical data, and the industry has suffered in consequence. At present there is definite need for coöperative countrywide survey, county by county, of the prospective buyers of automobiles-to establish a quota or fix a saturation point for the automobile business.

Chronic and incurable optimists in the field seem to believe that the country can absorb any amount whatsoever while of course there are very decisive limits which should statistically be established. The huge cost of such work is rather prohibitive for one concern, but coöperatively it can be done. Properly it should be the work of the Automolile Chamber of Commerce, but like all Associations it is limited politically and financially.

The possibilities for specialized coöperation are many. To a certain degree the organization purchasing agents' associations, eredit men's associations are specialized forms of coöperation, but they suffer the limitations of large bodies.

168. Public libraries and business data development.-The writer has been on record for some years that public libraries are not awake to their opportunity to establish a closer hold upon the business public. Even without special funds our libraries might readily make a more up to date collection of trade directories, business cata- 
logs, pamphlets and data of current and general value to business men. They do not now even maintain good collections of business books. Data on specific industries and specific business problem; of general applications should be coupled as a considerable and increasing volume of data exists but is not assembled for practical use. This is the service a library is intended for, and the delusion that the interests of the community lie in fiction, government reports and stale literature generally is a costly one to the public. Greater support and endorsement would come once business men increased their respect for libraries by finding something else than musty out of date tomes in them.

A really creative point of view on public library service to business would include an actual research staff, trained not in the narrow atmosphere of routine library practice, but in live business research such as business men desire and can use with profit. There should be a special alert telephone service arailable to business men, even if on a basis of nominal charges, a commercial pho. tography service by which quick copies of tables, statistics, charts and selected contents of books could be made far more rapidly and accurately than by copying from them. There should be an aggressive effort to compile specialized data, bibliographies, extracts and summaries on business subjects, not in the lumbrous library, professional style, but in business style. There should be an advisory board of business men directing such service, and bulletins should be issued endeavoring to show business men how to use the library for their profit.

It is a definite community loss when business men fail or succeed only indifferently at their work; and it is of course a truism that if they had better information 


\section{BUSINESS RESEARCH AND STATISTICS}

they would succeed better. The public library can be a very important link in the chain for greater local business prosperity by placing the results of other men's business knowledge and experience at the ready command of those who can profit most. Unfortunately for the community and themselves, the men who most need the benefits of business research are the most indifferent to it. A business branch of a public library has a distinct duty to perform in this respect.

As mentioned previously, the Business Branch of the Newark, N. J., Public Library has done some very interesting pioneering in this direction, with marked success and nation-wide application among business men.

169. The need for government business research and statistics.-American business gets no goverument coöperation. This is a cynical and trite fact, but a sorry one nevertheless, which it is now hoped will be altered in the face of the war coöperation developed. No matter how small may be the farmer in what remote part of the United States, no matter what insect or blight may fall upon his plant there are experiment stations and agricultural departments both state and national which will send on scientific details and oftentimes scientific men, and advisers. In fact, out in California farmers of certain trpes can wire to the state authorities and have shipments of special pest-eating and pest-destroying insects shipped to him which will stamp out the blight.

The agricultural department and experts are in a splendid coöperative league with the farmers everywhere to deveiop the fruits of nature; and the results are that the American farmers have more than doubled their ontput within recent years.

The business man has nothing comparable to such serv- 
ice at his command. Although he pays no less, and usually considerably more taxes than the farmer who gets such splendid service, and although he usually employs more men than the farmer, he finds a Government which is indifferent if not actually hostile to his problems. Instead of setting up expert assistance it sets up obstacles to him.

The Department of Commerce, forsooth, is devoted to exports, fisheries and lighthouses. This period of lack of coöperation seems now happily to be at an end, and a new period of Government coöperation developing. The Department of Commerce, even though neglected by Congress out of spite towards business, has made headway and will no doubt make considerably more headway in the future. A Department of Commerce which would serve the business man, as the Department of Agriculture serves the farmer would be a very wonderful institution. There would be leaflets on as many of the details of business management operation as there are detailed reports and booklets on thousands of insects and special subjects in the Department of Agriculture.

A practical plan of business coöperation therefore must very necessarily include a much larger appropria. tion for the Department of Commerce, a much more varied and active and immediately practical scope of operation for it, together with a plan and a campaign to make such information effective and to put it to use. It is one of the most astounding facts in America, that this comtry although conceded all over the world to be the most progressire business country in the world, has practically no trade statistics at its service. The census is in the main compiled from a sociological slant, and for most business purposes useless. 
Pressure is now being brought to bear upon Congress and the President (since at the moment of writing the Department of Commerce is without a head or a policy) to establish a Bureau of Domestic Commerce which will really serve business men capably on matters of internal business.

The New York Salesmanagers Club has taken the lead in this effort and is striving to have the Government avoid the mistake, now widely admitted, which it made in not appointing a reconstruction commission, a recommendation which the New York Salesmanagers Club also strongly recommended.

Other business organizations have gone on record for a much improved and developed Department of Commerce, especially with regard to study of domestic commerce, gathering of trade statistics, making of distribution and sales method investigations which will tend to raise the level of efficiency of all classes of distribution, retailers, jobbers, wholesalers, brokers and commission men, mail order houses, chain and department stores, manufacturers, importers and exporters. All of the classes mentioned above now find themselves facing problems of a serious nature and under changed conditions, and they need information and assistance which only the Goverimment can provide on a large enough scale.

We make the following definite recommendations, among others:

1. That the Department of Commerce open a Bureau of Domestic Trade, which will give attention to the additional recommendations listed herewith, and be headed by a practical business man with experience in providing the assistance needed. 
2. That a national organization of trade reporters be started, patterned after the efficient crop reporter plan now operated by the Department of Agriculture, which will make possible the tabulation of local data and trade conditions as to local prosperity, credit conditions, special conditions and opportunities to be made the basis of a fortnightly trade reporting service to business men, similar in idea to the crop reporter bulletins issued by the Department of Agriculture.

3. The creation of a general trade statistical division which will coördinate and rearrange for business use all data and statistics of business value which the government in any of its departments has available, and in addition undertake the compilation of new data, reports and statistics which business men need, such as an authoritative trade census of retailers and distributors, under various classes and subdivisions.

4. The undertaking of careful inquiries into trade methods from a constructive point of view, as. sembling of experiences of business houses on general problems of business.

5 The rearrangement of the plan and classification of the Census Burean so that the subdivisions and method of tabulation be of more practical business use.

6. The undertaking of researches in sales and distribution which will aim to work out solutions to problems of a practical nature.

7. The undertaking of a Consumption Census which will do for consumption what the Census now does for production-namely, provide statistics 


\section{BUSINESS RESEARCH AND STATISTICS}

as to volume of consumption of various articles by states, counties, and by industry classifications; also consumption studies of types and grades of families.

8. The undertaking of an Income Census which will provide data as to the approximate number of individuals and families with incomes of various grades, by geographical sections, states, cities and counties.

170. The costly failure to make reconstruction researches. -Warnings were plentiful before the war ended that the problems of reconstruction would be even more difficult than the problems of war. Unfortunately the ugly head of partisan jealousy intervened in the issue, and when Senator Weeks (Rep.) introduced a lengthy and detailed bill for reconstruction research and measures, the Democrats were placed at some political disadvantage. Although admitting the need for reconstruction study, the matter dragged until the President disposed of the dually-claimed political child a little after the manner of Solomon, by killing it, saying that business could take care of itself.

This is now admitted to have been a very serious economic mistake, costing the country and the world untold delay and money and convenience. A train cannot run itself, especially when there have been storms and washouts on the line! It needs a lot of track-walking study and testing. So did business after the war.

In fact, reconstruction is a very long continued process which in all likelihood will not be finished for years to come. The elements which call for most serious study and research in order to make this reconstruction sound, may be listed as follows: 


\section{Production.}

2. Factory conversion.

3. Export development and international commercial policy.

4. Merchant marine.

5. Fuel, food, and vital materials.

6. Transportation.

7. Price stabilization.

8. Commercial and industrial research and statistics.

9. Labor and employment management.

10. Post-war financing.

11. Government control.

12. Allotment and raw-material conservation.

13. Housing.

14. Distribution.

15. Sales-management.

16. Administrative efficiency.

17. Cost analysis.

18. Consumption efficiency.

19. Public administrative efficiency.

20. Retail and wholesale.

21. Publicity.

22. Industrial education.

23. Repatriation.

24. Occupational fitness and psychology.

25. Women in industry.

26. Credit conservation and control.

27. Tariff.

28. Agriculture.

29. Priority and coördination.

30. Special and miscellaneous.

If such a group of thirty committees looks formidable to anyone, let the eighty-five committees and boards of 


\section{BUSINESS RESEARCH AND STATISTICS}

Great Britain be remembered. There is immediate and practical work for every one of the above named com. mittees, even though the day is late, whose joint efforts could be unified by a priority and coördination committee, as indicated. 


\section{CHAPTER XXII}

INTERNATIONAL TRADE STATISTICS AND RESEARCH

171. The increased economic one-ness of the world.-The net economic result of the war has been to mesh the world into a far closer business unity than ever before. The coöperation of the allies, the necessities of centralized organization by Herbert Hoover to feed the world, the League of Nations and the general advance of intercommunication and inter-dependence have brought this about inevitably. So delicate is now the mechanism of world-business that costs of living, standards of living in one section of the world affect all sections of the world even to far off Asian isles. Japan has an "H. C. of L." problem along with every other nation. The nations of the world to-day are a closer family, economically speaking, than the thirteen colonies of the United States were in 1776 .

Such a situation calls to the practical business mind for coördination. A standardized international currency has been proposed, illustrating the trend of men's minds. Already the Swiss franc, because of the centralized neutral nature of Switzerland, has become, along with the pound sterling and the dollar, a generally acceptable medium of international exchange. The international exchange chaos has almost reduced the world to a state of barter.

The need of the day is unification and centralization 


\section{BUSINESS RESEARCH AND STATISTICS}

of economic matters among nations to keep pace with the one-ness so thoroughly developed already. Undoubtedly the League of Nations will in time develop in this direction.

At the International Trade Conference held by the United States Chamber of Commerce in October, 1919, steps were taken for an International League of Business.

172. The situation in world statistics and research.-For a world of civilized peoples, we seem hardly to have crept out of the tribal period in the matter of statistics. It is a distracting and well-nigh impossible task to make comparisou between countries in many matters of importance. Altho:gh ahead of the United States in other forms of statistics, England has nothing to compare with our census of manufactures. France and Germany have superior statistics in some directions, and an absence of them in others. One cannot even compare adequately France, Germany, England and America in such simple vital statistics as birth, marriage, divorce and death rates. On business matters there is a typically European secrecy and narrow-visioned guarding of statistics of simple character. There simply does not exist any extensive industrial data, and further, the gathering of such information is resented and challenged. Government agencies have made sporadic and abortive attempts with only inconsequential results.

As for the rest of the seventy-nine or eighty countries of the world, in which modern export nations endeavor to do business, the situation is even more hopeless. Simple subdivisions of population are in many cases not even obtainable. The researches for international data of any business value finds exceedingly little to work with. There are international trade directories of con. 
siderable value, but international statisties, except for world statistics on certain basic commodities, like rubber, wool, cotton, wheat, etc., are not to be had. A number of international yearbooks are published, but they all print the same old round of political, geographical and governmental data which has little if any business value.

Some glimpse can be seen of the need for international business research by a few actual problems which the writer has found necessary to concern himself with. There is a manufacturer who has something to sell to large business houses such as jobbers and wholesalers and manufarturers. Statistics at once became desirable of the number of these types of businesses in the various countries of the world. It does not exist in compiled form-it had to be worked out with great effort and expense. Another exporter desired to estimate the number of automobiles of various types now in use in various countries. This too was torturously hard to ascertain. A study had to be made of the possible consumption of automobiles in various countries. This, research soon showed, depended on roads, and road statistics also seemed for a time impossible to get, even roughly.

It is plain that trade development between nations hinges sharply upon information. The American Export Manufacturers Association has gone on record (October 1919) vigorously demanting an improved and efficient trade consular reporting service, and there is evidence that Congress is alive now to this need, since other nations appear to be ahear of us in this particular. The need for research training for consular trade reportmig service is the crux of the complaint against onr present service. Political appointees with no basic fitness cannot 


\section{BUSINESS RESEARCH AND STATISTICS}

possibly satisfy business men who must base large expenditure upon correct data. Not until the consular trade reporting is viewed upon from a business research angle and research standards applied to the problem will the results be satisfactory.

173. The encouraging example of the International Institute of Agriculture.-An institution highly unique and significant of things to come has been the International Institute of Agriculture at Rome. But for the war and the death of its founder and genius, David Lubin, it might have made an even greater record for itself.

Lubin was fired by a single great purpose, that of "a single numerical statement" for the various countries of the world, so that the basic information on world crop conditions might be as useful to the farmers as to the speculator and banker who had ample statistical and research assistance to work out the desired results from the maze of differing national statements and data. He found in Ricci a statistician who had a high grade of facility in such work, and the work of the Institute became internationally famous. It coördinated first figures of the wheat crop, showing the crops of the different countries, the total for the world, and the percentage of decrease or increase. This was later done also for rye, oats, barley and corn, and plans were under way to extend it to cotton and silk. Data in the monthly Bulletin of Agricultural Statistics also covered areas, crops, live stock, etc., while bibliographies of international literature, etc., were also issued. It was planned later to inventory and report on stocks in hand, exports and im. ports, floating cargoes, etc. A Bulletin of Economic Intelligence was also issued, and Mr. Lubin's aims and ideals were very high and ambitious. 
Unquestionably the Institute demonstrated the real need of the world for a concentrated and coördinated center of agricultural, economic and industrial statistics and research. The gain from such data is so decided that it cannot be overlooked. Unfortunately economic factors are so jealously interwoven with political and nationalistic considerations that there is no real likelihood of information of more than routine nature being made available publicly by public spirited agencies. The League of Nations is the logical center for international statistics, and I have outlined further on full details of a practical organization plan in connection with the League. There is not a great deal of immediate hope for such compilations by the League, and for some time to come vital business statistics of an international kind must be made through commercial sources, of which such examples as the National City Bank, the Business Bourse, International, Inc., Caldwell-Burnett Co., etc., are examples.

The British Government has announced its intention to organize a statistical bureau covering the whole empire, for business development use. This of necessity is a world wide enterprise.

174. Great need for world cotton statistics.-How real and immediate is the need for international statistics was illustrated by the addresses before the International Cotton Conference held at New Orleans October, 1919. As a Boston banker said, "production of cotton, as well as cotton manufacturing consumption, is international. So is the cotton financing. There should be a world cotton confederation."

O. P. Austin, statistician of the National City Bank, said: "The $6,000,000$ persons employed in the production, 


\section{BUSINESS RESEARCH AND STATISTICS}

manufacture and distribution of the finished product represent $30,000,000$ mouths to feed; the land on which it grows is worth about $\$ 6,000,000,000$; the factories which turn it into cloth another $\$ 6,000,000,000$; the finished product which they turn out in a year is worth $\$ 15,000,000,000$ at the door of the factory, and the capital invested in the growth, manufacture and distribution of the world crop and its product aggregates approximately $\$ 20,000,000,000$.

"Yet when we attempt to study the details of this enormous and rapidly growing industry we find only fragmentary information, gathered it is true, by many intelligent and painstaking individuals in different parts of the world, but lacking in basic sources of information or identity of terms in which their valuable information is stated.

"Such an organization, properly financed, and conducted by men thoroughly acquainted with the subject in all its branches and equipped to present the result of their studies in concise and uniform statistical terms, should cover the progress of the world crop at every step from the time that the lands are laid out for planting until the finished product is in the hands of the consumer; using the telegraphs and cables where necessary to gather information, coöperating with the governmental organizations in their periodical records of crop industries and conditions, encouraging uniformity of statement as to measurement of product and records of movement."

175. Other needs for international statistics.-An international scope for business, such as now seems necessary for America as well as other progressive nations, predicts the need for a digest of international ecoromics. There 
is need for data on a standard statistical formula covering all the countries of the world. These statistics shonid provide good data on population, numerically by classes, age, sex, occupation, geographical distribution and concentration. It should provide statistics on incomes, manniacture, agriculture, trade, finance and distribution conditions; consumption data, basic facts as to habits, standards of living, fashions, religions, point of view, amusements, building activity, savings, road conditions, transportation, ete.

Even more needed is data as to total world production of standard types of merchandise besides the few staples now so analyzed. The economic origin, location, treatment, transportation, manufacture, distribution and consumption of at least 100 or 200 articles of merchandise should be studied and tabulated from a world point of view.

176. An outline of proposed international research organization through the League of Nations.-Tlie League of $\mathrm{Na}$ tions, if organized and operaterl with as practical and thorough technical skill as any other great productive enterprise has been organized and operated, will pay big dividends to the peoples of the world, both great and small.

A great idea such as the League of Nations, which is primarily Amerisan in origin, should have a completely worked out American bill of specifications, if only to gire Emropean minds the benefit of American best thought on organization and integration for world business benefit.

More than this, since the Lengue of Nations is so nearly piroted upon economic considerations, and since America is the foremost nation in economic progress, it is especially incumbent upon America to work out a 


\section{BUSINESS RESEARCH AND STATISTICS}

correct vision of the economic possibilities of the League. America's motives are conceded to be altruistic, there. fore its suggestion for economic researches should meet with favor and acceptance.

The old world-preoccupied as it is with old time considerations of political balance of power, revenge, boun. laries, etc., and cynical and snobbish by tradition to everything concerning commercial or industrial matters, -is obviously not yet in a mood or position to think soundly of the vital economic factors involved. Knowl. edge of business research already can suggest important considerations for the success of the League.

It suggests, first of all, that the sound principles of executive organization be followed; wherein the ancient goverumental incumbrance of red tape and bureaucracy be eluded with the same decisiveness that secret diplomacy is now expected to be avoided.

The activities of the League should be very adequately departmented, with men at the head of these depart. ments who are real heads and able men of standing. They should have high responsibility and anthority and be vice-presidents of the League in order that its general executive council may be made up not of a few men over. burdened with too much responsibility, but of many men who are closely concentrating on specialized responsibility. Real intelligence and action is thus possible without delay.

By placing in charge of each division of work an able man with full responsibility and authority, and outlining his functions, the League becomes a great dynamic organization capable of making the same rapid economic progress through the use of impartial research and the stoppage of economic waste in great degree, as well as 
the lifting of standards of production and of living throughout the world.

Following are the various departments of a suggested League of Nations organization based on modern business research, including special departments of research which will be of great consequence to the world if permitted to serve unhampered by political considerations:

1. International Military Police:

Guard International Possessions.

Give Protection Against Unruly Elements.

Suppress Criminal Uprisings.

War Against Offending Nations.

2. International Naval Police:

Guard International Possessions.

Suppress Criminal Uprisings.

Make Display of Power to Unruly Groups.

Keep Seas Free.

3. In Charge Internationalized Territory:

Administrate Internationally Owned Territory.

Improve and Develop Facilities.

4. In Charge Commerce and Trade:

Allocation of Raw Materials.

Codification of Code of Standards of Trading.

Codification of Rules of International Trade.

Analysis of Economic Status and Friction.

Study of Tarifis and Trade Restrictions.

Recommendations for Economical Industrial Coöperation.

Management of Business Enterprises of International Nature.

Control of Prices on Basic Commodities.

5. Supreme Court of Arbitration:

Final Adjudication of Disputes. 


\section{BUSINESS RESEARCH AND STATISTICS}

Organization of Lower Courts. Special Inquiry Boards.

International Bar.

6. In Charge Codification of International Law:

Analysis of Public Law.

Formulation of International Precepts.

Codification of International Standards into Laws.

Legislative Suggestion to Nations.

7. Finanee:

Supervision Over Foreign Loans.

Establishment of International Coöperative Bank with World-wide Facilities.

Coöperative Financing of Great World Resources. Planning of Unified Instruments of Credit and Exchange.

Financing of Internationally Owned Enterprises. Budgeting of League of Nations Funds.

Advice on National Fiscal Policies to Individual Nations.

Operation of a World stock and Bond Exchange. 8. Reconstruction and Relief:

Rebuilding of Devastated Regions.

Relief of Distressed Regions and Peoples.

International Red Cross Administration.

International Y. M. C. A. and Other Social Efforts.

Maintenance of Alert Organization for Preventative Measures, Health and Sanitation Suggestions to Backward Nations, etc.

International Medical Council.

3. Statistical and Research:

Standard Compilation of Data of all Nations.

Standard Statistics of Business, Crop and Labor Conditions of all Nations. 
Researches for all Departments.

Statistics of League of Nations Activities.

Compilation of Reports and Investigations.

10. General Advisory and Conciliatory:

Minor Counsel on all Matters to Small or Back. ward Nations.

Settlement of Petty Complaints.

Investigations of Irregularities, Delays, Criticisms, etc.

11. Colonial Administration Protectorates:

Governing of International Colonies.

Temporary Governing of Countries in Distress or Otherwise Unable to Maintain Order or Menacing Public Law.

12. Engineering Counsel and Economic Exploration:

Expert Counsel and Suggestions on Industrial or Other Development.

Search, Appraisal of and Constructive Planning for a full Development of the most Important World Resources.

Special Administrative or Operative Commission of Technical Men for Countries calling for them.

13. Publicity Publication and Intercommunication:

Propaganda for Success and Popularity of League.

Central Agency for Dissemination of Official News of League Activities.

Routing and Planning of Speakers and Occasions to Boost the League's Activities.

Printing of League Magazine, Books and Official Matter.

Improvement of All Methods of Intercommunicacations Between Nations. 


\section{BUSINESS RESEARCE AND STATISTICS}

Centralized Facilities for World News Dissemina. tion at Low Cost.

Advertising of Appeals for Funds and General Support in All Countries.

14. Clearing IIouse and Bureau of Interchange:

Interdepartmental Suggestion and Communication.

Clearing House of Suggestions from Nations and Indiriduals to Departments.

Suggestions to Nations from Various Departments.

Inquiry and Correspondence.

15. In Charge Chartographic Survey:

Map Making.

Boundary Delineation.

Land and Ocean Surveys.

Geographical Exploration.

16. Ethnological study and Survey:

Expert Study of Race Conditions and Antago. nisms.

Preliminary Study of Nationalistic Disputes and Difficulties.

Data and Research in Ethnological Subjects. 17. Shipping:

Allocation and Control of Shipping on Mutual Agreement.

Study and Development of World Trade Routes.

Maritime Conventions and Usages.

Universalizing of Maritime Technique and Practice.

Study of Sea Power.

Ownership and Operation of Special Projects in Interest of World Shipping. 
18. Food and Agriculture:

Control of Basic Food Distribution Under Mutual Agreement.

Establishment of Price Control.

World-wide Agricultural Researches.

Development of Food Supply Sources.

World Crop and Food Statistics and Reports.

Development of Propaganda to Influence Food

Production and Food Consumption in Various

Nations, According to World Need.

Agricultural Experiment Stations in Various

Parts of the World, Coöperating where Possible

with National Experiment Stations.

19. Labor Emigration and Immigration:

Gathering of Data on Labor Conditions in all Parts of World.

Development of Labor Esprit de Corps for League.

Codifying Labor Attitude and Needs in all Countries.

International Employment Agency.

Analysis of Labor Costs of Production in all Countries.

Emigration and Immigration Regulations. 20. Personnel:

Investigation of Individuals Suggested for League. Bonding, Housing and General Arrangements for

Personnel of League Officials and Assistants.

Development of Esprit de Corps, Attention to Etiquette, Language Interpretations, Social Life, Political Aspects, etc., of Personinel.

21. International Exhibit and Library of Books and Records:

Charge of International Museum, Library, Files, 


\section{BUSINESS RESEARCH AND STATISTICS}

Records, Commercial Exhibitions, Art Treasures, Gifts and Special Displays.

22. Bureau of Standards:

Development of Universal Standards of Every Kind; Measurements, Mechanical Sizes, Shapes, Forms, etc.

Examination of New Devices, Plans and Ideas Offered for Universal Adoption or Protection. Testing of New Materials or Plans.

Regulation of International Time, Codes and Other Standards.

2.. Patents, Formulae, Trade-marks, International Trade Licensing:

International Registration of Patents, Trademarks, Formulae.

Licensing of Firms Engaging in International Trade.

Issuance of League Passports, Credentials, etc.

Registration of Travelers and Visitors.

24. Executive Administration:

General Detail Administration of League Offices.

Purchasing Supplies.

Hiring of Routine Assistance.

Design and Erection of Buildings.

Auditing and Bookkeeping.

25. World Production:

Study of Increase of World Production. Analysis of Economies of Production.

Subdivision Among Nations of Productive Enterprise.

Spread of Technical Knowledge of Production.

Vital Statistics of Production.

Coöperative Agreement for Production Efficiency. 
26. Distribution and Consumption:

Study of Standards of Living Among Nations.

Surveys of Our Consumption Possibilities and Needs.

Propaganda to Develop the Consumption of Surplus Foods and Equalize Standard of Living.

Analysis of Distribution Systems, Formulation of Coöperative Plans for Improvement.

27. Educational Coöperation:

Interchange of Professors and Lectures and Students.

Offering of International Scholarships.

Endowment of Chairs of Internationalism.

Founding of International University.

Compiling of Special Textbooks on International Subjects.

Operation of Extension Lectures and Schools in All Parts of World.

Educational Guidance to Nations. 


\section{CMAPTER XXIII}

THE RESEARCH SPIRIT AND PROFESSIONAL STANDARDS

177. The "nose" for inquiry and analysis.-We speak of the "nose for news," and credit it as an instinct which a man has or has not got. City editors know that some men will never make reporters, while some men or women seem to have the faculty as a natural development.

Business research has much that is akin to newspaper work, for both require perpetual inquiry, observation, cool dissection and impartial delineation. Consequently it may perhaps also be said of business research that those with a "nose" for inquiry and analysis will succeed best at it. A case comes to mind of a well educated young woman who had even had some success at social research, but who sinply blankly failed to get the point of view or develop the faculty of business research. She wosked indefatiguably but in vain. There are many such cases. There is necessary a certain zest and relish in breaking up a problem of business into parts and working out solutions, aud in securing from hidden, perhaps reluctant and difficult sources the information necessary to a rounded out presentation of facts and conclusions. An orderly mind, a disciplined sense of logic and practicality, an originality and resourcefulness in the ferreting out of sources, and a clear conception of business problems, aims and conditions are factors of great im316 
portance. A constructive vision of business and a training in modern business standards are also large assets.

The "nose for inquiry," strictly speaking, is an innate love of this type of work, a joy in its requirements, a sort of disciplined curiosity that never dies; an appetite and love for facts, accuracy, synthesis, clear thinking for their own sake. Such a person will "research" everything that he comes in contact with because his mind operates in a researching manner. Just as a reporter with a good "nose for news" sees a "story" in everything, so a researcher with a good "nose for inquiry" will see a problem in everything, see it in divisions and classifications and phrases, and have a hankering desire to attack the problem, while his training will be specialized on business research, his "nose" for inquiry will be deeper than that because it will be fundamentally a part of his character.

This type of mind, like all specialized types of ability is highly concentrative, and represents a business tool of great value to the business which realizes its value and knows how to use it. A good business man with many problems nowadays surrounds himself with a series of special abilities and just as he needs the accounting mind, the sales mind, the advertising mind, the financial mind, so also he makes use of the research mind; finding, indeed, more scope for profit and progress in this eclectic type of ability than in many of his departments, because it deals or can and should deal, with the very bases on which his business rests.

The "nose" for inquiry is of course to a large degree acquired, and is not "born" in people; although unquestionably not all people can acquire it since not all people have the farticular grouping of qualities essential to 


\section{BUSINESS RESEARCH AND STATISTICS}

success in business research work-though they may have the qualities for technical or chemical or social re. search work. The "nose" for inquiry is not, of course, coufined to researchers; many executives and heads of business have it, and can attribute their success largely to it. In fact most prominently successful people in many fields of business, science, literature, art or the professions, are marked with a high degree of spirit of inquiry.

178. The sense of devotion to the discovery of new iruth.In another sense the business research worker must be marked in spirit; he must have a genuine passion for serving truth, and a sense of adventure and pioneering in unearthing new truth. This spirit is pr:marily the spirit of science, as its devotees have known it since the days of the Greeks and Galileo and Bacon. This spirit is one of self-effacement in the pursuit of practical discovery and thoroughly attested fact. It is a spirit of patience in detail, persistence under difficulty and dauntlessness in the ain to arrive at the desired end. It is a spirit of taking infinite pains (that quality attributed generally to genius) and of verification, reëxamination, experiment and search. Thomas Edison is a unique example of genius and business researcher combined (in technical fields) since, as suggested, the qualities differ only in degree, not in kind. Mr. Edison's Laboratory contains great tiers of drawers in which are accumulated samples of every known material of whatever nature known to exist in the world (and some metorite material from other worlds). When Mr. Edison researches a technical problem it is researched to the end, regardless of sleep or expense or failure upon failure. And $\mathbf{M r}$. Edison is a business researcher in many aspects because 
he researches problems of business as well as problems of science. He is a business inventor par excellence and all the many business enterprises unde $1^{\circ}$ his name are operated in all respects under the same business research principles which govern his technical researches. Hundreds of millions of dollars are invested in businesses based on Mr. Edison's researches.

The scientists who give their entire lives to research of some single obscure angle of biology or geology or other science and are content if they have moved the body of scientific knowledge forward a few faces, have a spirit which to a degree is valubale in business research, bound up as it is with the profit motive and the discipline of immediate practical usefulness. The devotion to truth sceking is peculiarly necessary in business research inasmuch as there is constant pressure, such as does not exist in pure science, to sway investigations according to business interests involved. Hard situations are certain to develop in which the finding of business research make or break the fortunes of others, and run counter to the interests of individuals, corporations or special interests. Unflinching adherence to logic and facts, uncolored by bias or regard for the interests involved, is a basic re. quirement. Investigations are only as good as their makers, and statistics as good as the statistician. Confidence in the qualities of mind, and integrity of principle which actuate researchers are all-important. Anyone engaging in business research without such attitudes of mind and character is engaging in false pretense, consciously or unconsciously, and is an anomaly and a reproach. There are people whose general nature and point of view exclude them from successful research of any kind because of an habitual attiude of over-optimism 


\section{BUSINESS RESEARCH AND STATISTICS}

aud lack of observation and readiness to accept facts without question from any source. While the correct attitude for research is not that of perpetual suspicion and caustic disbelief; the correct attitude is a judicial attitude. A judge in court is not an investigator but he is a judge of the investigative material placed before him by opposing counsel- the facts for and against. His rigid judicial faculty is the highly important element; and so it is in all study of fact. An investigator must "hew to the line of truth" wherever the chips may fall-even if it revises his own prior investigations.

179. Avoidance of abnormal fixation of ideas.-In scien. tific research it is no mark of deficiency or humiliation to reverse one's jurgment after new facts present themselves, or to admit the findings of other researchers who have added to, changed or reversed one's own findings. It is necessary to conceive business research truth as general scientific truth is conceived by true scientistsas a general fabric of fact constantly under improvement, the goal being not personal credit or achievement as much as the improvement of the general fabric, the general body of knowledge. The rebuke to the intelligence of mankind is that discoverers of truth so often must ask in vain for recognition because of the existence of an abnormal fixation of ideas or routine of thought. This abnormal fixation of ideas is a danger among researchers as well, unless a particularly strong sense of humility of personal feeling is maintained. A researcher with an abnormally fixed idea is a fanatic and sorry spectacle, a travesty on research. A business man of any kind with an abnormally fixity of ideas is a hindrance to his own and his employees' progress.

Ideas are in their very nature fluid, even truth itself 
is a flux. No one with anything of the spirit of science dare claim too much, or become too certain of the unchangeability of facts and conclusions. The very atmosphere of business research is that of change, growtli, search, dissatisfaction with what is known and fervor to locate more of that which is unknown or partially known.

There are subtleties in fixity of ideas which require to be guarded against. Sometimes the ability to judge data is unimpaired, but the fixity of ideas concerns itself with methods of investigation, or modes of presentation or scope of inquiry or habit of approach to a problem. These foibles may only partially limit the value of the result. but may be the smaller factor which will seriously unbalance the general results.

Research decisions frequently turn upon hairs, and slight matters affect very important values.

180. Dangers in solidarity of professional feeling.-In a number of highly specialized business functions there is the tendency to give major allegiance to the profession as an entity rather than to business as an extity. In other words, there is a tendency among such special workers as advertising managers, engineers, chemists, business research workers, etc., to plan their work to appeal to their professional fellow workers, rather than to make profit for their house and to advance the practical business interest of the house. A statistician may care more for the plaudits of his fellow craftsman than for mastering the urgent problems of his firm. An advertising manager may write his advertising with the predominant desire, unconscious perhaps, to win approval from other advertising men. An engineer may be more jealous of his professional reputation than of the innate ralue in dollars and cents of his work to his firm. 


\section{BUSINESS RESEARCH AND STATISTICS}

The research worker, now that business research is becoming a more definite pro_assion with a beginning toward professional solidarity, will also be subject to this temptation. It cannot too strongly be stressed that a business research worker is in business to help make his employer more profit, and no sophistry or specious reasoning should permit this coldly practical aim to become slighted. A research worker is first of all a business man and then afterwards a member of a profession. A pure scientist occupies a wholly different groundhe is first of all a scientist and a scientist is separated by a very definite gulf from a business man. The scientist's aim is purely professional; the business researcher's aim must necessarily be only partly professional. When in scientific work, all ends must be bent to science; whereas in business all ends must be bent to business, for the ends and aims of business differ from those of science in that business is an endeavor to perform a service of economic value at a profit; whereas science aims only to add to the abstract body of knowledge. Pure science is a public end, and is usually so recognized by endowment and special favor, while business is a private enterprise, with only such public angles as are re quired to keep it in line with general human welfare.

Science is being made more and more a servant of business; but it is also being served by business, as many, if not most, of the important adrancements of pure science are born out of the profit incentive through business. Great special laboratories are maintained by business houses for the harnessing of science to business ends, for business men ind that pure scientific research, unspurred by the desire to profit immediately, often drags tediously, fantastically and vainly. Business does 
not care to wait for long years of leisurely research; it must get action to-morrow; so it speeds up the aims of pure science, or some of them at least, by capitalizing its benefits in advauce; speculating on it, to be blunt. It risks-and risk is its vital economic function-money on the possibility of future profit through the directly applied efforts of science. The General Electric Company, when asked whether its expenditures of millions on research have paid, reply that the investment has been exceedingly profitable, far beyo,nd expectations. The same repiy can be made of business research-the investment pays as a business enterprise; but only so if the motif of the researches is made business-like. Otherwise, however, valuable as pure science such work might be, it would represent loss or philanthropy-anything but business.

This point of view is exceedingly vital to the personal and commercial success of research workers, and an early clarification of ideas on the subject is highly advisable. Those with an unchangeable bent toward pure science, who are unmoved by the practical aims of business as the supreme consideration, should nerer become researchers. The introduction of psychologists into business, for in. stance, has suffered seriously as a practical enterprise by the over-professional point of view and the unconscious refusal to group themselves rather as business men with a specialty than as scientists. There is no place in business for a reiled contempt or indifference to basic business principle, any more than there is room in pure science for veiled contempt of basic scientific principle.

181. Limitations of professional interchange and courtesy. - Here again a difficult point arises in business research. If it is partly a profession, to what extent should the 
usual rules of professional interchange and courtesy and fooling of knowledge be carried?

Two standards now prevail largely; both in the writer's opinion, mistaken. One is a careless spirit of interchange which carries some possible injustice to the researcher's firm; and the other, even more untenable, that of seclusion and secrecy.

It is obvious that it is to the advantage both of profes. sional and business aims to coördinate and compare the work of research workers in various business houses, to whatever extent will work no injustice to the interests of the business firms involved. A nice sense of balance is required, in which there is greater danger from illiberality than from liberality of construction. As a rule, business research is upon problems either of no great interest to any other concern, or else of such a general nature as to benefit more from coöperation than by exclusiveness. At present there are only a few coördinated agencies for the dissemination of business research, and the research departments of many individual firms maintain a close seal upon their findings. They have orders from higher executives to exchange nothing nor talk of the work being done; and refrain from participation in organization of research workers. They are isolated workers, and their results are beld as the property of the firm. Certain types of investigation make this a matter of course, but an investigation of the question, for instance, of the problem of filing, or of bonus methods of paying salesmen, are problems which are general and only profit can come of coöperation. Some unusually live firms have been wise enough to make advertising capital out of their research work, because since only large firms can afford extensive research work-so at least runs the popular idea-there- 


\section{THE RESEARCH SPIRIT}

fore, the smaller firms eagerly relish the net results of research as developed by such large firms, and place a special value and good-will upon it.

In fact, there is strong political reason for a generous policy in such matters, as it has already been pointed out with some bitterness that large firms are taking the best analytical brains for research and holding the results of their research for their own greedy profit, while the smaller business man unable to afford research, must peg along without its benefits. Agitation for business research work by the Government in a Department of Domestic Commerce is based to an extent upon this situation. 


\section{CHAPTER XXIV}

IMAGINATION AND VISION IN RELATION TO RESEARCH

182. Imagination disciplined by fact.-The well-worn phrase about the dreamer who keeps his feet upon the earth illustrates the common realization that imagination and dreams have a decided tendency, like gases, to ascend away from the earth and disappear into the blue. There are many grades and kinds of dreamers in existence, both in and out of business. All of these have plenty of imagination-the only question that determines their relative degree of difference, and also their relative value to the world, is to what cxtent these imaginings are disciplined by facts. There are, of course, large numbers whose inventions are entirely worthless; whose imaginings are sheer abberations. These need not be considered here. There are, however, several varieties of business dreamers, ranging from the inventor, whose typical condition is that he has an invention entirely undisciplined by the fact of common usage and commercial availability; and also the much more common and pathetic type, the man who is selling an article or operating a business in the earnest belief and imagination that it will eventually make a great deal of money for him, whereas the facts which he himself could ascertain if he had the training and ability, would quickly disprove any such possibility. Such men are borne up in their course by the exaggerated stories of men who had excellent articles or types of business and who after years of effort finally came into 
big success. Of course the facts are that wherever such an instance of success after long waiting was achieved, the merit and the possibilities were there from the start for anyone who had the capacity to collect and analyze facts he night see.

Many millions of dollars in capital are put into enterprises that have absolutely no chance for success now or at any time, as would be amply demonstrated by a rigid examination of facts; but so great is the imaginative faith of inventors or promoters that even the most trusted of friends cannot persuade them to change their course. They are offended at the very idea of making researches to examine the basis and validity of what they so earnestly believe. They have more regard for their faith than in facts.

What is greatly needed among all business men, large and small, is a thorough respect for facts; and not only willingness but an eagerness to discipline their imagination with facts and sound deduction from facts. Toward this end it is wise to make a point of subjecting all find. ings of pure imagination that comes into the mind to a caustic test of facts. A failure of this ofttimes leaves a corner of the brain filled with unvouched for projections of the imagination which are not only harmful to the imagination, but also unbalanced in their effects upon judgment. On the other hand, facts should not be studied too literally and closely or a similar dis-balance steps in. Facts should always be viewed in their natural surroundings and not too rigidly in themselves. All facts tend to blur and fade in the region of imagination, melting into uncertainty, speculation and possibility; therefore, facts should be viewed as simply stepping-stones upon which to poise one's self for the next step, or the next fact. 


\section{¿28 BUSINESS RESEARCH AND STATISTICS}

Exact truth is always a line of facts stretching off hazily toward the disappearing horizon; and although the facts in the foreground may be sharp and clearly cut they are not the whole truth by any means. It takes the imaginative vision to visualize all those facts not immediately -isible and make up a clear picture of the whole. In this way by paying equal attention to the facts in hand and the facts unseen is the imagination trained and disciplined, and by such means the mind gets closer and closer to the actual truth.

183. Statistics as raw materials for imagination.-Even the most brilliant effort starts usually at some concrete point, however unrelated this point may be to the final result. Great inventions, great books and great pictures, as a rule, started germinating in the mind, because of some inconsequential happening or facts such as Newton and the fall of the apple, or Watt and the steaming teakettle. Exactly the same is true of able business conception. Common facts interpreted with imagination are thereby transmuted into new concepts, policies and ideas. In a smaller way facts react upon the imagination even in smaller business matters. The human mind is a great storehouse of facts filed away with no filing system connecting them excepting the link of association which the memory gives these facts as connecting lines with every other fact. Consequently a highly profitable train of thought is often started to a successful conclusion by a fact. A single slight suggestion culled out of a report of an investigator or a coun. selor, or an item out of a trade paper, or a chance remark, may develop into a full fledged, practical idea. It is important that the mind be deliberately fed with fresh facts in order to produce fresh value. Detailed analysis 
of the facts and figures about a business brooded over, studied and digested produce results-if not immediately, then in time. It is one of the proved peculiarities of the human mind, especially in relation to the higher qualities of creative imagination, that the mind can take in facts, observation, statistics, etc., and apparently give no sign of any result perhaps for a long time and then suddenly, without there being any apparent connection between the two, a result is produced. This type of action from the mind is quite as frequent in business as in any other work of the brain.

184. The intuitive faculty in relation to research.Although apparently a paradox, the use of intuition in research is a most important factor. Like the aviator who crossed the Atlantic the first time, speeding 125 miles an hour, through night, rain and sleet, depending upon instinct and intuition when neither sea, stars nor compass could be used to calculate navigation-so in modern business where the speed is high, the need for action and decision is imperative, must research and analysis take its chances when reaching out into regions where fact is no longer available. To repeat once again, business is based principally upon the factor of risk, and in the final consideration, all risks undertaken eall for a certain element of the intuitive. In science and in philosophy, even in such concrete mechanical matters as engineering, a certain instinctive groping is a familiar and inescapable element. The philosopher has one name for it, the scientist another, and between them there is conflict over the matter; whereas the engineer in his matter-of-fact way ealls it a margin of safety or factor of possible error and sets his calculations aceordingly. He doubles his allowance for safety. Those who believe that engineering is a highly exact pro- 


\section{BUSINESS RESEARCH AND STATISTICS}

fession, need only inquire among those who are trained in engineering to realize that even the engineer must deal with the intangible and the incalculable, and is by no means afraid to do so, by means of the intuitive method.

The type of business research which is creative and aggressive refuses to be bound by the known and provable, or to stay wholly within the confines of one hundred percent certainty. It asserts itself equal to every practical business need, and has no patience with unimaginative hack researchers whose only material and resource are hack sources of information. Business men are constantly and in an increasing degree putting up hard problems to the statistical departments and research counselors in their employ. They are asking for practical results in problems out of range of complete accuracy, and only ask that the results developed attain a greater degree of value than the present hit and miss method, because they have been passed through the best modern formula for research and analysis. Bluntly speaking they want guesses, but they want those guesses to be as scientific as possible.

Thus a great chain of stores requires that the total volume of business of its thousands of stores be prognosticated in advance by a statistical department; balancing a composite of general commercial and local and special statistical factors into a guess which is in some respects without calculable foundations. Yet a sense of prognostication is so well developed, such is the experience, that remarkably close approximations are obtainable.

But the intuitive faculty has a much more secure and sound basis in research than that of mere prognostication. 
Its most legitimate use is in the search for actual facts and figures and sources of information, or sidelights upon facts and figures.

Many business men develop remarkable intuition in the matter of statistics and research, because of an intuitive grasp of the general situation in business. They are thus enabled to lay their finger upon the kind of facts or figures that will assist them, or hit upon the elusive factor in a situation which is giving trouble and which when analyzed shows up the real situation. Executives whose statistical and research advisers confess themseives baffled at a situation, admitting all their special trained experience to be impotent, quite frequently hit by pure intuition upon the hidden cause; illustrating the value of a similar power of intuition in everyone who undertakes research work. Without it research work is distinctly limited in resource and usefulness.

185. Reasoning forward by analogy.-It is one of the most interesting of all uses of research and statistics to examine minutely into the aspects of one set of facts apparently unrelated to other sets of facts, in order to determine any possible relationship, and thus perhaps shed new light upon the problems in hand. This involves the use of vision and imagination, for until a possible relationship is demonstrated it may only be an intuition, a "hunch" or a guess. There may be most meaningful synchronism in various changes or data of one kind or another-synchronism from which important business deductions may be made.

Some relationships between facts appear to be casual, whereas there is often a most real but hidden relation. At the time of writing there is interest in the relation between our exrorts and our increased cost of living. 
The relationslip is disputed, but should be analyzed. A time-honored example of such analogy is the well authenticated, but once doubted relation between the price of wheat and the marriage rate.

A purely reasoning process-reasoning by analogymay uncover highly interesting relationships. The relation of basic facts concerning an individual business or industry are especially valuable to study. The coming of prohibition may and very likely will effect profound changes in national standards and certain business factors. The relation between good roads, literacy, volume of money in circulation, etc., to a particular business situation is often very sharp and definite.

Among the many basic factors worthy of examination in any analogous reasoning concerning differences in sales territory there may be listed:

1. Population per square mile;

2. Insurance in force per capita;

3. Population per mile of railway (steam or electric);

4. Per capita consumption of various articles;

5. Per capita value of realty and personal property;

6. Per capita school expenditure;

7. Average days of duration of school in various localities; number of enrolled pupils, percentage of literacy;

8. Savings bank depositors to 1,000 of population; average deposits for each depositor;

9. Percentage of total mileage of improved roads; number of miles of improved roads;

10. Marriage and Death and Birth rates.

These are but casual items-there are of course more of such items as applying to any given business situation, when considered broadly and imaginatively. 
Perhaps the most immediately practical method of applying reasoning by analogy is to study the practices and methods of other and totally unrelated lines of business. It is one of the tacit jests of cosmopolitan business men that they hear business men protest so frequently that their business "is different." An examination of methods used in other lines rarely fails to disclose most valuable suggestive information, to be adopted by the competent research mind.

THE END 


\section{,}




\section{INDEX}

Administration researches, general, 222.

Administrative problems and their call for solution, 14 . some of the subjects already given attention, 223 .

Advertising Bureau of A. N. P. A., 236.

Advertising gambling, 65 .

Advertising management problems, 235.

Advertising problems, technical, 237.

$\Lambda$ gricultural statisties, bulletin of, 304.

American Association of Advertising Agents and specialized research, 236.

American Export Manufacturers Association, 291, 303.

American man and his ready made suit, 29.

Analogy and research, 331 .

Analysis of consumer and consumption, 37.

Analytical idea vs. the one man genius, 4.

Analyzing a new project, 33.

Analyzing the consumers dollar, 217.

Antagonism to business, 16 .

Application of theory to business, wider, 7 .

Approximations and estimates, ralue of, 274 .

Armour, one of the pioneers in research, 54 .

Assembling information for business applieation, 203.

Associated advertising clubs of the world, 291.

Association of National Advertisers, 236.
Austin, O. P., statement on cotton statistics of, 305 .

Automatic selling the keynote of distributive efficiency, 118.

Averages and their technique, kinds of, 80 .

Averages, fundamentals in relation to, 77 .

Averages, law of, 68 .

Averages, visualization of, 84 .

Basic factors in analagous reasoning, 332 .

Basic raw material prognostications, 149.

Bias, two kinds of, 273.

British government to organize statistical bureau, 305 .

Budget idea in business, 212.

Budget, typical divisions of expense, 215.

Bulletin of agricultural statistics, 304.

Bulletin of economic intelligence, 304.

Bureau of Domestic Commerce, efforts to establish, 296.

Bureau of Foreign Commerce, 96 .

Bureau of standards of U. S., 52 .

Business, antagonism to, 16 .

business Bourse, an investigation of, 184.

international vital business statisties, 305 .

plan of coüperative research of, 291.

Business data coöperation, speeialized, 291.

Business data development and public libraries, 292.

Business finance management analysis, 237.

Business finance researches, 216 . 


\section{BUSINESS RESEARCH AND STATISTICS}

Business forecasting, 144.

Business organization, staff idea of, 164.

Business :

new place of research in, 6 . possibilities of application of research in, 159.

research akin to newspaper work, 316.

research and hidden causes, 190.

research and labor, 225.

Caldwell-Burnett Co., 30J.

Capacity of market, watching, $28 S$.

Capital must go to school, 226 .

Carnegie Foundation, 291.

Carnegie Institute, 291.

Carson and labor, Sir Edward. 224.

Casson on management, Herbert, 239.

Changing the "facts," 28.

Charts, securing data for graphic, 257.

Charts, tendency curve, 150.

Civic Federation, a type of specialized coöperation, 291.

Cluett-P'eabody, 29.

Commerce, Department of, 295.

"Competitive coöperation" in business, 285.

Complexities of labor problem, 10.

Congress, 113, 115, 295, 296, 303.

Consumer and consumption, analysis of, 37 .

Consumer response tests, $\mathbf{1 5 9}$.

Consumer's dollar, analyzing, 217. charts, 218, 219, 220.

Consumption conditions, surveys of basic, 100 .

Consumption, increasing per capita, 95.

Consumption investigations, some, 101.

Consumption study, per capita, SS.

Coöperative research, 290.
Cost work in trade association, importance of, 289 .

Cotton statistics, 305.

Curtis Publishing Co., investigations of, 185.

Data, collection of marketing and mechanical, 292.

Data development, business, 292.

Data for charts, securing, 257.

Data of in restigation, types and kinds of, 31.

Data required, for "Point" calculations, 107.

starting new projects, 34 .

Data, securing per capita, 96 .

Data, types of vital, 36 .

Dealer density, analysis of, 130. direct relation to distribution, 131.

Dean Inge and labor, 224.

Deficiencies of judgment, 275.

Department of Commerce of $U$. S., 59, 61, 295.

Department of research, dangers of, 57.

head of, 55 .

organization and scope of, 58.

Department store problems, 47.

Departments of research and data sources, 54 .

Devotion to discovery of new truth, 31s.

Difficulties in applying information, 201.

Discount, Ryzon method of, 135.

Distribution :

analyzing percentage of, 126. and Federal Trade commission, 115.

and market analysis, 11 .

elements of, 120.

expert's analysis, 127.

fundamental economic prohlems involved in, 113.

problems, inquiry into, 40, 113, 123.

research phase of, 115. service feature in, 138. 
Distributive :

development, 126 .

equality and quantity price, 133.

functions, perverted, 124 .

method, choice of, 125.

organization, 121.

ontlets, 122.

Distributors, number of, 117.

Dollar and budget idea in bnsiness finance research, 212.

Domestic Commerce, Bureau of, 296,325 .

Eastman Kodak Co., 246.

Economic:

elub, 291.

development, 16.

intelligence, bulletin of, 304 . problem involved in distribution, 113.

Psychology association, 244, 291.

relationships, problems of, 16.

result of the war, 301 .

surveys, general, 43.

Economy and efficiency in executive management, 14.

Edison, Thomas, as business researcher, 318.

Effect of research on business problems, 18.

Efforts to establish Bureau of Domestic Commerce, 296.

Element of success, most typical. 143.

Elements of successful distribution, 120.

Employment and labor management, 11.

Error, nature of, $26 \mathrm{~s}$.

Executive head, modern idea of, 2.

his sources of information, 196.

Executive, human faculties of an, 6.

Executire, modern business, 3.
Executive, a super-. 5 .

Executive, what makes an able, 16.5.

Experience, limitation of individual, 276 .

Fact and human nature, 21.

Factors of statisical interest, field, 157 .

Factory location upon distributive basis, 132.

Facts, 211, 327.

Facts:

and statistics, 9.

attitude toward, 28.

ehanging, 29.

checking up, 26.

executive application of, 196.

how to use them, 206 .

nature of, 21.

of an industry, fundamental, 31.

presentation of, 259.

tryout application of, 207.

Faculties of an executive, 6 .

Federal Trade Commission and distribution, 115.

Field investigations:

broad types of, 184.

obstacles of, 176.

technique, 172.

types and kinds of, 172 .

vital data of, 180 .

Figures, limitation of, 23.

Fixation of ideas, 320 .

Forecasting, principle of business, 144.

Foresight and profit, $1+3$.

Franklin Society, 290.

Fundamental economic problems involved in distribution, 113.

Fundamental factors in relation to averages, $\mathbf{7 7}$.

Fundamentals of business, 19.

General Electric Co., 323.

Genius in business, the "one man," 4.

Goodwill, measuring, 156. 
Government research and statistics, need of, 294 .

Graphic charts and maps:

attention and respect for, 263.

their part in research, 251.

to illustrate reports, 261.

Graphic charts, shape and form of, 262.

systems and plans, 264.

Graphic summaries and reviews, 39.

Harriman, an accountant, 189.

Harris, Emerson P., 131.

Hart Schaffner and Marx, 29, 44.

Harvard school of business administration, 46, 291.

Head of research department, type of man for, 55.

Hill and imagination, James J., S, 143.

Hoover, Herbert, 12s, 301.

How to use facts, 206.

Human element in business, 243.

Human nature and fact, 21.

Imagination disciplined by fact, 326.

Imagination in business, place of, 8 .

Imagination and statistics, 328 .

Import Statistics of Bureau of Foreign Commerce, 96.

Independent researches, 290 .

Individual experience, limitation of, 276 .

Indiridual qualities, study of, 15.

Information, difficulties in apply. ing, 201.

Information of greatest value, correct, 13.

Information, shaping for business application, 203.

Ingersoll watches, $119,123,198$.

Ingersoll, Wm. H., 217.

International cotton conference, 305.

statistics, need for, 305 .
International Institute of Agriculture, 304.

International League of Business, steps taken for, 302 .

International research, 302, 307.

International statisties, need for, $302,306$.

International Trade Conference, 302.

Intuition in research, 329 .

Investigation :

broad types of field, 184.

management by, 239.

sales management, 229 .

some consumption, 101.

territorial layout for dealer and consumer, 181.

Investigations :

and estimates, statistical, 189.

of distribution problems, 113.

scientific or technical, types of, 52 .

scientific or technical, value of, 50.

Ivory soap and distribution, 121.

Judgment, deficiencies of, 275.

Judgment making, process of business, 279 .

Keynote to distribution, 118.

Labor:

and employment management new professions, 11. as a commodity, 224 . -capital coöperation, 226. in affairs, participation of, 227.

inquiry, specific lines of, $22 \mathrm{~s}$.

problem, complexities of, 10 . study, need of, 223.

Law of averages, 6S, 121.

Layout for dealer and consumer investigation, 181.

Leadership makes success, 241. 
League of Nations, 301, 302, 305, 307,30 s.

suggested departments of, 309 .

Learning from research, 226.

Lubin, Darid, 304.

Management :

by investigation, 239.

problcms, office, 232.

problems of value to study, 233.

research and purchasing, 234.

scientific, 11, 14.

Margins and turnuver, retail, 137.

Margins, demand and jobbing, 136.

Market analysis, what it can determine, 12.

vital nature of, 9 S.

Market capacity, watching, $2 \$ 8$.

Marketing and mechanical data, collection of, 292.

Mellraith, James W., 24.

Measurement, sales resistance, 162.

Measuring goodwili, 156.

Measuring intangible factors of business, 152.

Mistakes in management, seven costly, 239.

Modern business, executire, 3. problems, 1. reaches of, 3 .

Morgan, 8, 143, 189.

Münster, Dr. Hugo, 203, 244.

Napoleon, 4, 200.

National City Bant, 305.

National Electric Company, 246.

National Industrial Council, $273,291$.

National Lead Co., 105.

National Research Council for scientific research, 52.

Net, $2+0$.

profit, 242.

Newark, N. J., Business Branch of Public Library, 61, 294.
New project, data necessary for starting, 34.

requirements in analyzing a, 33.

New York Salesmanagers Club, 296.

New York Telephone Company and special engineers, 143.

Nose for research, 316 .

Office management problems, 232. One-man "genius," the analytical idea rs., 4.

Organization chicf element of success, developing and shaping, 15 .

Outside point of vier, appreciating the, 198.

Over-practicality, tendency toward, 6.

Owen, Senator, 129.

Pacific coast hotel, demonstration of, 14.

Packers, prejudice against, 17.

Panama canal and distribution costs, 133.

Passing of the simple in business, 1.

Per capita consumption, increasing the, 95 .

contracts, 89 .

measure applied to individual sales volume, 93. study, SS.

Percentage of distribution, analyzing, 126.

Pioneers in research, 54 .

Place of imagination in business 8 .

l'oint calculated from sales performance, 108.

Point of riew, appreciating the outside, 198.

Point system, 104.

I'ossible researches, 46 .

I'ractice and theory of statistics, 24.

Presentation of facts, conrtneing, 259.

President Wilson, 113. 
Price problems, delicaey of, 2 S9. Iroblems :

of a business, range of the typical, 2.

of distribution and market analysis, 11.

of distribution, investigation of, $40,113$.

of distribution, research phase of, 115.

of economie relationships, 16 . of executive management, 14. of office manarement, 232 . of the future, trade, I4S. special department store, 47.

Producers, ratio to distributors, 117.

Production mauagement a highly technical prciession, 11.

Professional feelins, dangers in solidarity of, 321 .

Professional interchange, liwitations of, 323.

Professional standards and research spirit, 316.

Profit and foresight, 143.

Prognostication, basie raw material, 149.

Psychological problems calling for solution, 246.

Psychological research already proved, some uses of, 244.

Psyehology Association, Economic, 244.

Public libraries and business data development, 292.

Public library, Newark, N. J., 61, 294.

Purchasing management, research and, 234.

Quantity price, distributive equality and, 133.

Quantity selling greatest modern profit policy, 119.

Questionnaires, by mail, 173.

handled by resident investigators, 174 .

Quotas, setting of, 104.
Raw material, basic study of, 149.

Reaches of modern business, 3 .

Recommendations to Government, 296.

Reconstruction researches, elements for, 298.

failure to make, 298 .

Records and reports, adequate, 36.

Report, elements of a good, 260 .

Reports, reading of, 266.

Research and:

ana $\log y, 331$.

intuition, 329 .

investigation, value of, 18 .

other uses of, 159.

purchasing management, 234.

statistical organization and sources, $\check{9} 9$.

statistics, International

Trade, 301.

to understand new place of, 6.

Trade association, 286.

Research :

counselors special future in, 55.

dangers of, 57.

department, and data

sources, 54.

of advertising mediums, 64 .

organization and scope, $5 S$.

type of man to head, 55 .

independent coöperative, 290.

management, as distinct from others, 221.

National council for scientific, 52.

need for government business, 294.

nose for, 316.

pioneers, 54.

prevents waste and error, 12. specialized business, 291 .

spirit and professional standards, 316.

workers, requirements of, 62 . Researching future markets, 14\%. 
Retail problems of sales and manacement, 45. 55.

Risk, studying degree of, 153.

Rockefollor, 1 S..

foundation and research. 52. Rules for checking up facts, 27.

Russell Sase Foundation, 291.

Ryzon Baking Powder Co., 1:, 13.

Ryzon Sales Policy, 135.

Salesmanagement investiration, 2.29.

Salesmanaser's ciub, 291.

Sales policy, Iiyzon, 19,5.

Sales resistance measulement, 162.

Sameness of business, fundamental, 1?.

"Saturation Point," meaning of, 109.

Schwab and industrial generalslip, 227.

Srientifie and commercial research, synchronization letween, 72 .

Scientific and technical investiration, 50 .

Scientific management, and specialized factors. 11.

application of, to labor and production, 14.

Sciontific receralel, National Roseareh rouneil for, 52

Scoutt, Dr. Wilter Dill, 214.

Soars, Ricluad,

Sisars, Rowlucle \& Company, T?.

Solling and distribution, least fixed and exact, 11.

Selline, greatest profit policyquantity, 119.

Selliner. keynote of distributive "flic inney, antomatie, 11 S.

Senator Works, mos.

Sruvice in alstribution, 128 .

Siegel Cooper store, 1:4.

Size statistics, importance of, 239.
Sources of data, research dejartments and, 54.

Specialists, 164.

Specialized business data coöperation, 291.

Standard of living, 129.

Statistical :

and research organizations and sources, 5i)1.

inrestigations and estimates, 1 S9.

method, possibilities of application of, 189.

researches from records, 191.

Statistics:

and business research, need

for Goyrament, 294.

and data on sales possibili-

ties by territorial unit, 102.

and facts to business, relattion between, 9 .

and researeh, Interuational trade, 801.

as raw matrials for imatination, 32 ?

'horking up, 24;

firld for use of, 16 .

wivholong of, :- 4 .

to mulerstand the new ylare of, $f$.

Stlirly of stocks on liand, 25T.

Siabjects for rowereh on sales-

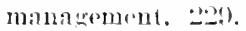

Suceess, most typical alement of. 143.

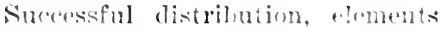
of, 120 .

Shmmaries and rovinws, arablice, $3:)$.

Sinperedexentive, 万.

survers and regorts by speciali<1s, loit.

Sinrrys of basic cousnmption (onflitions, 100.

Suift, $\approx 4$.

Syndirated selling forcing new bolinis: 120 . 


\section{BUSINESA RESEARCH AND STATISTICS}

Taylor, Dr. Alonzo E., 12s.

Technical and scientific investisutions, value of, 50 .

Telplones and typewiters, 16, 29.

Tendency curve charts, 150.

Tendency knowleclese and prognostications, 143 .

Tests of consumer response, 1-it.

Textile demand determinants, $1 s(3$.

The corporation, 1.

Theory and practice, new union of, 6 .

Theory to business, wider application of, 7 .

'Trade Association rescarches and statistics, 286.

Trade development hinges upon information, 303.

Trade problems of the future, 14s.

Truth, devotion to discovery of new, 318.

Turnover and margins, retail, 1:T.
Ineeda Biscuit, 138, 198.

Inited Drug Co., 126.

Cnited States:

Bureau of standards, 52 .

census, 23, 26.

Chamber of Commerce, 2 5 , 302.

United States Rubber ('o., 4.., 54.

Value of aplroximations and estimates, 274.

Visualization of the "average," Sit.

Vital data and statisties of fild survey, 150.

Vital types of data on business operation, 36 .

Watching market capacity, 2SS.

Wider application of theory to business, 7 .

Wilson, P'resident. 113.

Winchester Al'ms ('o, 12:?.

World statistics, scarcity of, 302 . 




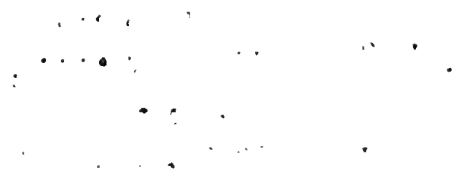


UC SOUTHERN REGIONAL LIBRARY FACILITY

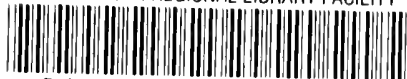

AA 0010184505

\section{- FR BPANCH, $Y$ UIF C.ALIFOTINIA, LIBRARY,

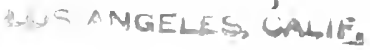


(n) 